\title{
Stretch-mediated cardiac hypertrophy and extracellular matrix remodelling
}

Citation for published version (APA):

Blaauw, E. (2013). Stretch-mediated cardiac hypertrophy and extracellular matrix remodelling. [Doctoral Thesis, Maastricht University]. Datawyse / Universitaire Pers Maastricht. https://doi.org/10.26481/dis.20130913eb

Document status and date:

Published: 01/01/2013

DOI:

10.26481/dis.20130913eb

Document Version:

Publisher's PDF, also known as Version of record

\section{Please check the document version of this publication:}

- A submitted manuscript is the version of the article upon submission and before peer-review. There can be important differences between the submitted version and the official published version of record.

People interested in the research are advised to contact the author for the final version of the publication, or visit the DOI to the publisher's website.

- The final author version and the galley proof are versions of the publication after peer review.

- The final published version features the final layout of the paper including the volume, issue and page numbers.

Link to publication

\footnotetext{
General rights rights.

- You may freely distribute the URL identifying the publication in the public portal. please follow below link for the End User Agreement:

www.umlib.nl/taverne-license

Take down policy

If you believe that this document breaches copyright please contact us at:

repository@maastrichtuniversity.nl

providing details and we will investigate your claim.
}

Copyright and moral rights for the publications made accessible in the public portal are retained by the authors and/or other copyright owners and it is a condition of accessing publications that users recognise and abide by the legal requirements associated with these

- Users may download and print one copy of any publication from the public portal for the purpose of private study or research.

- You may not further distribute the material or use it for any profit-making activity or commercial gain

If the publication is distributed under the terms of Article $25 \mathrm{fa}$ of the Dutch Copyright Act, indicated by the "Taverne" license above, 


\section{Stretch-mediated cardiac hypertrophy and extracellular matrix remodelling}


ISBN 9789461592439

Copyright: Erik Blaauw

Layout and cover: Datawyse / Universitaire Pers Maastricht

Druk: Datawyse / Universitaire Pers Maastricht

Financial support by the RESCAR Foundation Maastricht and by the Heart Foundation for the publication of this thesis is gratefully acknowledged. 


\title{
Stretch-mediated cardiac hypertrophy and extracellular matrix remodelling
}

\author{
PROEFSCHRIFT \\ ter verkrijging van de graad van doctor aan de Universiteit Maastricht, \\ op gezag van de Rector Magnificus Prof. dr. L.L.G. Soete \\ volgens het besluit van het College van Decanen, \\ in het openbaar te verdedigen \\ op vrijdag 13 september 2013 om 14:00 uur \\ door
}

\section{Erik Blaauw}

Geboren op 24 oktober 1980,

te Stadskanaal

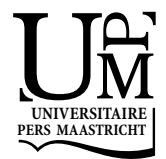




\section{Promotoren}

Prof. dr. G.J. van der Vusse

Prof. dr. F.W. Prinzen

\section{Copromotor}

Dr. M. van Bilsen

\section{Beoordelingscommissie}

Prof. dr. S. Heymans (voorzitter)

Prof. dr. Th. Arts

Dr. M. Blankensteijn

Prof. dr. A. van der Laarse (Universiteit Leiden)

Prof. dr. M.J. Post 


\section{Table of content}

Chapter 1

Background information and aim of the thesis.

Chapter 2

Effect of stretch and growth factors on cardiac hypertrophy and fibrosis: state of the art.

\section{Chapter 3}

Isolation and culturing of cardiomyocytes and fibroblasts from adult rabbit heart. Application of cyclic strain.

\section{Chapter 4}

Stretch-induced hypertrophy of isolated adult rabbit cardiomyocytes.

\section{Chapter 5}

The effect of stretch and growth factors on the expression of extracellular matrix components by rabbit cardiac fibroblasts.

\section{Chapter 6}

Effect of cyclic stretch of rabbit cardiomyocytes on the expression of factors involved in extracellular matrix remodelling

\section{Chapter 7}

Effect of AT-1 receptor blockade on ventricular pacing-induced asymmetric hypertrophy in rabbits

\section{Chapter 8}

General discussion and conclusions

Addendum I 

Chapter 1

Background information and aim of the thesis 


\section{BACKGROUND}

Cardiovascular diseases are one of the most frequent causes of death worldwide ${ }^{1}$ and are, in the Netherlands, responsible for approximately $30 \%$ of all deaths ${ }^{2}$. Heart failure accounts for $16 \%$ of all cardiac deaths ${ }^{3}$. Heart failure develops secondary to cardiac overload. This overload may originate from myocardial infarction, valvular disease or chronically increased blood pressure ${ }^{4}$. Challenged by the overloaded state, the heart initially responds with adaptive cardiomyocyte growth (hypertrophy). However, at a certain degree and/or duration of overload, hypertrophy becomes maladaptive and cardiac decompensation commences.

\section{Cardiac remodelling: hypertrophy and fibrosis}

Hypertension and valvular diseases result in elevated cardiac workload accompanied with increased wall stress due to elevated preload or afterload ${ }^{5,6}$. In case of systemic hypertension, the ensuing hypertrophy is of concentric nature (wall thickening at minor change in cavity volume), as this maintains normal wall stress according to the Laplace Law $^{5}$. Concentric hypertrophy is characterised by cardiomyocyte growth, mainly via enlargement of the cross-sectional area of these cells, without effecting ventricular cavity dimensions ${ }^{7,8}$. This adaptive process is eventually accompanied by proliferation of non-cardiomyocytes (fibroblasts) and deposition of extracellular matrix (ECM) constituents such as collagens ${ }^{9,10}$. Further unfavourable changes are alterations in expression of genes related to calcium handling that lead to slower and lower calcium transients in the cardiomyocytes ${ }^{11}$. These processes are elements of maladaptive remodelling, which negatively affect diastolic relaxation and systolic contractility. Both mechanical and biochemical factors are involved in the onset and progression of cardiac hypertrophy. Mechanical factors are generally linked to increased stretch of cardiomyocytes and other cell types in the cardiac muscle, such as fibroblasts. Candidates for biochemical factors are circulating hormones, such as (nor) adrenalin (nor)adrenaline and angiotensin II. In addition, circumstantial evidence points out a role for paracrine and/or autocrine growth factors ${ }^{12}$. However, the exact contribution of all these factors to the process of hypertrophy is unknown.

\section{Role of the renin-angiotensin system in hypertrophy and heart failure}

At present, treatment of cardiac hypertrophy is commonly aimed at preventing the progression towards cardiac dysfunction via administration of agents, such as angiotensin-II receptor type-1 (AT-1) blockers and angiotensin converting enzyme (ACE) inhibitors $^{1}$. These drugs interfere with the Renin-Angiotensin System (RAS) and their widespread use has resulted in significantly decreased hospitalisation and prolonged survival of heart failure patients ${ }^{13-16}$. Several factors are considered important mecha- 
nisms of action of these drugs in cardiac hypertrophy, such as lowering of systemic blood pressure and prevention, reduction and even reversal of adverse cardiac remodelling.

An important and still unsolved question is whether ACE inhibitors and AT-1 blockers reduce hypertrophy exclusively through their hypotensive effect or through a direct interaction with the hypertrophic process. Moreover, it is not clear whether the latter would be due to the circulating angiotensin II or due to angiotensin II that is locally produced in response to the mechanical overload.

\section{The role of stretch and angiotensin II in cardiac hypertrophy}

Angiotensin II (AngII) is an important humoral (systemic), and an auto- and/or paracrine (local) factor exerting a potent trophic effect on cardiac cells both in vivo ${ }^{17-20}$ and in vitro $^{12,21-23}$. In the past, it was believed that systemic blood was the main source of Angll for the heart. The importance of Angll as humoral factor, acting in an indirect way, was concluded from studies in which Angll was administered to intact experimental animals, resulting in a rise in systemic blood pressure followed by cardiomyocyte growth and impaired cardiac function ${ }^{19,24}$. Later studies clearly showed that also the myocardium itself expresses components of the RAS system such as renin, angiotensinogen, and $A C E^{25-27}$. These components are required for the local synthesis and degradation of Angll and, hence, for the autocrine and/or paracrine action of this growth hormone. The biological effect of Angll on the heart is mainly mediated via binding to and subsequent stimulation of AT-1 receptors ${ }^{21,22}$. Recent evidence shows that the AT-1 receptor can be activated independent from Ang $\|^{28,29}$. This alternative route is thought to occur via conformational changes in the receptor structure due to increased myocardial stretch and subsequent activation of downstream hypertrophic signalling pathways ${ }^{29}$. It is of note that the stretch-induced effects were partially prevented by pre-treatment with specific AT-1 antagonists, irrespective of the presence or absence of Angl| ${ }^{29}$. In vitro models also showed that stretch is a potent trigger for cardiomyocytes themselves to release AngII $^{12}$, but this observation appears to be controversial ${ }^{30}$. Extrapolation of these data to the human situation is further hampered by the fact that most studies on Angll and cardiomyocyte hypertrophy were performed on isolated neonatal instead of adult cardiomyocytes.

Despite the vast amount of literature pointing to an important role of Angll in cardiac hypertrophy and failure, the precise role of Angll and of AT-1 receptors therein is incompletely understood. In this respect it should be noted that (i) AT-1 receptor knockout mice still develop pressure overload-induced cardiac hypertrophy that is not different from wild type animals ${ }^{31}$ and (ii) transgenic mice with cardiomyocyte specific over-expression of AT-1 receptors develop cardiac hypertrophy in the absence of 
Angl| ${ }^{32}$. Therefore, the precise role of stretch and Angll, and their mutual relationship, in the onset and progression of cardiac hypertrophy and failure is still enigmatic.

\section{Other growth factors involved in cardiac remodelling}

Another way in which mechanical loading may lead to hypertrophy is through stimulation of production of growth factors. In recent years several growth factors have been suggested to be involved in the process of ventricular remodelling, whether hypertrophy, fibrosis or both. Important examples of such factors are transforming growth factor $\beta 1$ (TGF $\beta 1$ ), insulin-like growth factor-1 (IGF-1) and Connective Tissue Growth Factor (CTGF).

TGF $\beta$ s are a family of secreted signalling compounds with multiple effects on cardiac cells. Enhanced expression of TGF $\beta 1$ is associated with pathological remodelling processes $^{33-35}$, including cardiac hypertrophy and fibrosis. The biological action of TGF $\beta$ occurs primarily via TGF $\beta$ type-I and type-II receptors, which are present on cardiomyocytes and cardiac fibroblasts $^{36,37}$. Mechanical stimulation appears to be a potent trigger for cardiac TGF $\beta 1$ release ${ }^{38}$. This suggests that TGF $\beta$ may be one of the factors linking increased myocardial loading conditions to tissue remodelling processes.

IGF-1 plays a role in a broad range of physiological processes, including stimulation of cell division ${ }^{39-41}$ and enhanced protein synthesis ${ }^{40-42}$. The biological action of IGF-1 occurs primarily via the IGF-1 receptor (IGF-1R) present on the membrane of cardiomyocytes and cardiac fibroblasts ${ }^{41,43}$. The main source of IGF-1 in the heart is uncertain, but it has been suggested to be restricted to cardiac fibroblasts ${ }^{44}$. Beside the source, the trigger for IGF-1 in the cardiac muscle is also unclear. Potential stimuli for IGF-1 induction are Angll, other growth factors including TGF $\beta$, and increased mechanical loading of the heart ${ }^{44}$. When IGF-1 is excreted into the myocardial interstitial compartment, the availability and biological activity of IGF-1 is modulated by so-called IGFbinding proteins (IGFBPs).

One of the IGFBPs is known as IGFBP-rP2, later named CTGF ${ }^{45}$. Evidence is accumulating that CTGF plays an important role in remodelling of the left ventricular (LV) wall, including hypertrophy and fibrosis. However, the precise role of CTGF in cardiac structural remodelling remains elusive. At present, controversy exits about the main cellular source of CTGF in the heart. A number of studies identified that both cardiac fibroblast $^{46-48}$ and cardiomyocytes ${ }^{49-51}$ are important sources of CTGF. CTGF expression in vivo is associated with augmented mechanical load and larger availability of a variety of growth factors, such as TGF- $\beta 1^{33,52,53}$. These data suggests that TGF $\beta$, IGF- 1 and CTGF may be factors linking increased myocardial loading conditions to remodelling processes. 


\section{AIMS OF THIS THESIS}

The major aim of the present thesis was to elucidate the role of Angll and the various aforementioned growth factors in the process of hypertrophy of cardiac muscle cells and enhanced synthesis of ECM components following increased mechanical load, associated with cellular stretch. In the first part of the thesis, cardiomyocyte hypertrophy was investigated in vitro by implementing novel techniques to mimic cardiac overload-induced hypertrophy. To this end, we developed a technique to isolate ventricular muscle cells from adult rabbit hearts and to expose these cells to cyclic stretch allowing the investigation of the following research questions:

The major sub-aims of this thesis were to investigate whether

1) Cyclic stretch is a trigger for hypertrophic growth of cardiomyocytes i) directly, without involvement of autocrine/paracrine agents, or ii) indirectly, via release of autocrine factors from stretched cardiomyocytes and/or via the release of paracrine factors from stretched fibroblasts.

2) Cyclic stretch is a trigger for cardiac fibroblasts to induce the expression of ECM components i) directly, without involvement of autocrine/paracrine agents, or ii) indirectly, via release of autocrine factors released from stretched fibroblasts and/or via the release of paracrine factors from stretched cardiomyocytes.

3) Stretch up-regulates the expression of Connective Tissue Growth Factor (CTGF) in cardiomyocytes and cardiac fibroblasts.

With respect to sub-aim 1 , in the last part of the thesis, attempts were made to extrapolate the in vitro findings to the in vivo situation. Here, the research question addressed was: is stretch-induced cardiac muscle cell hypertrophy in vivo mediated by stretch-mediated release of autocrine/paracrine Angll?

\section{OUTLINE OF THIS THESIS}

Chapter 1 provides background information and describes the major aims and outline of the thesis.

Chapter 2 represents a concise review on the role of increased cardiac load in the development of cardiac muscle hypertrophy. Direct and indirect mechanisms will be discussed; the latter involve endocrine, paracrine and autocrine growth factors, such as AngII, TGF $\beta 1$ and IGF-1. Furthermore, this chapter focuses on possible mechanisms of how cardiac cells, such as cardiomyocytes and fibroblasts, sense stretch and how stretch is translated into intracellular signals resulting in hypertrophy and/or ECM deposition. 
Chapter 3 describes an improved technique to isolate and culture rabbit cardiomyocytes and non-cardiomyocytes (fibroblasts) and the conditions to subject the cells to cyclic equibiaxial stretch. This technique enabled us to study mechanisms of hypertrophy in adult cells rather than neonatal cardiomyocytes, the most frequently used cell type, and using a species that is closer to man than rodents.

In Chapter 4 the hypertrophic response of cardiomyocytes exposed to cyclic stretch generated by the Flexcell FX4000 apparatus is investigated. Moreover, this chapter describes the possible role of the growth factors AngII, TGF $\beta$ and IGF1 in the hypertrophic response and the possible paracrine crosstalk between cardiomyocytes and fibroblast therein.

In Chapter 5 and Chapter 6 the findings are presented regarding the effect of cyclic stretch and Angll treatment of isolated fibroblasts (Chapter 5) and cardiomyocytes (Chapter 6) on the expression of ECM components. Special attention was paid to the expression of CTGF. Furthermore, it was investigated if stretch-mediated paracrine factors from one cell type activated the other to produce ECM components and vice versa.

In Chapter 7, an in vivo study is described in which regional hypertrophy of the ventricular septal wall was induced by pacing of the left ventricular free wall in adult rabbits. The role of stretch-mediated autocrine/paracrine Angll was investigated in this model by continuous infusion of specific AT-1 receptor blocker irbesartan during the period of ventricular pacing.

In the general discussion (Chapter 8), the studies performed are put into a broader perspective, and suggestions for future investigations are made. 


\section{REFERENCES}

1. Arshad A, Mandava A, Kamath G, Musat D. Sudden cardiac death and the role of medical therapy. Prog Cardiovasc Dis. 2008;50(6):420-438.

2. Koek HL, Engelfriet-Rijk C, Bots ML. Hart- en vaatziekten in Nederland 2006, cijfers over ziekte en sterfte. Nederlandse Hartstichting:Den Haag; 2006.

3. I. Vaartjes IvD, F.L.J. Vi.

4. Kjeldsen SE, Julius S. Hypertsseren, M.L. Bots. Hart- en vaatziekten in Nederland. www.hartstichting.nl. 2010ension mega-trials with cardiovascular end points: effect of angiotensin-converting enzyme inhibitors and angiotensin receptor blockers. Am Heart J. 2004;148(5):747-754.

5. Sadoshima J, Izumo S. The cellular and molecular response of cardiac myocytes to mechanical stress. Annu Rev Physiol. 1997;59:551-571.

6. Wakatsuki T, Schlessinger J, Elson EL. The biochemical response of the heart to hypertension and exercise. Trends Biochem Sci. 2004;29(11):609-617.

7. Anversa P, Ricci R, Olivetti G. Quantitative structural analysis of the myocardium during physiologic growth and induced cardiac hypertrophy: a review. J Am Coll Cardiol. 1986;7(5):1140-1149.

8. Anversa P, Kajstura J, Cheng W, Reiss K, Cigola E, Olivetti G. Insulin-like growth factor-1 and myocyte growth: the danger of a dogma. Part I. Postnatal myocardial development: normal growth. Cardiovasc Res. 1996;32(2):219-225.

9. Brilla CG, Pick R, Tan LB, Janicki JS, Weber KT. Remodeling of the rat right and left ventricles in experimental hypertension. Circ Res. 1990;67(6):1355-1364.

10. Brilla CG, Maisch B. Regulation of the structural remodelling of the myocardium: from hypertrophy to heart failure. Eur Heart J. 1994;15 Suppl D:45-52.

11. Nass RD, Aiba T, Tomaselli GF, Akar FG. Mechanisms of disease: ion channel remodeling in the failing ventricle. Nat Clin Pract Cardiovasc Med. 2008;5(4):196-207.

12. Sadoshima J, Xu Y, Slayter HS, Izumo S. Autocrine release of angiotensin II mediates stretch-induced hypertrophy of cardiac myocytes in vitro. Cell. 1993;75(5):977-984.

13. Young JB, Dunlap ME, Pfeffer MA, Probstfield JL, Cohen-Solal A, Dietz R, Granger CB, Hradec J, Kuch J, McKelvie RS, McMurray JJ, Michelson EL, Olofsson B, Ostergren J, Held P, Solomon SD, Yusuf S, Swedberg K. Mortality and morbidity reduction with Candesartan in patients with chronic heart failure and left ventricular systolic dysfunction: results of the CHARM low-left ventricular ejection fraction trials. Circulation. 2004;110(17):2618-2626.

14. Lee VC, Rhew DC, Dylan M, Badamgarav E, Braunstein GD, Weingarten SR. Meta-analysis: angiotensinreceptor blockers in chronic heart failure and high-risk acute myocardial infarction. Ann Intern Med. 2004;141(9):693-704.

15. Names N. Effect of enalapril on survival in patients with reduced left ventricular ejection fractions and congestive heart failure. The SOLVD Investigators. N Engl J Med. 1991;325(5):293-302.

16. Names N. Effects of enalapril on mortality in severe congestive heart failure. Results of the Cooperative North Scandinavian Enalapril Survival Study (CONSENSUS). The CONSENSUS Trial Study Group. N Engl J Med. 1987;316(23):1429-1435.

17. Kim S, Ohta K, Hamaguchi A, Yukimura T, Miura K, Iwao H. Angiotensin II induces cardiac phenotypic modulation and remodeling in vivo in rats. Hypertension. 1995;25(6):1252-1259.

18. Geenen DL, Malhotra A, Scheuer J. Angiotensin II increases cardiac protein synthesis in adult rat heart. Am J Physiol. 1993;265(1 Pt 2):H238-243.

19. Dostal DE, Baker KM. Angiotensin II stimulation of left ventricular hypertrophy in adult rat heart. Mediation by the AT1 receptor. Am J Hypertens. 1992;5(5 Pt 1):276-280.

20. Higashi M, Shimokawa H, Hattori T, Hiroki J, Mukai Y, Morikawa K, Ichiki T, Takahashi S, Takeshita A. Long-term inhibition of Rho-kinase suppresses angiotensin Il-induced cardiovascular hypertrophy in rats in vivo: effect on endothelial NAD(P)H oxidase system. Circ Res. 2003;93(8):767-775.

21. Miyata $S$, Haneda T. Hypertrophic growth of cultured neonatal rat heart cells mediated by type 1 angiotensin II receptor. Am J Physiol. 1994;266(6 Pt 2):H2443-2451. 
22. Booz GW, Baker KM. Role of type 1 and type 2 angiotensin receptors in angiotensin II-induced cardiomyocyte hypertrophy. Hypertension. 1996;28(4):635-640.

23. Frank D, Kuhn C, Brors B, Hanselmann C, Ludde M, Katus HA, Frey N. Gene expression pattern in biomechanically stretched cardiomyocytes: evidence for a stretch-specific gene program. Hypertension. 2008;51(2):309-318.

24. Koide M, Carabello BA, Conrad CC, Buckley JM, DeFreyte G, Barnes M, Tomanek RJ, Wei CC, Dell'Italia LJ, Cooper Gt, Zile MR. Hypertrophic response to hemodynamic overload: role of load vs. renin-angiotensin system activation. The American journal of physiology. 1999;276(2 Pt 2):H350-358.

25. Baker KM, Chernin MI, Wixson SK, Aceto JF. Renin-angiotensin system involvement in pressure-overload cardiac hypertrophy in rats. Am J Physiol. 1990;259(2 Pt 2):H324-332.

26. Boer PH, Ruzicka M, Lear W, Harmsen E, Rosenthal J, Leenen FH. Stretch-mediated activation of cardiac renin gene. Am J Physiol. 1994;267(4 Pt 2):H1630-1636.

27. Zhang $X$, Dostal DE, Reiss $K$, Cheng W, Kajstura J, Li $P$, Huang H, Sonnenblick EH, Meggs LG, Baker KM, et al. Identification and activation of autocrine renin-angiotensin system in adult ventricular myocytes. $\mathrm{Am}$ J Physiol. 1995;269(5 Pt 2):H1791-1802.

28. Zou Y, Akazawa H, Qin Y, Sano M, Takano H, Minamino T, Makita N, Iwanaga K, Zhu W, Kudoh S, Toko H, Tamura K, Kihara M, Nagai T, Fukamizu A, Umemura S, liri T, Fujita T, Komuro I. Mechanical stress activates angiotensin II type 1 receptor without the involvement of angiotensin II. Nature cell biology. 2004;6(6):499-506.

29. Yasuda N, Miura S, Akazawa H, Tanaka T, Qin Y, Kiya Y, Imaizumi S, Fujino M, Ito K, Zou Y, Fukuhara S, Kunimoto S, Fukuzaki K, Sato T, Ge J, Mochizuki N, Nakaya H, Saku K, Komuro I. Conformational switch of angiotensin II type 1 receptor underlying mechanical stress-induced activation. EMBO reports. 2008;9(2):179-186.

30. van Kesteren CA, Saris JJ, Dekkers DH, Lamers JM, Saxena PR, Schalekamp MA, Danser AH. Cultured neonatal rat cardiac myocytes and fibroblasts do not synthesize renin or angiotensinogen: evidence for stretch-induced cardiomyocyte hypertrophy independent of angiotensin II. Cardiovasc Res. 1999;43(1):148-156.

31. Harada K, Komuro I, Shiojima I, Hayashi D, Kudoh S, Mizuno T, Kijima K, Matsubara H, Sugaya T, Murakami K, Yazaki Y. Pressure overload induces cardiac hypertrophy in angiotensin II type 1A receptor knockout mice. Circulation. 1998;97(19):1952-1959.

32. Paradis $P$, Dali-Youcef N, Paradis FW, Thibault G, Nemer M. Overexpression of angiotensin II type I receptor in cardiomyocytes induces cardiac hypertrophy and remodeling. Proc Natl Acad Sci U S A. 2000;97(2):931-936.

33. Rosenkranz S. TGF-beta1 and angiotensin networking in cardiac remodeling. Cardiovasc Res. 2004;63(3):423-432.

34. Villarreal FJ, Dillmann WH. Cardiac hypertrophy-induced changes in mRNA levels for TGF-beta 1, fibronectin, and collagen. Am J Physiol. 1992;262(6 Pt 2):H1861-1866.

35. Parker TG, Packer SE, Schneider MD. Peptide growth factors can provoke "fetal" contractile protein gene expression in rat cardiac myocytes. J Clin Invest. 1990;85(2):507-514.

36. Brand T, Schneider MD. The TGF beta superfamily in myocardium: ligands, receptors, transduction, and function. J Mol Cell Cardiol. 1995;27(1):5-18.

37. Li G, Li RK, Mickle DA, Weisel RD, Merante F, Ball WT, Christakis GT, Cusimano RJ, Williams WG. Elevated insulin-like growth factor-I and transforming growth factor-beta 1 and their receptors in patients with idiopathic hypertrophic obstructive cardiomyopathy. A possible mechanism. Circulation. 1998;98(19 Suppl):II144-149; discussion II149-150.

38. Lee $A A$, Delhaas $T$, McCulloch $A D$, Villarreal FJ. Differential responses of adult cardiac fibroblasts to in vitro biaxial strain patterns. J Mol Cell Cardiol. 1999;31(10):1833-1843.

39. Chen WH, Pellegata NS, Wang PH. Coordinated effects of insulin-like growth factor I on inhibitory pathways of cell cycle progression in cultured cardiac muscle cells. Endocrinology. 1995;136(11):5240-5243.

40. Fuller SJ, Mynett JR, Sugden PH. Stimulation of cardiac protein synthesis by insulin-like growth factors. Biochem J. 1992;282 ( Pt 1):85-90. 
41. Ito $H$, Hiroe M, Hirata $Y$, Tsujino M, Adachi S, Shichiri M, Koike A, Nogami A, Marumo F. Insulin-like growth factor-I induces hypertrophy with enhanced expression of muscle specific genes in cultured rat cardiomyocytes. Circulation. 1993;87(5):1715-1721.

42. Mendez R, Myers MG, Jr., White MF, Rhoads RE. Stimulation of protein synthesis, eukaryotic translation initiation factor $4 \mathrm{E}$ phosphorylation, and PHAS-I phosphorylation by insulin requires insulin receptor substrate 1 and phosphatidylinositol 3-kinase. Mol Cell Biol. 1996;16(6):2857-2864.

43. van Eickels $M$, Vetter $H$, Grohe $C$. Angiotensin-converting enzyme (ACE) inhibition attenuates insulin-like growth factor-I (IGF-I) induced cardiac fibroblast proliferation. Br J Pharmacol. 2000;131(8):1592-1596.

44. Hu BS, Landeen LK, Aroonsakool N, Giles WR. An analysis of the effects of stretch on IGF-I secretion from rat ventricular fibroblasts. Am J Physiol Heart Circ Physiol. 2007;293(1):H677-683.

45. Zhou Y, Capuco AV, Jiang H. Involvement of connective tissue growth factor (CTGF) in insulin-like growth factor-I (IGF1) stimulation of proliferation of a bovine mammary epithelial cell line. Domest Anim Endocrinol. 2008;35(2):180-189.

46. Ahmed MS, Oie E, Vinge LE, Yndestad A, Oystein Andersen G, Andersson Y, Attramadal T, Attramadal H. Connective tissue growth factor--a novel mediator of angiotensin II-stimulated cardiac fibroblast activation in heart failure in rats. J Mol Cell Cardiol. 2004;36(3):393-404.

47. Ahmed MS, von Lueder TG, Oie E, Kjekshus H, Attramadal H. Induction of myocardial connective tissue growth factor in pacing-induced heart failure in pigs. Acta Physiol Scand. 2005;184(1):27-36.

48. Lang C, Sauter M, Szalay G, Racchi G, Grassi G, Rainaldi G, Mercatanti A, Lang F, Kandolf R, Klingel K. Connective tissue growth factor: a crucial cytokine-mediating cardiac fibrosis in ongoing enterovirus myocarditis. J Mol Med. 2008;86(1):49-60.

49. Dean RG, Balding LC, Candido R, Burns WC, Cao Z, Twigg SM, Burrell LM. Connective tissue growth factor and cardiac fibrosis after myocardial infarction. J Histochem Cytochem. 2005;53(10):1245-1256.

50. Koitabashi N, Arai M, Kogure S, Niwano K, Watanabe A, Aoki Y, Maeno T, Nishida T, Kubota S, Takigawa $M$, Kurabayashi M. Increased connective tissue growth factor relative to brain natriuretic peptide as a determinant of myocardial fibrosis. Hypertension. 2007;49(5):1120-1127.

51. Ohnishi H, Oka T, Kusachi S, Nakanishi T, Takeda K, Nakahama M, Doi M, Murakami T, Ninomiya $Y$, Takigawa M, Tsuji T. Increased expression of connective tissue growth factor in the infarct zone of experimentally induced myocardial infarction in rats. J Mol Cell Cardiol. 1998;30(11):2411-2422.

52. Daniels A, van Bilsen $M$, Goldschmeding $R$, van der Vusse GJ, van Nieuwenhoven FA. Connective tissue growth factor and cardiac fibrosis. Acta Physiol (Oxf). 2009;195(3):321-338.

53. Leask A. TGFbeta, cardiac fibroblasts, and the fibrotic response. Cardiovasc Res. 2007;74(2):207-212. 

Chapter 2

Effect of stretch and growth factors on cardiac hypertrophy and fibrosis: state of the art 


\section{COMPOSITION OF THE HEART}

The heart is a muscular organ that pumps blood through the body to supply organs with oxygen and nutrients and to remove their waste products and heat. The cardiac muscle consists of parenchymal cells (cardiomyocytes), various types of non-striated muscle cells, (fibroblasts, endothelial cells, and vascular smooth muscle cells) and a non-cellular component, i.e., the extracellular matrix (ECM). The ECM is composed of structural proteins such as collagens, proteoglycans, and fibronectin, and also contains various non-structural proteins that are believed to be involved in signal-transduction and cell-cell communication. The latter class of proteins is often referred to as matricellular proteins and includes proteins like Connective Tissue Growth Factor (CTGF) ${ }^{1-4}$. From a quantitative point of view, the myocardial ECM is composed predominantly of type-I and type-III collagens. The collagens are organized into a specialized weave network, which under normal conditions provides support for cardiomyocytes, limits cardiomyocyte slippage, and maintains cardiomyocyte alignment during the cardiac cycle of contraction and relaxation ${ }^{5,6}$. Various types of physical connections between cardiac cells and between cells and ECM components have been identified. In addition to the cardiomyocyte syncytium, at least three different types of connections have been described $^{7}$, (i) cell-ECM interactions, principally between membrane-bound integrins and ECM proteins like fibronectin, laminin and collagen $^{2,4}$, (ii) fibroblast-fibroblast contacts via long filapodia ${ }^{7}$, and (iii) fibroblast-myocyte interactions via gap junction-like structures $^{8}$. The direct physical link between cardiac fibroblasts, cardiomyocytes and the ECM allows the cardiac cells to sense and respond to mechanical alterations and appears to be vital for normal cellular function on the one hand ${ }^{9}$ and in initiating the hypertrophic growth response of the cardiac muscle, on the other ${ }^{10}$.

\section{Cardiac hypertrophy}

During embryonic development, growth of the vertebrate heart is characterised by hyperplasia of myocardial cells. Shortly after birth, cardiomyocytes lose the ability to divide $^{11}$, and subsequently, the wall of the adult heart increases its volume predominantly by enlargement of cardiomyocyte volume, a process called physiological hypertrophy ${ }^{12}$. Physiological hypertrophy is also seen when the load of the heart is increased during pregnancy and strenuous physical exercise ${ }^{13}$. In contrast, pathological hypertrophy develops when the heart is exposed to a chronic increase in load, as is the case during hypertension and valvular disease. In that case the increase in cardiomyocyte size is frequently associated with a series of additional events, including the reexpression of fetal genes like atrial natriuretic factor (ANF) and an increased deposition of ECM constituents (fibrosis), resulting in adverse structural remodelling and cardiac dysfunction ${ }^{12}$. 
When the heart is subjected to volume overload, such as due to aortic and mitralvalve insufficiency, cardiomyocytes predominantly show a growth in their longitudinal direction. At the ventricular level this results in eccentric hypertrophy, an increase in ventricular size where the increase in cavity size is at least as large as that in wall mass without major effects on ECM volume and composition, see figure $1 \mathrm{~A}^{14}$. In contrast, under circumstances of pressure overload the heart compensates by increasing cardiomyocyte cross-sectional area, and hence, total wall thickness, in an attempt to normalize wall stress according to the Laplace Law (see figure $1 \mathrm{~B})^{14}$. If this process is insufficient to compensate for increased pressure, maladaptive hypertrophy develops and excessive ECM deposition will take place.

\section{Cardiac fibrosis}

Although cardiomyocytes contribute to $70 \%$ of the total volume of the myocardial wall, cardiac fibroblasts are an abundant cell type in the heart ${ }^{15}$, responsible for ECM synthe$\operatorname{sis}^{15}$ and, hence, maintenance of cardiac shape and ECM structure ${ }^{16,17}$. More specifically, cardiac fibroblasts are involved in the synthesis of, among others, collagens, fibronectin and $\mathrm{CTGF}^{18-21}$. Type-I collagen is the major collagenous product of these cells accounting for approximately $80 \%$ of the total newly synthesized collagen ${ }^{16}$. On the other hand, cardiac fibroblasts are known producers of non-collagenous proteins like fibronectin, which plays an important role in embryogenesis, cell adhesion and wound healing ${ }^{4}$. Under physiological conditions, synthesis and breakdown of ECM proteins are in equilibrium. One set of proteins involved in this equilibrium process is a family of extracellular matrix degrading enzymes, the matrix metalloproteinases (MMPs), the activity of which in turn is inhibited by Tissue Inhibitors of Metalloproteinases $(\text { TIMPs) })^{22}$.

Under pathological conditions, such as chronic hypertension and myocardial infarction, cardiac fibrosis develops. Fibrosis has been classified into two groups: (i) reactive interstitial fibrosis, and (ii) reparative (replacement) fibrosis. Remodelling of cardiac muscle during chronic hypertension is associated with reactive interstitial fibrosis. The activation of fibroblasts is brought about by both mechanical loading and growth factors, including Ang $\|^{23}$ and TGF $\beta^{2,42}$. The relative importance of direct mechanical activation versus the release of auto/paracrine growth factors in inducing ECM synthesis is not clear. During chronic hypertension, the balance between formation and breakdown of ECM tips the scale to net accumulation of collagen type-I and type-III and fibronectin, in the cardiac interstitial compartment ${ }^{4,25,26}$. This change is characterised by increasing the synthesis and inhibiting the breakdown of ECM components by fibroblasts. The latter is achieved by TIMPs, known inhibitors of $\mathrm{MMPs}^{22}$. Accumulation of collagens leads to impaired diastolic cardiac function by hampering ventricular filling ${ }^{1,12}$. Moreover, fibrosis slows down conduction of the electrical impulse, which may provide a substrate for cardiac arrhythmias. Reparative fibrosis is observed after, for example, 
myocardial infarction. This fibrotic process is characterized with cardiomyocyte loss and formation of scar tissue. During both reactive and reparative fibrosis, fibroblasts first increase their proliferative and migratory capacity followed by differentiation into myofibroblasts. The transition of fibroblasts into myofibroblasts is associated with ultrastructural and molecular changes, including a large increase in the number of microfilament bundles and $\alpha$-smooth muscle actin containing stress fibers. Myofibroblasts play an important role in wound healing and fibrosis in the cardiac muscle since they produce large amounts of collagens and are able to develop tension ${ }^{27}$. Since cardiomyocyte hypertrophy and fibrosis are often observed simultaneously, a functional interaction between cardiomyocytes and cardiac fibroblasts is implicated ${ }^{7,28}$. The required communication between cardiac cells is likely to involve excretion of paracrine growth factors $^{18,29-31}$.

\section{Response to increased mechanical loading}

During each heart beat, the cardiac ventricles and, hence, the cardiac cells, are exposed to forces, referred to as stresses. Wall stress is defined as force per unit of crosssectional area and increases with increasing cavity pressure and volume and decreases with increasing wall thickness. Intra-ventricular pressure and volume often increase during exercise and under pathological conditions such as hypertension and valvular diseases. This stress is sensed by the cellular cytoskeleton, sarcomeric proteins, and by ECM components, via the deformation of some of these components. Mechanical deformation, also known as strain, is complex in nature, because it is three-dimensional and differs between various regions of the ventricle ${ }^{32}$. At the cellular level, tissue strain results in stretching of cardiac cells. Within physiological limits this cellular stretch plays an important function in maintaining the size as well as vital properties of the cardiac cells ${ }^{9}$. 


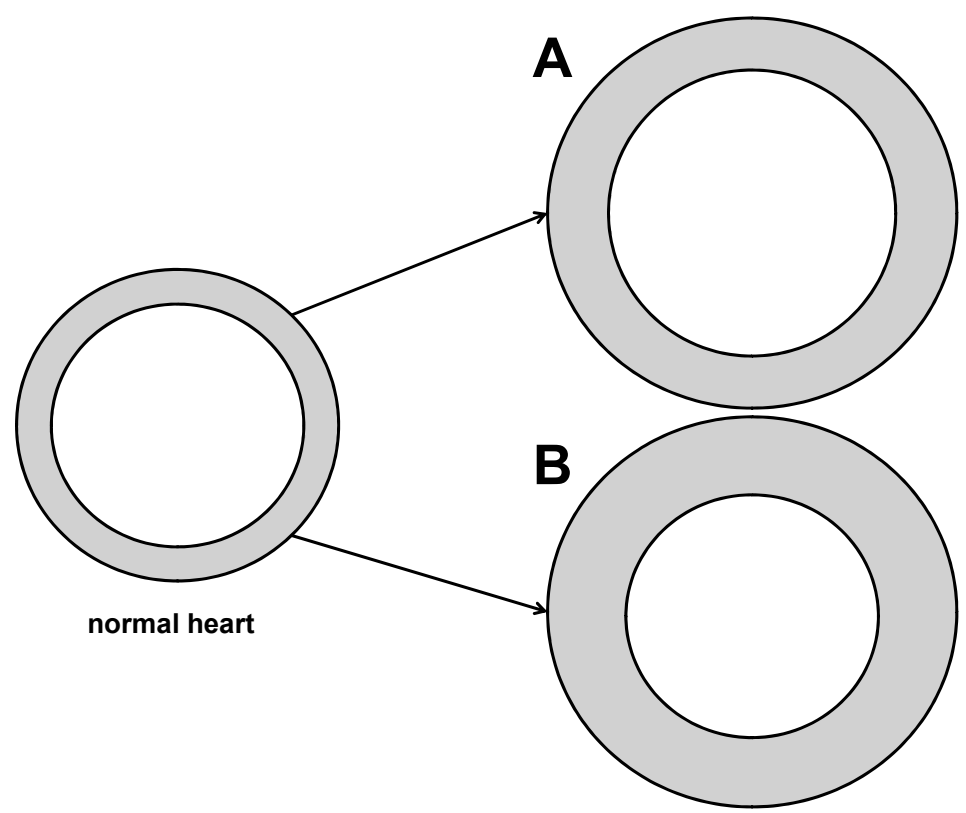

Figure 1: Differentiation between a normal heart and an (A) eccentrically (volume overload) and (B) concentrically (pressure overload) hypertrophied heart. Depicted are schematic short axis sections of the left ventricle.

The biological significance of mechanical factors as direct and principal triggers for cardiomyocyte enlargement and fibroblast-mediated ECM production in vivo is still a matter of intense debate $e^{33,34}$.

\section{Role of growth factors}

Hypertension not only increases the mechanical load of the myocardial cells, it is also associated with enhanced plasma levels of various neurohumoral factors. Moreover, beside exposure to humoral factors from the blood, the cardiac wall consists of different cell types that all have been shown to produce and excrete a variety of autocrine/paracrine factors ${ }^{2}$ (figure 2). Many of these endocrine and autocrine/paracrine factors were found to be able to stimulate cardiomyocyte hypertrophy and fibroblast-mediated ECM production. The role of several growth factors that are considered to play a critical role in cardiac remodelling, namely AngII, TGF $\beta$ and IGF1, is discussed in detail below.

\section{Angll: site of production and relationship to cardiomyocyte hypertrophy}

Indications for the pro-hypertrophic effect of Angll were obtained in the clinical setting. Patients with chronic hypertension eventually develop left ventricle hypertrophy (LVH). 
Treatment of these patients with anti-hypertensive agents, such as Angll receptor type1 (AT-1) blockers and angiotensin converting enzyme (ACE) inhibitors ${ }^{35}$, resulted in significantly less hospitalisation and improved survival ${ }^{36-39}$. At the same time, cardiac remodelling processes such as LV hypertrophy and ECM accumulation regressed, and progression into heart failure were partially prevented. These findings were substantiated in animal models ${ }^{40,41}$. The above-mentioned anti-hypertensive drugs interfere with the Renin Angiotensin System (RAS). The RAS has an important function in systemic blood pressure regulation. Over-activation of this system is associated with Angll formation and high blood pressure resulting in increased hemodynamic loading of the heart. AngIl, the active component of the RAS system, is an important humoral (systemic), and local autocrine/paracrine factor exerting a potent trophic effect on cardiac cells both in vivo ${ }^{29,42-44}$ and in vitro ${ }^{45-48}$. Angll is a multifunctional peptide, as it acts as vasoconstrictor, stimulates $\mathrm{Na}^{+} / \mathrm{H}^{+}$exchangers in the kidney, and enhances aldosterone and vasopressin secretion from the adrenal cortex and hypothalamus, respectively ${ }^{49}$. In the heart, Angll appears to stimulate cardiomyocyte growth and production of ECM by cardiac fibroblasts (see for details below). This Angll might be blood-borne, but the heart itself is also able to produce Angll. Extra-cardiac, endocrine Angll formation depends on angiotensinogen production in and release from the liver, renin excretion by the kidney, and that is ACE primarily present in lung and renal endothelial cells ${ }^{50}$ (figure 3 ). The expression of important components of the RAS system, such as renin, angiotensinogen and ACE was also established in rat cardiac tissue ${ }^{51}$, and in cultures of isolated neonatal rat cardiomyocytes ${ }^{52,53}$. The expression of these RAS components appeared to be regulated by enhanced ventricle loading and cellular stretch ${ }^{26,52,54,55}$. Stretch of cultured neonatal rat cardiomyocytes resulted in release of Ang $\mathrm{II}^{47}$.

It remains to be established whether other cardiac cell types, including fibroblasts and vascular cells, are also able to release Angll. Cardiac Angll production seems to depend on systemic ${ }^{50}$ and locally produced enzymes and factors, required for Angll formation and activation ${ }^{51,56,57}$. 


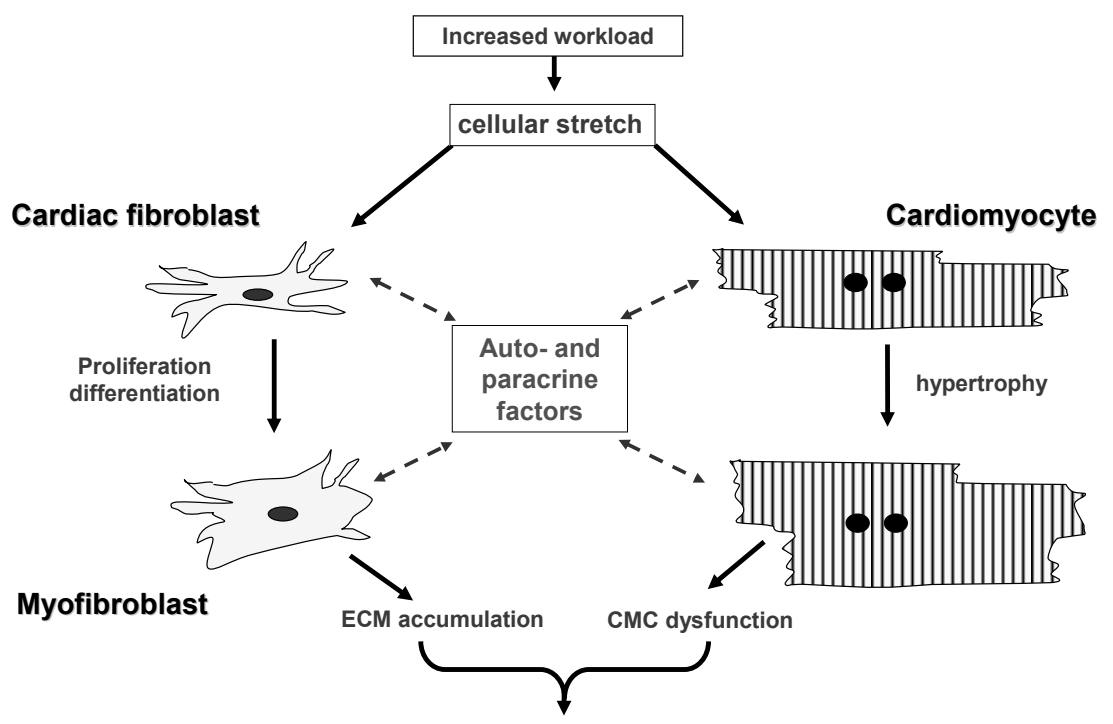

Fibrosis / cardiac dysfunction

Figure 2: Schematic representation how increased cardiac/myocardial workload might affect cardiomyocyte and cardiac fibroblast behaviour and phenotype. ECM and CMC refer to extracellular matrix and cardiomyocyte, respectively.

It has been shown that Angll acts directly on cultured neonatal and adult cardiomyocytes, fibroblasts and other cardiac cells resulting in cardiomyocyte hypertrophy, and fibroblast proliferation and formation of ECM constituents ${ }^{58}$. Pre-treatment of cultured neonatal rat cardiac cells with AT-1 blockers and ACE inhibitors resulted in inhibition of Angll-mediated hypertrophic effects ${ }^{53,58}$, suggesting that angiotensin I converting enzymes and AT-1 receptors play an important role in Angll-mediated effects. When Angll is excreted into the extracellular environment it can bind to its cognate receptor, the AT-1 receptor, to initiate hypertrophic effects in adult ${ }^{59}$ and neonatal rat cardiomyocytes. This is reflected by increased protein synthesis ${ }^{45,46}$ and enhanced mRNA expression of hypertrophic genes such as BNP and ANF ${ }^{58}$. Binding of Angll to AT-1 receptors results in activation of intracellular G-proteins ${ }^{60,61}$, initiating the activation of various downstream signalling cascades, including, (i) the mitogen-activated protein kinase (MAPK) Extracellular signal Regulated Kinase $(E R K)^{62}$, (ii) the Janus-associated kinases/signal transducers and activators of transcription (JAK/STAT), (iii) stressactivated protein kinase/c-Jun $\mathrm{NH}_{2}$-terminal kinase (SAPK/JNK) ${ }^{63}$ and (iv) the $\mathrm{Ca}^{2+} /$ calmodulin-dependent phosphatase calcineurin pathway. Other investigators showed that overexpression of AT-1 receptors in mice being deficient in $\mathrm{G}_{\alpha q}$-protein failed to develop cardiac hypertrophy in response to pressure overload ${ }^{64}$, indicating that $A T-1 / G_{\alpha q}$-protein mediated signalling is critically involved in the development of hypertrophy. Interventions like cardiac cell stretching ${ }^{65}$ and aortic ligation activated the 
same pathways as Angll, that is, activation of ERK ${ }^{65}$, the SAPK/JNK pathway ${ }^{66}$ and the calcineurin pathway ${ }^{67}$. For more details about the signalling pathways involved in cardiac hypertrophy the reader is referred to two excellent reviews ${ }^{65,68}$. In general, experimental data suggest that cell stretching, the binding of Angll to its receptor and the development of cardiac hypertrophy go together. However, recent findings have challenged this concept as stretch of cardiomyocytes is believed to induce a conformational change in the AT-1 receptor leading to the activation of downstream hypertrophic pathways without involvement of Angll binding ${ }^{69,70}$. The concept of Angll-independent AT-1 receptor activation has originally been proposed by Zou and coworkers ${ }^{69}$. It is of note, however, that their findings were obtained in short-lasting experiments using cell cultures of murine neonatal and adult cardiomyocytes. Since the development of cardiac hypertrophy is a long-lasting process, the concept of Zou and colleagues ${ }^{69}$ therefore needs further substantiation in the in vivo setting.

\section{Role of Angll in fibrosis}

As indicated above, the formation of ECM proteins is associated with mechanical load and concomitant activation of humoral systems, including the RAS system ${ }^{28}$. Several in vivo $^{28,40,71}$ and in vitro ${ }^{72-74}$ studies indicated that Angll plays an important role in cardiac fibrosis. In particular, the administration of Angll to animal models as well as cell cultures of neonatal and adult rat cardiac fibroblasts was found to increase the expression of collagen type-I and type-III, fibronectin, and the synthesis of other matrix related proteins, such as $\mathrm{CTGF}^{73-77,78}$. Cardiac fibroblasts express AT-1 receptors ${ }^{29,72,73}$ and probably several components of the RAS system as well, including ACE and angiotensinogen $^{52,79,80}$. These findings suggest that, in addition to cardiomyocytes, cardiac fibroblasts might play an important role in local Angll synthesis and therefore in Angllmediated ECM accumulation. Angll-induced effects on cardiac fibroblasts were most likely mediated by AT-1 receptors, since pre-treatment of fibroblasts with specific AT-1 receptor blockers, including losartan, irbesartan and candesartan, inhibited or prevented the Angll-mediated effects on ECM formation ${ }^{29,72,74,75}$. Although both cardiomyocytes and fibroblasts express AT-1 receptors, the expression of these receptors in fibroblasts is substantially (8-fold) higher ${ }^{53,81,82}$. Expression of AT-1 receptors was found to decline in cardiomyocytes derived from failing human hearts compared to those from healthy donor hearts ${ }^{83}$.

The collective findings therefore suggest that under these conditions, fibroblasts are the main targets of Angl| ${ }^{53,84}$.

\section{Site of TGF $\beta$ expression and role in cardiomyocyte hypertrophy}

An emerging body of evidence indicates that mechanical stimulation of cardiomyocytes and fibroblasts results in release of growth factors, which may act as autocrine/para- 
crine agents to modulate cellular transcription, cellular protein synthesis and cell function. Of particular interest are those factors known to be associated with the modulation of cardiomyocyte growth, including TGF $\beta$. TGF $\beta$ s are a family of secreted signalling compounds with multiple effects on cardiac cells. Until now, five isoforms have been described with TGF $\beta 1$, TGF $\beta 2$ and TGF $\beta 3$ being expressed in the heart ${ }^{85}$. Enhanced expression of TGF $\beta 1$ was associated with remodelling processes such as cardiac hypertrophy and fibrosis via cardiomyocyte growth and fibroblast activation, respectively $^{25,86,87}$.

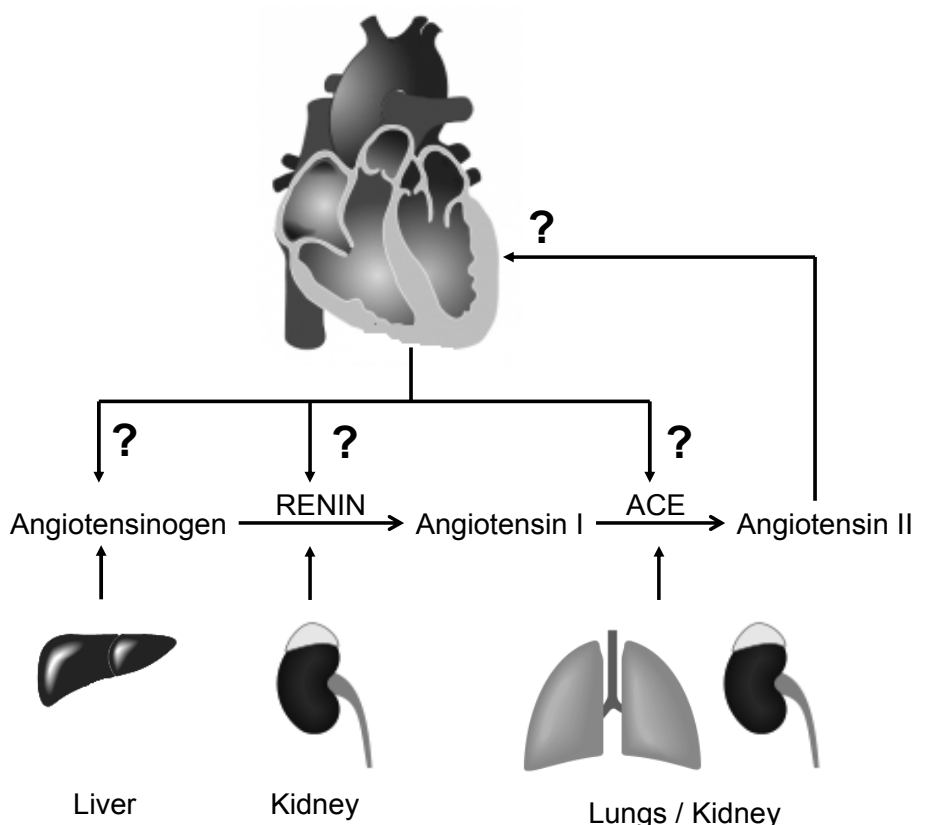

Figure 3: A simplified overview of the Renin-Angiotensin-System (RAS) cascade. Angiotensinogen is produced in and secreted from the liver into the systemic circulation. Renin, formed in the kidneys, cleaves angiotensin into angiotensin I, which in turn is converted to Angll by ACE. ACE is abundantly present in lung and kidney endothelial cells. Circulating Angll can bind to specific AT-1 receptors in the heart to initiate its putative hypertrophic effect. Components of the RAS system, including angiotensin, renin and ACE, are also present in the heart and lead to local Angll formation.

Under pathological conditions, mRNA levels of cardiac TGF $\beta$ were found to be increased compared to the healthy heart ${ }^{88}$. Both neonatal and adult murine cardiomyocytes express this growth factor ${ }^{89}$. The non-stressed heart contains significant quantities of latent TGF $\beta$ in the interstitial compartment ${ }^{90}$. Under challenging conditions, such as systemic hypertension, the latent TGF $\beta$ is converted into active TGF $\beta^{91}$. The latter is a crucial step, since the latent TGF $\beta$ is not able to bind to its cognate cell membrane receptors $^{24}$. The molecular mechanism responsible for the transition of latent to active 
TGF $\beta$ remains to be elucidated. Several proteins, including $\mathrm{MMPs}^{24}$ and thrombospondin ${ }^{92}$ have been proposed to act as TGF $\beta$ activators. Recent findings of Shi et al. showed that activation of TGF $\beta 1$ requires the binding of $\alpha_{v} \beta_{6}$ integrin to the highly conserved tripeptide sequence RGD (Arg-Gly-Asp) in the prodomain and exertion of force on this prodomain is involved in TGF $\beta 1$ activation ${ }^{93}$. There are three TGF $\beta$ receptors identified: the transmembrane type-I, type-II, and type-III receptors ${ }^{94,95}$. Both cardiomyocytes and cardiac fibroblasts express TGF $\beta$ type-I and type-II receptors on their surface membrane ${ }^{85,96}$. Binding of active TGF $\beta$ to its receptors resulted in phosphorylation of SMAD proteins. Once phosphorylated, SMAD heterotrimeric complexes are formed, which translocate to the nucleus, where they bind to SMAD-response elements to initiate gene transcription ${ }^{94,95,97}$. Beside activation of SMAD, TGF $\beta$ activates MAPKs ${ }^{24}$ including ERK and JNK, which are thought to play an important role in cardiomyocyte growth and, hence, cardiac hypertrophy ${ }^{98}$. These kinases also become activated in cultures of neonatal rat cardiomyocytes after stretch or stimulation with growth factors like Angl| ${ }^{65,66}$. Several in vitro and in vivo studies demonstrated that TGF $\beta$ promotes a hypertrophic response ${ }^{86,99}$, characterized by reactivation of the fetal gene programme $^{87,100}$. As described before, Angll has been suggested to play an important role in signalling processes involved in pathological cardiac hypertrophy. It has been proposed that Angll-mediated effects might be evoked indirectly via TGF $\beta$, since AT-1 blockers and ACE inhibitors lowered TGF $\beta 1$ levels in hypertrophied cardiac muscle ${ }^{101}$. This finding is supported by in vitro studies where Angll stimulates mRNA transcription and protein synthesis of TGF $\beta$ in neonatal rat cardiomyocytes ${ }^{82}$. The latter suggests that TGF $\beta$ induction in the hypertrophied cardiac muscle is mediated through Angll signalling.

\section{Role of TGF $\beta$ in cardiac fibrosis}

TGF $\beta$ is a potent stimulus for fibroblast-to-myofibroblast transition and for increased synthesis of ECM proteins ${ }^{86,102,103}$. In addition, TGF $\beta$ is thought to inhibit degradation of newly formed ECM proteins via inhibition of MMPs. The latter is accomplished by increased synthesis of protease inhibitors such as TIMPs ${ }^{97}$. The combined effects lead to enhanced accumulation of collagens and other ECM proteins. TGF $\beta 1$ is therefore both a growth factor and a pro-fibrotic cytokine, stimulating the production and deposition of ECM proteins.

Mechanical stimulation of cardiac fibroblasts was found to be a potent trigger for TGF $\beta 1$ release ${ }^{104}$. Exposure of neonatal and adult rat cardiac fibroblasts to static and/or cyclic stretch resulted in increased mRNA expression of collagen type-I and collagen type- $\mathrm{III}^{105}$. Cultured neonatal rat heart fibroblasts subjected to cyclic stretch released active TGF $\beta$ into the culture medium ${ }^{106}$. In parallel with TGF $\beta 1$ secretion, collagen typeI promoter activity was increased ${ }^{107}$. Transcription of the pro-collagen type-I gene was 
found to be stimulated by TGF $\beta 1$, since anti-TGF $\beta 1$ antibodies prevented the stimulatory response ${ }^{107}$. Exposure of cultured human ${ }^{108}$ and rat cardiac fibroblasts to TGF $\beta 1$ increased the expression of ECM mRNAs, including collagen type- ${ }^{107}$ and collagen type$\mathrm{III}^{109}$, and that of $\mathrm{CTGF}^{24,110}$. Furthermore, exposure of cardiac fibroblasts to TGF $\beta 1$ resulted in enhanced synthesis of TIMP-1 and stimulated the transition of fibroblast to myofibroblast ${ }^{103,108}$. Recent experimental data suggest that the pro-fibrotic effects of TGF $\beta$ may be partially mediated by CTGF ${ }^{111}$.

CTGF is considered to be an essential mediator for the biological actions of TGF $\beta 1$ and its downstream signal transduction pathway ${ }^{112,113}$. The CTGF protein contains four structural modules, which follow a 37 amino acid leader peptide sequence (i) an insulinlike growth factor binding protein module, (ii) a von Willebrand factor type $\mathrm{C}$ module, (iii) a thrombospondin-type I homology module and (iv) a carboxy-terminal cysteine knot motif, heparin-binding module ${ }^{114,115}$. These modules are able to bind growth factors, including IGF-1 and TGF $\beta 1$ and the interaction between CTGF and its binding partners modulates their biological activity ${ }^{116}$. Binding of growth factors to specific CTGF modules resulted in collagen deposition, cell proliferation and cell transdifferentation and this eventually led to fibrosis ${ }^{115}$. The TGF $\beta 1$-mediated effects on fibroblast CTGF and collagen mRNA expression ${ }^{110,117,118}$ were blocked by anti-CTGF antibodies and antisense oligonucleotides ${ }^{119}$. Therefore, CTGF is considered a downstream mediator of TGF $\beta 1$-related ECM formation by fibroblasts. Interestingly, exposure of neonatal rat cardiomyocytes and cardiac fibroblasts to TGF $\beta$ resulted in auto-induction of TGF $\beta^{120}$. The auto-induction of TGF $\beta 1$ might be important in cardiac pathology as TGF $\beta$ leads to remodelling of the heart. It is unclear, however, whether adult, fully differentiated cardiac cells behave similarly in this respect.

Summarizing, at present it is still unclear if and to what extent mechanical stimulation per se, and growth factors like TGF $\beta 1$ and CTGF are responsible for cardiac fibrosis.

\section{Site of IGF-1 production and relationship to cardiomyocyte hypertrophy}

IGF-1 is a protein composed of 70 amino acids with structural similarity to insulin. IGF-1 plays a role in a broad range of physiological processes, including cardiac development $^{121}$, stimulation of cell division ${ }^{122-124}$, enhanced protein synthesis ${ }^{123-125}$, cardiomyocyte contractility via interference with intracellular $\mathrm{Ca}^{2+}$ handling ${ }^{126,127}$, and expression of genes encoding myocardial contractile proteins ${ }^{124,128}$.

The presence of IGF-1 mRNA and protein has been established in cardiac muscle ${ }^{129}$. Moreover, cardiac IGF-1 content was increased in an experimental Angll-induced hypertension model ${ }^{130}$. The biological action of IGF-1 occurs primarily via the IGF-1 receptor (IGF-1R) present on the membrane of cardiomyocytes and cardiac fibroblasts ${ }^{124,131}$. IGF-1R is a member of the tyrosine kinase receptor family, and binding of IGF-1 to IGF$1 R$ results in phosphorylation of insulin receptor substrate (IRS) and subsequent downstream activation of kinases like PI3-kinase, Glycogen Synthase Kinase (GSK) and ERK ${ }^{132-}$ 
${ }^{134}$, which are known to be activated during hypertrophy ${ }^{135,136}$. Clinical and experimental studies showed a correlation between increased blood pressure and circulating IGF1 levels ${ }^{137}$. Furthermore, both cardiac mRNA and protein levels of IGF-1 were elevated in parallel with the development of hypertension in hypertensive rat models ${ }^{135}$. Chronic hypertension enhances cardiac wall stress and cellular stretch, which might be a trigger for enhanced IGF-1 expression by cardiac cells ${ }^{138}$. Although the precise role of IGF-1 in cardiac muscle is still unclear, it has been suggested that IGF-1 possesses protective properties as it was found to improve cardiac function after myocardial infarction in rats and in patients with congestive heart failure via reduction of cardiac afterload $^{139,140}$. Moreover, a recent study demonstrated that locally expressed cardiac IGF-1 results in physiological hypertrophy ${ }^{136}$. However, little is known about the site of IGF-1 production. Circulating IGF-1 is mainly secreted by the liver and the heart-specific IGF-1 production has been suggested to be restricted to cardiac fibroblasts ${ }^{138}$. Potential stimuli for enhancing cardiac fibroblast IGF-1 transcription and synthesis are Angll, other growth factors including TGF $\beta$, and increased mechanical loading of the heart ${ }^{138}$.

Immunohistochemical studies revealed that cardiac tissue expresses IGF-1 and that its expression is most likely confined to ventricular myocytes ${ }^{135,141}$, but other investigators failed to detect IGF-1 mRNA and protein in cell cultures of neonatal rat cardiomyocytes $^{142}$. Accordingly, the cellular source(s) of IGF-1 in the heart under normal and challenging conditions are still a matter of debate.

IGF-1 released by non-muscle cells may act as a paracrine factor as cardiomyocytes express IGF-1 receptors ${ }^{142}$. This notion is supported by in vitro experiments ${ }^{143,144}$ and patient studies ${ }^{145,146}$, showing that IGF-1 is associated with the development of cardiomyocyte hypertrophy. Moreover, administration of IGF-1 to neonatal and adult rat cardiomyocytes resulted in enhanced protein synthesis, increased myofibril production, and induction of ANF expression ${ }^{123,124,147,138}$. Although the expression of IGF-1 is increased during physiological challenges like exercise ${ }^{148,149}$ and under pathological circumstances such as systemic hypertension ${ }^{135}$, it is still unclear whether this growth factor is beneficial or detrimental for the cardiac muscle. Further studies are needed to understand the trigger, source and cellular function of IGF-1 in cardiac hypertrophy.

\section{Role of IGF-1 in cardiac fibrosis}

In addition to left ventricular hypertrophy, IGF-1 expression is associated with cardiac fibrosis. Exposure of isolated neonatal cardiac fibroblasts to IGF-1 results in enhanced proliferation $^{150}$, increased collagen transcription ${ }^{131,142,151}$ and activation of MMPs ${ }^{152}$, suggesting that IGF-1 plays an important role in fibrosis. A recent study supports the notion that IGF-1 acts as an autocrine/paracrine growth factor, since mechanical stretch of rat cardiac fibroblasts from adult rats resulted in increased expression of IGF$1^{138}$ and exposure of cardiac neonatal and adult rat fibroblasts to IGF-1 led to increased collagen expression ${ }^{142,152,153}$. The response of cardiac fibroblasts to IGF-1 differs be- 
tween fetal, neonatal and adult isolated cells ${ }^{154}$. Earlier studies suggested that ECM components including collagens also play an important role in regulating IGF-1 synthesis and function ${ }^{153}$.

Cellular stretch has been proposed to be an important stimulus for IGF-1 induction $^{130,142}$. Furthermore, IGF-1 transcription during mechanical stretch was found to be frequency- and time-dependent ${ }^{138}$. When IGF-1 is excreted into the myocardial interstitial compartment, the availability and biological activity of IGF-1 is modulated by socalled IGF-binding proteins (IGFBPs). One of the IGFBPs is known as IGFBP-rP2, later named $\mathrm{CTGF}^{134}$. Interaction of CTGF with IGF-1 enhances IGF-1 activity and induces collagen production by fibroblasts ${ }^{155}$. This effect of IGF-1 on fibroblast proliferation and collagen synthesis is mediated via specific IGF-1 receptors and via CTGF binding ${ }^{156}$. The expression of IGF-1 receptors on cardiac fibroblasts is partially Angll dependent, since ACE blockers interfere with IGF-1 mediated processes ${ }^{131}$. To fully understand the potential role of IGF-1 in cardiac fibrosis, further experimentation is required.

\section{Other growth factors and cell types involved in cardiac remodelling}

Besides mechanical stimulation and the growth factors discussed above, other factors such as endothelin-1, cardiotrophin-1, aldosterone, and natriuretic peptides, have been implicated in the development of myocardial hypertrophy and fibrosis ${ }^{25,98,115}$. Although much attention has been paid to cardiac fibroblasts and cardiomyocytes, other cells present in the cardiac muscle might also play an important role in these processes. It has been shown that cultures of vascular smooth muscle cells subjected to stretch release endothelin-1 $(E T-1)^{157}$, while stretched endothelial cells released growth factors such as TGF $\beta^{106}$. Furthermore, exposure of neonatal cardiomyocytes to $\alpha$-adrenergic agonists and ET-1 resulted in CTGF upregulation and enhanced transcription of hypertrophic genes like ANF and increased protein synthesis. Accordingly, it is to be expected that factors other than AngII, TGF- $\beta$ and IGF-1, and cell types other than cardiomyocytes and fibroblasts, are of significance in cardiac hypertrophy and fibrosis, warranting future research to elucidate their precise role in the development of cardiac remodelling.

\section{Models to study hypertrophy: in vivo and in vitro limitations}

Our knowledge about the nature of the main triggers of cardiac hypertrophy and fibrosis and their mutual interaction in the clinical setting still shows important gaps. Experimental models, both intact animals ${ }^{158}$ and isolated cells ${ }^{159}$, are important tools to fill these gaps. In vivo models are well suited to investigate alterations in (i) gene expression, (ii) tissue mass, (iii) ECM composition and (iv) cardiac function, in relation to global changes in hemodynamic load. However, understanding the exact mechanisms of hypertrophy and fibrosis in in vivo models is limited due to the fact that the heart is 
composed of multiple cell types and that changes in hemodynamic load are often accompanied by changes in plasma levels of neurohumoral factors and growth factors.

Another limitation of the experimental in vivo models is that hearts of species that are commonly used in experimental studies (mice, rats, dogs, and pigs) differ from the human heart in various aspects, thereby hampering proper extrapolation of findings to the clinical setting. Notably, most experimental studies have been performed in small animals (mice and rats). The use of genetically modified mouse models, in particular, has greatly advanced our understanding of the complex nature of cardiac growth and fibrosis $^{158}$ and of potential molecular mechanisms involved in these remodelling processes. However, the cardiac structure, vasculature, gene expression pattern and functional characteristics, like predominant expression of $\beta$ - MHC, calcium handling and action potential morphology, between murine and human hearts deviate substantially. Accordingly, comparison should be done with care. In this respect, the physiology of hearts of larger animal species, such as the rabbit, shows more resemblance to the human heart ${ }^{158,160}$. It would therefore be worthwhile to use the rabbit for in vitro and in vivo studies aimed at investigating the mechanisms underlying cardiac hypertrophy and fibrosis.

In order to dissect and better understand the complex in vivo situation with is cell heterogeneity and involvement of autocrine/paracrine factors in cardiac hypertrophy and fibrosis, in vitro experimental models of isolated heart cells have been developed. In vitro studies have been mainly performed using primary cultures of cardiac cells from neonatal and adult rats. Isolated cardiac cells were allowed to attach and grow on silicon membranes pre-coated with extracellular matrix components, such as collagen, fibronectin or laminin ${ }^{159}$. Surface receptors like integrins and cadherins, present on the cell membrane attach to the ECM constituents present on the pre-coated silicone membranes. To study the involvement of mechanical factors the isolated cardiac cells were generally subjected to static or cyclic stretch in uni- or biaxial directions ${ }^{47,161}$. In this way, a host of the growth factors and signalling molecules involved in mechanobiology, and implicated in the regulation of stretch-induced cardiac hypertrophy have been identified. Notably, most of these studies were performed with primary cultures of neonatal rat cardiomyocytes, which were initially used as the mainstay model system for the analysis of cardiomyocyte responses ${ }^{47,106,157}$. Stretch of neonatal rat cardiomyocytes resulted in molecular alterations including re-activation of the fetal gene programme, upregulation of pro-inflammatory cytokines, excretion of growth factors, and disturbed expression of genes involved in $\mathrm{Ca}^{2+}$ handling ${ }^{2,98}$. Collectively, these studies suggested an important role of Angll in stretch-induced remodelling of the cardiac muscle cell ${ }^{162,163}$. In addition to Angll, other growth factors such as transforming growth factor (TGF- $\beta 1$ ) and IGF-1 have been associated with cardiac fibrosis and cardiomyocyte growth $^{24,83,86,99,107,110,136,142,151}$. It should be noted, however, that neonatal cardiomyocytes differ from adult cardiomyocytes in that the former are not fully differentiated ${ }^{164}$ and still have a relatively high expression of fetal genes, like alpha-myosin heavy chain 
$(\alpha-\mathrm{MHC})^{165}$. In this respect, cardiac cells isolated from adult hearts seem to be a more appropriate in vitro model to investigate mechanisms underlying myocardial hypertrophy and fibrosis.

\section{CONCLUDING REMARKS}

Despite compelling evidence that mechanical stimulation as well as growth factors play significant roles in cardiac fibrosis and hypertrophy, it is still unclear which trigger is primarily responsible for the initiation of these processes and which cell types are involved in what part of the process. Although valuable contributions to this field have already been made using cells isolated from neonatal rat hearts and in vivo rodent models, the translational value will be higher when such experiments are performed with (cells isolated from) adult hearts of larger species, such as the rabbit. Therefore, for the studies in the present thesis the rabbit was chosen as species of investigation and in vitro experiments were performed on cells isolated from adult hearts, and on intact hearts of adult rabbits in vivo. 


\section{REFERENCES}

1. Zannad F, Rossignol P, Iraqi W. Extracellular matrix fibrotic markers in heart failure. Heart Fail Rev. 2009.

2. Gupta V, Grande-Allen KJ. Effects of static and cyclic loading in regulating extracellular matrix synthesis by cardiovascular cells. Cardiovasc Res. 2006;72(3):375-383.

3. Chen CC, Lau LF. Functions and mechanisms of action of CCN matricellular proteins. Int J Biochem Cell Biol. 2009;41(4):771-783.

4. Farhadian F, Contard F, Corbier A, Barrieux A, Rappaport L, Samuel JL. Fibronectin expression during physiological and pathological cardiac growth. J Mol Cell Cardiol. 1995;27(4):981-990.

5. Borg TK, Caulfield JB. Collagen in the heart. Tex Rep Biol Med. 1979;39:321-333.

6. Weber KT, Jalil JE, Janicki JS, Pick R. Myocardial collagen remodeling in pressure overload hypertrophy. A case for interstitial heart disease. Am J Hypertens. 1989;2(12 Pt 1):931-940.

7. Banerjee I, Yekkala K, Borg TK, Baudino TA. Dynamic interactions between myocytes, fibroblasts, and extracellular matrix. Ann N Y Acad Sci. 2006;1080:76-84.

8. Kakkar R, Lee RT. Intramyocardial fibroblast myocyte communication. Circ Res. 2010;106(1):47-57.

9. Ross RS, Borg TK. Integrins and the myocardium. Circ Res. 2001;88(11):1112-1119.

10. Takeda N, Manabe I. Cellular Interplay between Cardiomyocytes and Nonmyocytes in Cardiac Remodeling. Int J Inflam. 2011;2011:535241.

11. Zak R. Cell proliferation during cardiac growth. Am J Cardiol. 1973;31(2):211-219.

12. McMullen JR, Jennings GL. Differences between pathological and physiological cardiac hypertrophy: novel therapeutic strategies to treat heart failure. Clin Exp Pharmacol Physiol. 2007;34(4):255-262.

13. Mone SM, Sanders SP, Colan SD. Control mechanisms for physiological hypertrophy of pregnancy. Circulation. 1996;94(4):667-672.

14. Heineke J, Molkentin JD. Regulation of cardiac hypertrophy by intracellular signalling pathways. Nat Rev Mol Cell Biol. 2006;7(8):589-600.

15. Manabe I, Shindo T, Nagai R. Gene expression in fibroblasts and fibrosis: involvement in cardiac hypertrophy. Circ Res. 2002;91(12):1103-1113.

16. Eghbali M. Cardiac fibroblasts: function, regulation of gene expression, and phenotypic modulation. Basic Res Cardiol. 1992;87 Suppl 2:183-189.

17. Visse R, Nagase H. Matrix metalloproteinases and tissue inhibitors of metalloproteinases: structure, function, and biochemistry. Circ Res. 2003;92(8):827-839.

18. Camelliti P, Borg TK, Kohl P. Structural and functional characterisation of cardiac fibroblasts. Cardiovasc Res. 2005;65(1):40-51.

19. Schild C, Trueb B. Mechanical stress is required for high-level expression of connective tissue growth factor. Exp Cell Res. 2002;274(1):83-91.

20. Tyagi SC, Lewis K, Pikes D, Marcello A, Mujumdar VS, Smiley LM, Moore CK. Stretch-induced membrane type matrix metalloproteinase and tissue plasminogen activator in cardiac fibroblast cells. J Cell Physiol. 1998;176(2):374-382.

21. Bashey RI, Donnelly M, Insinga F, Jimenez SA. Growth properties and biochemical characterization of collagens synthesized by adult rat heart fibroblasts in culture. J Mol Cell Cardiol. 1992;24(7):691-700.

22. Spinale FG. Matrix metalloproteinases: regulation and dysregulation in the failing heart. Circ Res. 2002;90(5):520-530.

23. Weber KT, Swamynathan SK, Guntaka RV, Sun Y. Angiotensin II and extracellular matrix homeostasis. Int J Biochem Cell Biol. 1999;31(3-4):395-403.

24. Bujak M, Frangogiannis NG. The role of TGF-beta signaling in myocardial infarction and cardiac remodeling. Cardiovasc Res. 2007;74(2):184-195.

25. Rosenkranz S. TGF-beta1 and angiotensin networking in cardiac remodeling. Cardiovasc Res. 2004;63(3):423-432.

26. Weber KT, Brilla CG, Campbell SE. Regulatory mechanisms of myocardial hypertrophy and fibrosis: results of in vivo studies. Cardiology. 1992;81(4-5):266-273. 
27. Santiago JJ, Dangerfield AL, Rattan SG, Bathe KL, Cunnington RH, Raizman JE, Bedosky KM, Freed DH, Kardami E, Dixon IM. Cardiac fibroblast to myofibroblast differentiation in vivo and in vitro: expression of focal adhesion components in neonatal and adult rat ventricular myofibroblasts. Dev Dyn. 2010;239(6):1573-1584.

28. Berk BC, Fujiwara K, Lehoux S. ECM remodeling in hypertensive heart disease. J Clin Invest. 2007;117(3):568-575.

29. Kim NN, Villarreal FJ, Printz MP, Lee AA, Dillmann WH. Trophic effects of angiotensin II on neonatal rat cardiac myocytes are mediated by cardiac fibroblasts. Am J Physiol. 1995;269(3 Pt 1):E426-437.

30. LaFramboise WA, Scalise D, Stoodley P, Graner SR, Guthrie RD, Magovern JA, Becich MJ. Cardiac fibroblasts influence cardiomyocyte phenotype in vitro. Am J Physiol Cell Physiol. 2007;292(5):C1799-1808.

31. Kohl P. Cardiac cellular heterogeneity and remodelling. Cardiovasc Res. 2004;64(2):195-197.

32. Villarreal FJ, Lew WY. Finite strains in anterior and posterior wall of canine left ventricle. Am J Physiol. 1990;259(5 Pt 2):H1409-1418.

33. Bader M. Tissue renin-angiotensin-aldosterone systems: Targets for pharmacological therapy. Annu Rev Pharmacol Toxicol. 2010;50:439-465.

34. Matsusaka T, Katori H, Homma T, Ichikawa I. Mechanism of cardiac fibrosis by angiotensin. New insight revealed by genetic engineering. Trends Cardiovasc Med. 1999;9(7):180-184.

35. Arshad A, Mandava A, Kamath G, Musat D. Sudden cardiac death and the role of medical therapy. Prog Cardiovasc Dis. 2008;50(6):420-438.

36. Young JB, Dunlap ME, Pfeffer MA, Probstfield JL, Cohen-Solal A, Dietz R, Granger CB, Hradec J, Kuch J, McKelvie RS, McMurray JJ, Michelson EL, Olofsson B, Ostergren J, Held P, Solomon SD, Yusuf S, Swedberg K. Mortality and morbidity reduction with Candesartan in patients with chronic heart failure and left ventricular systolic dysfunction: results of the CHARM low-left ventricular ejection fraction trials. Circulation. 2004;110(17):2618-2626.

37. Lee VC, Rhew DC, Dylan M, Badamgarav E, Braunstein GD, Weingarten SR. Meta-analysis: angiotensinreceptor blockers in chronic heart failure and high-risk acute myocardial infarction. Ann Intern Med. 2004;141(9):693-704.

38. Names N. Effect of enalapril on survival in patients with reduced left ventricular ejection fractions and congestive heart failure. The SOLVD Investigators. N Engl J Med. 1991;325(5):293-302.

39. Saito K, Gutkind JS, Saavedra JM. Angiotensin II binding sites in the conduction system of rat hearts. Am J Physiol. 1987;253(6 Pt 2):H1618-1622.

40. Yamamoto K, Mano T, Yoshida J, Sakata Y, Nishikawa N, Nishio M, Ohtani T, Hori M, Miwa T, Masuyama T. ACE inhibitor and angiotensin II type 1 receptor blocker differently regulate ventricular fibrosis in hypertensive diastolic heart failure. J Hypertens. 2005;23(2):393-400.

41. Jorde UP. Suppression of the renin-angiotensin-aldosterone system in chronic heart failure: choice of agents and clinical impact. Cardiol Rev. 2006;14(2):81-87.

42. Geenen DL, Malhotra A, Scheuer J. Angiotensin II increases cardiac protein synthesis in adult rat heart. Am J Physiol. 1993;265(1 Pt 2):H238-243.

43. Dostal DE, Baker KM. Angiotensin II stimulation of left ventricular hypertrophy in adult rat heart. Mediation by the AT1 receptor. Am J Hypertens. 1992;5(5 Pt 1):276-280.

44. Higashi M, Shimokawa H, Hattori T, Hiroki J, Mukai Y, Morikawa K, Ichiki T, Takahashi S, Takeshita A. Long-term inhibition of Rho-kinase suppresses angiotensin Il-induced cardiovascular hypertrophy in rats in vivo: effect on endothelial NAD(P)H oxidase system. Circ Res. 2003;93(8):767-775.

45. Miyata S, Haneda T. Hypertrophic growth of cultured neonatal rat heart cells mediated by type 1 angiotensin II receptor. Am J Physiol. 1994;266(6 Pt 2):H2443-2451.

46. Booz GW, Baker KM. Role of type 1 and type 2 angiotensin receptors in angiotensin II-induced cardiomyocyte hypertrophy. Hypertension. 1996;28(4):635-640.

47. Sadoshima J, Xu Y, Slayter HS, Izumo S. Autocrine release of angiotensin II mediates stretch-induced hypertrophy of cardiac myocytes in vitro. Cell. 1993;75(5):977-984. 
48. Frank D, Kuhn C, Brors B, Hanselmann C, Ludde M, Katus HA, Frey N. Gene expression pattern in biomechanically stretched cardiomyocytes: evidence for a stretch-specific gene program. Hypertension. 2008;51(2):309-318.

49. Adams KF, Jr. Pathophysiologic role of the renin-angiotensin-aldosterone and sympathetic nervous systems in heart failure. Am J Health Syst Pharm. 2004;61 Suppl 2:S4-13.

50. Wollert KC, Drexler $\mathrm{H}$. The renin-angiotensin system and experimental heart failure. Cardiovasc Res. 1999;43(4):838-849.

51. Lindpaintner K, Ganten D. The cardiac renin-angiotensin system. An appraisal of present experimental and clinical evidence. Circ Res. 1991;68(4):905-921.

52. Malhotra R, Sadoshima J, Brosius FC, 3rd, Izumo S. Mechanical stretch and angiotensin II differentially upregulate the renin-angiotensin system in cardiac myocytes In vitro. Circ Res. 1999;85(2):137-146.

53. Lijnen $\mathrm{P}$, Petrov V. Renin-angiotensin system, hypertrophy and gene expression in cardiac myocytes. $J$ Mol Cell Cardiol. 1999;31(5):949-970.

54. Passier RC, Smits JF, Verluyten MJ, Daemen MJ. Expression and localization of renin and angiotensinogen in rat heart after myocardial infarction. Am J Physiol. 1996;271(3 Pt 2):H1040-1048.

55. Shyu KG, Chen JJ, Shih NL, Chang H, Wang DL, Lien WP, Liew CC. Angiotensinogen gene expression is induced by cyclical mechanical stretch in cultured rat cardiomyocytes. Biochem Biophys Res Commun. 1995;211(1):241-248.

56. Schunkert H, Dzau VJ, Tang SS, Hirsch AT, Apstein CS, Lorell BH. Increased rat cardiac angiotensin converting enzyme activity and mRNA expression in pressure overload left ventricular hypertrophy. Effects on coronary resistance, contractility, and relaxation. J Clin Invest. 1990;86(6):1913-1920.

57. Linz W, Scholkens BA, Han YF. Beneficial effects of the converting enzyme inhibitor, ramipril, in ischemic rat hearts. J Cardiovasc Pharmacol. 1986;8 Suppl 10:S91-99.

58. Sadoshima J, Izumo S. Molecular characterization of angiotensin II--induced hypertrophy of cardiac myocytes and hyperplasia of cardiac fibroblasts. Critical role of the AT1 receptor subtype. Circ Res. 1993;73(3):413-423.

59. Sil P, Sen S. Angiotensin II and myocyte growth: role of fibroblasts. Hypertension. 1997;30(2 Pt 1):209216.

60. Sadoshima J, Izumo S. The heterotrimeric G q protein-coupled angiotensin II receptor activates p21 ras via the tyrosine kinase-Shc-Grb2-Sos pathway in cardiac myocytes. Embo J. 1996;15(4):775-787.

61. Dostal DE, Hunt RA, Kule CE, Bhat GJ, Karoor V, McWhinney CD, Baker KM. Molecular mechanisms of angiotensin II in modulating cardiac function: intracardiac effects and signal transduction pathways. $J$ Mol Cell Cardiol. 1997;29(11):2893-2902.

62. Yamazaki T, Komuro I, Kudoh S, Zou Y, Shiojima I, Mizuno T, Takano H, Hiroi Y, Ueki K, Tobe K, et al. Angiotensin II partly mediates mechanical stress-induced cardiac hypertrophy. Circ Res. 1995;77(2):258265.

63. Kudoh S, Komuro I, Mizuno T, Yamazaki T, Zou Y, Shiojima I, Takekoshi N, Yazaki Y. Angiotensin II stimulates c-Jun NH2-terminal kinase in cultured cardiac myocytes of neonatal rats. Circ Res. 1997;80(1):139146.

64. Wettschureck N, Rutten H, Zywietz A, Gehring D, Wilkie TM, Chen J, Chien KR, Offermanns S. Absence of pressure overload induced myocardial hypertrophy after conditional inactivation of Galphaq/Galpha11 in cardiomyocytes. Nat Med. 2001;7(11):1236-1240.

65. Sadoshima J, Izumo S. The cellular and molecular response of cardiac myocytes to mechanical stress. Annu Rev Physiol. 1997;59:551-571.

66. Komuro I, Kudo S, Yamazaki T, Zou Y, Shiojima I, Yazaki Y. Mechanical stretch activates the stressactivated protein kinases in cardiac myocytes. Faseb J. 1996;10(5):631-636.

67. Shimoyama M, Hayashi D, Takimoto E, Zou Y, Oka T, Uozumi H, Kudoh S, Shibasaki F, Yazaki Y, Nagai R, Komuro I. Calcineurin plays a critical role in pressure overload-induced cardiac hypertrophy. Circulation. 1999;100(24):2449-2454.

68. Lammerding J, Kamm RD, Lee RT. Mechanotransduction in cardiac myocytes. Ann N Y Acad Sci. 2004;1015:53-70. 
69. Zou Y, Akazawa H, Qin Y, Sano M, Takano H, Minamino T, Makita N, Iwanaga K, Zhu W, Kudoh S, Toko H, Tamura K, Kihara M, Nagai T, Fukamizu A, Umemura S, liri T, Fujita T, Komuro I. Mechanical stress activates angiotensin II type 1 receptor without the involvement of angiotensin II. Nat Cell Biol. 2004;6(6):499-506.

70. Yasuda N, Miura S, Akazawa H, Tanaka T, Qin Y, Kiya Y, Imaizumi S, Fujino M, Ito K, Zou Y, Fukuhara S, Kunimoto S, Fukuzaki K, Sato T, Ge J, Mochizuki N, Nakaya H, Saku K, Komuro I. Conformational switch of angiotensin II type 1 receptor underlying mechanical stress-induced activation. EMBO Rep. 2008;9(2):179-186.

71. Yoshida J, Yamamoto K, Mano T, Sakata Y, Nishikawa N, Miwa T, Hori M, Masuyama T. Angiotensin II type 1 and endothelin type $A$ receptor antagonists modulate the extracellular matrix regulatory system differently in diastolic heart failure. J Hypertens. 2003;21(2):437-444.

72. Crabos $M$, Roth $M$, Hahn AW, Erne P. Characterization of angiotensin II receptors in cultured adult rat cardiac fibroblasts. Coupling to signaling systems and gene expression. J Clin Invest. 1994;93(6):23722378.

73. Villarreal FJ, Kim NN, Ungab GD, Printz MP, Dillmann WH. Identification of functional angiotensin II receptors on rat cardiac fibroblasts. Circulation. 1993;88(6):2849-2861.

74. Lijnen PJ, Petrov VV, Fagard RH. Induction of cardiac fibrosis by angiotensin II. Methods Find Exp Clin Pharmacol. 2000;22(10):709-723.

75. Crawford DC, Chobanian AV, Brecher P. Angiotensin II induces fibronectin expression associated with cardiac fibrosis in the rat. Circ Res. 1994;74(4):727-739.

76. Brilla CG, Zhou G, Matsubara L, Weber KT. Collagen metabolism in cultured adult rat cardiac fibroblasts: response to angiotensin II and aldosterone. J Mol Cell Cardiol. 1994;26(7):809-820.

77. Bouzegrhane F, Thibault G. Is angiotensin II a proliferative factor of cardiac fibroblasts? Cardiovasc Res. 2002;53(2):304-312.

78. Kim S, Ohta K, Hamaguchi A, Yukimura T, Miura K, Iwao H. Angiotensin II induces cardiac phenotypic modulation and remodeling in vivo in rats. Hypertension. 1995;25(6):1252-1259.

79. Katwa LC, Campbell SE, Tyagi SC, Lee SJ, Cicila GT, Weber KT. Cultured myofibroblasts generate angiotensin peptides de novo. J Mol Cell Cardiol. 1997;29(5):1375-1386.

80. Lal H, Verma SK, Golden HB, Foster DM, Smith M, Dostal DE. Stretch-induced regulation of angiotensinogen gene expression in cardiac myocytes and fibroblasts: opposing roles of JNK1/2 and p38alpha MAP kinases. J Mol Cell Cardiol. 2008;45(6):770-778.

81. Gallagher AM, Bahnson TD, Yu H, Kim NN, Printz MP. Species variability in angiotensin receptor expression by cultured cardiac fibroblasts and the infarcted heart. Am J Physiol. 1998;274(3 Pt 2):H801-809.

82. Gray MO, Long CS, Kalinyak JE, Li HT, Karliner JS. Angiotensin II stimulates cardiac myocyte hypertrophy via paracrine release of TGF-beta 1 and endothelin-1 from fibroblasts. Cardiovasc Res. 1998;40(2):352363.

83. Matsubara H. Renin-angiotensin system in human failing hearts: message from nonmyocyte cells to myocytes. Circ Res. 2001;88(9):861-863.

84. Serneri GG, Boddi M, Cecioni I, Vanni S, Coppo M, Papa ML, Bandinelli B, Bertolozzi I, Polidori G, Toscano T, Maccherini M, Modesti PA. Cardiac angiotensin II formation in the clinical course of heart failure and its relationship with left ventricular function. Circ Res. 2001;88(9):961-968.

85. Brand T, Schneider MD. The TGF beta superfamily in myocardium: ligands, receptors, transduction, and function. J Mol Cell Cardiol. 1995;27(1):5-18.

86. Villarreal FJ, Dillmann WH. Cardiac hypertrophy-induced changes in mRNA levels for TGF-beta 1, fibronectin, and collagen. Am J Physiol. 1992;262(6 Pt 2):H1861-1866.

87. Parker TG, Packer SE, Schneider MD. Peptide growth factors can provoke "fetal" contractile protein gene expression in rat cardiac myocytes. J Clin Invest. 1990;85(2):507-514.

88. Yu HC, Burrell LM, Black MJ, Wu LL, Dilley RJ, Cooper ME, Johnston Cl. Salt induces myocardial and renal fibrosis in normotensive and hypertensive rats. Circulation. 1998;98(23):2621-2628. 
89. Thompson NL, Flanders KC, Smith JM, Ellingsworth LR, Roberts AB, Sporn MB. Expression of transforming growth factor-beta 1 in specific cells and tissues of adult and neonatal mice. J Cell Biol. 1989;108(2):661-669.

90. Annes JP, Munger JS, Rifkin DB. Making sense of latent TGFbeta activation. J Cell Sci. 2003;116(Pt 2):217224.

91. Lyons RM, Keski-Oja J, Moses HL. Proteolytic activation of latent transforming growth factor-beta from fibroblast-conditioned medium. J Cell Biol. 1988;106(5):1659-1665.

92. Murphy-Ullrich JE, Poczatek M. Activation of latent TGF-beta by thrombospondin-1: mechanisms and physiology. Cytokine Growth Factor Rev. 2000;11(1-2):59-69.

93. Shi M, Zhu J, Wang R, Chen X, Mi L, Walz T, Springer TA. Latent TGF-beta structure and activation. Nature. 2011;474(7351):343-349.

94. Massague J. How cells read TGF-beta signals. Nat Rev Mol Cell Biol. 2000;1(3):169-178.

95. Massague J. TGFbeta signaling: receptors, transducers, and Mad proteins. Cell. 1996;85(7):947-950.

96. Li G, Li RK, Mickle DA, Weisel RD, Merante F, Ball WT, Christakis GT, Cusimano RJ, Williams WG. Elevated insulin-like growth factor-I and transforming growth factor-beta 1 and their receptors in patients with idiopathic hypertrophic obstructive cardiomyopathy. A possible mechanism. Circulation. 1998;98(19 Suppl):II144-149; discussion II149-150.

97. Schiller M, Javelaud D, Mauviel A. TGF-beta-induced SMAD signaling and gene regulation: consequences for extracellular matrix remodeling and wound healing. J Dermatol Sci. 2004;35(2):83-92.

98. Ruwhof C, van der Laarse A. Mechanical stress-induced cardiac hypertrophy: mechanisms and signal transduction pathways. Cardiovasc Res. 2000;47(1):23-37.

99. Azhar M, Schultz Jel J, Grupp I, Dorn GW, 2nd, Meneton P, Molin DG, Gittenberger-de Groot AC, Doetschman T. Transforming growth factor beta in cardiovascular development and function. Cytokine Growth Factor Rev. 2003;14(5):391-407.

100. Rosenkranz S, Flesch M, Amann K, Haeuseler C, Kilter H, Seeland U, Schluter KD, Bohm M. Alterations of beta-adrenergic signaling and cardiac hypertrophy in transgenic mice overexpressing TGF-beta(1). American journal of physiology. 2002;283(3):H1253-1262.

101. Kim S, Ohta K, Hamaguchi A, Yukimura T, Miura K, Iwao H. Effects of an AT1 receptor antagonist, an ACE inhibitor and a calcium channel antagonist on cardiac gene expressions in hypertensive rats. Br J Pharmacol. 1996;118(3):549-556.

102. Dugina V, Fontao L, Chaponnier C, Vasiliev J, Gabbiani G. Focal adhesion features during myofibroblastic differentiation are controlled by intracellular and extracellular factors. J Cell Sci. 2001;114(Pt 18):32853296.

103. Cucoranu I, Clempus R, Dikalova A, Phelan PJ, Ariyan S, Dikalov S, Sorescu D. NAD(P)H oxidase 4 mediates transforming growth factor-beta1-induced differentiation of cardiac fibroblasts into myofibroblasts. Circ Res. 2005;97(9):900-907.

104. Lee $A A$, Delhaas $T$, McCulloch $A D$, Villarreal FJ. Differential responses of adult cardiac fibroblasts to in vitro biaxial strain patterns. J Mol Cell Cardiol. 1999;31(10):1833-1843.

105. MacKenna D, Summerour SR, Villarreal FJ. Role of mechanical factors in modulating cardiac fibroblast function and extracellular matrix synthesis. Cardiovasc Res. 2000;46(2):257-263.

106. Ruwhof $C$, van Wamel AE, Egas JM, van der Laarse A. Cyclic stretch induces the release of growth promoting factors from cultured neonatal cardiomyocytes and cardiac fibroblasts. Mol Cell Biochem. 2000;208(1-2):89-98.

107. Lindahl GE, Chambers RC, Papakrivopoulou J, Dawson SJ, Jacobsen MC, Bishop JE, Laurent GJ. Activation of fibroblast procollagen alpha $1(\mathrm{I})$ transcription by mechanical strain is transforming growth factorbeta-dependent and involves increased binding of CCAAT-binding factor (CBF/NF-Y) at the proximal promoter. J Biol Chem. 2002;277(8):6153-6161.

108. Chua CC, Chua BH, Zhao ZY, Krebs C, Diglio C, Perrin E. Effect of growth factors on collagen metabolism in cultured human heart fibroblasts. Connect Tissue Res. 1991;26(4):271-281. 
109. Eghbali M, Tomek R, Sukhatme VP, Woods C, Bhambi B. Differential effects of transforming growth factor-beta 1 and phorbol myristate acetate on cardiac fibroblasts. Regulation of fibrillar collagen mRNAs and expression of early transcription factors. Circ Res. 1991;69(2):483-490.

110. Chen MM, Lam A, Abraham JA, Schreiner GF, Joly AH. CTGF expression is induced by TGF- beta in cardiac fibroblasts and cardiac myocytes: a potential role in heart fibrosis. J Mol Cell Cardiol. 2000;32(10):18051819.

111. Leask A, Abraham DJ. TGF-beta signaling and the fibrotic response. Faseb J. 2004;18(7):816-827.

112. Blom IE, Goldschmeding R, Leask A. Gene regulation of connective tissue growth factor: new targets for antifibrotic therapy? Matrix Biol. 2002;21(6):473-482.

113. Abreu JG, Ketpura NI, Reversade B, De Robertis EM. Connective-tissue growth factor (CTGF) modulates cell signalling by BMP and TGF-beta. Nat Cell Biol. 2002;4(8):599-604.

114. Gressner OA, Gressner AM. Connective tissue growth factor: a fibrogenic master switch in fibrotic liver diseases. Liver Int. 2008;28(8):1065-1079.

115. Daniels A, van Bilsen M, Goldschmeding R, van der Vusse GJ, van Nieuwenhoven FA. Connective tissue growth factor and cardiac fibrosis. Acta Physiol (Oxf). 2009;195(3):321-338.

116. Matsui Y, Sadoshima J. Rapid upregulation of CTGF in cardiac myocytes by hypertrophic stimuli: implication for cardiac fibrosis and hypertrophy. J Mol Cell Cardiol. 2004;37(2):477-481.

117. Brunner A, Chinn J, Neubauer M, Purchio AF. Identification of a gene family regulated by transforming growth factor-beta. DNA Cell Biol. 1991;10(4):293-300.

118. Igarashi A, Okochi H, Bradham DM, Grotendorst GR. Regulation of connective tissue growth factor gene expression in human skin fibroblasts and during wound repair. Mol Biol Cell. 1993;4(6):637-645.

119. Kothapalli D, Frazier KS, Welply A, Segarini PR, Grotendorst GR. Transforming growth factor beta induces anchorage-independent growth of NRK fibroblasts via a connective tissue growth factor-dependent signaling pathway. Cell Growth Differ. 1997;8(1):61-68.

120. Flanders KC, Holder MG, Winokur TS. Autoinduction of mRNA and protein expression for transforming growth factor-beta S in cultured cardiac cells. J Mol Cell Cardiol. 1995;27(2):805-812.

121. Wang P. Insulin-like growth factor 1 and the heart. Endocrinology of Cardiovascular Function. 1998:225234.

122. Chen WH, Pellegata NS, Wang PH. Coordinated effects of insulin-like growth factor I on inhibitory pathways of cell cycle progression in cultured cardiac muscle cells. Endocrinology. 1995;136(11):5240-5243.

123. Fuller SJ, Mynett JR, Sugden PH. Stimulation of cardiac protein synthesis by insulin-like growth factors. Biochem J. 1992;282 ( Pt 1):85-90.

124. Ito $H$, Hiroe $M$, Hirata $Y$, Tsujino $M$, Adachi S, Shichiri M, Koike A, Nogami A, Marumo F. Insulin-like growth factor-I induces hypertrophy with enhanced expression of muscle specific genes in cultured rat cardiomyocytes. Circulation. 1993;87(5):1715-1721.

125. Mendez R, Myers MG, Jr., White MF, Rhoads RE. Stimulation of protein synthesis, eukaryotic translation initiation factor 4E phosphorylation, and PHAS-I phosphorylation by insulin requires insulin receptor substrate 1 and phosphatidylinositol 3-kinase. Mol Cell Biol. 1996;16(6):2857-2864.

126. Freestone NS, Ribaric S, Mason WT. The effect of insulin-like growth factor-1 on adult rat cardiac contractility. Mol Cell Biochem. 1996;163-164:223-229.

127. Coolican SA, Samuel DS, Ewton DZ, McWade FJ, Florini JR. The mitogenic and myogenic actions of insulin-like growth factors utilize distinct signaling pathways. J Biol Chem. 1997;272(10):6653-6662.

128. Florini JR, Ewton DZ, Coolican SA. Growth hormone and the insulin-like growth factor system in myogenesis. Endocr Rev. 1996;17(5):481-517.

129. Serneri GG, Modesti PA, Boddi M, Cecioni I, Paniccia R, Coppo M, Galanti G, Simonetti I, Vanni S, Papa L, Bandinelli B, Migliorini A, Modesti A, Maccherini M, Sani G, Toscano M. Cardiac growth factors in human hypertrophy. Relations with myocardial contractility and wall stress. Circ Res. 1999;85(1):57-67.

130. Brink M, Chrast J, Price SR, Mitch WE, Delafontaine P. Angiotensin II stimulates gene expression of cardiac insulin-like growth factor I and its receptor through effects on blood pressure and food intake. Hypertension. 1999;34(5):1053-1059. 
131. van Eickels $M$, Vetter $H$, Grohe $C$. Angiotensin-converting enzyme (ACE) inhibition attenuates insulin-like growth factor-I (IGF-I) induced cardiac fibroblast proliferation. Br J Pharmacol. 2000;131(8):1592-1596.

132. Seimi SK, Seinosuke K, Tsuyoshi S, Tomomi U, Tetsuaki H, Miki K, Ryuji T, Kenji I, Mitsuhiro Y. Glycogen synthase kinase-3beta is involved in the process of myocardial hypertrophy stimulated by insulin-like growth factor-1. Circ J. 2004;68(3):247-253.

133. Foncea R, Andersson M, Ketterman A, Blakesley V, Sapag-Hagar M, Sugden PH, LeRoith D, Lavandero S. Insulin-like growth factor-I rapidly activates multiple signal transduction pathways in cultured rat cardiac myocytes. J Biol Chem. 1997;272(31):19115-19124.

134. Zhou Y, Capuco AV, Jiang H. Involvement of connective tissue growth factor (CTGF) in insulin-like growth factor-I (IGF1) stimulation of proliferation of a bovine mammary epithelial cell line. Domest Anim Endocrinol. 2008;35(2):180-189.

135. Donohue TJ, Dworkin LD, Lango MN, Fliegner K, Lango RP, Benstein JA, Slater WR, Catanese VM. Induction of myocardial insulin-like growth factor-I gene expression in left ventricular hypertrophy. Circulation. 1994;89(2):799-809.

136. Matthews KG, Devlin GP, Stuart SP, Conaglen JV, Bass JJ. Cardiac IGF-I manipulation by growth hormone following myocardial infarction. Growth Horm IGF Res. 2004;14(3):251-260.

137. Andronico G, Mangano MT, Nardi E, Mule G, Piazza G, Cerasola G. Insulin-like growth factor 1 and sodium-lithium countertransport in essential hypertension and in hypertensive left ventricular hypertrophy. J Hypertens. 1993;11(10):1097-1101.

138. Hu BS, Landeen LK, Aroonsakool N, Giles WR. An analysis of the effects of stretch on IGF-I secretion from rat ventricular fibroblasts. American journal of physiology. 2007;293(1):H677-683.

139. Duerr RL, Huang S, Miraliakbar HR, Clark R, Chien KR, Ross J, Jr. Insulin-like growth factor-1 enhances ventricular hypertrophy and function during the onset of experimental cardiac failure. $J$ Clin Invest. 1995;95(2):619-627.

140. Donath MY, Sutsch G, Yan XW, Piva B, Brunner HP, Glatz Y, Zapf J, Follath F, Froesch ER, Kiowski W. Acute cardiovascular effects of insulin-like growth factor $I$ in patients with chronic heart failure. $J$ Clin Endocrinol Metab. 1998;83(9):3177-3183.

141. Matthews KG, Devlin GP, Conaglen JV, Stuart SP, Mervyn Aitken W, Bass JJ. Changes in IGFs in cardiac tissue following myocardial infarction. J Endocrinol. 1999;163(3):433-445.

142. Horio T, Maki T, Kishimoto I, Tokudome T, Okumura H, Yoshihara F, Suga S, Takeo S, Kawano Y, Kangawa K. Production and autocrine/paracrine effects of endogenous insulin-like growth factor-1 in rat cardiac fibroblasts. Regul Pept. 2005;124(1-3):65-72.

143. Munoz JP, Collao A, Chiong M, Maldonado C, Adasme T, Carrasco L, Ocaranza P, Bravo R, Gonzalez L, Diaz-Araya G, Hidalgo C, Lavandero S. The transcription factor MEF2C mediates cardiomyocyte hypertrophy induced by IGF-1 signaling. Biochem Biophys Res Commun. 2009;388(1):155-160.

144. Kawahara Y, Tanonaka K, Arino T, Maki T, Ishihara N, Takagi N, Yagi A, Takeo S. Effects of tanshinone VI on insulin-like growth factor-1-induced hypertrophy of isolated cardiomyocytes from neonatal rats. Exp Clin Cardiol. 2004;9(3):165-168.

145. Abe N, Matsunaga T, Kameda K, Tomita H, Fujiwara T, Ishizaka H, Hanada H, Fukui K, Fukuda I, Osanai T, Okumura K. Increased level of pericardial insulin-like growth factor-1 in patients with left ventricular dysfunction and advanced heart failure. J Am Coll Cardiol. 2006;48(7):1387-1395.

146. Chisalita SI, Dahlstrom U, Arnqvist HJ, Alehagen U. Increased IGF1 levels in relation to heart failure and cardiovascular mortality in an elderly population: impact of ACE inhibitors. Eur J Endocrinol. 2011;165(6):891-898.

147. Donath MY, Zapf J, Eppenberger-Eberhardt M, Froesch ER, Eppenberger HM. Insulin-like growth factor I stimulates myofibril development and decreases smooth muscle alpha-actin of adult cardiomyocytes. Proc Natl Acad Sci U S A. 1994;91(5):1686-1690.

148. Koziris LP, Hickson RC, Chatterton RT, Jr., Groseth RT, Christie JM, Goldflies DG, Unterman TG. Serum levels of total and free IGF-I and IGFBP-3 are increased and maintained in long-term training. J Appl Physiol. 1999;86(4):1436-1442. 
149. Neri Serneri GG, Boddi M, Modesti PA, Cecioni I, Coppo M, Padeletti L, Michelucci A, Colella A, Galanti G. Increased cardiac sympathetic activity and insulin-like growth factor-I formation are associated with physiological hypertrophy in athletes. Circ Res. 2001;89(11):977-982.

150. Reiss K, Cheng W, Kajstura J, Sonnenblick EH, Meggs LG, Anversa P. Fibroblast proliferation during myocardial development in rats is regulated by IGF-1 receptors. Am J Physiol. 1995;269(3 Pt 2):H943951.

151. Butt RP, Laurent GJ, Bishop JE. Collagen production and replication by cardiac fibroblasts is enhanced in response to diverse classes of growth factors. Eur J Cell Biol. 1995;68(3):330-335.

152. Kanekar S, Borg TK, Terracio L, Carver W. Modulation of heart fibroblast migration and collagen gel contraction by IGF-I. Cell Adhes Commun. 2000;7(6):513-523.

153. Gillery P, Leperre A, Maquart FX, Borel JP. Insulin-like growth factor-I (IGF-I) stimulates protein synthesis and collagen gene expression in monolayer and lattice cultures of fibroblasts. J Cell Physiol. 1992;152(2):389-396.

154. Diaz-Araya G, Borg TK, Lavandero S, Loftis MJ, Carver W. IGF-1 modulation of rat cardiac fibroblast behavior and gene expression is age-dependent. Cell Commun Adhes. 2003;10(3):155-165.

155. Lam S, van der Geest RN, Verhagen NA, van Nieuwenhoven FA, Blom IE, Aten J, Goldschmeding R, Daha $M R$, van Kooten $C$. Connective tissue growth factor and igf-I are produced by human renal fibroblasts and cooperate in the induction of collagen production by high glucose. Diabetes. 2003;52(12):29752983.

156. Grotendorst GR, Rahmanie H, Duncan MR. Combinatorial signaling pathways determine fibroblast proliferation and myofibroblast differentiation. Faseb J. 2004;18(3):469-479.

157. van Wamel AJ, Ruwhof C, van der Valk-Kokshoorn LJ, Schrier PI, van der Laarse A. Stretch-induced paracrine hypertrophic stimuli increase TGF-beta1 expression in cardiomyocytes. Mol Cell Biochem. 2002;236(1-2):147-153.

158. Hasenfuss G. Animal models of human cardiovascular disease, heart failure and hypertrophy. Cardiovasc Res. 1998;39(1):60-76.

159. Brown TD. Techniques for mechanical stimulation of cells in vitro: a review. J Biomech. 2000;33(1):3-14.

160. Hollenberg NK. Implications of species difference for clinical investigation: studies on the reninangiotensin system. Hypertension. 2000;35(1 Pt 2):150-154.

161. Yamamoto K, Dang QN, Maeda Y, Huang H, Kelly RA, Lee RT. Regulation of cardiomyocyte mechanotransduction by the cardiac cycle. Circulation. 2001;103(10):1459-1464.

162. Suo M, Hautala N, Foldes G, Szokodi I, Toth M, Leskinen H, Uusimaa P, Vuolteenaho O, Nemer M, Ruskoaho $\mathrm{H}$. Posttranscriptional control of BNP gene expression in angiotensin II-induced hypertension. $\mathrm{Hy}$ pertension. 2002;39(3):803-808.

163. Blaauw E, van Nieuwenhoven FA, Willemsen $P$, Delhaas $T$, Prinzen FW, Snoeckx LH, van Bilsen M, van der Vusse GJ. Stretch-induced hypertrophy of isolated adult rabbit cardiomyocytes. Am J Physiol Heart Circ Physiol. 2010;299(3):H780-787.

164. Ueno $H$, Perryman MB, Roberts $R$, Schneider MD. Differentiation of cardiac myocytes after mitogen withdrawal exhibits three sequential states of the ventricular growth response. The Journal of cell biology. 1988;107(5):1911-1918.

165. Sadoshima J, Jahn L, Takahashi T, Kulik TJ, Izumo S. Molecular characterization of the stretch-induced adaptation of cultured cardiac cells. An in vitro model of load-induced cardiac hypertrophy. J Biol Chem. 1992;267(15):10551-10560. 

Chapter 3

Isolation and culturing of cardiomyocytes and fibroblasts from adult rabbit heart.

Application of cyclic strain 


\section{ABSTRACT}

Background: Both mechanical and humoral triggers have been put forward to explain the hypertrophic and fibrotic response of challenged cardiac muscle. So far, information about the effect of cyclic strain on isolated cardiac myocytes from adult hearts is virtually lacking.

Aim: The present aims were: (1) develop a reproducible technique for isolation of cardiac muscle cells from the adult rabbit heart with sufficient yield and high quality, (2) determine the proper culture and attachment conditions for exposure of (i) isolated rabbit cardiomyocytes to cyclic strain without inducing dedifferentiation and/or cell death, (ii) isolation of cardiac rabbit fibroblasts. In addition, culture protocols for stretching cardiac cells on silicone membranes were developed and validated.

Methods: The isolation of cardiac myocytes and fibroblasts from adult rabbits was performed according to a modified previously published procedure ${ }^{16}$. Isolated rabbit cardiomyocytes and fibroblasts were exposed to $10 \%$ cyclic equibiaxial stretch $(1 \mathrm{~Hz})$ for up to $48 \mathrm{~h}$ using the Flexcell FX-4000 system.

Results: The standardized isolation protocol resulted in 20 to 25 million CMC per left ventricle per isolation. Commonly, $70-80 \%$ of the isolated cardiomyocytes were viable, calcium-tolerant and rod-shaped. More than $80 \%$ of the rabbit cardiac fibroblasts and rabbit cardiomyocytes remained attached to the pre-coated non-strained silicone membranes for $96 \mathrm{~h}$. Subjecting cardiomyocytes and fibroblasts to $10 \%$ cyclic equibiaxial strain $(1 \mathrm{~Hz})$ for $48 \mathrm{~h}$ did not affect cell viability.

Conclusion: We developed a standardized isolation protocol for cardiac rabbit fibroblasts and rod-shaped cardiomyocytes. Both cell types can be cultured for up to 2-4 days and subjected to cyclic equibiaxial strain without significant effects on cell viability or morphological changes. 


\section{INTRODUCTION}

Both neurohumoral factors and increased mechanical load most likely play a role in the development of cardiac hypertrophy in vivo. However, the question still remains which of the two is the primary and/or most important trigger for hypertrophy, although a combination of both cannot be excluded. In vivo studies are too complex to provide unambiguous answers because of cardiac cellular heterogeneity and potential autocrine and/or paracrine cell-cell interactions. To overcome these complications, in vitro models have been developed. In general, these models commonly used primary cultures of cardiomyocytes isolated from neonatal rat hearts and exposed to hormones and/of static strain ${ }^{1-4}$. The preference for neonatal rat cardiomyocytes is mainly due to the fact that these cells are relatively easy to isolate and to keep in culture. However, to extrapolate results from these studies to the adult myocardium with fully differentiated cells is cumbersome. First, neonatal cardiomyocytes are not fully differentiated ${ }^{5}$ and still express a relatively high level of fetal genes, like alpha-myosin heavy chain ( $\alpha$ $\mathrm{MHC})^{6}$. Second, it is preferable to use cardiomyocytes from a species mimicking the features of the human heart as much as possible. In this regard, the rabbit is considered to be a more appropriate species than, for instance, rat or mouse as source of cardiac muscle cells. The rabbit heart closely resemble the human heart since both species (1) predominantly express the beta-MHC isoform ${ }^{7},(2)$ have comparable action potential characteristics $^{8,9}$ and (3) possess a positive force-frequency relation ${ }^{10,11}$. Third, from a physiological point of view, static strain hardly mimics the cyclic increase and decline in workload of cardiomyocytes in situ during, respectively, systole and diastole. Therefore, it is felt that subjecting cardiomyocytes cells to cyclic strain is physiologically more appropriate. During the last decade progress has been made in investigating the role of strain as a trigger for cardiomyocyte hypertrophy by implementing devices generating cyclic rather than static strain ${ }^{12-14}$. This approach is possible by applying e.g. the Flexcell FX-4000 apparatus. So far, information about the effect of cyclic strain on isolated cardiac myocytes from adult hearts is virtually lacking. 
Moreover, recent findings indicate that not only cardiomyocytes are responsive to cyclic strain, but cardiac fibroblasts could be involved in the strain-induced hypertrophic response as well ${ }^{15}$. Based on these considerations, the technical aims of the present thesis were:

(i) To develop a reproducible technique for isolation of cardiac muscle cells from the adult rabbit heart with sufficient yield and high quality (see part 1 of this chapter).

(ii) To determine the proper culture and attachment conditions for exposure of isolated rabbit cardiomyocytes to cyclic strain without inducing dedifferentiation and/or cell death (part 2).

(iii) To develop a reliable technique to isolate and culture fibroblasts from the adult rabbit heart (part 3)

(iv) To establish proper conditions for subjecting cardiac fibroblast from adult rabbits to cyclic strain, and growth factors without inducing cell death (part 4)

This chapter describes the development of the techniques required to achieve these goals. 
PART 1:

\section{RABBIT CARDIOMYOCYTE ISOLATION AND CULTURING PROCEDURE}

\section{MATERIALS AND METHODS}

\section{Animals}

Adult male white New Zealand rabbits (weighing 2.5 to $3.0 \mathrm{~kg}$ ) were used for cardiomyocyte isolation. Animal experiments were performed with the approval of the Animal Ethical Committee of Maastricht University and conform to the Guide for the Care and Use of Laboratory Animals published by the US National Institutes of Health (NIH Publication No. 85-23 revised 1996).

\section{Isolation of cardiomyocytes}

Several days prior to the isolation the plastic tubes of the isolation apparatus were rinsed with $0.25 \mathrm{M} \mathrm{NaOH}$ and milli-Q. The isolation of cardiac myocytes from adult rabbits was performed according to a modification of a previously published procedure $^{16}$. Animals were anaesthetised with ketamine $(35 \mathrm{mg} / \mathrm{kg})$ and xylazine $(5 \mathrm{mg} / \mathrm{kg})$ via intramuscular injection, followed by intravenous administration of $2500 \mathrm{U}$ of heparin via an ear vein in order to prevent blood clotting. Approximately two minutes after heparin injection, rabbits were sacrificed by cervical dislocation and the heart was quickly excised. Isolated hearts were rinsed with pre-oxygenated ice-cold modified Krebs-Henseleit buffer $\mathrm{A}$ [KH-A; pH 7.4 set at room temperature (RT, 19-21 $\left.{ }^{\circ} \mathrm{C}\right)$ ], consisting of (in mM) $\mathrm{NaCl}$ (133), $\mathrm{KCl}(5), \mathrm{MgCl}_{2}$ (2), $\mathrm{NaH}_{2} \mathrm{PO}_{4}$ (1.2), glucose (10), HEPES (10), taurine (6), creatine (6), and a low concentration of calcium ions $\left(10 \mu \mathrm{M} \mathrm{CaCl}_{2}\right) . \mathrm{KH}-\mathrm{A}$ solution was prepared in milli-Q from plastic bottles and filtrated through a "bottle top low binding" protein filter (pore size $0.22 \mu \mathrm{m}$ ). Non-cardiac tissue was removed and the aorta outflow tract was kept as long as possible. Subsequently, the aorta was attached to a home-made plastic cannula (length $=10 \mathrm{~mm}$ and internal diameter $=3 \mathrm{~mm}$ ). To remove coronary blood and, in particular, plasma calcium ions, hearts were perfused in a retrograde, non-recirculating Langendorff mode at constant flow $(25 \mathrm{ml} / \mathrm{min})$ using a pump (Watson Marlow type 501, mode 135) with pre-oxygenated (i.e., 30 min gassed with $100 \%$ oxygen prior to the perfusion) $\mathrm{KH}-\mathrm{A}$ buffer at $37^{\circ} \mathrm{C}$ for $10 \mathrm{~min}$ The temperature of $\mathrm{KH}-\mathrm{A}$ was controlled by a thermostatic water bad.

Thereafter, the perfusion buffer was switched to a collagenase-containing digestion buffer consisting of $150 \mathrm{ml}$ fresh $\mathrm{KH}$-A buffer supplemented with $1.5 \mathrm{~g}$ Bovine Serum Albumin (BSA, 1\% w/v, fraction V) and $290 \mathrm{U} / \mathrm{ml}$ collagenase type II (batch information can be found on http://www.worthington-biochem.com/cls/match.php). The digestion buffer $\left(\mathrm{pH} 7.4,37^{\circ} \mathrm{C}\right)$ was allowed to recirculate until the cardiac tissue became soft 
(varying from 7 to $11 \mathrm{~min}$ after the onset of perfusion depending on collagenase batch). To prevent fungal and bacterial infections the cell isolation procedure was routinely performed in a flow hood and gloves were worn. After digestion, the heart was removed from the cannula and atria, right ventricular tissue (the latter was used for fibroblast isolation, see part 3 / addendum I) and fat tissue were cut off from the left ventricle.

Left ventricular tissue was transferred to fresh $150 \mathrm{ml}$ pre-oxygenated (by blowing $100 \%$ oxygen over the surface area for $\sim 30 \mathrm{~min}$ prior to recovery) Krebs-Henseleit buffer $\mathrm{B}(\mathrm{KH}-\mathrm{B}, \mathrm{pH} 7.4$, see addendum I, table 2) containing (in $\mathrm{mM}$ ): $\mathrm{NaCl}(120), 5 \mathrm{KCl}(5)$, $\mathrm{MgCl}_{2}$ (2), $\mathrm{NaH}_{2} \mathrm{PO}_{4}$ (1.2), glucose (10), HEPES (10), taurine (6), creatine (6), 2,3butanedione monoxime (BDM (20)), plus $\mathrm{CaCl}_{2}(10 \mu \mathrm{M})$, BSA fraction $\mathrm{V}(1 \% \mathrm{w} / \mathrm{v})$ at room temperature (RT) for $10 \mathrm{~min}$. BDM was added to the $\mathrm{KH}-\mathrm{B}$ buffer to enhance cell viability $^{17}$. BDM at $20 \mathrm{mM}$ or higher prevents adherence of fibroblasts (own observation), enhancing the purity of the cardiomyocyte cultures (>99\%). Left ventricular tissue was subsequently transferred to a $2 \mathrm{~L}$ glass beaker, containing $250 \mathrm{ml}$ of fresh $\mathrm{KH}-\mathrm{B}$ at RT. Subsequently the ventricle was cut open from basis to apex and the entire wall was divided in a subendo- and subepicardial part with a pair of scissors. Thereafter, cardiac cells were loosened by manual shaking of the two slabs of tissue with a tweezer. Routinely, this procedure resulted in a virtually complete dissociation of the tissue. Thereafter, the isolated cells were filtered through sterile gauze (ES Kompressen, Hartmann, Nijmegen, the Netherlands) and allowed to recover at RT for $20 \mathrm{~min}$. After recovery, $\mathrm{Ca}^{2+}$ concentration was stepwise increased from $10 \mu \mathrm{M}$ to 50,75, 100, 150, 200, 400, 800 and $1200 \mu \mathrm{M}$, by adding appropriate amounts of $100 \mathrm{mM} \mathrm{CaCl}_{2}$ solution to the incubation buffer with intervals of 3 min each during manual shaking of the cell suspension.

\section{Culturing CMC on BioFlex plates}

Immediately after normalizing the calcium ion concentration to $1.2 \mathrm{mM}$, the cardiomyocyte suspension was divided over $50 \mathrm{ml}$ plastic tubes. Cardiomyocytes were collected by a mild centrifugation step at $50 \mathrm{~g}$ (250 rpm, Universal 30F, Hettich Zentrifugen, Tuttlingen, Germany) at RT for 3 min. Supernatant, containing mainly nonmyocytes, was discarded and the cardiomyocyte-containing pellet was resuspended in a plastic $50 \mathrm{ml}$ tube containing $30 \mathrm{ml}$ of freshly prepared recovery medium, i.e., M199, supplemented with Fetal Bovine Serum (FBS; 5\% vol/vol), L-carnitine (final concentration, $2 \mathrm{mM})$, taurine $(5 \mathrm{mM})$, creatine $(5 \mathrm{mM})$, insulin $(0.25 \mathrm{mU} / \mathrm{ml})$, penicillin $(100$ $\mathrm{U} / \mathrm{ml})$, streptomycin $(100 \mu \mathrm{g} / \mathrm{ml})$ and gentamicin $(0.05 \mathrm{mg} / \mathrm{ml})$. To prevent nonmyocyte proliferation, $10 \mu \mathrm{M}$ cytosine-1- $\beta$-D-arabinofuranoside (AraC) was added to all culture media. Cells were counted using a Burker Turk chamber and cell viability was assessed by trypan blue (0.05\%) exclusion. After counting, cardiomyocytes were diluted in recovery medium to a final concentration of $3.75 \times 104$ cells $/ \mathrm{ml}$, and plated at a den- 
sity of $7.5 \times 10^{4}$ cells/well ( $2 \mathrm{ml} /$ well) on the pre-coated Bioflex plates (see below). Cells were transferred to a humidified $95 \% \mathrm{O}_{2} / 5 \% \mathrm{CO}_{2}$ incubator $\left(37^{\circ} \mathrm{C}\right)$. After $2-3 \mathrm{~h}$, recovery medium was aspirated and refreshed to remove non-attached, non-viable cells. The next day the recovery medium was refreshed once more.

The following day (third day), one hour prior to the experiment, recovery medium ( $5 \%$ FBS vol/vol) was replaced by $3 \mathrm{ml}$ of experimental medium containing M199 with $0.5 \%$ FBS (vol/vol) instead of 5\% FBS (vol/vol). This standard protocol is shown in figure 1.

\section{Standard CMC strain protocol}

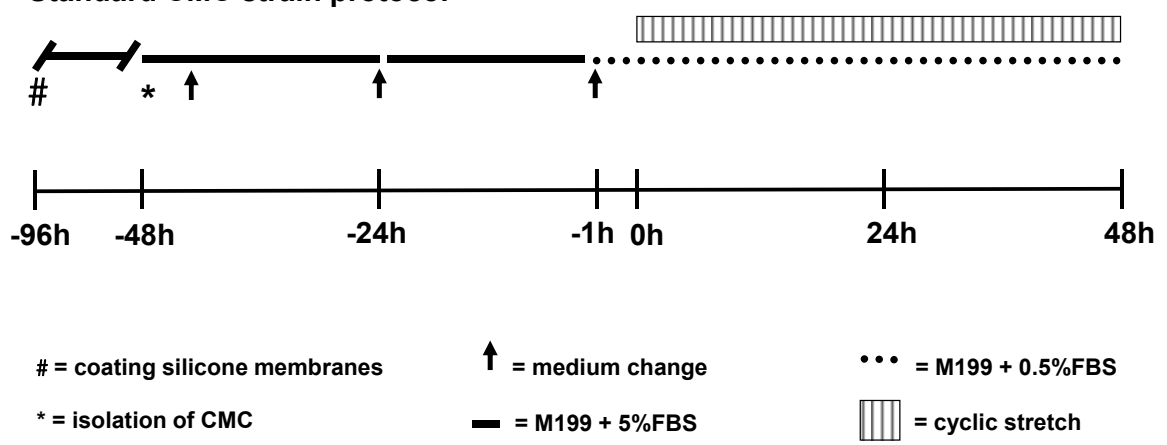

Figure 1: Standard culture conditions and experimental protocol used for the routine cyclic strain experiments of rabbit cardiomyocytes (CMC), described in this thesis. Immediately after isolation $\left({ }^{*}-48 \mathrm{~h}\right) \mathrm{CMC}$ were cultured in $5 \%$ fetal bovine serum (FBS) enriched culture medium (recovery medium) and the medium was refreshed after $2-3 \mathrm{~h}$ and $24 \mathrm{~h}$ (indicated by $-24 \mathrm{~h}$ ). One hour prior to the strain experiment $(-1 \mathrm{~h})$ the serum enriched medium ( $5 \%$ FBS) was aspirated and replaced by $0.5 \%$ FBS containing culture medium (experimental medium). During the strain experiments the experimental medium was not refreshed. 

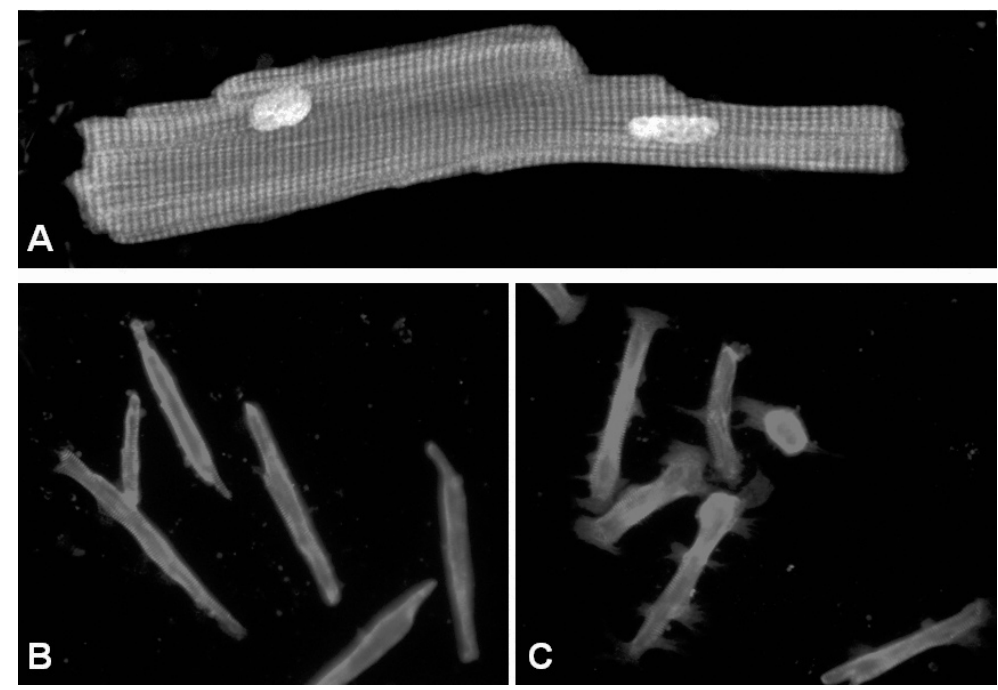

Figure 2: Representative pictures of rabbit cardiomyocytes photographed directly after isolation (A); after 4 days of culture on laminin pre-coated silicone membranes (Bioflex plates) (B), and after 48h of cyclic biaxial stretch $(10 \% / 1 \mathrm{~Hz})(\mathrm{C})$. Scale bars correspond with $25 \mu \mathrm{M}$ and cells in panel B and C were stained for $\alpha$ actinin.

\section{RESULTS}

\section{Isolation yield and cell viability}

The above described standard protocol resulted in a relatively high yield, i.e., on the average 20 to 25 million CMC per left ventricle per isolation. These numbers correspond with approximately $25 \%$ of the total number of cardiomyocytes present in the adult rabbit left ventricle, assuming that LV ventricle volume consist of $70 \%$ cardiomyocytes (total left ventricle wet weight was approximately $4.0 \mathrm{~g}$; own data obtained from 7 rabbits) and that cardiomyocytes possess a cylinder-like 3-D shape (average length of $120 \mu \mathrm{M}$ and a diameter of $19 \mu \mathrm{M}$ ). Commonly, $70-80 \%$ of the isolated cardiomyocytes were viable, calcium-tolerant and rod-shaped (figure 2). To obtain this high yield of viable, rod-shaped cells, the following adjustments were made to earlier published protocols $^{16}$ : (1) a recovery period of $10 \mathrm{~min}$ was introduced after perfusion with collagenase and prior to opening of the ventricle (2) BDM was added to prevent cardiomyocyte contraction and (3) calcium ions were stepwise and slowly reintroduced till the physiological concentration was reached. 


\section{PART 2:}

\section{RABBIT CARDIOMYOCYTES SUBJECTED TO CYCLIC EQUIBIAXIAL STRAIN}

\section{MATERIALS AND METHODS}

\section{Exposure to cyclic equibiaxial strain: features of the Flexcell FX-4000}

By means of the Flexcell FX-4000 system (Flexcell ${ }^{\circledR}$ International Corp., Hillsborough, USA) isolated cells can be subjected to either passive (static) or dynamic (cyclic) equibiaxial strains under standardized conditions. The FX-4000 consists of different units, a system controller (computer with special software), a Flexlink (unit with valves), a vacuum pump and an incubator, in which the holder (the so-called "Flexcell ${ }^{\circledR}$ vacuum pressure baseplate") with BioFlex plates is placed (figure 3). The holder is connected via tubes to the Flexlink which contains a valve mechanism regulating pressures generated by the pump and, hence, to provide different strain regimens. The regimens can be configured (frequency, \% strain, type of strain and time frame) according to the experimental protocol (see manual FX-4000T ${ }^{\mathrm{TM}}$ Flexcell Tension Plus V4.0 for more details). In the holder, special loading stations (existing of 6 loading posts each) can be placed on top of which BioFlex culture plates with silicone membranes are mounted, as shown in figure $4 \mathrm{~A}$. When vacuum is applied to a BioFlex culture plate, the silicone membrane with attached cells deforms over the top planar surface of the cylindrical loading post, creating uniform equibiaxial strain as indicated in figure 4B. This results in equibiaxial strain on the area of the membrane over the loading station. After the programmed time duration the cells can be used for further analysis.

\section{Pre-preparations for strain experiments}

Several days before strain experiments are scheduled, the aluminium holder of the Flexcell FX-4000 ${ }^{\mathrm{TM}}$ was placed in a humidified $95 \% \mathrm{O}_{2} / 5 \% \mathrm{CO}_{2}$ incubator $\left(37^{\circ} \mathrm{C}\right)$ to prevent condensation inside the holder and moisture in the plastic Flex-tubes during cyclic straining. One to $2 \mathrm{~h}$ prior to the strain experiments, silicone lubricant (no. 51360, Loctite / Henkel Technologies, Brussels, Belgium) was applied on top of the loading posts, to minimize friction between silicone membrane and loading post surface. After silicone lubricant was applied, the loading posts were placed inside the incubator.

Furthermore, minimally 2 days prior to cardiomyocyte isolation, Silicone Flexcell membranes of the 6-wells Bioflex plates (coated with collagen type 1 ; Flexcell ${ }^{\circledR}$ International Corp., Hillsborough, USA) were pre-coated with $650 \mu \mathrm{L}$ of $15 \mu \mathrm{g} / \mathrm{ml}$ laminin (Invitrogen, Breda, the Netherlands)/PBS solution, to minimize detachment of cardiomyocytes prior and during strain experiments. Laminin solutions were prepared in sterile PBS $\left(4^{\circ} \mathrm{C}\right)$. The pre-coated plates were stored in a humidified $95 \% \mathrm{O}_{2} / 5 \% \mathrm{CO}_{2}$ incubator 
$\left(37^{\circ} \mathrm{C}\right)$. Plates can be used till 1 week after coating with laminin. Subsequently, the laminin/PBS solutions were aspirated just before cells were transferred to the Flexcell plates.

\section{Pilot studies: culture- and strain protocols}

Pilot studies were performed to assess optimal conditions for applying cyclic strain to isolated rabbit cardiomyocytes. When cells were kept under serum free conditions and subjected to varying frequencies $(0.33,0.5$ and $1 \mathrm{~Hz})$ and degrees of strain (respectively $10 \%$ and $20 \%$ ), they failed to remain viable and detached from the silicone Flexcell membranes within the first 12 hours (data not shown). Subsequently different culture protocols were tested to improve the experimental conditions. Our criteria for a satisfactory protocol were: low number of detached cells during 4 days of culture, no or minimal signs of dedifferentiation. Pilot studies were performed with and without addition of Bovine Serum Albumin, with and without insulin, serum free (1\% BSA instead of serum) versus Fetal Bovine Serum (FBS)-enriched culture medium (10\%, 5\% and 0.5\%). The results of these pilot-studies indicated that: (1) insulin was necessary in the culture media to maintain cell viability, (2) BSA negatively affected cell viability, and (3) detachment of cardiomyocytes could be substantially prevented by using $5 \%$ (recovery medium) and $0.5 \%$ FBS-enriched culture medium (experimental medium) prior to and during the strain protocol, respectively. Finally these observations resulted in the standardized culture and strain protocol, as indicated in figure 1.

\section{Standardized strain protocol}

For strain experiments, cardiomyocytes were routinely subjected to $10 \%$ of cyclic equibiaxial strain, produced by a Flexcell $\mathrm{FX}-4000^{\mathrm{TM}}$ strain unit with computercontrolled application of sinusoidal negative pressure at a frequency of $1 \mathrm{~Hz}$ for up to $48 \mathrm{~h}$, using our standardized culture and strain protocol. In parallel, control (nonstrained) cardiomyocytes were subjected to identical conditions except that strain was prevented by using FlexStops ${ }^{\mathrm{TM}}$. 


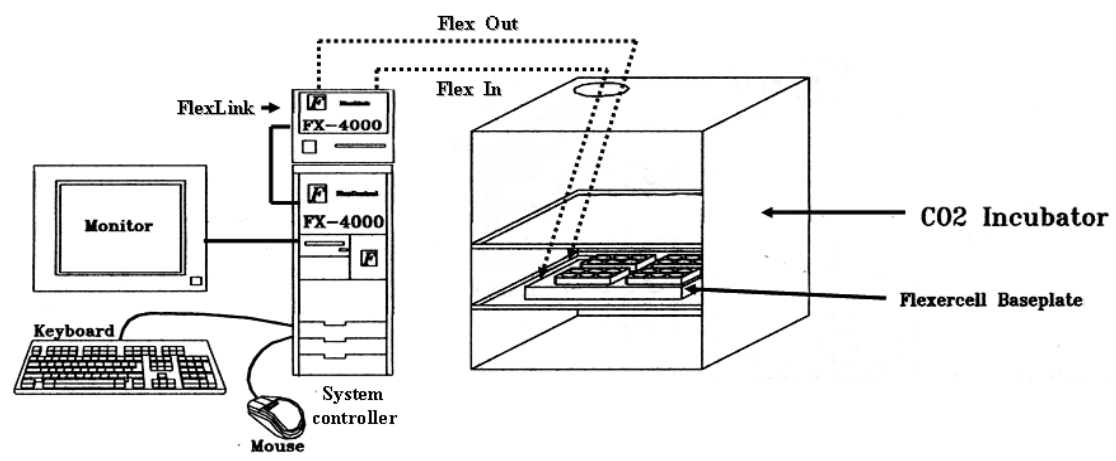

Figure 3: Diagram of the equipment used to subject cardiomyocytes to strain with the Flexcell $\mathrm{FX}-4000 \mathrm{~T}^{\mathrm{TM}}$ system. Picture is adapted and modified from the manual FX-4000T ${ }^{\mathrm{TM}}$ Flexcell Tension Plus V4.0 users manual (www.flexcellint.com / www.dunnlab.de).

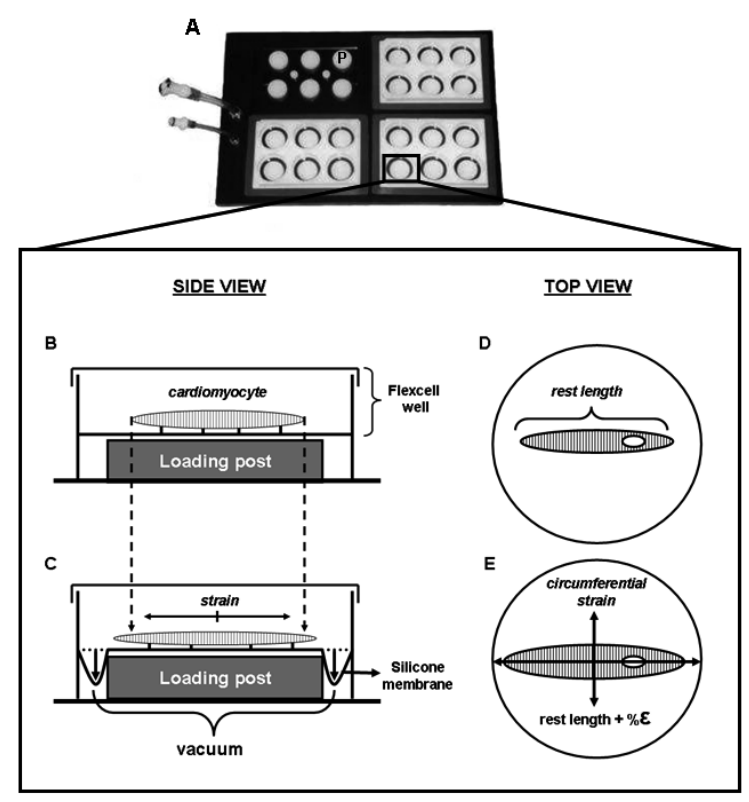

Figure 4: Diagram of the top view of a holder (panel A) with 4-loading stations, each consisting of 6 cylindrical loading posts (P). On top of the loading stations 6-well-BioFlex culture plates are positioned. More detailed side- and top views of one BioFlex ${ }^{\circledR}$ well show the silicone membrane (panels B and D) and a myocyte (panels $\mathrm{C}$ and $\mathrm{E}$ ) in unstrained, and strained condition, respectively. During cyclic strain the membrane with attached cardiomyocytes deforms across the cylindrical loading post, creating an equibiaxial strain (E). 


\section{Possible pitfalls using the FX-4000 apparatus}

A weight of approximately $0.5 \mathrm{~kg}$ (bottle of $500 \mathrm{ml}$ filled with milli-Q) should be placed on top of each 6-well BioFlex plate to ensure optimal vacuum, necessary for adequate deformation of the silicone Flexcell membranes. In our hands, it turned out that the programmed percentage strain was not completely identical to the experimental strain. A deviation of $1 \%$ was accepted. When the deviation was found to be more than $1 \%$ the set-up (membranes and 6-wells BioFlex plate connections) was checked for air leakage. Furthermore, the application of lubricant on top of each loading post is mandatory, because omission of silicone lubricant will easily lead to friction and heat production, resulting in an increase of medium temperature of approximately $1^{\circ} \mathrm{C}$.

\section{RESULTS}

\section{Cell viability}

Detachment of rabbit cardiomyocytes was prevented by incubating the cells in FBSenriched medium (5\%) (recovery medium) prior to and (0.5\%) (experimental medium) during the strain experiment protocol.

Under the conditions applied (pre-coating, medium), more than $80 \%$ of the cells remained attached to the pre-coated non-strained silicone membranes for the total duration of the protocol (96 h). Subjecting cardiomyocytes to $10 \%$ cyclic equibiaxial strain $(1 \mathrm{~Hz})$ for $48 \mathrm{~h}$ did not affect cell viability to a significant extent; more than $70 \%$ of plated $\mathrm{CMC}$ remained attached to the silicone membranes.

\section{CONCLUSION}

We developed a standardized isolation protocol with a high yield of viable, rod-shaped cardiomyocytes which can be cultured for up to 4 days and subjected to cyclic equibiaxial strain $(10 \% / 1 \mathrm{~Hz})$ for 2 days on laminin pre-coated silicone membranes without significant effects on cell viability. 


\section{PART 3:}

\section{FIBROBLAST ISOLATION AND CULTURE}

\section{MATERIALS AND METHODS}

\section{Fibroblast isolation}

After perfusion with collagenase (see protocol for cardiomyocyte isolation), the right ventricle (RV) was dissected from the left ventricle with a pair of scissors and directly transferred to a sterile plastic $50 \mathrm{ml}$ tube, which contained $25 \mathrm{ml}$ of $10 \%$ FBS in DMEM* (Gibco number 22320) with $0.05 \mathrm{mg} / \mathrm{ml}$ gentamicin, followed by cutting the right ventricle in small pieces using a scissor. Thereafter, the suspension was shaken manually during approximately $4 \mathrm{~min}$ upon which the cell suspension was centrifuged for $3 \mathrm{~min}$ at $50 \mathrm{~g}(250 \mathrm{rpm})$ to remove cardiomyocytes (pellet). Fibroblasts were collected from the supernatant by a centrifugation step at $300 \mathrm{~g}(1500 \mathrm{rpm})$ at RT for $5 \mathrm{~min}$.

\section{Culturing rabbit fibroblast}

After centrifugation, the supernatant was discarded and the fibroblast-containing pellet was resuspended in $15 \mathrm{ml}$ DMEM, supplemented with FBS (10\% vol/vol) and gentamicin $(0.05 \mathrm{mg} / \mathrm{ml})$. The fibroblast suspension was added to a $75 \mathrm{~cm}^{2}$ plastic cell culture flask with ventilation cap and stored in a humidified $95 \% \mathrm{O}_{2} / 5 \% \mathrm{CO}_{2}$ incubator $\left(37^{\circ} \mathrm{C}\right)$ overnight. The next day fibroblasts were washed twice with $\operatorname{DMEM}^{*}\left(37^{\circ} \mathrm{C}\right)$ to remove non-attached and non-viable cells and the attached fibroblasts were put on DMEM, supplemented with FBS (10\% vol/vol) and gentamicin $(0.05 \mathrm{mg} / \mathrm{ml})$. The medium was refreshed every 2 to 3 days. 


\section{PART 4:}

\section{FIBROBLASTS SUBJECTED TO CYCLIC STRAIN OR GROWTH FACTORS}

\section{MATERIALS AND METHODS}

Culture and strain protocol for rabbit fibroblast

When fibroblasts had grown to confluence (>90\% after $10-14$ days; passage 0 ), the cells were detached using $2 \mathrm{ml}$ 0.25\% trypsin-EDTA (Gibco, number 25200) per $75 \mathrm{~cm}^{2}$ flask. After $15-20 \mathrm{~s}$, the trypsin-EDTA solution was aspirated and cells were collected in 100 $\mathrm{ml}$ recovery medium (see for more details part 1: culturing $\mathrm{CMC}$ ), existing of M199 supplemented with FBS ( $5 \%$ vol/vol), L-carnitine (final concentration, $2 \mathrm{mM}$ ), taurine (5 $\mathrm{mM})$, creatine $(5 \mathrm{mM})$, insulin $(0.25 \mathrm{mU} / \mathrm{ml})$, penicillin $(100 \mathrm{U} / \mathrm{ml})$, streptomycin (100 $\mu \mathrm{g} / \mathrm{ml})$, gentamicin $(0.05 \mathrm{mg} / \mathrm{ml})$, without AraC. Thereafter, $2 \mathrm{ml}$ of the $100 \mathrm{ml}$ cell suspension was added per well of a 6-wells Bioflex plates (coated with collagen type 1; Flexcell ${ }^{\circledR}$ International Corp., Hillsborough, USA) which were pre-coated with $15 \mu \mathrm{g} / \mathrm{ml}$ laminin (Invitrogen, Breda, the Netherlands)/PBS solution. These passage 1 fibroblasts were transferred to a humidified $95 \% \mathrm{O}_{2} / 5 \% \mathrm{CO}_{2}$ incubator $\left(37^{\circ} \mathrm{C}\right)$.

The next day, the medium was aspirated and refreshed to remove non-attached, non-viable cells. The following day (third day), cells were $50-70 \%$ confluent (figure 5). One hour before subjecting the cells to cyclic stretch, the high-serum M199 medium (5\% FBS vol/vol) (recovery medium) was replaced by $3 \mathrm{ml} \mathrm{low}$-serum containing M199* (0.5\% FBS vol/vol) (experimental medium). After $1 \mathrm{~h}$, cyclic stretch $(10 \%$ at $1 \mathrm{~Hz})$ was started for maximal $48 \mathrm{~h}$.

This standard protocol is shown in figure 6. For detailed information about the materials used in part 3 and 4 , such as order numbers and manufacturers, see addendum I.

\section{CONCLUSION}

We developed a standardized protocol for fibroblast isolation from adult rabbit myocardium. The fibroblasts can subsequently be subjected to cyclic equibiaxial strain ( $10 \%$ / $1 \mathrm{~Hz}$ ) for 2 days on silicone membranes without significant effects on cell viability or morphological changes. 


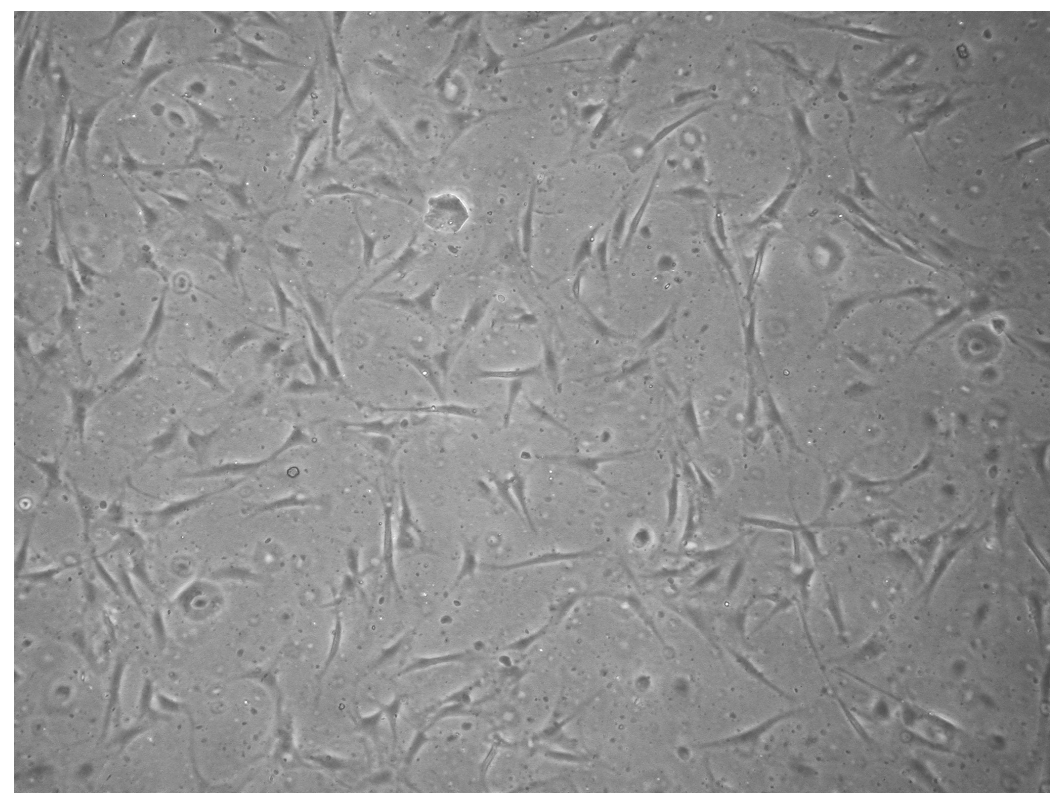

Figure 5: Representative light microscopic picture of un-stimulated rabbit fibroblasts cultured during $48 \mathrm{~h}$ on silicone membranes (Bioflex plates). Cells were isolated and grown using the standard fibroblast protocol. Fibroblasts had a comparable phenotype after exposure to $48 \mathrm{~h}$ cyclic strain.

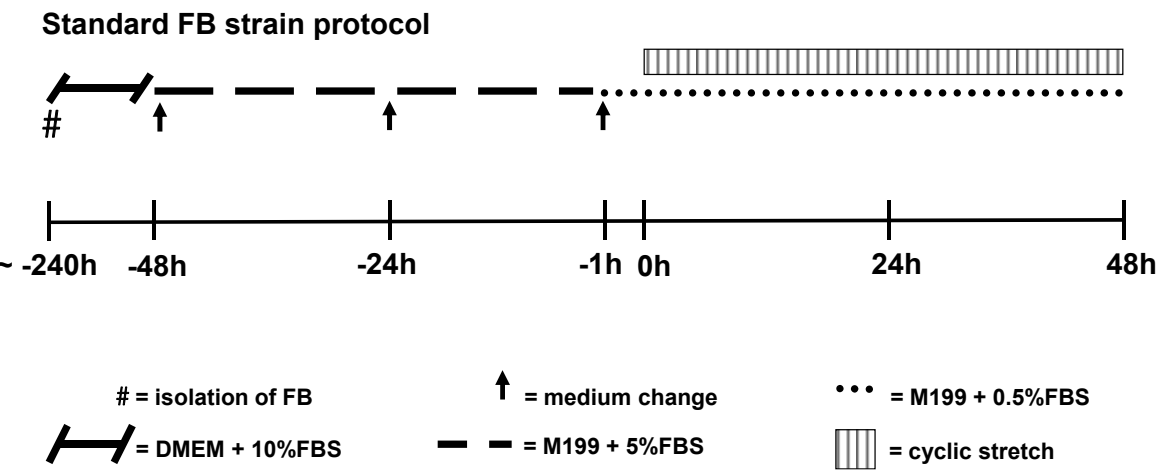

Figure 6: Schematic representation of standard culture conditions and experimental protocol used for routine cyclic strain experiments of cardiac rabbit fibroblasts (FB), as described in this thesis. 


\section{REFERENCES}

1. Sadoshima J, Xu Y, Slayter HS, Izumo S. Autocrine release of angiotensin II mediates stretch-induced hypertrophy of cardiac myocytes in vitro. Cell. 1993;75(5):977-984.

2. Zou Y, Akazawa H, Qin Y, Sano M, Takano H, Minamino T, Makita N, Iwanaga K, Zhu W, Kudoh S, Toko H, Tamura K, Kihara M, Nagai T, Fukamizu A, Umemura S, liri T, Fujita T, Komuro I. Mechanical stress activates angiotensin II type 1 receptor without the involvement of angiotensin II. Nature cell biology. 2004;6(6):499-506.

3. van Wamel JE, Ruwhof C, van der Valk-Kokshoorn EJ, Schrier PI, van der Laarse A. Rapid gene transcription induced by stretch in cardiac myocytes and fibroblasts and their paracrine influence on stationary myocytes and fibroblasts. Pflugers Arch. 2000;439(6):781-788.

4. Frank D, Kuhn C, Brors B, Hanselmann C, Ludde M, Katus HA, Frey N. Gene expression pattern in biomechanically stretched cardiomyocytes: evidence for a stretch-specific gene program. Hypertension. 2008;51(2):309-318.

5. Ueno $H$, Perryman MB, Roberts $R$, Schneider MD. Differentiation of cardiac myocytes after mitogen withdrawal exhibits three sequential states of the ventricular growth response. The Journal of cell biology. 1988;107(5):1911-1918.

6. Sadoshima J, Jahn L, Takahashi T, Kulik TJ, Izumo S. Molecular characterization of the stretch-induced adaptation of cultured cardiac cells. An in vitro model of load-induced cardiac hypertrophy. The Journal of biological chemistry. 1992;267(15):10551-10560.

7. Sanbe A, James J, Tuzcu V, Nas S, Martin L, Gulick J, Osinska H, Sakthivel S, Klevitsky R, Ginsburg KS, Bers DM, Zinman B, Lakatta EG, Robbins J. Transgenic rabbit model for human troponin I-based hypertrophic cardiomyopathy. Circulation. 2005;111(18):2330-2338.

8. Varro A, Lathrop DA, Hester SB, Nanasi PP, Papp JG. Ionic currents and action potentials in rabbit, rat, and guinea pig ventricular myocytes. Basic research in cardiology. 1993;88(2):93-102.

9. Bers DM. Cardiac $\mathrm{Na} / \mathrm{Ca}$ exchange function in rabbit, mouse and man: what's the difference? Journal of molecular and cellular cardiology. 2002;34(4):369-373.

10. Endoh M. Force-frequency relationship in intact mammalian ventricular myocardium: physiological and pathophysiological relevance. European journal of pharmacology. 2004;500(1-3):73-86.

11. Hasenfuss G, Mulieri LA, Blanchard EM, Holubarsch C, Leavitt BJ, Ittleman F, Alpert NR. Energetics of isometric force development in control and volume-overload human myocardium. Comparison with animal species. Circulation research. 1991;68(3):836-846.

12. Nadruz W, Jr., Corat MA, Marin TM, Guimaraes Pereira GA, Franchini KG. Focal adhesion kinase mediates MEF2 and c-Jun activation by stretch: role in the activation of the cardiac hypertrophic genetic program. Cardiovascular research. 2005;68(1):87-97.

13. Yamamoto K, Dang QN, Maeda Y, Huang H, Kelly RA, Lee RT. Regulation of cardiomyocyte mechanotransduction by the cardiac cycle. Circulation. 2001;103(10):1459-1464.

14. Pikkarainen S, Tokola H, Majalahti-Palviainen $T$, Kerkela R, Hautala N, Bhalla SS, Charron F, Nemer M, Vuolteenaho O, Ruskoaho H. GATA-4 is a nuclear mediator of mechanical stretch-activated hypertrophic program. The Journal of biological chemistry. 2003;278(26):23807-23816.

15. Hu BS, Landeen LK, Aroonsakool N, Giles WR. An analysis of the effects of stretch on IGF-I secretion from rat ventricular fibroblasts. American journal of physiology. 2007;293(1):H677-683.

16. Mitcheson JS, Hancox JC, Levi AJ. Cultured adult cardiac myocytes: future applications, culture methods, morphological and electrophysiological properties. Cardiovasc Res. 1998;39(2):280-300.

17. Thum T, Borlak J. Butanedione monoxime increases the viability and yield of adult cardiomyocytes in primary cultures. Cardiovascular toxicology. 2001;1(1):61-72. 


\section{Chapter 4}

\section{Stretch-induced hypertrophy of isolated adult rabbit cardiomyocytes}

Erik Blaauw, Frans van Nieuwenhoven, Peter Willemsen, Tammo Delhaas, Frits Prinzen, Luck Snoeckx, Marc van Bilsen, Ger van der Vusse.

Am J Physiol Heart Circ Physiol. 2010 299(3):H780-7. 


\section{ABSTRACT}

Background: Both mechanical and humoral triggers have been put forward to explain the hypertrophic response of the challenged cardiomyocyte.

Aim: The present aim was to investigate whether cyclic equibiaxial stretch is a direct stimulus for isolated cardiac myocytes from adult rabbits to develop hypertrophy and to explore the potential involvement of the autocrine/paracrine factors angiotensin II (AngII), Transforming Growth Factor- $\beta 1$ (TGF $\beta 1$ ) and Insulin-like Growth Factor-1 (IGF1 ) in this process.

Methods: Isolated cardiomyocytes were exposed to $10 \%$ cyclic equibiaxial stretch (1 $\mathrm{Hz}$ ) for up to $48 \mathrm{~h}$, or treated with Angll (100 nM), TGFß1 (5 ng/ml), IGF-1 (100 ng/ml), Angll-type 1 receptor (AT-1) blockers, or conditioned medium of stretched fibroblasts.

Results: Cyclic stretch significantly increased cell surface area $(+3.1 \%)$, protein synthesis $(+21 \%)$ and BNP mRNA expression (6-fold) in cardiomyocytes. TGF $\beta 1$ expression was increased (+42\%) transiently at $4 \mathrm{~h}$, while cardiomyocyte IGF-1 expression was not detectable under all experimental conditions. AT-1 blockers candesartan and irbesartan (100 nM) did not prevent the stretch-induced hypertrophic response. Direct exposure to AngII, TGFB1 or IGF-1 did not enhance cardiomyocyte BNP expression. In cardiac fibroblasts, stretch elicited a significant 2-fold increase in TGFB1 and IGF-1 expression. Conditioned medium of stretched fibroblasts increased BNP expression in cardiomyocytes ( 2-fold; P=0.07).

Conclusion: This study clearly indicates that cyclic stretch is a strong, direct trigger to induce hypertrophy in fully differentiated rabbit cardiomyocytes. The present findings do not support the notion that stretch-mediated hypertrophy of rabbit cardiomyocytes involves autocrine/paracrine actions of AngII, TGFB1 or IGF-1. 


\section{INTRODUCTION}

Chronically increased workload on the mammalian heart results in hypertrophic growth and predisposes to the development of heart failure ${ }^{1}$. At present, research is focusing on the primary triggers and the intracellular signalling pathways responsible for hypertrophic growth of cardiomyocyte ${ }^{2}$. Increased stretch is considered an important factor initiating the sequel of events leading to cardiomyocyte hypertrophy ${ }^{3-5}$. It is, however, unclear whether in the adult heart overload-induced hypertrophy is mediated by stretch sensors per se connected to downstream intracellular signalling pathways or by neuro-humoral and growth factors or a combination thereof. In vivo the separate role of mechanical triggers and growth factors is difficult to investigate because of their interdependence ${ }^{6}$. Therefore, in vitro systems have been developed allowing investigation of isolated cardiomyocytes under standardized conditions ${ }^{7}$. In these systems, mechanical stretch induced cardiomyocyte hypertrophy, concomitant with secretion of angiotensin II (AngII) ${ }^{7,8}$. Exposure of quiescent cardiomyocytes to AngIl also induced hypertrophy ${ }^{6}$, although results are not equivocal ${ }^{9,10}$. Furthermore, exposure of cardiomyocytes to Transforming Growth Factor- $\beta 1$ (TGF $\beta 1)^{11,12}$ or Insulin-like Growth Factor-1 $(\text { IGF-1 })^{13}$ elicited a hypertrophic response. Extrapolation of these findings to the intact adult heart in situ is not straightforward. First, previous experiments were commonly performed on cardiomyocytes isolated from neonatal rat hearts. Neonatal cardiomyocytes are not fully differentiated ${ }^{14}$ and still have a relatively high expression of fetal genes, like beta-myosin heavy chain ${ }^{7}$. Moreover, hearts from rodents differ substantially from the human heart with respect to action potential duration, EC-coupling and calcium ion handling ${ }^{15,16}$, and the force-frequency relationship ${ }^{17}$. Finally, static stretch, although generally applied in in vitro experiments, does not mimic the rhythmic changes in workload during systole and diastole of the heart in situ. The aims of the present study were to investigate whether cyclic equibiaxial stretch in vitro is a direct stimulus for cardiac rabbit cardiomyocytes to develop hypertrophy and to determine to what extent the autocrine/paracrine action of AngII, TGF $\beta 1$ or IGF-1 is involved in the hypertrophic response. Thereto, fully differentiated, rabbit cardiomyocytes were either subjected to cyclic equibiaxial stretch or treated with AngII, TGF 31 , IGF-1 and/or specific Angll receptor AT-1 blockers. Changes in cell morphology, protein synthesis, and mRNA expression of the hypertrophic marker gene Brain Natriuretic Protein (BNP) were assessed. The cardiomyocyte mRNA expression of Atrial Natriuretic Factor (ANF), TGF-1 and IGF-1 was also determined. Finally, also isolated cardiac fibroblasts from adult rabbits were exposed to cyclic equibiaxial stretch, and TGF $\beta 1$ and IGF-1 mRNA expression was measured. The effect of conditioned medium of stretched and non-stretched fibroblasts on cardiomyocyte BNP and ANF mRNA expression was assessed as well. 


\section{MATERIALS AND METHODS}

\section{Animals}

Cardiomyocytes and fibroblasts were isolated from adult male white New Zealand rabbits ( $3 \mathrm{~kg}$ ). Experiments were performed with approval of the Animal Ethical Committee of Maastricht University conform to the Guide for the Care and Use of Laboratory Animals published by the US National Institutes of Health (NIH Publication No. 85-23 revised 1996).

\section{Isolation of rabbit cardiomyocytes}

Isolation of cardiomyocytes was performed according to a modified Mitcheson procedure $^{18}$. In short, animals were anaesthetized with ketamine $(35 \mathrm{mg} / \mathrm{kg}$; Eurovet Animal Health B.V., Bladel, the Netherlands) and xylazine (5 mg/kg; Produlab Pharma, Raamsdonksveer, the Netherlands) via intramuscular injection, followed by intravenous administration of $2500 \mathrm{U}$ heparin (Leo Pharma B.V., Breda, the Netherlands). Rabbits were sacrificed by cervical dislocation, and hearts were excised and rinsed in ice-cold modified Krebs-Henseleit buffer $\mathrm{A}(\mathrm{KH}-\mathrm{A}, \mathrm{pH} 7.4$ ), consisting of (in $\mathrm{mM}$ ) $\mathrm{NaCl}(133), \mathrm{KCl}(5)$, $\mathrm{MgCl}_{2}(2), \mathrm{NaH}_{2} \mathrm{PO}_{4}(1.2)$, glucose (10), HEPES (10), creatine (6), taurine (6), and a low calcium ion concentration $\left(10 \mu \mathrm{M} \mathrm{CaCl}_{2}\right)$. After removal of non-cardiac tissue, the aorta was cannulated and the heart was retrogradely perfused with oxygenated $\mathrm{KH}-\mathrm{A}$ buffer ( $25 \mathrm{ml} / \mathrm{min}$ ) at $37^{\circ} \mathrm{C}$ for $10 \mathrm{~min}$. Thereafter, the perfusion buffer was switched to a collagenase-containing digestion buffer consisting of $150 \mathrm{ml}$ fresh $\mathrm{KH}-\mathrm{A}$ buffer supplemented with Bovine Serum Albumin (BSA, 1\% w/v, fraction V, Roche Diagnostics, Mannheim, Germany) and $290 \mathrm{U} / \mathrm{ml}$ collagenase type II (Worthington, Lakewood, NJ, USA). The digestion buffer $\left(\mathrm{pH} 7.4,37^{\circ} \mathrm{C}\right)$ was oxygenated and recirculated for 8-10 min. Then, atrial and right ventricular tissue was removed and the left ventricle was incubated in Krebs-Henseleit buffer $\mathrm{B}(\mathrm{KH}-\mathrm{B}, \mathrm{pH} 7.4$ ) containing (in $\mathrm{mM}) \mathrm{NaCl}(120), \mathrm{KCl}(5)$, $\mathrm{MgCl}_{2}$ (2), $\mathrm{NaH}_{2} \mathrm{PO}_{4}$ (1.2), glucose (10), HEPES (10), creatine (6), taurine (6), supplemented with $\mathrm{CaCl}_{2}(10 \mu \mathrm{M})$, and $\mathrm{BSA}$ fraction $\mathrm{V}(1 \% \mathrm{w} / \mathrm{v})$ at RT for $10 \mathrm{~min}$. Butanedione monoxime (BDM, $20 \mathrm{mM}$ ) was added to prevent cardiomyocyte contraction. Thereafter, the left ventricle was transferred to fresh $\mathrm{KH}-\mathrm{B}$ at RT and cut in small pieces. Gentle shaking resulted in complete dissociation of ventricular tissue. Dissociated cells were filtered through nylon gauze and allowed to recover at RT for $20 \mathrm{~min}$. Thereafter, $\mathrm{Ca}^{2+}$ was gradually increased from $10 \mu \mathrm{M}$ to 50,75, 100, 150, 200, 400, 800 and $1200 \mu \mathrm{M}$, each step interspersed by $3 \mathrm{~min}$. Cardiomyocytes were subsequently collected by a mild centrifugation step at $50 \mathrm{~g}$ at RT for $3 \mathrm{~min}$. The supernatant was discarded and cardiomyocytes were resuspended in $25 \mathrm{ml}$ "recovery medium", consisting of M199 (Gibco, \#31153; Invitrogen, Breda, the Netherlands) supplemented with Fetal Bovine Serum (FBS; 5\% vol/vol; Gibco), L-carnitine (final concentration, $2 \mathrm{mM}$ ), taurine (5 mM), peni- 
cillin $(100 \mathrm{U} / \mathrm{ml})$, streptomycin $(100 \mathrm{mg} / \mathrm{ml})$ and gentamicin $(0.05 \mathrm{mg} / \mathrm{ml})$. To prevent non-cardiomyocyte proliferation, culture media contained cytosine-1- $\beta$-D-arabinofuranoside (AraC; $10 \mu \mathrm{M})$.

Cells were counted using a Burker Turk chamber and cell viability was assessed by trypan blue exclusion.

\section{Isolation of rabbit heart fibroblasts}

After collagenase perfusion, right ventricular tissue was dissected and cut in small pieces in DMEM (Gibco \#22320), supplemented with FBS (10\% vol/vol) and gentamicin $(0.05 \mathrm{mg} / \mathrm{ml})$ (DMEM*). Suspension was shaken manually and centrifuged at $50 \mathrm{~g}$ for 3 min to remove cardiomyocytes. Fibroblasts were collected from the supernatant by subsequent centrifugation at $300 \mathrm{~g}$ at RT for $5 \mathrm{~min}$. Pelleted fibroblasts were resuspended in DMEM*, and cultured in $75 \mathrm{~cm}^{2}$ plastic cell culture flask in a humidified $95 \%$ air / $5 \% \mathrm{CO}_{2}$ incubator at $37^{\circ} \mathrm{C}$. The next day, fibroblasts were washed twice with DMEM*; thereafter medium was refreshed every 2 to 3 days till cultures were confluent ( 10 days).

\section{Experimental protocols}

Silicone Flexcell membranes (6-wells Bioflex plates, pre-coated with collagen-I; Flexcell ${ }^{\circledR}$ Dunn Labortechnik, Asbach, Germany) were coated with $15 \mu \mathrm{g} / \mathrm{ml}$ laminin (Invitrogen, Breda, the Netherlands). Cardiomyocytes were plated at a density of $7.5 \times 10^{4}$ cells/well on the coated Bioflex plates. Cells were cultured in a humidified $95 \%$ air $/ 5 \% \mathrm{CO}_{2}$ incubator at $37^{\circ} \mathrm{C}$. After $2-3 \mathrm{~h}$, medium was aspirated and refreshed to remove nonattached, non-viable cells. The next day, recovery medium was refreshed once more. The day thereafter, $1 \mathrm{~h}$ before the experiment, recovery medium was replaced by a comparable medium containing $0.5 \%$ FBS instead of 5\% FBS ("experimental medium"). When fibroblast cultures were confluent ( $>90 \%$; passage 0 ), cells were detached using $0.25 \%$ trypsin-EDTA (Gibco, \#25200) and collected in $100 \mathrm{ml}$ "recovery medium" without AraC. Thereafter, $2 \mathrm{ml}$ of the cell suspension was added per well of the collagen-I and laminin coated 6-wells Bioflex plates. The next day, recovery medium was aspirated and refreshed. The following day, fibroblasts were $50-70 \%$ confluent. One hour before the experiment, recovery medium was replaced by $3 \mathrm{ml}$ "experimental medium" without AraC. Cardiomyocytes and fibroblasts were subjected to $10 \%$ cyclic equibiaxial stretch, produced by a Flexcell $\mathrm{FX}-4000^{\mathrm{TM}}$ strain unit (Dunn Labor-technik) with computer-controlled application of sinusoidal negative pressure $(1 \mathrm{~Hz})$ for up to $48 \mathrm{~h}$. Control, non-stretched cells were subjected to identical conditions; stretch was prevented by using FlexStops ${ }^{\mathrm{TM}}$ (Dunn Labor-technik). In a subset of experiments, cardiomyocytes were cultured on collagen-I and laminin coated Silicone Flexcell membranes 6-well plates, and exposed to TGFB1 (5 ng/ml) (R\&D systems, Minneapolis, MN, USA), IGF-1 
(100 ng/ml) (R\&D systems), Angll (100 nM) (Sigma, Zwijndrecht, the Netherlands), or pre-incubated with the AT-1 receptor blockers candesartan (100 nM) (CV 11974: the active form of candesartan, AstraZeneca, Zoetermeer, the Netherlands) or irbesartan (100 nM) (Haorui Pharma-Chem Inc., Edison, NJ, USA) 30 min prior to start of stretch experiments. TGF $\beta 1$, IGF-1, Angll and candesartan were dissolved in PBS and irbesartan in $100 \%$ ethanol; the final ethanol concentration was $1 \%$. Test experiments revealed that $1 \%$ ethanol did not affect the experimental outcome. With respect to Angll, positive control tests were performed to explore the responsiveness of isolated rabbit cardiac fibroblasts and cardiomyocytes to Angll doses at time intervals applied in the present study. Exposure of fibroblasts and cardiomyocytes to $100 \mathrm{nM}$ Angll for $48 \mathrm{~h}$ resulted in $35 \% \pm 5 \%$ increase and $51 \% \pm 8 \%$ decline in collagen-I expression, respectively, clearly indicating that the cells are able to respond to a single dose of exogenous Angll.

\section{Fibroblast-conditioned medium}

Stretched fibroblast-conditioned medium was collected after $48 \mathrm{~h}$ cyclic stretch. Control fibroblast-conditioned medium was prepared from non-stretched fibroblasts and from stretched plates without cells ("control medium") after 48h incubation. Collected, pooled medium was stored at $-20^{\circ} \mathrm{C}$ before use. Cardiomyocytes were exposed to conditioned media for up to $48 \mathrm{~h}$. Before application, the conditioned and control media were 1:1 diluted with "experimental medium" to a total volume of $2 \mathrm{ml}$.

\section{RNA isolation and real-time quantitative PCR (qPCR)}

After the experiment, cardiomyocytes and fibroblasts were washed twice with PBS, and total RNA was extracted with TRI-Reagent (Sigma, Steinheim, Germany). RNA concentration and purity were determined using the Nanodrop ND-1000 (Witec, Luzern, Switzerland). Total RNA (100 ng) was used for DNasel treatment (Sigma) to remove contaminating genomic DNA and subsequently for cDNA synthesis (Iscript cDNA synthesis kit; Biorad, Hercules, CA, USA). Gene expression analysis was performed by qPCR on an iCycler Real-Time PCR detection system (Biorad) using iQ SYBR-Green supermix (Biorad). Primer sets are indicated in Table 1. Gene expression differences were normalized on reference gene Cyclophilin-A. 
Table 1: Sequences of oligonucleotide primers used for real-time quantitative PCR. Cyclo, BNP, ANF, IGF-1 and TGF1 $\beta$ refer to Cyclophilin-A, Brain Natriuretic Protein, Atrial Natriuretic Factor, Insulin-like Growth Factor-I, and Transforming Growth Factor-beta1, respectively.

\begin{tabular}{llll}
\hline Gene & Forward 5'- & Reverse 5'- & Tm \\
\hline Cyclo & AAGAAGATCACCATTGCCAAC & GAGCTAGAGGAATGGTCAGGTG & $63^{\circ} \mathrm{C}$ \\
BNP & GCTCTCCTGCTCCTCCTCTT & GCAGCTGGGAGACCTTGTT & $64^{\circ} \mathrm{C}$ \\
ANF & CCGTGAGCTTCCTCTTCTGT & CCAAGTGGTCCAGCAAATTC & $63^{\circ} \mathrm{C}$ \\
IGF-1 & AGCTGGTGGATGCTCTTCAGTT & GAAGCAGCACTCATCCACGAT & $60^{\circ} \mathrm{C}$ \\
TGF $\boldsymbol{1} 1$ & AAGGGCTACCACGCCAACTT & CCGGGTTGTGCTGGTTGTAC & $60^{\circ} \mathrm{C}$ \\
\hline
\end{tabular}

\section{${ }^{3} \mathrm{H}$-Leucine incorporation}

Cardiomyocytes were exposed to ${ }^{3} \mathrm{H}$-leucine $(1 \mu \mathrm{Ci} / \mathrm{ml}$; GE-Healthcare, Amersham, Little Chalfont, UK) for $48 \mathrm{~h}$. Thereafter, cardiomyocytes were washed twice with ice-cold PBS and proteins were precipitated with $4 \%$ trichloroacetic acid at $4{ }^{\circ} \mathrm{C}$ for $60 \mathrm{~min}$. Proteins were subsequently scraped from the plate and concentrated by centrifugation $\left(10,000 \mathrm{~g}, 4^{\circ} \mathrm{C}, 15 \mathrm{~min}\right)$. Pellets were dissolved in $0.5 \mathrm{M} \mathrm{NaOH}$ for liquid scintillation counting.

\section{Cardiomyocyte dimensions}

Phase contrast micrographs were taken using a digital Nikon-Coolpix-990 camera. Cell width and length were measured using ImageJ software ( 150 randomly chosen cells per well) (NIH, Bethesda, MD, USA). Cell surface area $\left(\mu \mathrm{m}^{2}\right)$ was calculated according to: cell length $x$ cell width.

\section{Statistical analysis}

Measurements were performed on cardiomyocytes and fibroblasts from three independent isolations, respectively, with two or three wells per isolation. For each set of control wells per isolation the mean was set at 1.0; subsequently the individual values obtained in control and time-matched treated wells, respectively, were normalized on the mean of the control values. Thereafter, the normalized values obtained in the six or nine individual wells are expressed as mean \pm SEM. Finally, data were analyzed by 2tailed Student t-test to compare differences evoked by stretch or treatment with growth factors or blockers. P-values $<0.05$ were considered statistically significant. 


\section{RESULTS}

\section{Yield of cardiomyocyte isolation and cell viability}

The present procedure, modified after the previously published protocol of Mitcheson and colleagues ${ }^{18}$, resulted in a relatively high yield of rabbit cardiomyocytes, i.e., 20 to 25 million cells per left ventricle per isolation. Commonly, $70 \%-80 \%$ of the freshly isolated cardiomyocytes were viable, calcium-tolerant and rod-shaped. After seeding on the silicone Flexcell membrane, $96 \% \pm 3 \%$ of the cardiomyocytes remained attached during $48 \mathrm{~h}$ pre-incubation. The percentage of cells that remained attached to the silicone membrane subjected to non-stretch or cyclic stretch ( $10 \%$ cyclic equibiaxial stretch at $1 \mathrm{~Hz}$ ) for another $48 \mathrm{~h}$ averaged $90 \%$ and $77 \%$, respectively. Representative photographs of cardiomyocytes attached to Flexcell membranes after $48 \mathrm{~h}$ rest or cyclic stretch are shown in Fig 1A-D.

\section{Stretch-induced cardiomyocyte hypertrophy and protein synthesis}

Width, length and surface area of non-stretched control cardiomyocytes amounted to

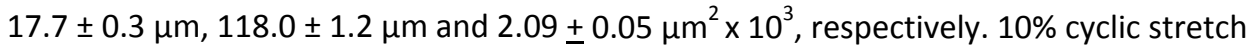
for $48 \mathrm{~h}$ resulted in a significant increase in cardiomyocyte surface area by $3.1 \%$ (Figure 2A). The increase in surface area was caused predominantly by increased cell width (data not shown). Cyclic stretch also significantly increased (+21\%) protein synthesis (Figure 2B). These findings indicate that cyclic stretch is a potent and direct trigger to elicit a hypertrophic response in isolated rabbit cardiomyocytes.

\section{Stretch-induced alterations in cardiomyocyte gene expression}

Expression of the hypertrophy marker BNP was significantly increased 6-fold after $48 \mathrm{~h}$ of stretch (Figure $2 \mathrm{C}$ ). BNP expression showed a moderate $(+55 \%)$ increase at $24 \mathrm{~h}$ of cyclic stretch (data not shown). Cyclic stretch resulted in a transient increase $(+47 \%$ at $4 \mathrm{~h}$ ) in ANF mRNA expression. No change in mRNA ANF expression was observed after $48 \mathrm{~h}$ cyclic stretch (data not shown). Stretch only transiently increased TGF $\beta 1$ expression by $42 \%$ at 4 h (Figure 3 ). IGF-1 mRNA expression in cardiomyocytes remained undetectable (data not shown).

\section{Effect of AngIl and AT-1 blockers on cardiomyocyte dimensions and gene expression}

Treatment with Angll for $48 \mathrm{~h}$ did not increase significantly cardiomyocyte surface area. Moreover, AT-1 blockade with candesartan and irbesartan had no significant effect on the cyclic stretch-induced increase in cell surface area (Figure 4A). Treatment of cardiomyocytes with Angll did not alter BNP mRNA expression (Figure 4B). Neither did 
exposure of cardiomyocytes to the AT-1 blockers candesartan or irbesartan affect the expression level of this molecular marker of cardiac hypertrophy during stretch conditions (Figure 4B). ANF mRNA expression was not altered in Angll-treated rabbit cardiomyocytes. Neither did the two AT-1 blockers affect ANF mRNA expression (data not shown).

\section{Stretch-induced alterations in gene expression in isolated fibroblasts}

To explore a potential paracrine role of fibroblast-derived growth factors in cardiomyocyte hypertrophy, cyclic stretch was also applied on rabbit cardiac fibroblasts. Exposure of fibroblasts to cyclic stretch for $48 \mathrm{~h}$ significantly increased TGF $\beta 1$ and IGF-1 expression by $60 \%$ and $100 \%$, respectively (Figure $5 \mathrm{~A}$ and $5 \mathrm{~B}$ ).

\section{Effect of TGF $\beta 1$ and IGF-1, and fibroblast-conditioned medium on cardiomyocyte gene expression}

Neither $4 \mathrm{~h}$ nor $48 \mathrm{~h}$ of TGF 1 and IGF-1 treatment evoked cardiomyocyte BNP mRNA expression (Figure 6). Exposure of rabbit cardiomyocytes to TGF $\beta 1$ or IGF-1 resulted in a small and transient increase in ANF mRNA expression of cardiomyocytes by $\sim 30 \%$ at $4 \mathrm{~h}$ $(P<0.05)$ (data not shown). Treatment of cardiomyocytes with conditioned medium of stretched fibroblasts resulted in a $\sim 2$-fold $(P=0.07)$ increase in cardiomyocyte $B N P$ mRNA expression at $48 \mathrm{~h}$. Control medium and conditioned medium of non-stretched fibroblasts did not alter cardiomyocyte BNP mRNA expression (Figure 7). Similar treatments had no effect on cardiomyocyte ANF mRNA expression (data not shown). 

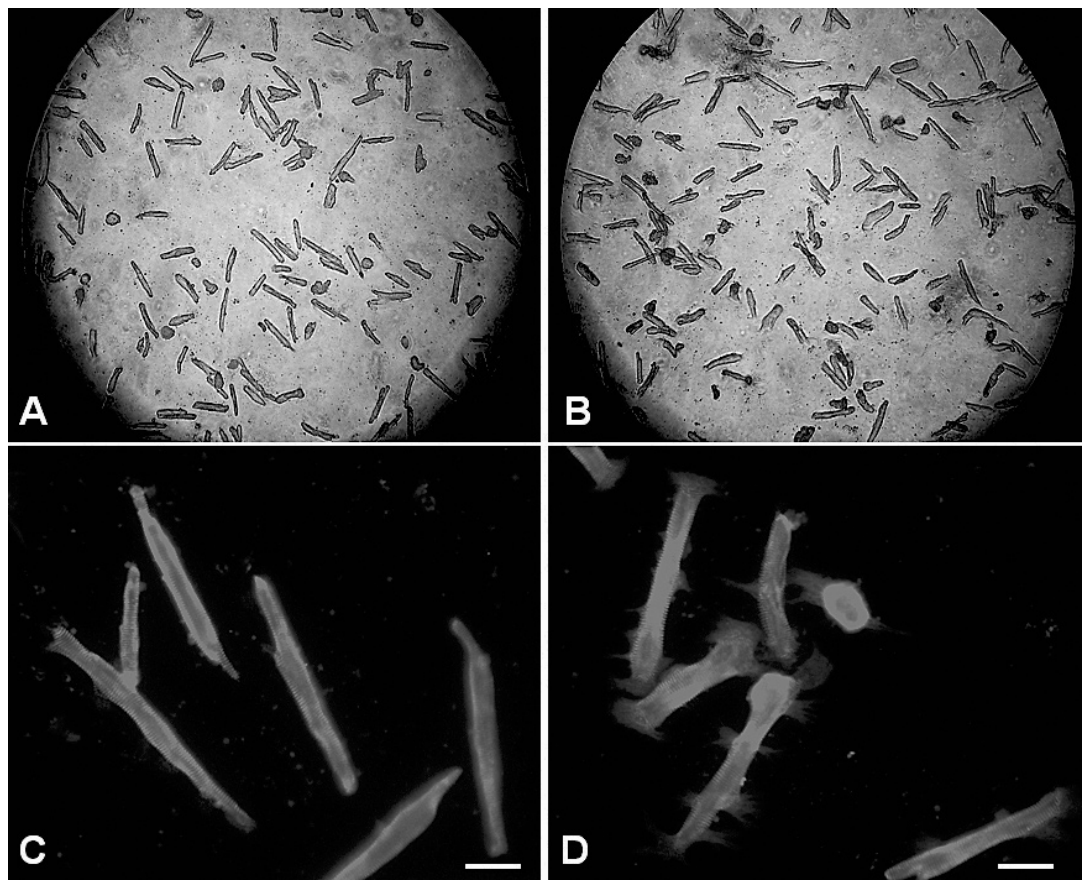

Figure 1: Representative photograph of rabbit cardiomyocytes attached to silicone Flexcell membranes. (A) and $(B)$ show an overview picture of rabbit cardiomyocytes attached to silicone Flexcell membranes subjected to $48 \mathrm{~h}$ non-stretch or cyclic equibiaxial stretch, respectively, following $48 \mathrm{~h}$ pre-incubation (magnification 100x). (C) and (D) show detailed pictures of the same cardiomyocytes after $48 \mathrm{~h}$ non-stretch or cyclic stretch, respectively. Cells were stained for F-actin according to ${ }^{50}$. Scale bars in (C) and (D) correspond to $25 \mu \mathrm{m}$

A

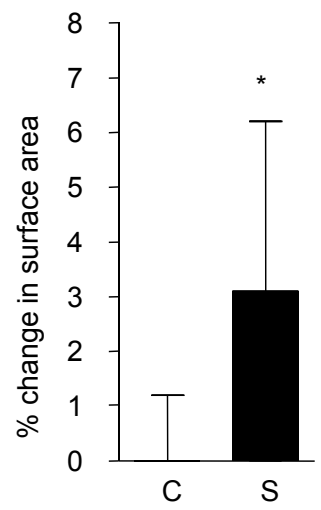

B

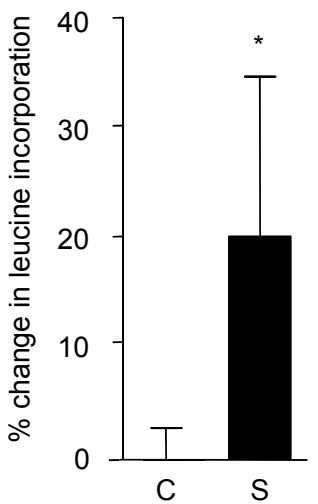

C

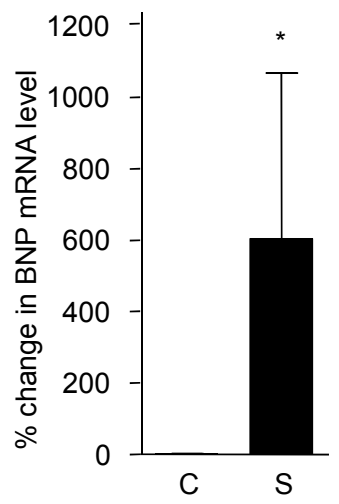

Figure 2: Effect of cyclic stretch on rabbit cardiomyocyte (A) surface area, (B) ${ }^{3} \mathrm{H}$-leucine and (C) BNP mRNA expression. Cells were exposed to stretch for $48 \mathrm{~h}$. The changes in stretched cells $(n=9)$ are shown as percentage of the average values of corresponding parameters in control, non-stretched cells $(n=9)$. Asterisk refers to $\mathrm{P}<0.05$ vs. control. 

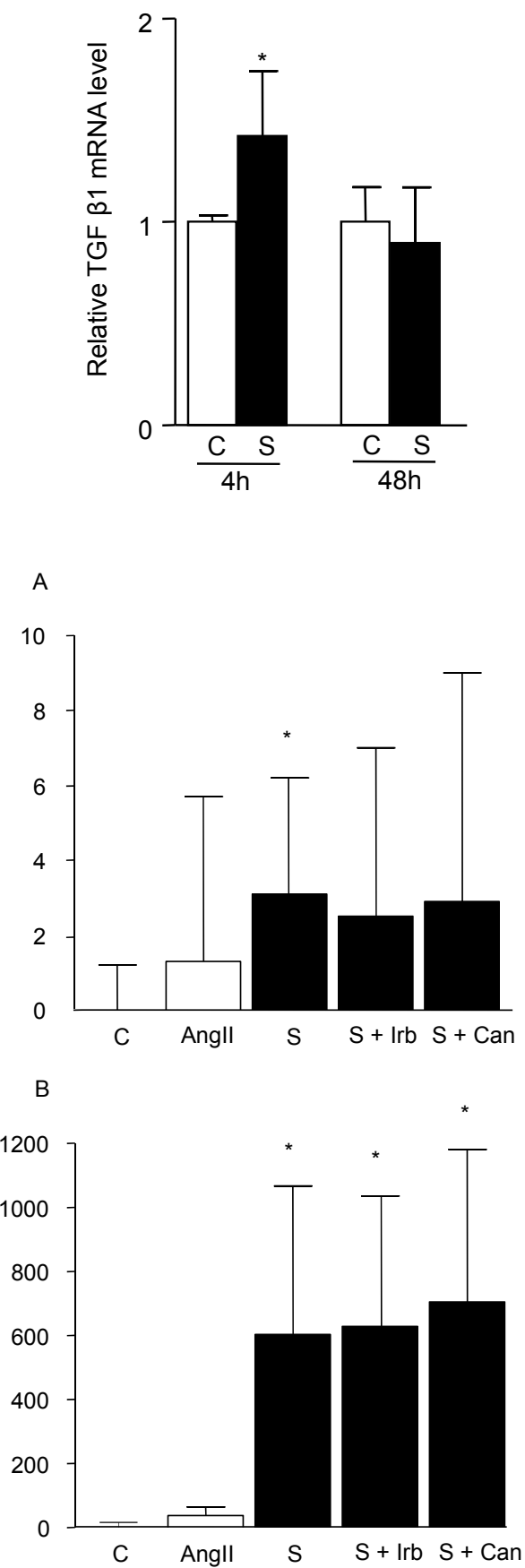

Figure 3: Effect of cyclic stretch on rabbit cardiomyocyte TGF $\beta 1$ mRNA expression. mRNA levels of TGF $\beta 1$ in stretched cardiomyocytes $(S ; n=9)$ are expressed relative to those of time-matched control cardiomyocytes $(C ; n=9)$. Asterisk indicates $P<0.05$ versus corresponding control.

Figure 4: Effect of Angll (Angll; $n=9$ ), stretch (S; $\mathrm{n}=9$ ), stretch plus AT-1 antagonist irbesartan ( + Irb, $n=9$ ) and stretch plus AT-1 agonist candesartan $(S+C a n, n=9)$ on $(A)$ cell surface area and on (B) BNP mRNA expression of rabbit cardiomyocytes after 48h. Effect on surface area and BNP mRNA expression is shown as percentage change compared to non-stretched controls (C) in case of Angll and $\mathrm{S}$, and compared to controls plus irbesartan $(\mathrm{C}+$ irb) and candesartan $(C+$ can $)$ in case of stretch plus Angll antagonists. Asterisk indicates $\mathrm{P}<0.05$ versus corresponding control. Values of both $\mathrm{S}+\mathrm{irb}$ and $\mathrm{S}+$ can are not significantly different from those of $S$ alone. 
A

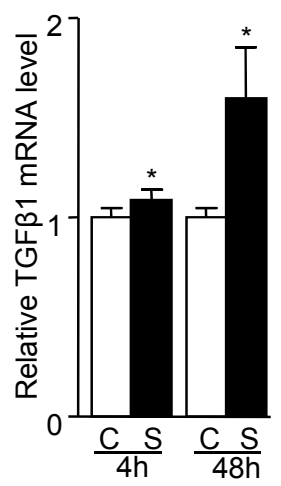

B

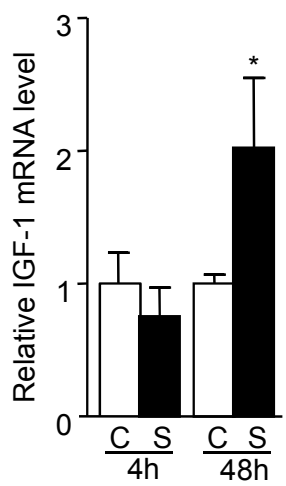

Figure 5: Effect of cyclic stretch for $4 \mathrm{~h}$ and $48 \mathrm{~h}$ on mRNA expression of (A) TGFB1 and (B) IGF-1 in rabbit cardiac fibroblasts, respectively. mRNA levels of TGF $\beta 1$ or IGF-1 in stretched fibroblasts $(S ; n=6)$ are expressed relative to those of nonstretched, time-matched control cardiac fibroblasts $(C ; n=6)$ are expressed relative to those of non-stretched, time-matched control cardiac fibroblasts ( $C ; n=6)$.
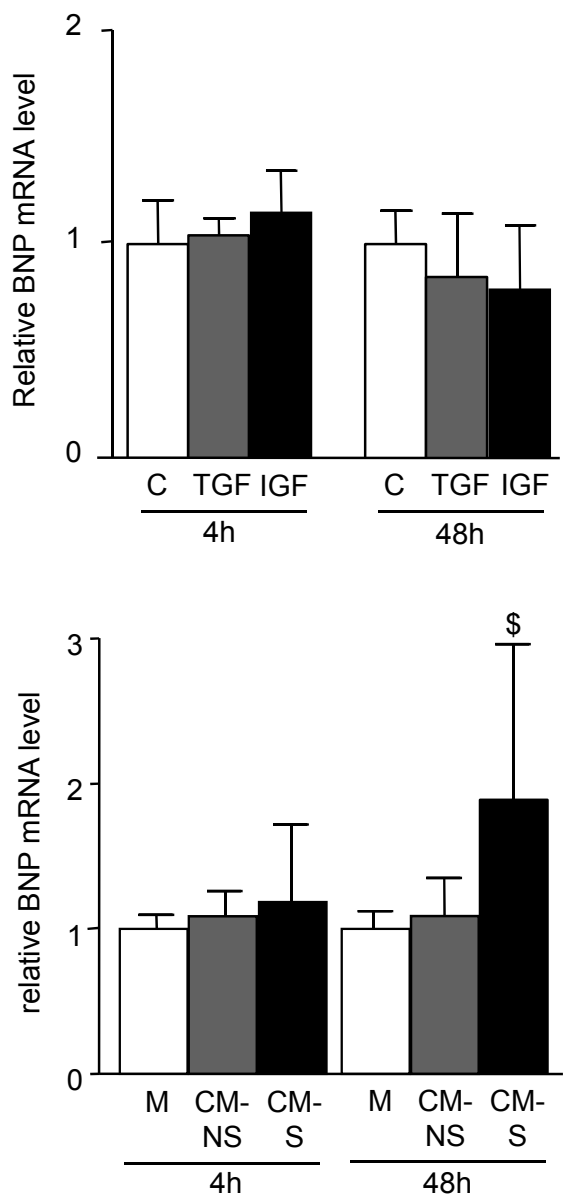

Figure 6: Effect of $4 \mathrm{~h}$ and $48 \mathrm{~h}$ exposure to TGF $\beta 1$ $(n=9)$ or IGF-1 $(n=9)$ on cardiomyocyte BNP mRNA expression. mRNA levels of treated cardiomyocytes are expressed relative to those of time-matched control cardiomyocytes (C; $\mathrm{n}=9$ ). Treatment with growth factor failed to induce a significant effect.
Figure 7: Effect of $4 \mathrm{~h}$ or $48 \mathrm{~h}$ exposure of rabbit cardiomyocytes to conditioned medium from non-stretched or stretched rabbit fibroblasts on BNP mRNA expression. mRNA levels of cardiomyocytes treated with conditioned medium from either $48 \mathrm{~h}$ non-stretched fibroblasts (CMNS; $n=6$ ) or stretched fibroblasts (CM-S; $n=6$ ) are expressed relative to corresponding timematched control cardiomyocytes treated with control medium $((M ; n=6)$. $\$$ indicates $P=0.07$ when compared with corresponding timematched control (M). 


\section{DISCUSSION}

\section{Stretch-induced cardiomyocyte hypertrophy}

The present study shows that cyclic stretch is a potent, direct trigger to induce hypertrophy in fully differentiated cardiomyocytes, derived from the adult rabbit heart. This conclusion is based on the observation that cellular surface area is increased, protein synthesis enhanced, and BNP mRNA expression up-regulated, when cardiomyocytes are exposed to $48 \mathrm{~h}$ cyclic stretch in vitro. Indications are lacking that the hypertrophic response is caused by autocrine and/or paracrine action of Angll, as treatment of cardiomyocytes with specific AT-1 receptor blockers did not abrogate the stretch-induced hypertrophic response and direct exposure of rabbit cardiomyocytes to Angll did not evoke enhanced expression of the molecular hypertrophy marker BNP. Moreover, a possible autocrine/paracrine action of TGF 31 and IGF1 in stretch-induced hypertrophy of rabbit cardiomyocytes is also less likely since direct exposure of cardiomyocytes to these two growth factors did not result in increased BNP mRNA expression. Furthermore, cyclic stretch did not elicit enhanced cardiomyocyte expression of IGF-1 and only a small, but transient induction or TGF 31 mRNA expression during $4 \mathrm{~h}$ stretch. We cannot exclude that in addition of a direct effect of stretch on cardiomyocyte hypertrophy an, as yet not identified, growth factor released from fibroblasts is able also to exert an hypertrophic effect on the cardiomyocyte, because conditioned medium from cardiac fibroblasts exposed to $48 \mathrm{~h}$ cyclic stretch, evoked a 2 fold increase in cardiomyocyte BNP expression.

Throughout the investigation, mRNA expression of BNP, rather than that of ANF, was considered a bona fide and sensitive molecular marker for cardiomyocyte hypertrophy. This notion corroborates earlier studies in rabbit hearts showing the superiority of BNP in diagnosing overload-induced left ventricular dysfunction ${ }^{19,20}$ Comparable conclusions were drawn in studies on patients suffering from depressed left ventricular function $^{21,22}$. Contrasting findings were obtained in studies performed on rats, indicating that ANF mRNA expression is superior to BNP ${ }^{23}$ or equally appropriate as $\mathrm{BNP}^{24}$ to disclose LV hypertrophy. The deviant findings may point to substantial species differences.

\section{Role of Angll and AT-1 receptors in stretch-induced cardiomyocyte hypertrophy}

Although earlier studies indicated that Angll could act as autocrine or paracrine factor in stretch-induced hypertrophy of cardiomyocytes ${ }^{25,26}$, the present study failed to reveal these actions of AngIl. Exposure of quiescent cardiomyocytes to Angll did neither increase cellular dimensions nor BNP expression (Figures $4 A$ and $4 B$, respectively). Theoretically, the lack of effect could be due to rapid degradation of Angll supplemented to the incubation medium. However, Van Kesteren and colleagues ${ }^{10}$ measured the half-life 
time of Angll after addition to the incubation medium of isolated cardiomyocytes. The half-life time amounted to 7 hours. The corollary of their finding is that in our study, during the first $24 \mathrm{~h}$ the concentration of exogenous Angll dropped to $10 \mathrm{nmol} / \mathrm{l}$; still sufficiently high to evoke a response, if any. Moreover, it can be deduced from the fact that Angll at the applied dose and time intervals affected collagen-I mRNA levels both in cardiac fibroblasts and cardiomyocytes (see Material and Methods) that rabbit cardiomyocytes indeed are intrinsically able to respond to this growth factor, but that Angll did not elicit a hypertrophic growth response. The main difference between the present experimental set-up and previous ones is that in the past experiments were mainly performed on immortalized $\mathrm{H} 9 \mathrm{C} 2$ cell lines ${ }^{27}$ or on cultured neonatal cardiomyocytes, predominantly from rat origin. The contrasting properties of neonatal and adult cardiomyocytes are substantiated by experiments showing that cardiomyocytes reduce their responsiveness to Angll during the process of maturation ${ }^{6}$. A critical autocrine role of Angll in the cardiomyocyte hypertrophic response has also been disputed in a recent review ${ }^{28}$, supported by experimental observations ${ }^{10,29}$. Moreover, Wenzel and colleagues ${ }^{30}$ suggested that Angll is involved in the transition from cardiac hypertrophy to failure rather than in the primary hypertrophic process.

The observation that the AT-1 blockers candesartan and irbesartan failed to inhibit stretch-induced cardiomyocyte hypertrophy also rules out the possibility that cardiac hypertrophy is caused by direct stretch-activation of Angll type-1 receptors. This conclusion contrasts with previous findings of Zou and colleagues ${ }^{31}$ who showed that stretch imposed on wild-type rat neonatal cardiomyocytes and on adult mouse cardiomyocytes, lacking the angiotensinogen gene, induced cardiomyocyte hypertrophy via activation of AT-1 receptors in the absence of Angll and that candesartan effectively blocked the hypertrophic response.

Later studies performed by the same investigators indicated that stretch-induced conformational changes of the receptor elicited this hypertrophic response. Candesar$\tan$ maintained the receptor in its inactive conformation ${ }^{32}$. The apparent discrepancy between these findings $s^{31,32}$ and our results could be explained by species differences. Our findings do, however, not exclude an intermediary role of Angll in stretch-induced cardiac hypertrophy. For instance, stretch of cardiomyocytes in situ may increase their endogenous production and release of Angll, which, in turn, may prompt the release of other growth factors from non-cardiomyocytes in the intact heart ${ }^{33,34}$. Theoretically, these growth factors may modulate the stretch-induced hypertrophic response of the challenged cardiomyocytes.

\section{Potential autocrine or paracrine action of TGF $\beta 1$ and IGF-1 in rabbit cardiomyocyte hypertrophy}

With respect to the potential role of other growth factors, Figure 3 shows that stretch induced a small, but significant increase in TGF $\beta 1$ expression in the rabbit cardiomyo- 
cyte, while stretch of cardiac fibroblasts resulted in a substantially enhanced expression of this growth factor (Figure 5A). However, since direct exposure of the cardiomyocytes to exogenous TGF $\beta 1$ for $4 \mathrm{~h}$ and $48 \mathrm{~h}$ did not result in enhanced BNP mRNA expression (Figure 6) and evoked only a minor and transient increase in ANF expression, it is unlikely that TGF $\beta 1$ plays an autocrine or paracrine role in the hypertrophic response of stretched rabbit cardiomyocytes.

The autocrine involvement of IGF-1 in the hypertrophic process is even less likely, because stretch of cardiomyocytes did not result in a measurable increase in IGF-1 mRNA expression. Although stretched fibroblasts increased significantly their expression of IGF-1, no convincing proof was obtained for a paracrine role as direct exposure of rabbit cardiomyocytes to IGF-1 for $4 \mathrm{~h}$ and $48 \mathrm{~h}$ did not elicit a hypertrophic response in terms of enhanced BNP expression (Figure 6).

In contrast to our findings, previous studies have indicated that TGF $\beta 1$ and IGF-1 may act as potent trophic factors on cardiomyocytes ${ }^{35,36}$. The discrepancy between the earlier observations and ours is most likely due to inherent differences between neonatal and adult cardiomyocytes in addition to species differences, i.e., rat vs. rabbit. Terminally differentiated cardiomyocytes are known to respond differently to IGF-1 than neonatal cardiomyocytes ${ }^{37}$. Furthermore, the IGF-1 mediated hypertrophic response is associated with activation of the PI3K-Akt/PKB signaling pathway, which is linked to cardiomyocyte survival, regeneration, and physiological hypertrophy rather than to maladaptive, pathological hypertrophy ${ }^{38,39}$. The latter might explain the absence of a substantially enhanced BNP mRNA expression in adult rabbit cardiomyocytes exposed to IGF-1, because increased expression of this marker gene is associated with maladaptive hypertrophy ${ }^{40}$.

\section{Additional role for fibroblasts in stretch-induced cardiomyocyte hypertrophy}

Despite the lack of convincing evidence for a paracrine action of TGF $\beta 1$, IGF-1 and Angll, it should be emphasized that exposure of cardiomyocytes for $48 \mathrm{~h}$ to conditioned medium of stretched cardiac rabbit fibroblasts induced a borderline significant $\sim 2$-fold increase in BNP mRNA expression (Figure 7). This finding might infer the presence of as yet unidentified factors released by stretched fibroblasts, adding to the direct hypertrophic effect of stretch on cardiomyocytes. It cannot be excluded that the hypertrophic effect of conditioned media of stretched cardiac fibroblasts, as observed in the present experimental set-up, is underestimated as a consequence of dilution in the incubation medium in contrast to the in situ situation in the cardiac interstitial compartment. The present study also does not exclude that other cell types, like endothelial cells and smooth muscle cells, could produce paracrine factors in the mechanically challenged heart in situ ${ }^{41,42}$. 


\section{mechanisms of stretch-induced cardiomyocyte hypertrophy}

It should be emphasized that the present findings strongly suggest that cyclic stretch exerts a direct effect on the adult cardiomyocyte resulting in a hypertrophic response. As the underlying mechanisms were not studied, one may speculate about the identity of the stretch-sensors and the nature of the signaling pathways involved. Regarding the stretch-sensors, several models have been put forward to explain the sensing of changes in stretch of the cardiac muscle cells ${ }^{43,44}$.

Stretch-activated ion channels in the sarcolemma are potential candidates for mechano-sensing by modulating the intracellular calcium ion concentration. In addition, integrins and associated proteins such as melusin and ILK have been postulated to transmit the mechanical signal to the cytoskeleton. Moreover, sarcolemmal nonreceptor-type tyrosine kinases have been linked to stretch-sensing. Furthermore, Z-disc proteins, such as titin and related compounds, have been shown to act as molecular structures sensing cardiomyocyte deformation ${ }^{2,43,45}$. A plethora of intracellular signaling pathways has been proposed to transmit the mechanical signal, sensed by the stretchsensor, to the nucleus of the challenged cardiomyocyte, eventually resulting in enhanced protein synthesis, increased cell volume and expression of specific molecular markers of cardiomyocyte hypertrophy ${ }^{2,25,45-47}$.

\section{Summarizing comments}

The collective findings indicate that sustained cyclic stretch is a potent, direct trigger to evoke a hypertrophic response in isolated, rabbit cardiomyocytes. In the present experimental set-up no strong indications were found for autocrine and/or paracrine effects of AngII, TGF 1 and IGF-1 on cardiomyocyte hypertrophy. The moderate, borderline significant hypertrophic effect of conditioned medium of stretched fibroblasts suggests that certain biochemical factors secreted by fibroblasts might play an, at most additional, role in the induction of cardiomyocyte hypertrophy. It is of note that our findings were obtained in experiments performed on isolated, adult rabbit cardiomyocytes instead of commonly used immortalized cardiac muscle cell lines or cultures of neonatal cardiomyocytes ${ }^{8,25,48,49}$. This crucial difference in experimental design, in addition to cyclic rather than static stretch as mechanical trigger, might explain the deviant findings emerging from the present study with respect to the role of growth factors such as AngII, TGF $\beta 1$ and IGF-1 in the onset of cardiac hypertrophy. Rabbit cardiomyocytes are considered to be a more appropriate cardiomyocyte preparation when attempting to extrapolate the experimental findings to the human heart. This notion is based on the fact that adult rabbit cardiomyocytes are fully differentiated and differ from cardiomyocytes obtained from small rodents with respect to action potential duration, EC-coupling and calcium ion handling and the force-frequency relationship ${ }^{15-}$ 17 


\section{REFERENCES}

1. Gaasch WH, Zile MR. Left ventricular diastolic dysfunction and diastolic heart failure. Annu Rev Med. 2004;55:373-394.

2. Hoshijima $M$, Hattori $T$, Inoue $M$, Araki $D$, Hanagata $H$, Miyauchi $A$, Takigawa $M$. CT domain of CCN2/CTGF directly interacts with fibronectin and enhances cell adhesion of chondrocytes through integrin alpha5beta1. FEBS Lett. 2006;580(5):1376-1382.

3. Swynghedauw B. Molecular mechanisms of myocardial remodeling. Physiol Rev. 1999;79(1):215-262.

4. Bupha-Intr T, Holmes JW, Janssen PM. Induction of hypertrophy in vitro by mechanical loading in adult rabbit myocardium. Am J Physiol Heart Circ Physiol. 2007;293(6):H3759-3767.

5. Villarreal FJ, Dillmann WH. Cardiac hypertrophy-induced changes in mRNA levels for TGF-beta 1 , fibronectin, and collagen. Am J Physiol. 1992;262(6 Pt 2):H1861-1866.

6. Schluter KD, Wenzel S. Angiotensin II: a hormone involved in and contributing to pro-hypertrophic cardiac networks and target of anti-hypertrophic cross-talks. Pharmacol Ther. 2008;119(3):311-325.

7. Sadoshima J, Jahn L, Takahashi T, Kulik TJ, Izumo S. Molecular characterization of the stretch-induced adaptation of cultured cardiac cells. An in vitro model of load-induced cardiac hypertrophy. J Biol Chem. 1992;267(15):10551-10560.

8. van Wamel JE, Ruwhof C, van der Valk-Kokshoorn EJ, Schrier PI, van der Laarse A. Rapid gene transcription induced by stretch in cardiac myocytes and fibroblasts and their paracrine influence on stationary myocytes and fibroblasts. Pflugers Arch. 2000;439(6):781-788.

9. Kent RL, McDermott PJ. Passive load and angiotensin II evoke differential responses of gene expression and protein synthesis in cardiac myocytes. Circ Res. 1996;78(5):829-838.

10. van Kesteren CA, van Heugten HA, Lamers JM, Saxena PR, Schalekamp MA, Danser AH. Angiotensin IImediated growth and antigrowth effects in cultured neonatal rat cardiac myocytes and fibroblasts. $J \mathrm{Mol}$ Cell Cardiol. 1997;29(8):2147-2157.

11. Parker TG, Packer SE, Schneider MD. Peptide growth factors can provoke "fetal" contractile protein gene expression in rat cardiac myocytes. J Clin Invest. 1990;85(2):507-514.

12. Villarreal FJ, Lee AA, Dillmann WH, Giordano FJ. Adenovirus-mediated overexpression of human transforming growth factor-beta 1 in rat cardiac fibroblasts, myocytes and smooth muscle cells. J Mol Cell Cardiol. 1996;28(4):735-742.

13. Horio T, Maki T, Kishimoto I, Tokudome T, Okumura H, Yoshihara F, Suga S, Takeo S, Kawano Y, Kangawa K. Production and autocrine/paracrine effects of endogenous insulin-like growth factor-1 in rat cardiac fibroblasts. Regul Pept. 2005;124(1-3):65-72.

14. Ueno $H$, Perryman MB, Roberts $R$, Schneider MD. Differentiation of cardiac myocytes after mitogen withdrawal exhibits three sequential states of the ventricular growth response. J Cell Biol. 1988;107(5):1911-1918.

15. Lindahl GE, Chambers RC, Papakrivopoulou J, Dawson SJ, Jacobsen MC, Bishop JE, Laurent GJ. Activation of fibroblast procollagen alpha $1(\mathrm{I})$ transcription by mechanical strain is transforming growth factorbeta-dependent and involves increased binding of CCAAT-binding factor (CBF/NF-Y) at the proximal promoter. J Biol Chem. 2002;277(8):6153-6161.

16. Varro A, Lathrop DA, Hester SB, Nanasi PP, Papp JG. Ionic currents and action potentials in rabbit, rat, and guinea pig ventricular myocytes. Basic Res Cardiol. 1993;88(2):93-102.

17. Hasenfuss G, Mulieri LA, Blanchard EM, Holubarsch C, Leavitt BJ, Ittleman F, Alpert NR. Energetics of isometric force development in control and volume-overload human myocardium. Comparison with animal species. Circ Res. 1991;68(3):836-846.

18. Mitcheson JS, Hancox JC, Levi AJ. Cultured adult cardiac myocytes: future applications, culture methods, morphological and electrophysiological properties. Cardiovasc Res. 1998;39(2):280-300.

19. Birner CM, Ulucan C, Fredersdorf S, Rihm M, Lowel H, Stritzke J, Schunkert H, Hengstenberg C, Holmer S, Riegger G, Luchner A. Head-to-head comparison of BNP and IL-6 as markers of clinical and experimental heart failure: Superiority of BNP. Cytokine. 2007;40(2):89-97. 
20. Luchner A, Muders F, Dietl O, Friedrich E, Blumberg F, Protter AA, Riegger GA, Elsner D. Differential expression of cardiac ANP and BNP in a rabbit model of progressive left ventricular dysfunction. Cardiovasc Res. 2001;51(3):601-607.

21. Yasue H, Yoshimura M, Sumida H, Kikuta K, Kugiyama K, Jougasaki M, Ogawa H, Okumura K, Mukoyama $\mathrm{M}$, Nakao K. Localization and mechanism of secretion of B-type natriuretic peptide in comparison with those of A-type natriuretic peptide in normal subjects and patients with heart failure. Circulation. 1994;90(1):195-203.

22. Maeda K, Tsutamoto T, Wada A, Hisanaga T, Kinoshita M. Plasma brain natriuretic peptide as a biochemical marker of high left ventricular end-diastolic pressure in patients with symptomatic left ventricular dysfunction. Am Heart J. 1998;135(5 Pt 1):825-832.

23. Su X, Brower G, Janicki JS, Chen YF, Oparil S, Dell'Italia LJ. Differential expression of natriuretic peptides and their receptors in volume overload cardiac hypertrophy in the rat. J Mol Cell Cardiol. 1999;31(10):1927-1936.

24. Kinnunen $P$, Vuolteenaho $O$, Ruskoaho $H$. Mechanisms of atrial and brain natriuretic peptide release from rat ventricular myocardium: effect of stretching. Endocrinology. 1993;132(5):1961-1970.

25. Sadoshima J, Xu Y, Slayter HS, Izumo S. Autocrine release of angiotensin II mediates stretch-induced hypertrophy of cardiac myocytes in vitro. Cell. 1993;75(5):977-984.

26. Miyata S, Haneda T, Osaki J, Kikuchi K. Renin-angiotensin system in stretch-induced hypertrophy of cultured neonatal rat heart cells. Eur J Pharmacol. 1996;307(1):81-88.

27. Stuck BJ, Lenski M, Bohm M, Laufs U. Metabolic switch and hypertrophy of cardiomyocytes following treatment with angiotensin $\|$ are prevented by AMP-activated protein kinase. J Biol Chem. 2008;283(47):32562-32569.

28. Reudelhuber TL, Bernstein KE, Delafontaine P. Is angiotensin II a direct mediator of left ventricular hypertrophy? Time for another look. Hypertension. 2007;49(6):1196-1201.

29. Xiao HD, Fuchs S, Bernstein EA, Li P, Campbell DJ, Bernstein KE. Mice expressing ACE only in the heart show that increased cardiac angiotensin II is not associated with cardiac hypertrophy. Am J Physiol Heart Circ Physiol. 2008;294(2):H659-667.

30. Wenzel S, Abdallah Y, Helmig S, Schafer C, Piper HM, Schluter KD. Contribution of PI 3-kinase isoforms to angiotensin II- and alpha-adrenoceptor-mediated signalling pathways in cardiomyocytes. Cardiovasc Res. 2006;71(2):352-362.

31. Zou Y, Akazawa H, Qin Y, Sano M, Takano H, Minamino T, Makita N, Iwanaga K, Zhu W, Kudoh S, Toko H, Tamura K, Kihara M, Nagai T, Fukamizu A, Umemura S, liri T, Fujita T, Komuro I. Mechanical stress activates angiotensin II type 1 receptor without the involvement of angiotensin II. Nat Cell Biol. 2004;6(6):499-506.

32. Yasuda N, Miura S, Akazawa H, Tanaka T, Qin Y, Kiya Y, Imaizumi S, Fujino M, Ito K, Zou Y, Fukuhara S, Kunimoto S, Fukuzaki K, Sato T, Ge J, Mochizuki N, Nakaya H, Saku K, Komuro I. Conformational switch of angiotensin II type 1 receptor underlying mechanical stress-induced activation. EMBO Rep. 2008;9(2):179-186.

33. Sharma HS, van Heugten HA, Goedbloed MA, Verdouw PD, Lamers JM. Angiotensin II induced expression of transcription factors precedes increase in transforming growth factor-beta 1 mRNA in neonatal cardiac fibroblasts. Biochem Biophys Res Commun. 1994;205(1):105-112.

34. Gray MO, Long CS, Kalinyak JE, Li HT, Karliner JS. Angiotensin II stimulates cardiac myocyte hypertrophy via paracrine release of TGF-beta 1 and endothelin-1 from fibroblasts. Cardiovasc Res. 1998;40(2):352363.

35. Duerr RL, McKirnan MD, Gim RD, Clark RG, Chien KR, Ross J, Jr. Cardiovascular effects of insulin-like growth factor-1 and growth hormone in chronic left ventricular failure in the rat. Circulation. 1996;93(12):2188-2196.

36. Brand T, Schneider MD. The TGF beta superfamily in myocardium: ligands, receptors, transduction, and function. J Mol Cell Cardiol. 1995;27(1):5-18. 
37. Donath MY, Zapf J, Eppenberger-Eberhardt M, Froesch ER, Eppenberger HM. Insulin-like growth factor I stimulates myofibril development and decreases smooth muscle alpha-actin of adult cardiomyocytes. Proc Natl Acad Sci U S A. 1994;91(5):1686-1690.

38. Crackower MA, Oudit GY, Kozieradzki I, Sarao R, Sun H, Sasaki T, Hirsch E, Suzuki A, Shioi T, Irie-Sasaki J, Sah R, Cheng HY, Rybin VO, Lembo G, Fratta L, Oliveira-dos-Santos AJ, Benovic JL, Kahn CR, Izumo S, Steinberg SF, Wymann MP, Backx PH, Penninger JM. Regulation of myocardial contractility and cell size by distinct PI3K-PTEN signaling pathways. Cell. 2002;110(6):737-749.

39. Shioi T, Kang PM, Douglas PS, Hampe J, Yballe CM, Lawitts J, Cantley LC, Izumo S. The conserved phosphoinositide 3-kinase pathway determines heart size in mice. Embo J. 2000;19(11):2537-2548.

40. Yamaguchi H, Yoshida J, Yamamoto K, Sakata Y, Mano T, Akehi N, Hori M, Lim YJ, Mishima M, Masuyama T. Elevation of plasma brain natriuretic peptide is a hallmark of diastolic heart failure independent of ventricular hypertrophy. J Am Coll Cardiol. 2004;43(1):55-60.

41. Chien S, Li S, Shyy YJ. Effects of mechanical forces on signal transduction and gene expression in endothelial cells. Hypertension. 1998;31(1 Pt 2):162-169.

42. Stegemann JP, Hong $H$, Nerem RM. Mechanical, biochemical, and extracellular matrix effects on vascular smooth muscle cell phenotype. J Appl Physiol. 2005;98(6):2321-2327.

43. Knoll R, Hoshijima M, Chien K. Cardiac mechanotransduction and implications for heart disease. J Mol Med. 2003;81(12):750-756.

44. Brancaccio M, Hirsch E, Notte A, Selvetella G, Lembo G, Tarone G. Integrin signalling: the tug-of-war in heart hypertrophy. Cardiovasc Res. 2006;70(3):422-433.

45. Lammerding J, Kamm RD, Lee RT. Mechanotransduction in cardiac myocytes. Ann N Y Acad Sci. 2004;1015:53-70.

46. Barry SP, Davidson SM, Townsend PA. Molecular regulation of cardiac hypertrophy. Int J Biochem Cell Biol. 2008;40(10):2023-2039.

47. Heineke J, Molkentin JD. Regulation of cardiac hypertrophy by intracellular signalling pathways. Nat Rev Mol Cell Biol. 2006;7(8):589-600.

48. Frank D, Kuhn C, Brors B, Hanselmann C, Ludde M, Katus HA, Frey N. Gene expression pattern in biomechanically stretched cardiomyocytes: evidence for a stretch-specific gene program. Hypertension. 2008;51(2):309-318.

49. Sadoshima J, Izumo S. The cellular and molecular response of cardiac myocytes to mechanical stress. Annu Rev Physiol. 1997;59:551-571.

50. Driesen RB, Verheyen FK, Debie W, Blaauw E, Babiker FA, Cornelussen RN, Ausma J, Lenders MH, Borgers M, Chaponnier C, Ramaekers FC. Re-expression of alpha skeletal actin as a marker for dedifferentiation in cardiac pathologies. J Cell Mol Med. 2009;13(5):896-908. 

Chapter 5

The effect of stretch and growth factors on the expression of extracellular matrix components by rabbit cardiac fibroblasts 


\section{ABSTRACT}

Background: Cardiac fibroblasts subjected to overload commonly increase their expression of extracellular matrix (ECM) constituents.

Aim: To investigate whether stretch and autocrine/paracrine growth factors are direct stimuli for isolated cardiac fibroblasts from adult rabbits to enhance expression of ECM proteins, such as collagens (Col-I and Col-III) and fibronectin (FN), and the matricellular protein Connective Tissue Growth Factor (CTGF).

Methods: Fibroblasts isolated from adult rabbit hearts were subjected to $10 \%$ cyclic equibiaxial stretch $(1 \mathrm{~Hz})$, treated with angiotensin II (Angll, $100 \mathrm{nM})$, Transforming Growth Factor- $\beta 1$ (TGF $\beta 1,5 \mathrm{ng} / \mathrm{ml}$ ) and Insulin-like Growth Factor-1 (IGF-1, $100 \mathrm{ng} / \mathrm{ml}$ ), or exposed to conditioned medium of rabbit cardiomyocytes stretched for up to $48 \mathrm{~h}$.

Results: Cyclic stretch increased the expression of FN, but moderately decreased Col-I and Col-III mRNA expression. Stretch induced a rapid, transient increase in CTGF expression at $4 \mathrm{~h}$ and a slower increase in TGF $\beta 1$ and IGF-1 expression (by $59 \%$ and $100 \%$, respectively, at $48 \mathrm{~h}$ ). Exogenous TGF $\beta 1$ elicited a 6 -fold increase in TGF $\beta 1$ and a 2 -fold increase in IGF-1 expression at $48 \mathrm{~h}$. In the presence of exogenous TGF $\beta 1$ fibroblasts showed increased Col-I, FN and CTGF expression. Exposure of fibroblasts to exogenous Angll mildly increased the expression of Col-I, Col-III and FN. IGF-1 treatment caused a mild decline in CTGF and Col-III expression. Exposure of fibroblasts to conditioned medium of stretched rabbit cardiomyocytes resulted in increased CTGF expression, while Col-III expression decreased. The expression of Col-I, TGF $\beta 1$ and IGF-1 was not affected. Conclusion: Cyclic stretch is a strong, direct trigger to induce CTGF and FN and growth factors (TGF $\beta 1$ and IGF-1) in rabbit cardiac fibroblasts and to down regulate collagens. The stretch-induced changes of FN and Col-III expression might be provoked by autocrine action of TGF $\beta 1$. Stretch may exert a direct effect on fibroblast CTGF expression; moreover factors derived from stretched cardiomyocytes appear to up regulate CTGF expression in fibroblasts. A potential candidate acting on fibroblasts in a paracrine fashion is TGFB1. 


\section{INTRODUCTION}

The cardiac muscle is composed of cardiomyocytes and non-cardiomyocytes (fibroblasts and endothelial cells), encapsulated in the extracellular matrix (ECM). The primary function of the ECM is to maintain shape and structure of the heart and to facilitate transduction of mechanical stimuli through the cardiac wall. The main building blocks of cardiac ECM are the fibrillar collagens. Collagen-I (Col-I) accounts for $85 \%$ of the cardiac collagens, while collagen-III (Col-III) is less abundant ${ }^{1}$. In addition to collagens, non-collagen proteins such as Fibronectin (FN) and Connective Tissue Growth Factor (CTGF) have been identified to play an important role in ECM function and in regulating collagen expression ${ }^{2,3}$. While $\mathrm{FN}$ serves a structural role as adhesive link between cells and the ECM, CTGF is a matricellular protein, important as a regulator of ECM homeostasis and cellular communication with the interstitial compartment ${ }^{2}$. Under physiological conditions the synthesis and degradation of collagens and matricellular proteins are in equilibrium. However, in the setting of heart disease, enhanced workload and/or local biochemical alterations, the balance can tip towards increased collagen deposition ${ }^{4,5}$, eventually resulting in excessive accumulation of ECM proteins, commonly designated as "cardiac fibrosis" ${ }^{1,6-8}$. Fibrosis will increase cardiac stiffness and, hence, impair diastolic relaxation and systolic contraction ${ }^{1,9}$. Moreover, fibrosis provides a pro-arrhythmogenic substrate ${ }^{10}$.

Physical triggers have been suggested to be involved in enhanced ECM production in the heart ${ }^{4,11,12}$. This could be either direct or indirect. The direct pathway involves the translation of a mechanical signal into enhanced expression of ECM proteins ${ }^{13}$ whereas the indirect pathway employs the stretch-mediated production and excretion of profibrotic growth factors, such as angiotensin II (AngII), Transforming Growth Factor $\beta 1$ (TGF $\beta 1)$ and Insulin-like Growth Factor-1 (IGF-1) ${ }^{4,14,15}$ as an intermediate step. Since fibroblasts are also known to release TGF $\beta 1$, IGF-1 and possibly also Angl| ${ }^{15-17}$, they may play a paramount role in regulating ECM production and deposition of ECM proteins. However, other cell types in the heart, including cardiomyocytes, are also able to produce TGF $\beta 1^{18}$, and Angll ${ }^{17}$, thus creating a paracrine regulation of cardiac fibroblast ECM production. This notion is supported by several in vitro studies showing that exposure of fibroblasts to Angll and TGFB1 resulted in enhanced mRNA levels of structural ECM and matricellular proteins ${ }^{4,17,19}$.

The aim of the present study was to investigate the role of stretch and growth factors (the latter; autocrine or paracrine) in the early fibrotic response of cardiac fibroblasts. To this end, fibroblasts and cardiomyocytes were isolated from the adult rabbit heart, and subjected to cyclic equibiaxial stretch for up to $48 \mathrm{~h}$. Alternatively, fibroblasts were exposed to the growth factors, TGF 1 1, IGF-1 or AngII, or to conditioned medium of the stretched cardiac cardiomyocytes. The short-term (4h) and long-term (48h) effects of 
these interventions on the mRNA expression levels of Col-I, Col-III, FN, CTGF, TGF 31 and IGF-1 were assessed.

\section{MATERIALS AND METHODS}

\section{Animals}

Cardiac fibroblasts were isolated from adult male white New Zealand rabbits, varying in weight from 2.5 to $3.5 \mathrm{~kg}$. Animal experiments were performed with the approval of the Animal Ethical Committee of Maastricht University, the Netherlands, and conform to the Guide for the Care and Use of Laboratory Animals published by the US National Institutes of Health (NIH Publication No. 85-23 revised 1996).

\section{Isolation and culturing of fibroblasts}

The details of the isolation and culturing of cardiac fibroblasts from the right ventricle of the adult rabbit heart are given in full detail in chapter 3 of this thesis. Rabbit heart fibroblasts were cultured in a $75 \mathrm{~cm}^{2}$ plastic cell culture flask containing DMEM, supplemented with FBS (10\% vol/vol) and gentamicin $(0.05 \mathrm{mg} / \mathrm{ml})$ and transferred to a humidified $95 \% \mathrm{O}_{2} / 5 \% \mathrm{CO}_{2}$ incubator at $37^{\circ} \mathrm{C}$. When fibroblasts had grown to confluence (>90\% after 10 to 14 days; passage 0 ), cells were detached, and collected in 100 ml "culturing medium", consisting of M199 (Invitrogen; Breda, the Netherlands; no. 31153) supplemented with Foetal Bovine Serum (FBS; 5\% vol/vol; Gibco), L-carnitine (final concentration $2 \mathrm{mM})$, taurine $(5 \mathrm{mM})$, penicillin $(100 \mathrm{U} / \mathrm{ml})$, streptomycin $(100$ $\mathrm{mg} / \mathrm{ml}$ ) and gentamicin $(0.05 \mathrm{mg} / \mathrm{ml})$. Two $\mathrm{ml}$ of the $100 \mathrm{ml}$ cell suspension was transferred to each well of 6-well Bioflex plates (coated by the manufacturer with Col-I; Dunn Labortechnik $\mathrm{GmbH}$, Asbach, Germany) that had been pre-coated with laminin (15 $\mathrm{\mu g} / \mathrm{ml}$ PBS solution). The next day, culturing medium was aspirated and refreshed. On the day thereafter (day 3 ), when the fibroblasts had reached $50-70 \%$ confluence (passage 1 fibroblasts), cells were used for further experiments.

\section{Experimental protocols}

One hour prior to the start of the experiment, culture medium was replaced by $3 \mathrm{ml}$ of comparable medium containing $0.5 \%$ FBS instead of 5\% FBS (vol/vol) ("experimental medium"), for stretch experiments or by $2 \mathrm{ml}$ of experimental medium for growth factor exposure. For stretch experiments, fibroblasts were subjected to $10 \%$ of cyclic equibiaxial stretch, produced by a Flexcell $\mathrm{FX}-4000^{\mathrm{TM}}$ strain unit (Dunn Labortechnik $\mathrm{GmbH}$ ) with computer-controlled application of sinusoidal negative pressure at a frequency of $1 \mathrm{~Hz}$ for up to $48 \mathrm{~h}$. Control, non-stretched fibroblasts were exposed to iden- 
tical conditions except that cellular stretch was prevented using FlexStops ${ }^{\text {TM }}$ (Dunn Labortechnik GmbH).

In a subset of experiments, fibroblasts were cultured on laminin and collagen-I precoated Silicone Flexcell membranes 6-well plates, and exposed to Angll (100 nM) (Sigma, Zwijndrecht, the Netherlands), TGFB1 ( $5 \mathrm{ng} / \mathrm{ml}$ ) (R\&D systems, MN, USA), and IGF-1 (100 ng/ml) (R\&D systems). TGF $\beta 1$, Angll, and IGF-1 were dissolved in phosphatebuffered saline (PBS).

\section{Cardiomyocyte-conditioned medium}

Conditioned cardiomyocyte medium was collected after $48 \mathrm{~h}$ from stretched ("CM-S medium") as well as non-stretched cardiomyocytes ("CM-NS medium") (cultured as described in detail chapter 3). Medium collected from wells without cells was used as "control medium". The distinct media per experimental condition were pooled and subsequently stored at $-20^{\circ} \mathrm{C}$ till further use.

To study paracrine effects on fibroblasts, conditioned medium from stretched and nonstretched cardiomyocytes and "control medium" was 1:1 diluted in experimental medium (total volume of $2 \mathrm{ml}$ ) and applied on quiescent cardiac fibroblasts for up to $48 \mathrm{~h}$.

\section{RNA isolation and real-time quantitative PCR}

At the end of the experimental procedure, fibroblasts were washed twice with PBS and total RNA was extracted with TRI Reagent (Sigma, Steinheim, Germany), according to the manufacturers protocol. RNA concentration was measured on the Nanodrop ND1000 (Witec Ag, Luzern, Switzerland) and calculated from the OD $260 \mathrm{~nm}$. RNA purity was determined by calculating the ratio of OD 260/280 nm. Hundred $\mathrm{ng}$ of total RNA was used for DNasel treatment (Sigma) to remove contaminating genomic DNA and subsequently utilized for cDNA synthesis (Iscript cDNA synthesis kit, Biorad Inc., Hercules, CA, USA). Gene expression analysis was performed by quantitative PCR (qPCR) on an iCycler Real-Time PCR detection system (Biorad) using the iQ SYBR-Green supermix (Biorad). For all primer sets used (table 1), optimal temperature and dilution curves were assessed to check for linearity. Gene expression differences were calculated using the comparative $\Delta C_{t}$ method ${ }^{20}$, and qBase software (Biorad). The housekeeping gene cyclophilin-A was used as reference gene.

\section{Statistical analysis}

Data are expressed as mean \pm SD. All measurements were performed on fibroblasts from 2 or 3 independent isolations with three wells per isolation. For each time-point (either obtained at $4 \mathrm{~h}$ or $48 \mathrm{~h}$ ), experimental data were expressed relative to corresponding control data per experiment. To this end, first, the mean $(x)$ of the control 
group for each, independent isolation was calculated by averaging the qbase qPCR data of the 3 control wells. Then, each individual control value was divided by $x$, resulting in 3 normalized control data points per isolation. The average of the 3 normalized control data points is by definition 1.00. Subsequently, the three individual values obtained in the experimental wells (fibroblasts subjected to cyclic stretch or growth factor treatment), were divided by $x$ (mean value of the 3 corresponding control wells), resulting in three normalized experimental values per individual isolation. In case of 2 or 3 isolations the total number of normalized control and normalized experimental values per treatment amounted to 6 or 9, respectively. The mean and SD of the 6 or 9 normalized values are shown in the figures or text. Statistical analyses were performed using SPSS software (version 15.0). Data were analyzed by unpaired Student t-test. A p-value equal or below 0.05 was considered to reflect a statistically significant difference.

Table 1: Sequences of oligonucleotide primers used for real-time quantitative PCR. Cyclo, Col-I, Col-III, CTGF, FN, IGF-1 and TGFB1 refer to Cyclophilin-A, collagen-I, collagen-III, Connective Tissue Growth Factor, Fibronectin, Insulin-like Growth Factor-I, and Transforming Growth Factor-beta1, respectively.

\begin{tabular}{llll}
\hline Gene & Forward 5'- & Reverse 5'- & Tm \\
\hline Cyclo & AAGAAGATCACCATTGCCAAC & GAGCTAGAGGAATGGTCAGGTG & $63^{\circ} \mathrm{C}$ \\
Col-I & ATGGATGAGGAAACTGGCAACT & GCCATCGACAAGAACAGTGTAAGT & $62^{\circ} \mathrm{C}$ \\
Col-III & TGATTTTTGCTGTTCCACCA & GCACCATTGAGACATTTTGA & $63^{\circ} \mathrm{C}$ \\
CTGF & CACAGAGTGGAGCGCCTGTTC & GATGCACTTTTTGCCCTTCTTAATG & $63^{\circ} \mathrm{C}$ \\
FN & GCAGACCAGTTCAGGGAGTC & GTGATGGTCTCGGTCTTGGT & $61^{\circ} \mathrm{C}$ \\
IGF-1 & AGCTGGTGGATGCTCTTCAGTT & GAAGCAGCACTCATCCACGAT & $60^{\circ} \mathrm{C}$ \\
TGF $\boldsymbol{\beta 1}$ & AAGGGCTACCACGCCAACTT & CCGGGTTGTGCTGGTTGTAC & $60^{\circ} \mathrm{C}$ \\
\hline
\end{tabular}

\section{RESULTS}

\section{Stretch-induced changes in fibroblast gene expression}

To explore the early and late effects of cyclic stretch on cardiac fibroblasts from adult rabbits, the cells were exposed to $4 \mathrm{~h}$ and $48 \mathrm{~h}$ of $10 \%$ stretch at $1 \mathrm{~Hz}$ and potential changes in the expression of CTGF, FN, Col-I, Col-III, TGF $\beta$ and IGF-1 were determined at the mRNA level. Cyclic stretch for $4 \mathrm{~h}$ evoked a small, but significant transient increase $(+35 \%)$ in CTGF mRNA (figure 1A). After prolonged cyclic stretch (48h) the expression of FN increased almost 2-fold (figure 1B), while expression of both Col-I and Col-III mRNA decreased, (figure $1 C$ and 1D, respectively). Expression of the growth factors TGF $\beta$ and IGF-1 substantially increased after prolonged stretch of the fibroblasts (figure $1 \mathrm{E}$ and $1 F$, respectively). As cyclic stretch induced the expression of TGF 31 and IGF-1, factors known to influence fibroblast function, it was investigated if these factors could act as autocrine/paracrine factors. 


\section{Effect of exogenous TGF $\beta 1$}

Exposure of cardiac fibroblasts to exogenous TGFB1 leads to a rapid, approximately two-fold, transient increase in CTGF mRNA expression (figure $2 \mathrm{~A}$ ) and significantly increased $\mathrm{FN}$ expression by $22 \%$ and $93 \%$ at $4 \mathrm{~h}$ and $48 \mathrm{~h}$, respectively, (figure $2 \mathrm{~B}$ ). TGF 31 enhanced Col-I expression by $71 \%(P<0.05)$ (figure $2 \mathrm{C}$ ), while Col-III expression was significantly reduced by $26 \%$ at 48 h (figure $2 \mathrm{D}$ ). TGF1 $\beta$ did not affect the expression of Col-I and Col-III at $4 \mathrm{~h}$ (figure $2 \mathrm{C}$ and 2D, respectively). Exposure of fibroblasts to TGF $\beta 1$ had a marked stimulatory effect on the expression of TGF $\beta 1$ itself and that of IGF-1. After $48 \mathrm{~h}$ expression of these growth factors had increased more than 6-fold and 2fold, respectively (figure $2 \mathrm{E}$ and $2 \mathrm{~F}$ ).

A

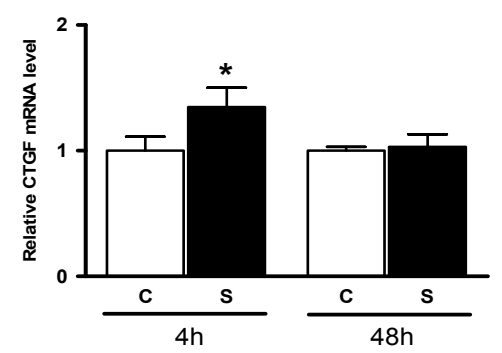

C
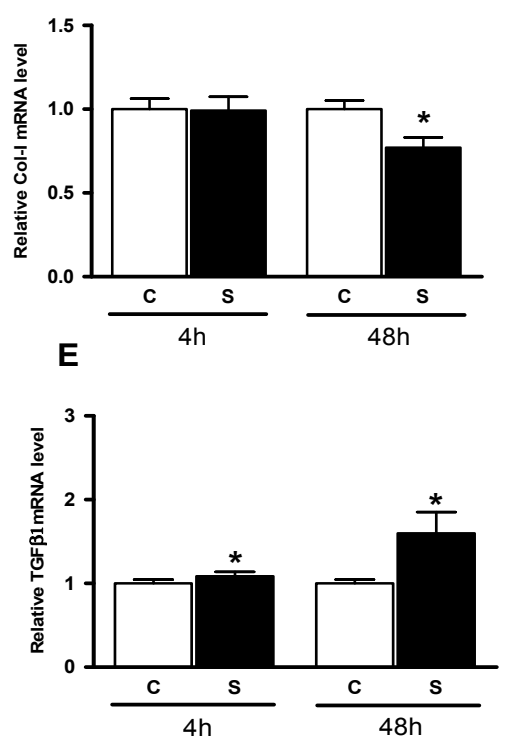

B

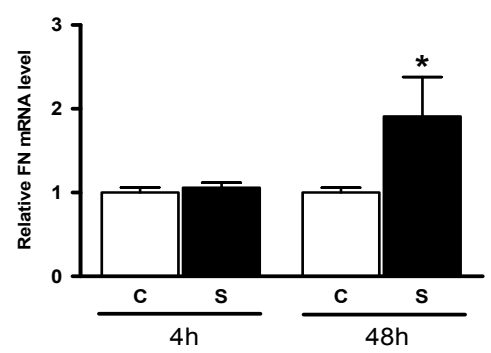

D
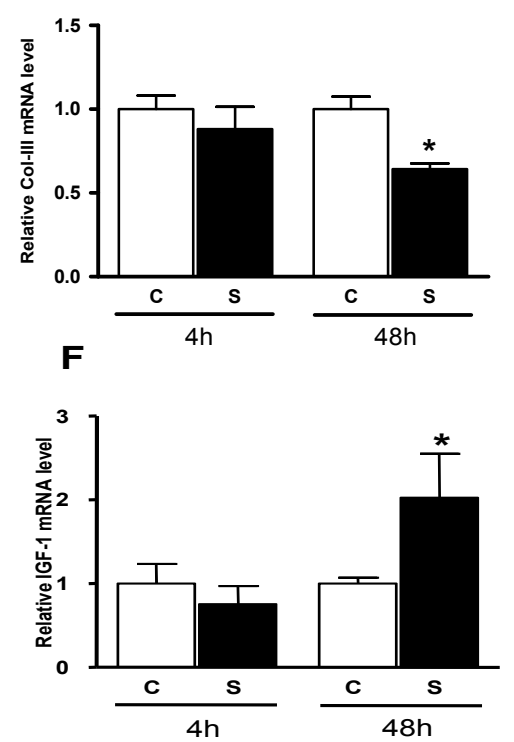

Figure 1: Effect of cyclic stretch on mRNA expression of (A) CTGF, (B) FN, (C) Col-I, (D) Col-III, (E) TGFB1 and (F) IGF-1 in rabbit cardiac fibroblasts exposed to stretch (s) for $4 \mathrm{~h}$ and $48 \mathrm{~h}$, respectively. Data are expressed as fold change compared to corresponding time-matched, non-stretched controls (c). Asterisk refers to a statistical difference with time-matched controls $(\mathrm{P}<0.05)$. 
A

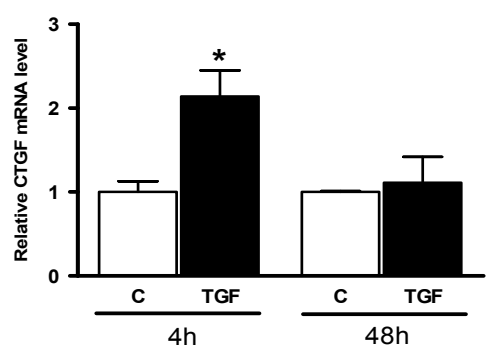

C
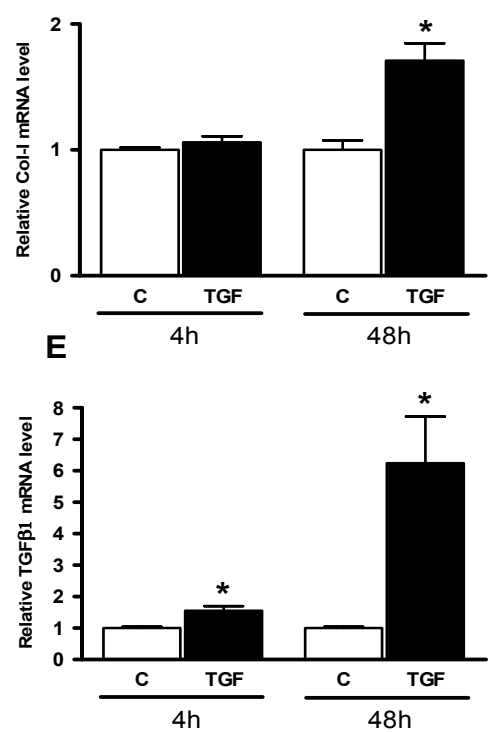

B

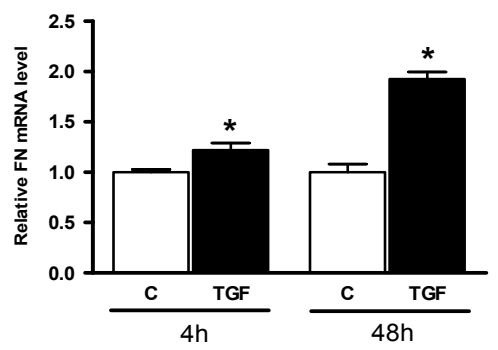

D
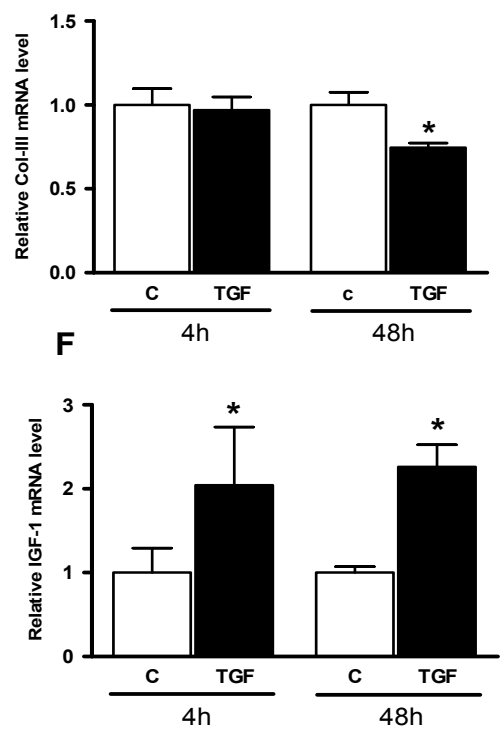

Figure 2: Effect of exogenous TGFB1 on rabbit cardiac fibroblast mRNA expression of (A) CTGF, (B) FN, (C) ColI, (D), Col-III, (E) TGF $\beta 1$ and (F) IGF-1 after exposure for $4 \mathrm{~h}$ and $48 \mathrm{~h}$, respectively. Data are expressed as fold change compared to corresponding time-matched, non-treated controls (c). Asterisk refers to a statistical difference with time-matched controls $(\mathrm{P}<0.05)$. 


\section{Effect of exogenous IGF-1}

Exposure of rabbit cardiac fibroblasts to exogenous IGF-1 resulted in a significant decline in CTGF mRNA expression both after $4 \mathrm{~h}$ and $48 \mathrm{~h}$ (-21\% and $-30 \%$, respectively) (figure 3A). IGF-1 treatment did not affect fibroblast expression of FN and Col-I (figure $3 B$ and $3 C$, respectively). Col-III mRNA expression was unaffected by IGF-1 after $4 \mathrm{~h}$, but was significantly up-regulated (+25\%) at $48 \mathrm{~h}$ of IGF-1 treatment (figure 3D). IGF-1 exposure exerted no effect on TGF $\beta 1$ expression at $4 \mathrm{~h}$, but significantly down-regulated TGF 1 1 expression (-11\%) at 48h (figure 3E). IGF-1 evoked a mild, but significant increase $(+22 \%)$ of IGF-1 expression at $48 \mathrm{~h}$ (figure $3 \mathrm{~F}$ ).

\section{Effect of exogenous Angll}

Finally, given the reported pro-fibrotic effects of Angll, rabbit cardiac fibroblasts were also exposed to Angll. Treatment of the cells with Angll for $4 \mathrm{~h}$ did not evoke significant changes in the expression of the genes investigated (figure $4 \mathrm{~A}-\mathrm{F}$ ). However, prolonged Angll exposure for $48 \mathrm{~h}$ was associated with moderate increases in fibroblast FN, Col-I, Col-III and TGF $\beta 1$ mRNA (figure 4B-E). The expression of IGF-1 almost doubled (figure $4 \mathrm{~F})$.

\section{Effect of cardiomyocyte-conditioned medium}

Exposure of rabbit cardiac fibroblasts to conditioned medium of either non-stretched or stretched cardiomyocytes (48h medium) resulted in a transient but significant increase in fibroblast CTGF expression ( $20 \%$ and $30 \%$ at $4 \mathrm{~h}$, respectively) (figure $5 \mathrm{~A}$ ). There was no effect of conditioned media from non-stretched and stretched cardiomyocytes on fibroblast FN expression (figure 5B). Col-I expression was only slightly, but significantly enhanced by conditioned media from non-stretched cardiomyocytes at $48 \mathrm{~h}$ (figure $5 \mathrm{C}$ ). In contrast to Col-I, Col-III expression declined significantly (-13\%) by conditioned medium of stretched cardiomyocytes after $4 \mathrm{~h}$ exposure; this inhibitory effect disappeared at $48 \mathrm{~h}$ (figure 5D). No substantial effect on the expression of TGF $\beta 1$ and IGF-1 could be observed (figure $5 \mathrm{E}$ and $5 \mathrm{~F}$, respectively). Only medium of non-stretched cardiomyocytes was able to induce a small, but significant increase $(20 \%)$ in fibroblast TGF $\beta 1$ expression (figure 5E). 
A

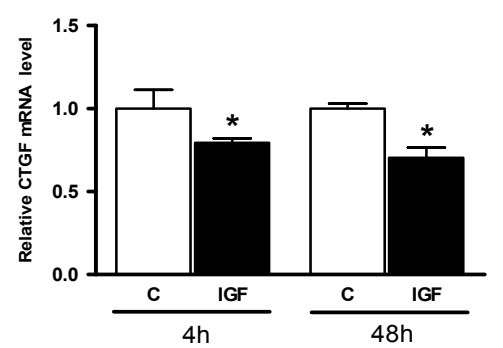

C
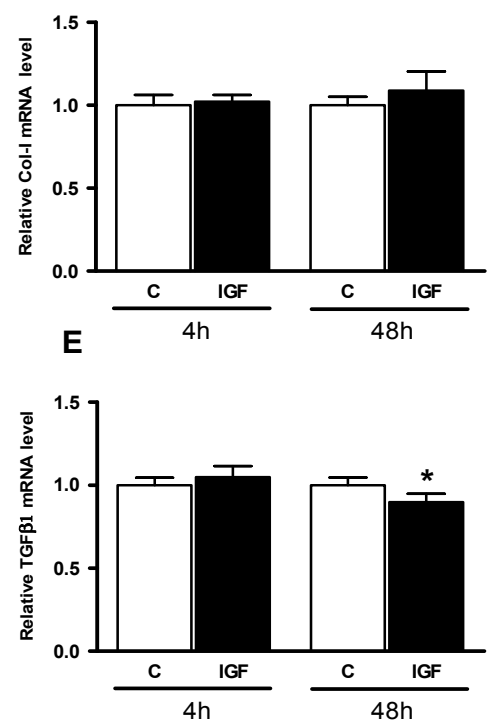

B

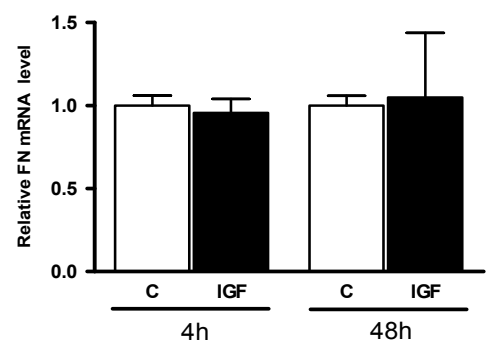

D
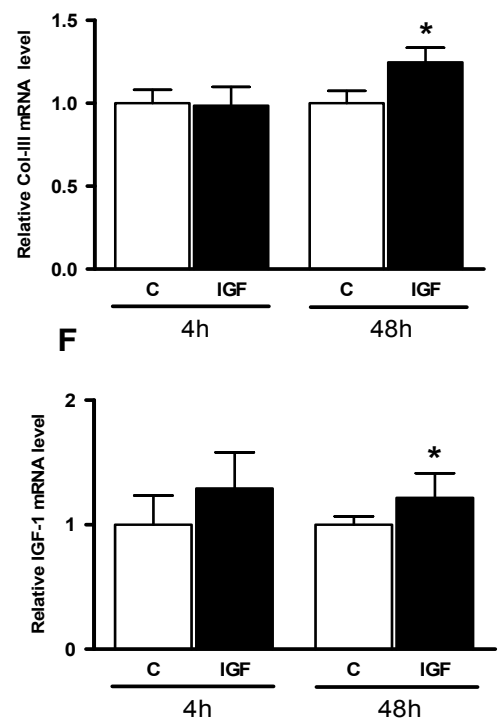

Figure 3: Effect of IGF-1 on rabbit cardiac fibroblast mRNA expression of (A) CTGF, (B) Fibronectin (FN), (C) Col-I, (D) Col-III, (E) TGFB1 and (F) IGF-1 after exposure for $4 \mathrm{~h}$ and $48 \mathrm{~h}$, respectively. Data are expressed as fold change compared to corresponding, non-treated time controls (c). Asterisk refers to $P<0.05$. 
A

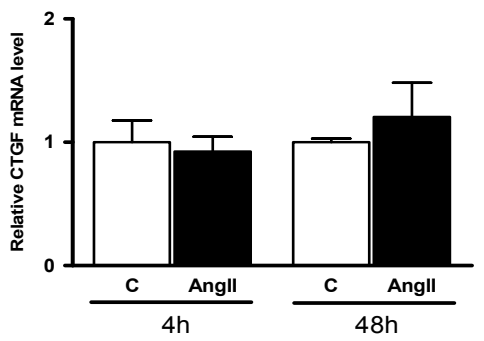

C
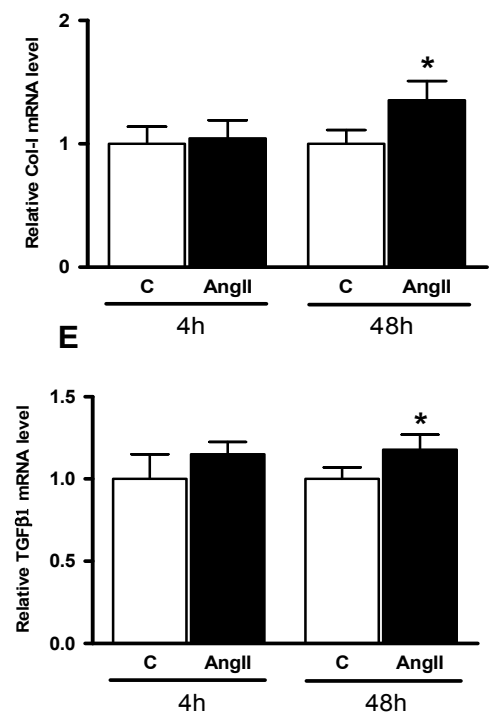

B

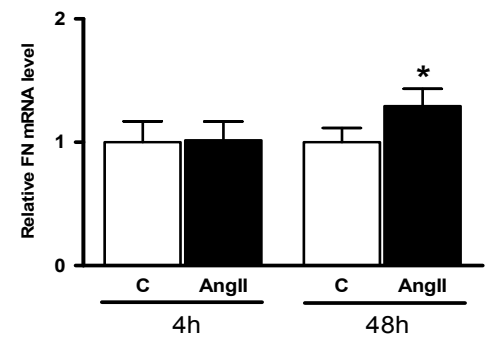

D
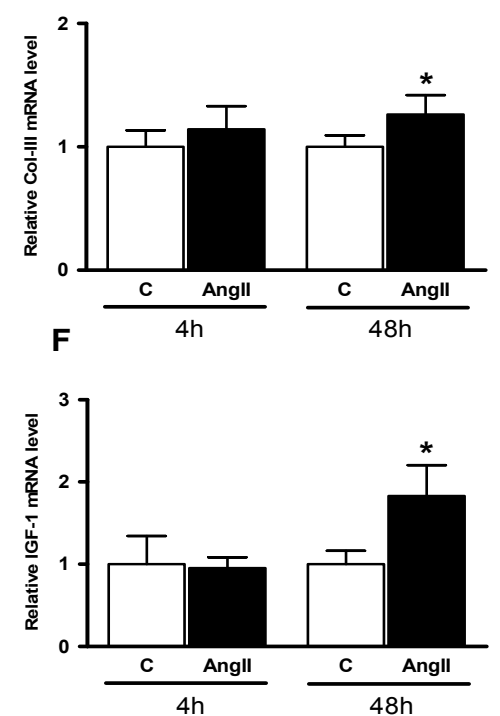

Figure 4: Effect of Angll on rabbit cardiac fibroblast mRNA expression of (A) CTGF, (B) FN, (C) Col-I, (D) Col-III, (E) TGF $\beta 1$ and (F) IGF-1 after exposure for $4 \mathrm{~h}$ and $48 \mathrm{~h}$, respectively. Data are expressed as fold change compared to corresponding time-matched, non-treated controls (c). Asterisk refers to a statistical difference with time-matched controls $(\mathrm{P}<0.05)$. 

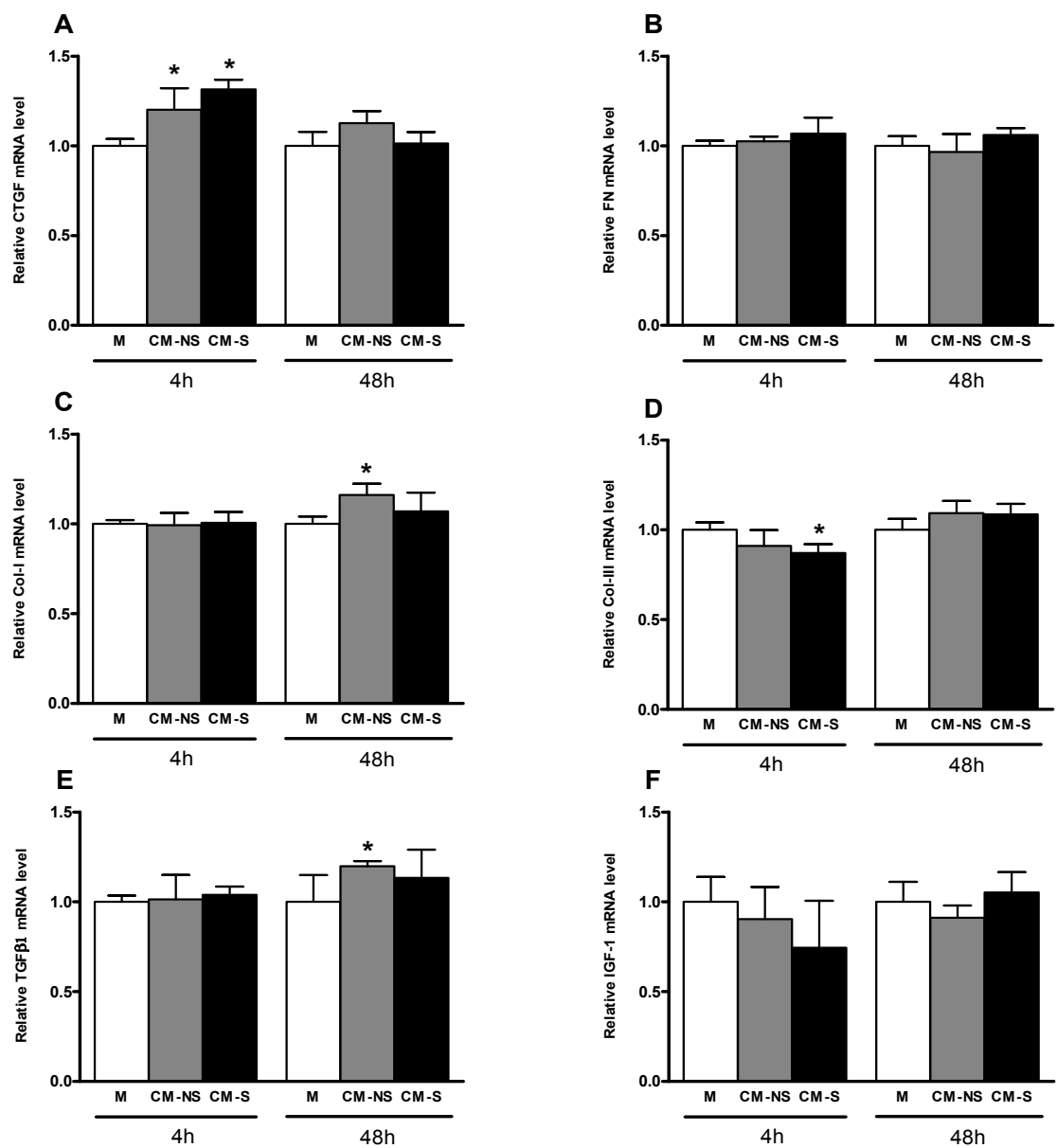

Figure 5: Effect of treatment with conditioned medium from $48 \mathrm{~h}$ non-stretched (CM-NS) or stretched (CM-S) rabbit cardiomyocytes on fibroblast mRNA expression of (A) CTGF, (B) FN, (C) Col-I, (D) Col-III, (E) TGFB1 and (F) IGF-1 after exposure for $4 \mathrm{~h}$ and $48 \mathrm{~h}$, respectively. Data are expressed as fold change compared to timematched control fibroblasts treated with control medium (M). Asterisk refers to a statistical difference with time-matched controls $(P<0.05)$. 


\section{DISCUSSION}

The present study indicates that cyclic stretch of rabbit cardiac fibroblasts did not directly induce upregulation, but rather downregulation, of collagens type I and III. Cyclic stretch of the fibroblasts did induce the expression of the matricellular protein CTGF, the ECM protein FN and the growth factors TGF $\beta 1$ and IGF-1. Exposure of fibroblasts to TGF $\beta 1$ resulted in enhanced expression of Col-I, FN, CTGF and growth factors TGF $\beta 1$ and IGF-1, thus indicating an autocrine regulatory role for TGF $\beta 1$. The up-regulation of CTGF in stretched fibroblasts might be caused by a fast, direct response to stretch per se, as well as a slower response mediated by autocrine or paracrine action of TGF $\beta 1$. The collective findings further suggest that cyclic stretch-mediated changes of $F N$ and Col-III may be caused by autocrine action of TGF $\beta 1$ released by stretched fibroblasts. A potential role of IGF-1 and AngII in stretch-induced up- or down-regulation of collagen and FN mRNA is less certain.

\section{Stretch- and growth factor-induced changes in collagen and FN mRNA expression}

Our study clearly shows that cardiac fibroblasts from adult rabbits decrease their Col-I and Col-III mRNA expression when subjected to cyclic stretch for $48 \mathrm{~h}$. At first glance, this may be a surprising observation as most previous studies showed increased cardiac fibroblast expression of Col-I and/or Col-III in response to stretch ${ }^{13,21}$. It is of note that the majority of the latter studies were performed on cultured fibroblasts isolated from neonatal rat hearts and cultured in the presence of high serum ${ }^{13,22}$. However, Husse and co-workers ${ }^{23}$ recently showed that in the presence of serum, cyclic stretch induced a significant decline in collagen mRNA expression in rat cardiac fibroblasts. Since in our study the rabbit fibroblasts were exposed to stretch in the presence of $0.5 \% \mathrm{FBS}$, it could be speculated that rabbit cardiac fibroblasts are also sensitive to serum factors.

With respect to the mechanism underlying the decreased expression of Col-I and Col-III in stretched fibroblasts, the question can be raised whether stretch per se is responsible for this effect or whether one should consider the involvement of autocrine-acting growth factors, the expression of which is stimulated by stretching the fibroblasts. Since neither exogenous TGF $\beta 1$, IGF-1 nor Angll depressed the expression of Col-I in the rabbit cardiac fibroblast, an autocrine, inhibitory effect of these growth factors can be excluded. It is of note that the responsiveness of cardiac fibroblasts to IGF-1 was found to depend on the developmental stage of fibroblasts as fetal and neonatal heart fibroblasts are more responsive to IGF-1 compared to adult cardiac fibroblasts $^{24}$. The present findings are in support of the latter observation.

The situation for Col-III is more complex. TGF $\beta 1$ exposure resulted in a decline of Col-III expression, while IGF-1 and Angll exposure showed an up-regulation of Col-III mRNA (Figures 2-4). Therefore, an autocrine action of TGF $\beta 1$ on Col-III expression cannot be excluded. Earlier studies indicated that exposure of rabbit cardiac fibroblasts to 
TGF $\beta 1$ increased both Col-I and Col-III expression ${ }^{19}$. No explanation is at hand for the obviously deviant findings.

No clear-cut conclusions can be drawn about potential paracrine effects of cardiomyocyte-derived growth factors. Figure 5 indicates that conditioned media from stretched cardiomyocytes did not affect the expression of Col-I in fibroblasts. As discussed below, the absence of effect could be explained by the fact that growth factors released in the surrounding medium are diluted to a great extent and, hence, their biological activity may fall below a critical level. Nevertheless, the slight decrease in ColIII expression is in favor of TGF $\beta 1$ acting as paracrine agent released from stretched cardiomyocytes.

The stretch-induced expression of FN might be caused by stretch per se, without involvement of autocrine growth factors, and/or mediated by the autocrine action of TGF $\beta 1$. The time-related patterns of stretch-induced FN and TGF $\beta 1$ mRNA expression in fibroblasts are similar (figures $1 \mathrm{~B}$ and $1 \mathrm{E}$ ) and the pattern of TGF $\beta 1$-induced FN expression mimics that of stretch-induced $F N$ expression (figures $2 B$ vs. $1 B$ ). Furthermore, the lack of effect of exogenous IGF-1 on fibroblast FN (figure 3B) precludes an autocrine action of IGF-1, which is in line with previous observations in renal fibroblasts ${ }^{25}$. The stimulatory effect of Angll on FN expression was very mild in comparison with the effect of stretch (figure $4 \mathrm{~B}$ and $1 \mathrm{~B}$ ), which makes Angll a less likely candidate for autocrine factor in stretch-induced FN up-regulation.

\section{Stretch- and growth factor-induced up-regulation of CTGF}

The main cellular source of CTGF in the heart is thought to be the cardiac fibroblast ${ }^{26-28}$. During cardiac remodelling other cell types, including cardiomyocytes, may express increased quantities of CTGF as well ${ }^{29,30}$. However, the nature of the initial trigger for enhanced transcription of CTGF is still incompletely understood as in vivo their expression is associated with pressure overload and the concurrent expression of a variety of growth factors, such as TGF- $\beta$, AngII and IGF- $1^{26,27}$. For instance, CTGF expression was found to be enhanced by TGF $\beta 1$ in several fibroblast cell lines, in primary cultures of isolated fibroblasts, and during fibrotic disorders of various tissues ${ }^{30,31}$.

The present study shows that cyclic stretch resulted in a fast, transient upregulation of CTGF in rabbit cardiac fibroblasts. This finding suggests that stretch per se is the stimulus for CTGF mRNA expression, i.e., via stretch-sensitive intracellular signaling pathways without involvement of autocrine growth factors. This notion is supported by the observation that stretch-induced up-regulation of the growth factors TGF $\beta 1$ and IGF-1 followed, rather than preceded, the up-regulation of CTGF in time. Moreover, exposure of cardiac fibroblasts to IGF-1 or Angll either down-regulated CTGF expression or did not exert any effect at all.

The conclusion that TGF $\beta 1$ most likely does not act as autocrine agent in case of fibroblast CTGF expression deviates from a previous observation that CTGF expression 
in human skin fibroblasts is mediated via an autocrine action of TGF $\beta 1^{31}$. However, studies on human fetal lung fibroblasts revealed that antibodies against TGF $\beta 1$ did not inhibit the stretch-induced up-regulation of CTGF, also rendering an autocrine role for TGF $\beta 1$ less likely ${ }^{29}$.

Additional experiments with conditioned media revealed that rabbit cardiac fibroblasts up-regulate CTGF expression in a fast and transient fashion when exposed to factors released by cardiomyocytes subjected to cyclic stretch. Therefore, it cannot be excluded that in vivo, in addition to a direct effect of stretch per se, TGF $\beta 1$ released from cardiomyocytes act as a paracrine factor, responsible for the up-regulation of fibroblast CTGF expression. A possible paracrine action of TGF $\beta 1$ is substantiated by the observation that exposure of rabbit cardiac fibroblasts to this growth factor resulted in a substantial induction of CTGF mRNA (Figure 2A). However, other, as yet unidentified, paracrine agents could play a role as well. In this respect, growth factors such as ET-1 and TNF $\alpha$ should be considered ${ }^{12,32}$.

\section{Upregulation of growth factor expression in cardiac fibroblasts}

The intriguing observation that treatment of rabbit cardiac fibroblasts with exogenous TGF $\beta 1$ stimulates substantially the expression of both TGF $\beta 1$ itself and of IGF-1 (figure $2 \mathrm{E}$ and $2 \mathrm{~F}$ ) could have important physiological ramifications. First, the stretch induced upregulation of TGF $\beta 1$ (figure 1) might result in a positive feed-forward loop by which TGF $\beta 1$ enhances its own expression in an autocrine fashion. Concomitantly, TGF $\beta 1$ produced by stretched fibroblasts might induce the upregulation of fibroblast IGF-1. This property seems to be specific for TGF $\beta 1$, because IGF-1, the expression of which is also induced by stretch (figure 1 ), does only very mildly up-regulate its own expression and down-regulates the expression of fibroblast TGF $\beta 1$ (figure 3). The stimulatory effect of TGF $\beta 1$ on its own expression was already shown in neonatal cardiac fibroblasts ${ }^{33}$ and we now show that this also applies to rabbit cardiac fibroblasts. Exogenous Angll, the third growth factor investigated in our study, mimicked the effect of TGF $\beta 1$ with respect to activating the expression of IGF-1, but Angll-induced up-regulation of TGF $\beta 1$ in cardiac fibroblasts appeared to be very mild (figure 4).

\section{Extrapolation of in vitro findings to the intact heart in vivo}

Extrapolation of the present findings to the in vivo situation is not straightforward. Assuming that mRNA expression reflects protein synthesis and secretion, the present findings suggest that stretch of cardiac fibroblasts under physiologically relevant conditions (normal percentage elongation, presence of serum factors, etc) mitigates the expression of two important constituents of ECM, i.e., Col-I and Col-III, probably preventing chronic overproduction of the structural proteins under physiological condi- 
tions. This idea fits with data from animal models of volume overload showing reduced collagen contents ${ }^{34,35}$.

It also is in agreement with computer simulation of the optimal adaptive response of the myocardium to volume overload ${ }^{36}$. It should be emphasized, however, that other factors like time duration and intensity of stretch exposure and quality of the substrates to which the cells adhere (plastic, collagen, laminin, FN), might also influence fibroblast behaviour and response to external triggers ${ }^{37}$. Moreover, the collagen content in the ECM also depends on the activity of collagen-degrading enzymes and their inhibitors ${ }^{38}$. These notions should be taken into account when extrapolating in vitro data to the in vivo situation.

The observation in the present study that cyclic stretch is a potent trigger to enhance FN transcription in rabbit cardiac fibroblasts is in line with previous in vivo data from hearts exposed to chronic pressure overload ${ }^{26,27}$. Under physiological conditions the ECM protein FN is expressed in the myocardium at a low level, and is induced during cardiac structural remodelling ${ }^{26,27}$. FN expression was found to be transiently increased during the initial phase of pressure overload ${ }^{26,39}$. Moreover, the enhanced expression of FN was associated with up-regulation of its integrin receptor $\alpha 5 \beta 1^{40}$.

As discussed above, here we showed that cyclic stretch is a potent trigger to enhance CTGF in rabbit cardiac fibroblasts. Therefore, the present findings might indicate that increased CTGF expression does not automatically result in up-regulation of Col-I and Col-III in cardiac fibroblasts, in spite of the notion that enhanced CTGF expression is associated with increased ECM synthesis ${ }^{29}$ and that the putative in vivo function of CTGF includes stimulation of proliferation, migration and adhesion of fibroblasts ${ }^{41}$.

\section{Study limitations and future perspectives}

The present study is marred by a number of limitations, hampering extrapolation of the in vitro findings to the in vivo situation. First, we studied the effect of $10 \%$ stretch and compared the outcome with the behavior of quiescent fibroblasts. Myocardial cells in vivo shorten $\sim 10 \%$ during systole, and are being stretched to a similar extent during diastole. So the $10 \%$ stretch could be considered physiological, while the quiescent "control" state might actually be non-physiological. Probably a higher degree of stretch is required to mimic overload-induced changes in gene expression that may occur under in vivo conditions.

Second, in the present study only mRNA levels of collagens, matricellular proteins and growth factors were determined. Future experiments should include the determination of the time course of changes in the intra- and extracellular concentration of the corresponding proteins and growth factors such as Angll.

Third, the conclusions regarding the potential role of growth factors as autocrine and/or paracrine agents are indirect. In future experiments this aspect should be inves- 
tigated in more detail by using anti-bodies directed against the growth factor under investigation or its cognate receptor(s).

Fourth, stretch is not the sole mechanical stimulus of cardiac fibroblasts in $s i t u^{42}$. In future experiments isolated fibroblasts should be exposed to extracellular fluid flow (mimicking interstitial fluid movement in the intact heart) as well.

Finally, the outcome of experiments with conditioned medium of stretched and quiescent cardiac cells might lead to erroneous conclusions. It should be kept in mind that absence of proof is no proof of absence. The activity of the conditioned medium might be too low due to dilution of factors released by the cardiomyocytes in the surrounding medium. As outlined in the addendum from chapter 3 , the ratio extracellular volume over cardiomyocyte volume in vivo is $>500$-fold smaller than the ratio of the volume of cultured cardiomyocytes over the volume of the incubation medium in vitro. The corollary of this is that factors released by stretched cardiomyocytes become far more diluted in the extracellular environment in vitro than in the intact heart in vivo. To overcome this technical problem, conditioned media should be concentrated before applying to the isolated fibroblasts. Alternatively, experiments could be performed making use of devices allowing for co-culturing fibroblasts and cardiomyocytes under physiologically relevant conditions ${ }^{43}$. 


\section{REFERENCES}

1. Zannad F, Rossignol P, Iraqi W. Extracellular matrix fibrotic markers in heart failure. Heart Fail Rev. 2009.

2. Bornstein $\mathrm{P}$, Sage EH. Matricellular proteins: extracellular modulators of cell function. Curr Opin Cell Biol. 2002;14(5):608-616.

3. White ES, Baralle FE, Muro AF. New insights into form and function of fibronectin splice variants. $J$ Pathol. 2008;216(1):1-14.

4. Rosenkranz S. TGF-beta1 and angiotensin networking in cardiac remodeling. Cardiovasc Res. 2004;63(3):423-432.

5. Weber KT, Brilla CG, Campbell SE. Regulatory mechanisms of myocardial hypertrophy and fibrosis: results of in vivo studies. Cardiology. 1992;81(4-5):266-273.

6. Brown RD, Ambler SK, Mitchell MD, Long CS. The cardiac fibroblast: therapeutic target in myocardial remodeling and failure. Annu Rev Pharmacol Toxicol. 2005;45:657-687.

7. Kanekar S, Borg TK, Terracio L, Carver W. Modulation of heart fibroblast migration and collagen gel contraction by IGF-I. Cell Adhes Commun. 2000;7(6):513-523.

8. Villarreal FJ, Dillmann WH. Cardiac hypertrophy-induced changes in mRNA levels for TGF-beta 1 , fibronectin, and collagen. Am J Physiol. 1992;262(6 Pt 2):H1861-1866.

9. McMullen JR, Jennings GL. Differences between pathological and physiological cardiac hypertrophy: novel therapeutic strategies to treat heart failure. Clin Exp Pharmacol Physiol. 2007;34(4):255-262.

10. de Jong S, van Veen TA, van Rijen HV, de Bakker JM. Fibrosis and cardiac arrhythmias. J Cardiovasc Pharmacol. 2011;57(6):630-638.

11. Banerjee I, Yekkala K, Borg TK, Baudino TA. Dynamic interactions between myocytes, fibroblasts, and extracellular matrix. Ann N Y Acad Sci. 2006;1080:76-84

12. MacKenna D, Summerour SR, Villarreal FJ. Role of mechanical factors in modulating cardiac fibroblast function and extracellular matrix synthesis. Cardiovasc Res. 2000;46(2):257-263.

13. Carver W, Nagpal ML, Nachtigal M, Borg TK, Terracio L. Collagen expression in mechanically stimulated cardiac fibroblasts. Circ Res. 1991;69(1):116-122.

14. Bujak M, Frangogiannis NG. The role of TGF-beta signaling in myocardial infarction and cardiac remodeling. Cardiovasc Res. 2007;74(2):184-195.

15. Hu BS, Landeen LK, Aroonsakool N, Giles WR. An analysis of the effects of stretch on IGF-I secretion from rat ventricular fibroblasts. American journal of physiology. 2007;293(1):H677-683.

16. Dostal DE, Rothblum KN, Conrad KM, Cooper GR, Baker KM. Detection of angiotensin I and II in cultured rat cardiac myocytes and fibroblasts. Am J Physiol. 1992;263(4 Pt 1):C851-863.

17. Singh VP, Baker KM, Kumar R. Activation of the intracellular renin-angiotensin system in cardiac fibroblasts by high glucose: role in extracellular matrix production. American journal of physiology. 2008;294(4):H1675-1684.

18. Takahashi N, Calderone A, Izzo NJ, Jr., Maki TM, Marsh JD, Colucci WS. Hypertrophic stimuli induce transforming growth factor-beta 1 expression in rat ventricular myocytes. J Clin Invest. 1994;94(4):14701476.

19. Eghbali M, Tomek R, Sukhatme VP, Woods C, Bhambi B. Differential effects of transforming growth factor-beta 1 and phorbol myristate acetate on cardiac fibroblasts. Regulation of fibrillar collagen mRNAs and expression of early transcription factors. Circ Res. 1991;69(2):483-490.

20. Vandesompele J, De Preter K, Pattyn F, Poppe B, Van Roy N, De Paepe A, Speleman F. Accurate normalization of real-time quantitative RT-PCR data by geometric averaging of multiple internal control genes. Genome Biol. 2002;3(7):RESEARCH0034.

21. Bishop JE, Lindahl G. Regulation of cardiovascular collagen synthesis by mechanical load. Cardiovasc Res. 1999;42(1):27-44.

22. Butt RP, Bishop JE. Mechanical load enhances the stimulatory effect of serum growth factors on cardiac fibroblast procollagen synthesis. J Mol Cell Cardiol. 1997;29(4):1141-1151. 
23. Husse B, Briest W, Homagk L, Isenberg G, Gekle M. Cyclical mechanical stretch modulates expression of collagen I and collagen III by PKC and tyrosine kinase in cardiac fibroblasts. Am J Physiol Regul Integr Comp Physiol. 2007;293(5):R1898-1907.

24. Diaz-Araya G, Borg TK, Lavandero S, Loftis MJ, Carver W. IGF-1 modulation of rat cardiac fibroblast behavior and gene expression is age-dependent. Cell Commun Adhes. 2003;10(3):155-165.

25. Lam S, van der Geest RN, Verhagen NA, van Nieuwenhoven FA, Blom IE, Aten J, Goldschmeding R, Daha $\mathrm{MR}$, van Kooten $\mathrm{C}$. Connective tissue growth factor and igf-I are produced by human renal fibroblasts and cooperate in the induction of collagen production by high glucose. Diabetes. 2003;52(12):29752983.

26. Farhadian F, Contard F, Corbier A, Barrieux A, Rappaport L, Samuel JL. Fibronectin expression during physiological and pathological cardiac growth. J Mol Cell Cardiol. 1995;27(4):981-990.

27. Daniels A, van Bilsen M, Goldschmeding R, van der Vusse GJ, van Nieuwenhoven FA. Connective tissue growth factor and cardiac fibrosis. Acta Physiol (Oxf). 2009;195(3):321-338.

28. Samuel JL, Barrieux A, Dufour S, Dubus I, Contard F, Koteliansky V, Farhadian F, Marotte F, Thiery JP, Rappaport L. Accumulation of fetal fibronectin mRNAs during the development of rat cardiac hypertrophy induced by pressure overload. J Clin Invest. 1991;88(5):1737-1746.

29. Shi-Wen X, Leask A, Abraham D. Regulation and function of connective tissue growth factor/CCN2 in tissue repair, scarring and fibrosis. Cytokine Growth Factor Rev. 2008;19(2):133-144.

30. Chen MM, Lam A, Abraham JA, Schreiner GF, Joly AH. CTGF expression is induced by TGF- beta in cardiac fibroblasts and cardiac myocytes: a potential role in heart fibrosis. J Mol Cell Cardiol. 2000;32(10):18051819.

31. Igarashi A, Okochi H, Bradham DM, Grotendorst GR. Regulation of connective tissue growth factor gene expression in human skin fibroblasts and during wound repair. Mol Biol Cell. 1993;4(6):637-645.

32. Kemp TJ, Aggeli IK, Sugden PH, Clerk A. Phenylephrine and endothelin-1 upregulate connective tissue growth factor in neonatal rat cardiac myocytes. J Mol Cell Cardiol. 2004;37(2):603-606.

33. Flanders KC, Holder MG, Winokur TS. Autoinduction of mRNA and protein expression for transforming growth factor-beta S in cultured cardiac cells. J Mol Cell Cardiol. 1995;27(2):805-812.

34. Ruzicka M, Keeley FW, Leenen FH. The renin-angiotensin system and volume overload-induced changes in cardiac collagen and elastin. Circulation. 1994;90(4):1989-1996.

35. Grossman W, Jones D, McLaurin LP. Wall stress and patterns of hypertrophy in the human left ventricle. J Clin Invest. 1975;56(1):56-64.

36. Arts T, Lumens J, Kroon W, Delhaas T. Control of whole heart geometry by intramyocardial mechanofeedback: a model study. PLoS Comput Biol. 2012;8(2):e1002369.

37. Atance J, Yost MJ, Carver W. Influence of the extracellular matrix on the regulation of cardiac fibroblast behavior by mechanical stretch. J Cell Physiol. 2004;200(3):377-386.

38. Visse R, Nagase H. Matrix metalloproteinases and tissue inhibitors of metalloproteinases: structure, function, and biochemistry. Circ Res. 2003;92(8):827-839.

39. Knowlton AA, Connelly CM, Romo GM, Mamuya W, Apstein CS, Brecher P. Rapid expression of fibronectin in the rabbit heart after myocardial infarction with and without reperfusion. J Clin Invest. 1992;89(4):1060-1068.

40. Hoshijima M, Hattori T, Inoue M, Araki D, Hanagata H, Miyauchi A, Takigawa M. CT domain of CCN2/CTGF directly interacts with fibronectin and enhances cell adhesion of chondrocytes through integrin alpha5beta1. FEBS Lett. 2006;580(5):1376-1382.

41. Brigstock DR. The CCN family: a new stimulus package. J Endocrinol. 2003;178(2):169-175.

42. Galie PA, Russell MW, Westfall MV, Stegemann JP. Interstitial fluid flow and cyclic strain differentially regulate cardiac fibroblast activation via AT1R and TGF-beta1. Exp Cell Res. 2012;318(1):75-84.

43. Ikeda K, Tojo K, Udagawa T, Otsubo C, Ishikawa M, Tokudome G, Hosoya T, Tajima N, Nakao K, Kawamura M. Cellular physiology of rat cardiac myocytes in cardiac fibrosis: in vitro simulation using the cardiac myocyte/cardiac non-myocyte co-culture system. Hypertens Res. 2008;31(4):693-706. 

Chapter 6

Effect of cyclic stretch of rabbit cardiomyocytes on the expression of factors involved in extracellular matrix remodelling 


\section{ABSTRACT}

Background: Extracellular matrix (ECM) remodelling in overloaded hearts is generally considered to be exclusively caused by cardiac fibroblasts. A possible contribution of cardiomyocytes in this process has been hardly investigated.

Aim: To investigate whether stretch is a direct stimulus forcardiomyocytes from adult rabbits to enhance the mRNA expression of the matricellular protein Connective Tissue Growth Factor (CTGF) and of ECM proteins, such as collagen-I (Col-I) and III (Col-III) and fibronectin (FN). Moreover, we explored the potential involvement of autocrine/paracrine growth factors such as angiotensin II (AngII), Transforming Growth Factor- $\beta 1$ (TGF $\beta 1$ ) and Insulin-like Growth Factor-1 (IGF-1) in the cardiomyocyte response to stretch.

Methods: Cardiomyocytes, isolated from the adult rabbit left ventricle, were subjected to $10 \%$ cyclic equibiaxial stretch $(1 \mathrm{~Hz})$, treated with Angll $(100 \mathrm{nM})$, TGFß1 $(5 \mathrm{ng} / \mathrm{ml})$ or IGF-1 (100 ng/ml) or exposed to conditioned medium of stretched rabbit cardiac fibroblasts for up to $48 \mathrm{~h}$.

Results: Under non-stretched conditions cardiac myocytes from adult rabbits appear to express CTGF mRNA in the same order of magnitude as cardiac fibroblasts. Cyclic stretch of cardiomyocytes for $48 \mathrm{~h}$ increased CTGF mRNA expression 2.9-fold, but did not affect FN and Col-I mRNA expression. Col-III expression was mildly enhanced at $4 \mathrm{~h}$, followed by a downregulation at $48 \mathrm{~h}$. Exposure for $48 \mathrm{~h}$ to exogenous TGF $\beta 1$ enhanced CTGF expression 3.3-fold, Col-I expression 1.7-fold, and TGF $\beta 1$ expression 2.6-fold. Exposure of cardiomyocytes to IGF-1 or Angll showed only minor effects on Col-I, Col-III and FN expression. Conditioned medium of stretched cardiac rabbit fibroblasts increased cardiomyocyte CTGF and TGF $\beta 1$ expression, but had no effect on FN, Col-I and Col-III.

Conclusion: Both cyclic stretch of cardiomyocytes and exposure of quiescent cardiomyocytes to conditioned medium of stretched fibroblasts induce mRNA expression of CTGF and TGF $\beta 1$ in rabbit cardiomyocytes. The present findings are in favor of an autocrine and/or paracrine action of TGF $\beta 1$ on cardiomyocyte CTGF expression. As expected, stretch of rabbit cardiomyocytes has minimal influence on the expression of extracellular matrix proteins such as Col-I, Col-III and FN by this cell type, but allows for paracrine activation of ECM components in fibroblasts by cardiomyocyte-derived CTGF and TGF $\beta 1$. 


\section{INTRODUCTION}

Cardiac tissue is a complex structure, consisting of muscle (cardiomyocytes) and nonmuscle cells, such as fibroblasts and endothelial cells. In between the syncytium of cardiomyocytes, the extracellular matrix (ECM) is located consisting of proteins such as collagens and fibronectin (FN). Pathological conditions, such as chronic hemodynamic overload, leads to enhanced production and deposition of extracellular matrix material $^{1-3}$, eventually resulting in fibrosis and diastolic dysfunction.

Evidence is accumulating that growth factors, produced locally in the cardiac wall, play a pivotal role in the regulation of cardiac ECM content and composition ${ }^{4-6}$. Experimental studies indicate that the synthesis and release of growth factors by cardiac cells are modulated by both mechanical and hormonal triggers ${ }^{7-10}$. The latter may result in intra-cardiac feed-back and feed-forward loops involved in the regulation of ECM homeostasis. A special group of so-called matricellular proteins is known to be an important regulator of ECM homeostasis. Connective Tissue Growth Factor (CTGF) is a member of this group and is strongly implicated in the development of cardiac fibrosis ${ }^{2}$. The expression of CTGF is enhanced by several growth factors such as Transforming Growth Factor $\beta 1$ (TGF 1 1), angiotensin II (AngII) and Insulin Growth factor-1 (IGF-1), but also by cellular stretch ${ }^{2,11,12}$. Fibroblasts are established producers of TGF $\beta 1$ and IGF-1 ${ }^{13,14}$ and much attention has been paid to this cell type in modulating myocardial ECM, and in changing the expression of $\mathrm{CTGF}^{2,15,16}$ (see also chapter 5).

Besides modulating ECM, these growth factors also exert a hypertrophic effect on neonatal cardiac muscle cells, emphasizing the bimodal role of growth factors in cardiac remodelling under conditions of chronically increased mechanical load ${ }^{5,7}$. Previous studies showed that TGF $\beta 1$ stimulates cardiomyocytes to increase the transcription of hypertrophic genes on the one hand, and fibroblasts to enhance collagen-I (Col-I) and collagen-III (Col-III) synthesis, on the other ${ }^{17}$. Also Angll and IGF-1 are known to exert growth promoting effects on cardiomyocytes and to stimulate the expression of ECM proteins by fibroblasts ${ }^{9,14,18,19}$.

In the light of the effects of the aforementioned growth factors on both cardiac cell types, we investigated the involvement of rabbit cardiomyocytes in the synthesis of ECM and matricellular proteins, a field that has hardly been studied ${ }^{6}$.

To this purpose the following research questions were addressed. First, does cyclic stretch alter cardiomyocyte mRNA expression of matricellular proteins like CTGF and of structural ECM proteins like Col-I, Col-III and FN, and of auto/paracrine factors TGFB1 and IGF-1? Second, are autocrine/paracrine factors derived from fibroblasts involved in cardiomyocyte mRNA expression? 
To investigate these questions, cardiomyocytes were isolated from the left ventricle of adult rabbit hearts and subjected to $10 \%$ cyclic equibiaxial stretch for up to $48 \mathrm{~h}$, or exposed to growth factors such as AngII, TGF $\beta 1$ and IGF-1, or to conditioned media of non-stretched or stretched cardiac fibroblasts.

\section{MATERIALS AND METHODS}

\section{Animals}

Isolated cardiomyocytes and fibroblasts were obtained from adult male white New Zealand rabbits (weighing 2.5 to $3.5 \mathrm{~kg}$ ). Animal experiments were performed with the approval of the Animal Ethical Committee of Maastricht University, the Netherlands, and conform to the Guide for the Care and Use of Laboratory Animals published by the US National Institutes of Health (NIH Publication No. 85-23 revised 1996).

\section{Isolation and culturing of rabbit cardiomyocytes}

The details of the isolation and culturing of rabbit cardiomyocytes from the left ventricle of the adult rabbit heart are given in full detail in chapters 3 and 4 of this thesis. Immediately after isolation, adult cardiomyocytes were transferred to recovery medium, i.e., M199 (InVitrogen; Breda, the Netherlands; no. 31153), supplemented with Fetal Bovine Serum (FBS; 5\% vol/vol), L-carnitine (final concentration, $2 \mathrm{mM}$ ), taurine (5 $\mathrm{mM})$, creatine $(5 \mathrm{mM})$, insulin $(0.25 \mathrm{mU} / \mathrm{ml})$, penicillin $(100 \mathrm{U} / \mathrm{ml})$, streptomycin (100 $\mu \mathrm{g} / \mathrm{ml})$, gentamicin $(0.05 \mathrm{mg} / \mathrm{ml})$ and $10 \mu \mathrm{M}$ cytosine-1- $\beta$-D-arabinofuranoside (AraC), and plated at a density of $7.5 \times 10^{4}$ cells/well on 6-wells Bioflex plates, pre-coated with collagen type-I (Flexcell ${ }^{\circledR}$ International Corp., Hillsborough, USA) and coated with 15 $\mu \mathrm{g} / \mathrm{ml}$ laminin (Invitrogen, Breda, the Netherlands) dissolved in PBS. Cardiomyocytes were transferred to a humidified $95 \% \mathrm{O}_{2} / 5 \% \mathrm{CO}_{2}$ incubator $\left(37^{\circ} \mathrm{C}\right)$. After $2 \mathrm{~h}$ to $3 \mathrm{~h}$, recovery medium was aspirated to remove non-attached, non-viable cells and replaced by fresh medium. The next day the medium was refreshed once more.

\section{protocols}

The following day (third day), one hour prior to the experiment, recovery medium was replaced by $3 \mathrm{ml}$ of comparable medium containing $0.5 \%$ FBS instead of $5 \%$ FBS (vol/vol) without AraC ("experimental medium") for stretch experiments or by $2 \mathrm{ml}$ of experimental medium for growth factor exposure. For stretch experiments, cardiomyocytes were routinely subjected to $10 \%$ cyclic equibiaxial stretch, produced by a Flexcell FX- $4000^{\mathrm{TM}}$ strain unit (Dunn Labortechnik $\mathrm{GmbH}$, Asbach, Germany) with computercontrolled application of sinusoidal negative pressure at a frequency of $1 \mathrm{~Hz}$ (60 cy- 
cles/min) for up to $48 \mathrm{~h}$. Control, non-stretched cardiomyocytes were exposed to identical conditions except that cellular stretch was prevented by using FlexStops ${ }^{\mathrm{TM}}$ (Dunn Labortechnik $\mathrm{GmbH}$ ).

In a subset of experiments, cardiomyocytes, cultured on laminin and Col-I pre-coated Silicone Flexcell membranes 6-well plates, were exposed to exogenous Angll (100 nM) (Sigma, Zwijndrecht, the Netherlands), TGFß1 (5 ng/ml) (R\&D systems, MN, USA), and IGF-1 (100 ng/ml) (R\&D systems). TGF 1 1, AngIl, and IGF-1 were dissolved in phosphatebuffered saline (PBS).

\section{Cardiac fibroblast-conditioned medium}

Rabbit cardiac fibroblasts were isolated as described in detail in chapter 3 and 5. Conditioned medium from cardiac fibroblasts was collected after $48 \mathrm{~h}$ of cyclic stretch ("CM-S medium"). Conditioned medium was also collected from non-stretched cardiac fibroblasts ("CM-NS medium"). Medium collected from dishes stretched without cells was used as "control medium". The distinct media per experimental condition were pooled and subsequently stored at $-20^{\circ} \mathrm{C}$ till further use.

To study paracrine effects on cardiomyocytes, the conditioned media from stretched and non-stretched cardiac fibroblasts and "control medium" were 1:1 diluted in experimental medium without AraC (total volume of $2 \mathrm{ml}$ ). Non-stretched cardiomyocytes were exposed for up to $48 \mathrm{~h}$ to cardiac fibroblasts-conditioned and control media.

\section{RNA isolation and real-time quantitative PCR}

At the end of the experimental procedure, cardiomyocytes were washed twice with PBS, scraped from the plate, and total RNA was extracted with TRI Reagent (Sigma, Steinheim, Germany), according to the manufacturers protocol. RNA concentration was measured on the Nanodrop ND-1000 (Witec Ag, Luzern, Switzerland) and calculated from the OD $260 \mathrm{~nm}$. RNA purity was determined by calculating the ratio of OD $260 / 280 \mathrm{~nm}$. Hundred $\mathrm{ng}$ of total RNA was subjected to DNasel treatment (Sigma) to remove contaminating genomic DNA and subsequently utilized for cDNA synthesis (Iscript cDNA synthesis kit, Biorad Inc., Hercules, CA, USA). Gene expression analysis was performed by quantitative PCR (qPCR) on an iCycler Real-Time PCR detection system (Biorad) using the iQ SYBR-Green supermix (Biorad). For all primer sets used (Table 1), optimal temperature and dilution curves were assessed to check for linearity. Gene expression differences were calculated using the comparative $\Delta \mathrm{C}_{\mathrm{t}}$ method $^{20}$, and qBase software (Biorad). The housekeeping gene Cyclophilin-A was used as reference gene. 


\section{Statistical analysis}

Data are expressed as mean \pm SD. All measurements were performed on cardiomyocytes from two or three independent isolations with three wells per isolation. For each time point (either obtained at $4 \mathrm{~h}$ or $48 \mathrm{~h}$ ), experimental data were expressed relative to corresponding control data per experiment. To this end, first, for each independent isolation the mean $(x)$ of the control group was calculated by averaging the qbase qPCR data of the 3 control wells. Then, each individual control value was divided by $x$, resulting in 3 normalized control data points per isolation.

The average of the 3 normalized control data points is by definition 1.00. Subsequently, the three individual values obtained in the experimental wells (fibroblasts subjected to cyclic stretch or growth factor treatment), were divided by $x$ (mean value of the 3 corresponding control wells), resulting in three normalized experimental values per individual isolation. In case of 2 or 3 isolations the total number of normalized control and experimental values per treatment amounted to 6 or 9 , respectively. The mean and SD of the 6 or 9 normalized values are shown in the figures or text. Statistical analyses were performed using SPSS software (version 15.0). Data were analyzed by unpaired Student t-test. A p-value equal or below 0.05 was considered to reflect a statistically significant difference.

Table 1: Sequences of oligonucleotide primers used for real-time quantitative PCR. Cyclo, Col-I, Col-III, CTGF, FN, IGF-1 and TGF1 $\beta$ refer to Cyclophilin-A, Collagen-I, Collagen-III, Connective Tissue Growth Factor, Fibronectin, Insulin-like Growth Factor-I, and Transforming Growth Factor-beta1, respectively.

\begin{tabular}{llll}
\hline Gene & Forward 5'- & Reverse 5'- & Tm \\
\hline Cyclo & AAGAAGATCACCATTGCCAAC & GAGCTAGAGGAATGGTCAGGTG & $63^{\circ} \mathrm{C}$ \\
Col-I & ATGGATGAGGAAACTGGCAACT & GCCATCGACAAGAACAGTGTAAGT & $62^{\circ} \mathrm{C}$ \\
Col-III & TGATTTTTGCTGTTCCACCA & GCACCATTGAGACATTTTGA & $63^{\circ} \mathrm{C}$ \\
CTGF & CACAGAGTGGAGCGCCTGTTC & GATGCACTTTTTGCCCTTCTTAATG & $63^{\circ} \mathrm{C}$ \\
FN & GCAGACCAGTTCAGGGAGTC & GTGATGGTCTCGGTCTTGGT & $61^{\circ} \mathrm{C}$ \\
IGF-1 & AGCTGGTGGATGCTCTTCAGTT & GAAGCAGCACTCATCCACGAT & $60^{\circ} \mathrm{C}$ \\
TGF $\boldsymbol{\beta} \mathbf{1}$ & AAGGGCTACCACGCCAACTT & CCGGGTTGTGCTGGTTGTAC & $60^{\circ} \mathrm{C}$ \\
\hline
\end{tabular}

\section{RESULTS}

\section{Gene expression levels in cardiomyocytes and fibroblasts}

The mRNA levels of extra cellular proteins Coll-I, Coll-III and FN, displayed as Ct value, are more than 1000-fold lower in non-stretched cardiomyocytes compared to nonstretched fibroblasts (data of stretched fibroblasts are from chapter 5). However, the difference in mRNA expression levels of CTGF and TGF $\beta 1$ between cardiomyocytes and fibroblast is much smaller (table 2). Given the much larger volume of cardiomyocytes 
than fibroblasts, it is tempting to state that cardiomyocytes may be an additional source of CTGF and TGF $\beta 1$.

Under all experimental conditions, the mRNA expression of IGF-1 in rabbit cardiomyocytes was below level of detection (table 2).

\section{Stretch-induced changes in cardiomyocyte gene expression}

Exposure of isolated rabbit cardiomyocytes to cyclic stretch for $4 \mathrm{~h}$ did not affect mRNA expression of CTGF and FN (Figure $1 \mathrm{~A}$ and $1 \mathrm{~B}$ ). Prolongation of cyclic stretch to $48 \mathrm{~h}$ significantly enhanced CTGF mRNA expression by 2.9-fold (figure 1A), but not of FN (figure 1B). Cyclic stretch failed to induce mRNA expression of Col-I in cardiomyocytes (figure 1C). In contrast, the expression of Col-III mRNA in cardiomyocytes was found to be significantly increased by $25 \%$ at $4 \mathrm{~h}$ and significantly decreased by $42 \%$ after $48 \mathrm{~h}$ of cyclic stretch (figure 1D). Exposure of cardiomyocytes to cyclic stretch evoked a significant increase in the mRNA expression of TGF $\beta 1$ after $4 \mathrm{~h}$ of stimulation. This stimulatory effect was lost after $48 \mathrm{~h}$ of cyclic stretch (figure $1 \mathrm{E}$ ).

\section{Effect of exogenous TGF $\beta 1$}

Treatment of quiescent cardiomyocytes with TGF $\beta 1$ significantly increased CTGF mRNA expression by 1.5 -fold and 2.4 -fold at $4 \mathrm{~h}$ and $48 \mathrm{~h}$, respectively (figure $2 \mathrm{~A}$ ). TGF 31 treatment did not affect mRNA expression of FN (figure 2B). TGF $\beta 1$ exposure significantly increased Col-I mRNA expression 1.5-fold and 1.8-fold at $4 \mathrm{~h}$ and $48 \mathrm{~h}$, respectively) (figure 2C). Col-III expression in cardiomyocytes exposed to TGF $\beta 1$ for $48 \mathrm{~h}$ was significantly decreased (figure 2D). Treatment of cardiomyocytes with TGF $\beta 1$ for $4 \mathrm{~h}$ and 48h significantly increased TGF 1 mRNA expression by 3.4-fold and 2.6- fold, respectively (figure $2 \mathrm{E}$ ). 
Table 2: Gene expression differences measured by quantitative PCR (qPCR) on an iCycler Real-Time PCR detection system (Biorad) in control rabbit cardiomyocytes (CMC) and control rabbit cardiac fibroblasts (FB). Gene expression is expressed as $\mathrm{Ct}$ value and measured at $4 \mathrm{~h}$ and $48 \mathrm{~h}$, indicated by ${ }^{*}$ and ${ }^{* *}$, respectively. Cyclo, Col-I, Col-III, CTGF, FN, IGF-1, TGF $\beta 1$ and ND refer to Cyclophilin-A, Collagen-I, Collagen-III, Connective Tissue Growth Factor, Fibronectin, Insulin-like Growth Factor-1, Transforming Growth Factor- $\beta 1$ and not detectable, respectively.

\begin{tabular}{lllll}
\hline Gene & Ct CMC & Ct FB & $\begin{array}{l}\text { Ct CMC }- \text { Ct FB } \\
=\Delta C t\end{array}$ & $\begin{array}{l}\text { Fold difference } \\
\text { FB vs CMC } \\
=\left(\mathbf{2}^{\mathbf{C C t}}\right)\end{array}$ \\
\hline Cyclo* & 21.1 & 18.2 & 3.0 & 7.8 \\
CTGF* & 21.1 & 18.8 & 2.3 & 5.0 \\
Col-I* & 28.7 & 18.8 & 10.0 & 1002 \\
Col-III* & 27.6 & 18.4 & 9.3 & 613 \\
FN* & 26.2 & 17.3 & 8.9 & 467 \\
TGF $\beta 1^{*}$ & 27.4 & 23.3 & 4.1 & 17.3 \\
IGF-1* & ND & 28.0 & - & - \\
\hline \hline Cyclo** & 21.0 & 18.4 & 2.6 & 6.1 \\
CTGF** & 23.2 & 17.2 & 6.0 & 63 \\
Col-I** & 27.6 & 17.2 & 10.4 & 1360 \\
Col-III** & 25.5 & 17.2 & 8.3 & 308 \\
FN** & 23.6 & 15.6 & 8.0 & 254 \\
TGF $\beta$ 1** & 25.4 & 23.0 & 2.4 & 5.3 \\
IGF-1** & ND & 22.5 & - & - \\
\hline & & & &
\end{tabular}

\section{Effect of exogenous IGF-1}

The effect of exposure to IGF-1 on cardiomyocyte mRNA expression is shown in figure $3 \mathrm{~A}$ through E. Treatment of quiescent cardiomyocytes with IGF-1 for $48 \mathrm{~h}$ resulted in a small, but significant down-regulation of CTGF mRNA expression (figure 3A). The expression of CTGF at $4 \mathrm{~h}$ was found to be unaffected. IGF-1 treatment did not influence mRNA expression of FN, Col-I and Col-III. Treatment of quiescent cardiomyocytes with IGF-1 resulted in a transient, statistically significant increase (1.4-fold, 4h) in TGF 31 mRNA expression (figure $3 \mathrm{E}$ ). At $48 \mathrm{~h}$ expression of TG $\beta 1$ had returned to basal levels.

\section{Effect of exogenous Angll}

Treatment of quiescent cardiomyocytes with Angll significantly decreased CTGF mRNA expression at $4 \mathrm{~h}$. This inhibitory effect could not be observed after prolonged exposure for $48 \mathrm{~h}$ (figure $4 \mathrm{~A}$ ). Furthermore, Angll exposure did not affect FN and Col-I expression at $4 \mathrm{~h}$ (figure $4 \mathrm{~B}$ and $4 \mathrm{C}$ respectively), but both $\mathrm{FN}$ and Col-I were significantly downregulated after $48 \mathrm{~h}$. Angll treatment did not affect mRNA expression of Col-III (figure 4D). Exposure of quiescent cardiomyocytes to Angll for $4 \mathrm{~h}$ did not affect TGF $\beta 1$ mRNA 
expression. In contrast, cardiomyocytes exposed to Angll for $48 \mathrm{~h}$ showed a significant decline in TGFB1 mRNA expression (figure 4E).

\section{Effect of fibroblast-conditioned medium}

When non-stretched cardiomyocytes were exposed to conditioned medium from stretched fibroblasts, cardiomyocyte CTGF mRNA levels were significantly increased both after $4 \mathrm{~h}$ and $48 \mathrm{~h}$ (1.7-fold and 2.3-fold, respectively, figure 5A). Conditioned medium of non-stretched fibroblasts (48h medium) resulted also in enhanced CTGF mRNA expression (1.6-fold). Cardiomyocyte expression of FN, Col-I and Col-III was not affected by conditioned medium either from non-stretched or stretched cardiac fibroblasts (figure 5B, 5C and 5D, respectively). Exposure of non-stretched cardiomyocytes for $48 \mathrm{~h}$ to conditioned medium of stretched fibroblasts evoked a significant 1.6-fold increase in TGF $\beta 1$ mRNA expression (figure $5 \mathrm{E}$ ). Shorter exposure time (4h) failed to induce cardiomyocyte TGF $\beta 1$ mRNA expression. 
A
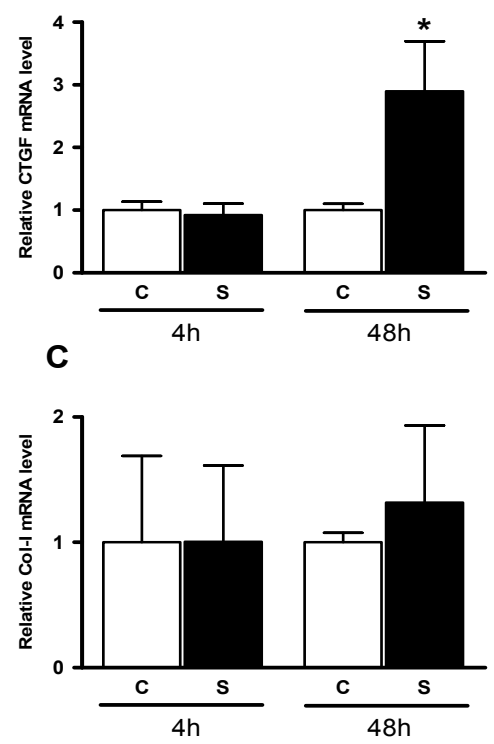

E

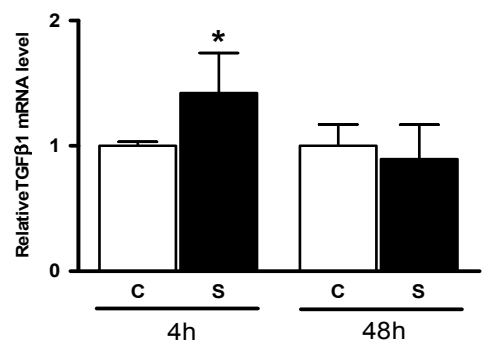

B
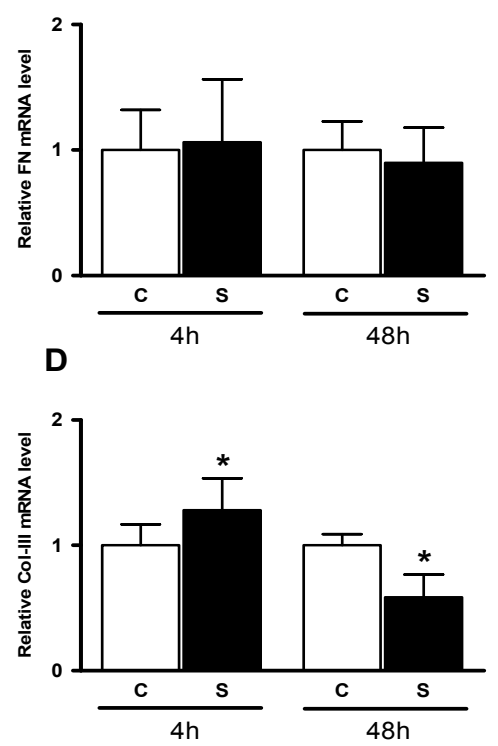

Figure 1: mRNA expression of (A) Connective Tissue Growth Factor (CTGF), (B) Fibronectin (FN), (C) collagen-I (Col-I), (D) collagen-III (Col-III), and (E) Tissue Growth Factor- $\beta 1$ (TGF $\beta 1$ ) in cardiac myocytes from adult rabbits exposed to cyclic stretch for $4 \mathrm{~h}$ and $48 \mathrm{~h}$, respectively. Data are expressed as fold change compared to corresponding time-matched, non-stretched controls. Asterisk refers to a statistical difference with timematched controls $(\mathrm{P}<0.05)$. 
A

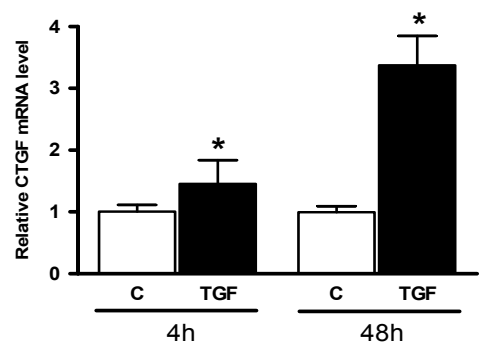

C

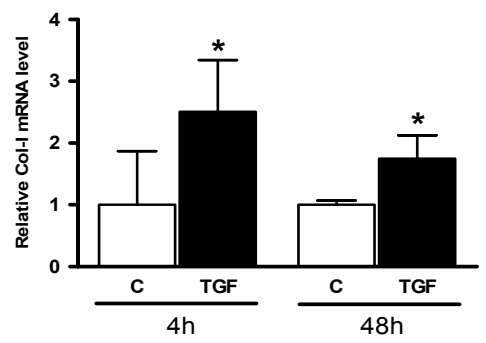

E

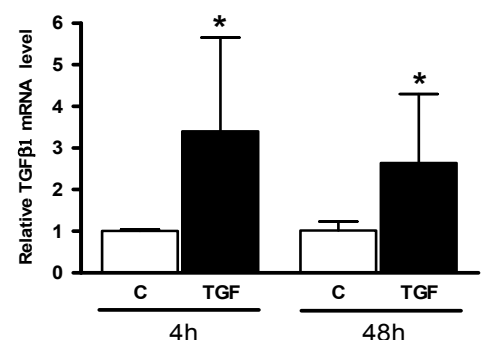

\section{B}

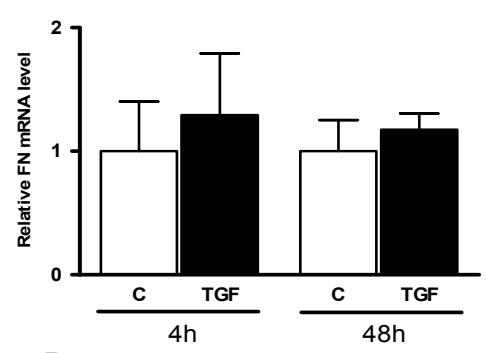

D

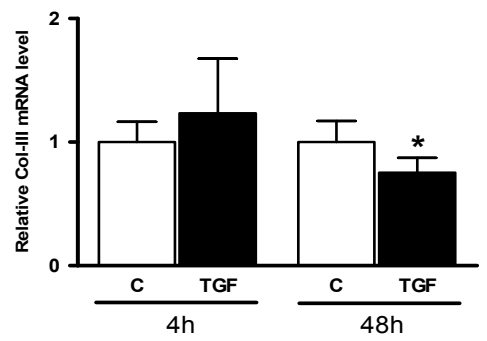

Figure 2: Effect of TGF $\beta 1$ treatment of quiescent cardiomyocytes on mRNA expression of (A) Connective Tissue Growth Factor (CTGF), (B) Fibronectin (FN), (C) collagen-I (Col-I), (D) collagen-III (Col-III) and (E) Tissue Growth Factor- $\beta 1$ (TGF $\beta 1$ ) for $4 \mathrm{~h}$ and $48 \mathrm{~h}$, respectively. Data are expressed as fold change compared to corresponding time-matched, non-treated controls. Asterisk refers to a statistical difference with timematched controls $(P<0.05)$. 
A

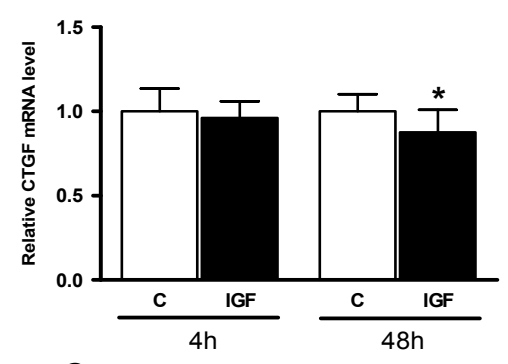

C

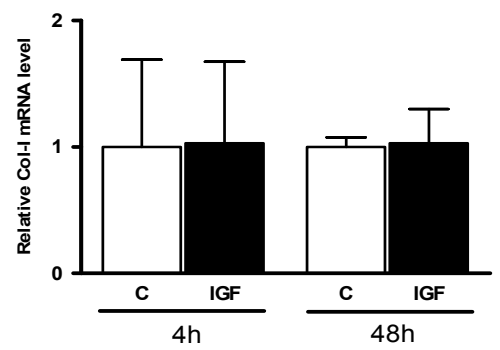

E

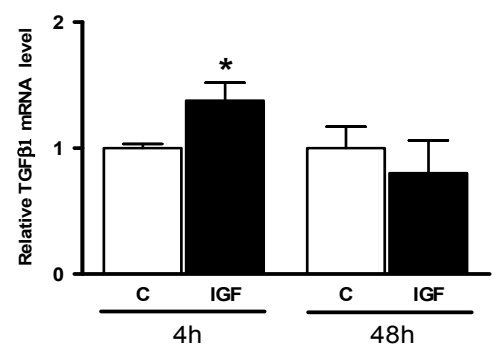

B

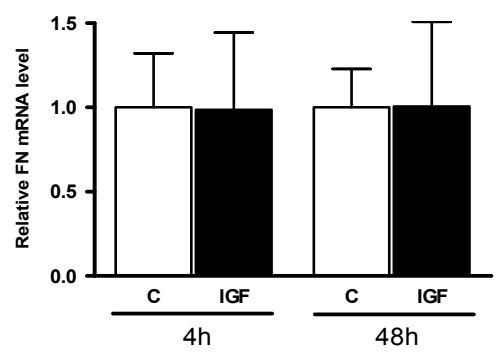

D

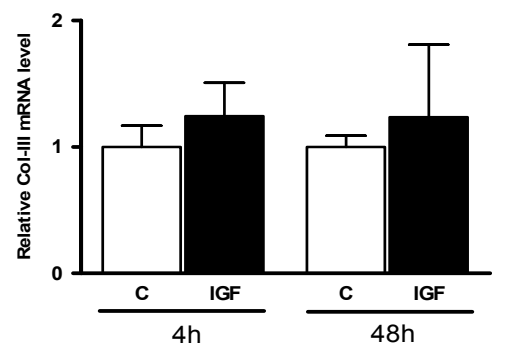

Figure 3: Effect of IGF-1 treatment of rabbit cardiomyocytes on mRNA expression of (A) Connective Tissue Growth Factor (CTGF), (B) Fibronectin (FN), (C) collagen-I (Col-I), (D) collagen-III (Col-III) and (E) Tissue Growth Factor- $\beta 1$ (TGF $\beta 1$ ) after $4 \mathrm{~h}$ and $48 \mathrm{~h}$, respectively. Data are expressed as fold change compared to corresponding, non-treated time controls. Asterisk refers to $\mathrm{P}<0.05$. 
A

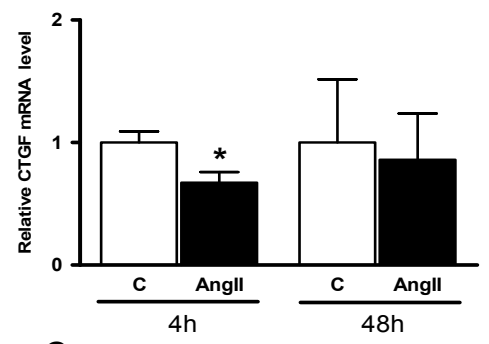

C

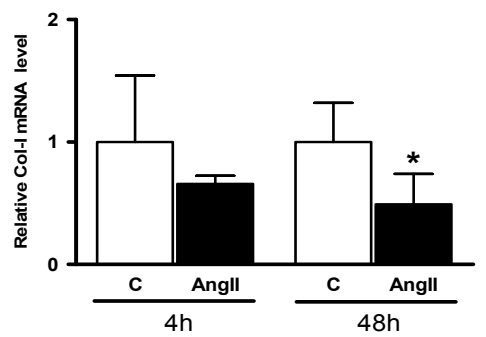

E

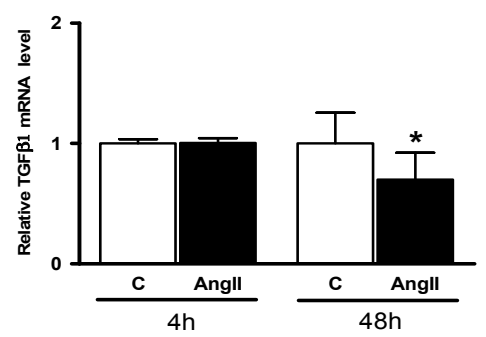

B

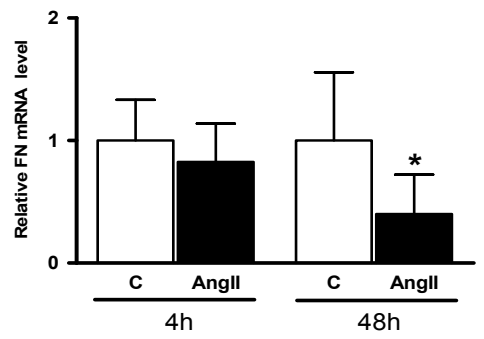

D

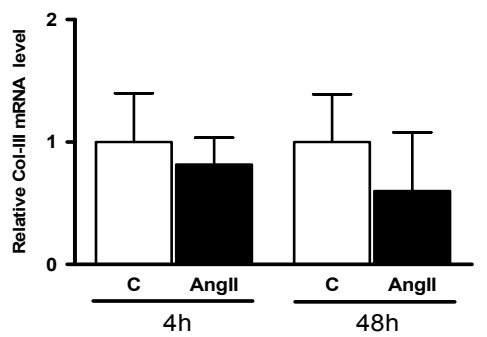

Figure 4: Effect of Angll treatment of rabbit cardiomyocytes on mRNA expression of (A) Connective Tissue Growth Factor (CTGF), (B) Fibronectin (FN), (C) collagen-I (Col-I), (D) collagen-III (Col-III) and (E) Tissue Growth Factor- $\beta 1$ (TGF $\beta 1$ ) after exposure for $4 \mathrm{~h}$ and $48 \mathrm{~h}$, respectively. Data are expressed as fold change compared to corresponding time-matched, non-treated controls. Asterisk refers to a statistical difference with timematched controls $(P<0.05)$. 

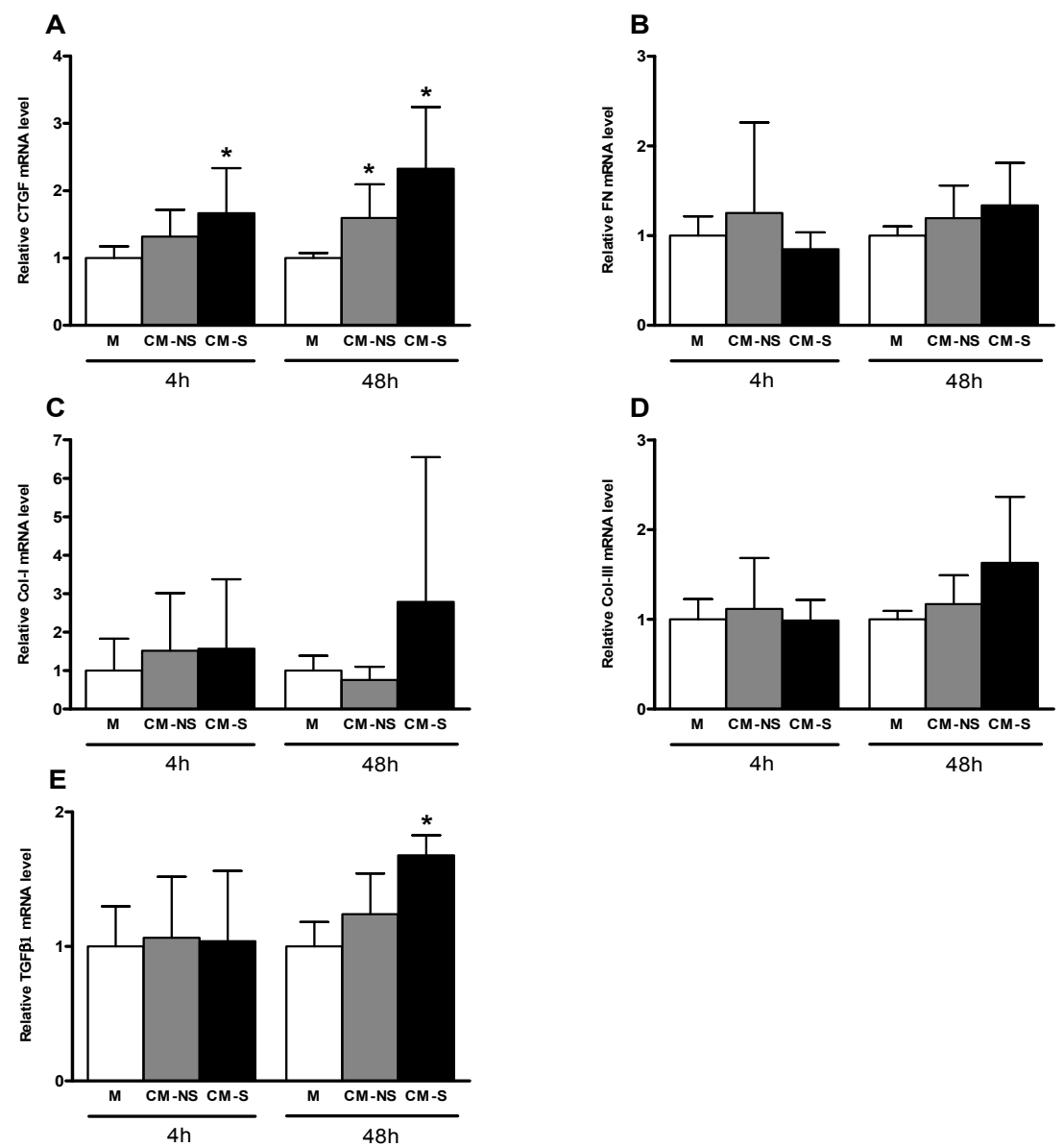

Figure 5: Effect of treatment of non-stretched cardiomyocytes with conditioned medium from 48h nonstretched (CM-NS) or cyclically stretched (CM-S) cardiac fibroblasts on cardiomyocyte mRNA expression of (A) Connective Tissue Growth Factor (CTGF), (B) Fibronectin (FN), (C) collagen-I (Col-I), (D) collagen-III (Col-III), and (E)Tissue Growth Factor- $\beta 1$ (TGF $\beta 1$ ) after $4 \mathrm{~h}$ and $48 \mathrm{~h}$, respectively. Data are expressed as fold change compared to time-matched control cardiomyocytes treated with control medium (M). Asterisk refers to a statistical difference with time-matched controls $(P<0.05)$.

\section{DISCUSSION}

The present study demonstrates that both prolonged cyclic stretch and exposure to TGF $\beta 1$ and to conditioned medium of fibroblasts are potent triggers to increase the mRNA expression of CTGF and TGF $\beta 1$ in cardiac myocytes from adult rabbits. Cardiomyocytes turn out to be an additional source of total cardiac TGF $\beta 1$ and CTGF. TGF $\beta 1$ may play an autocrine and/or paracrine role in up-regulation of CTGF expression in 
cardiomyocytes. A modulating action of IGF-1 or Angll on cardiomyocyte expression of CTGF is unlikely. The contribution of cardiac myocytes from adult rabbits to stretch- or growth factor induced expression of ECM proteins (Col-I, Col-III, and FN) appears to be minimal, which is in line with the common notion that cardiac fibroblasts rather than cardiomyocytes are the main producers of these ECM constituents.

\section{Expression of ECM genes in non-stimulated cardiomyocytes}

At present, little is known about the role of cardiomyocytes in ECM remodelling. As expected we show that compared to cardiac fibroblasts from adult rabbits, cardiomyocytes express low mRNA levels of the structural extracellular matrix proteins Col-I, ColIII and FN under non-stimulated as well as under stretched conditions. The conclusion is therefore justified that, from a quantitative point of view, the contribution of cardiomyocytes to overall cardiac expression of ECM proteins is almost negligible (table 2). This conclusion corroborates previous reports by Eghbali ${ }^{17}$ and Weber $^{1}$ arguing that cardiac fibroblasts are primarily responsible for the synthesis of collagens in the heart. On the other hand, Pathak and coworkers showed that cardiomyocytes affect collagen production via cross talk ${ }^{21}$, indicating that cardiomyocytes are likely to regulate ECM remodelling indirectly via the production of paracrine factors. A possible candidate for cross talk in the study of Pathak and colleagues was TGF $\beta 1^{22}$.

\section{Stretch-induced increase of CTGF expression in cardiomyocytes}

The finding that cyclic stretch increases the CTGF mRNA expression by 2.9-fold in rabbit cardiomyocytes strongly suggests that cardiomyocytes play an additional role in the regulation of the production of this matricellular protein and, hence, in the biological function of CTGF in cardiac tissue. This notion is supported by data shown in table 2, showing that the expression levels in cardiomyocytes and fibroblasts are in the same order of magnitude. Earlier studies revealed that in embryonic and neonatal rat cardiomyocytes CTGF expression is induced when these cells are exposed to TGF $\beta 1$ or AngII $^{4,23-26}$. Ohnishi and colleagues ${ }^{27}$ and Dean and coworkers ${ }^{3}$ reported that cardiomyocyte CTGF expression is enhanced in the border zone of regionally infracted rat hearts in situ. However, to the best of our knowledge we are the first to show that mechanical stress up-regulates the expression of CTGF in isolated adult cardiomyocytes. The corollary of this finding is that in addition to rabbit cardiac fibroblasts (see also chapter 5) adult cardiac muscle cells may respond to mechanical stress by increasing the production and, hence, extracellular deposition of CTGF.

In view of the physiological functions of CTGF in the myocardial wall, i.e., modulation of the biological activity of various growth factors, synthesis of ECM-proteins and

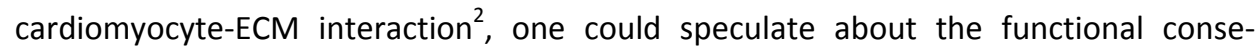
quences of stretched-induced expression of CTGF by adult cardiomyocytes. 


\section{Possible mechanism of stretch-induced CTGF expression}

The observation that cyclic stretch evokes an increase in cardiomyocyte CTGF expression (figure 1) raises the question how the mechanical signal leads to enhanced expression of CTGF. The mechanical trigger is likely sensed by the cardiac muscle cell via "stretch sensors", and information is subsequently transmitted to the cell nucleus; the "stretch sensors" most likely include cell membrane-bound integrins connected to the RhoA, RhoK, Src, FAK and PI3K signaling pathways ${ }^{2}$ on the one hand and deformational changes of the cytoskeleton ${ }^{28}$ on the other. Irrespective of the precise nature of the signaling pathway in the first option the "stretch-responsive element" in the CTGF promoter is activated giving rise to increased expression of CTGF.

Alternatively, the increase in cardiomyocyte CTGF expression may be evoked in a more indirect way involving the expression and release of growth factors by stretched cardiomyocytes. These growth factors subsequently stimulate cardiomyocyte CTGF expression in an autocrine fashion via specific membrane receptors and associated signaling pathway(s). A likely candidate for autocrine modulation of cardiomyocyte CTGF expression is TGF $\beta 1$. The present study indicates that this growth factor indeed fulfils several criteria to act as autocrine agent. First, cyclic stretch increases the content of TGF $\beta 1$ mRNA in the challenged rabbit cardiomyocyte. Second, exposure of resting rabbit cardiomyocytes to exogenous TGF $\beta 1$ results in a significant up-regulation of CTGF. Also the time pattern of the events favors the notion that TGF $\beta 1$ could be an autocrine factor in regulating CTGF expression: cyclic stretch results first in increased expression of TGF $\beta 1$ (figure 1E) followed in time by enhanced CTGF mRNA content (figure $1 \mathrm{~A}$ ).

Since exogenous TGF $\beta 1$ increases the expression of cardiomyocyte TGF $\beta 1$, it is tempting to speculate that TGF $\beta 1$ is involved in a positive feed-forward loop in regulating cardiomyocyte CTGF expression. The latter notion corroborates earlier findings in cultured rat neonatal cardiomyocytes ${ }^{29}$. The present observations do, however, not exclude that the direct pathway, i.e. without involvement of growth factors, and the autocrine TGFB1-mediated pathway operate in parallel.

The regulatory role of TGF $\beta 1$ in CTGF expression has been observed in a variety of cell types ${ }^{2,25}$. Chen and colleagues ${ }^{4}$ convincingly showed that TGF $\beta 1$ up-regulates CTGF expression in cultures neonatal rat cardiomyocytes. Furthermore, Wang et al. ${ }^{30}$ reported that in the murine H9c2 cell-line CTGF expression is dependent on TGF $\beta$ pathway signaling.

To the best of our knowledge, here we show for the first time that TGF $\beta 1$ also induces CTGF expression in cardiomyocytes from rabbit origin. However, Dean and coworkers ${ }^{3}$ challenged the notion that increased TGF $\beta 1$ expression is involved in CTGF expression in vivo. They studied the expression of CTGF and TGF $\beta 1$ in regionally infarcted rat left ventricles and observed major temporal and regional differences in the expression of CTGF and TGF $\beta 1$. Nishida and colleagues ${ }^{31}$ suggested that TGF $\beta 1$ is not required for the primary increase in cardiac CTGF expression but, conversely, that CTGF 
promotes TGF $\beta 1$ expression. Further studies are obviously needed to reconcile the in vitro and in vivo findings.

Besides TGF $\beta 1$, hypothetically IGF-1 could be an additional factor in up-regulating CTGF expression in the cardiac muscle cell. Data presented in this chapter are, however, not in favor of a substantial role of IGF-1 therein. IGF-1 expression remains below the level of detection both under resting and cyclic stretch conditions and exposure of cardiomyocytes to exogenous IGF-1 does not result in enhanced CTGF expression (figure 3). Also, exposure of isolated cardiomyocytes to exogenous Angll evoked a transient decline, rather than an increase in CTGF mRNA expression (figure 4). This finding excludes an autocrine role of Angll in stretch-induced cardiomyocyte CTGF expression. The present observation is remarkable because Angll has been shown to induce the expression of CTGF in a variety of cell types. Vascular smooth muscle cells, fibroblasts and cultured neonatal cardiomyocytes respond to exogenous Angll by increasing CTGF mRNA ${ }^{24,32,33}$. Moreover, left ventricular CTGF levels were enhanced in rats with renovascular hypertension which is accompanied by substantial increase in circulating Angll levels ${ }^{33}$. Administration of Angll to intact mice also increased left ventricular CTGF expression ${ }^{24}$. The contrasting findings between the present study on adult rabbit cardiomyocytes and earlier studies on cultured rat neonatal cardiac muscle cells, showing an up-regulation of CTGF when exposed to Angll, could be explained by both species and agedifferences.

The inability of adult rabbit cardiomyocytes to express IGF-1 corroborates earlier observations in cultured rat neonatal cardiomyocytes ${ }^{34}$. The latter authors concluded that cardiac fibroblasts are the main producers of IGF-1 in the myocardium. Horio and colleagues $^{34}$ also showed that exposure of cultured neonatal cardiomyocytes to IGF-1 increased protein synthesis and cardiac muscle cell volume, stressing the notion that IGF-1 secreted by cardiac fibroblasts could induce extracellular matrix protein production by fibroblasts in an autocrine fashion and hypertrophy in cardiomyocytes in a paracrine fashion. In contrast, immunohistochemical studies of stretched left ventricular tissue showed that IGF-1 protein is expressed in cardiomyocytes, rapidly after the exposure to mechanical stress, i.e., after $20 \mathrm{~min}$. The positive signal tapered off $40 \mathrm{~min}$ lat$\mathrm{er}^{35}$. Given the rapidity and transient nature of the response, it cannot be excluded that IGF-1 is synthesized/secreted elsewhere in the body and taken up by cardiomyocytes subjected to an acute change in mechanical loading.

Accordingly, immunohistochemical studies cannot be taken as convincing evidence that cardiac muscle cells in vivo are able to produce IGF-1. 


\section{Paracrine regulation of cardiomyocyte CTGF expression by TGF $\beta 1$}

The present findings clearly show that in addition to a direct effect of stretching the cardiomyocyte, CTGF expression in the cardiac muscle cell can also be induced by factors released by cardiac fibroblasts (figure 5). The identity of the stimulating factor(s), acting as paracrine agent, has not been disclosed in the present study. On basis of the results obtained with experiments in which isolated cardiomyocytes were exposed to exogenous growth factors such as TGF $\beta 1$, IGF-1 and Angll, only TGF $\beta 1$ fulfils the criteria of paracrine factor, i.e., induction of CTGF mRNA expression. Notably, conditioned medium of stretched fibroblasts also enhances the expression of cardiomyocyte TGF $\beta 1$ mRNA expression (chapter 5). This observation, corroborating earlier findings in rat neonatal fibroblasts and cardiomyocytes ${ }^{8,36}$, could indicate that fibroblasts are able to reinforce the positive feed-forward loop of TGF $\beta 1$-induced cardiomyocyte CTGF expres$\operatorname{sion}^{29}$. In addition to TGF $\beta 1$, other as yet unidentified factors could also play a paracrine role in regulating the expression of CTGF in rabbit cardiac muscle cells.

\section{Limitations of the study and future perspectives}

In this chapter the parameters studied were mainly the expression of mRNA of proteins of interest rather than the production and release of the proteins themselves. Therefore conclusions about the functional significance of the present findings should be done with caution. Moreover, the effect of exogenous growth factors was studied only on non-stretched cardiomyocytes. Combining stretch and growth factor treatment of cardiomyocytes may provide an answer to the question as to whether a mechanical challenge alters the sensitivity of cardiac muscle cells to the modulating action, if any, of growth factors either acting as autocrine or paracrine agents. The specificity and the identity of the putative growth factors, modulating the cardiomyocyte expression of matricellular and extracellular matrix proteins, could be explored in more detail when cardiomyocytes were exposed to antibodies raised against the respective growth factors and/or their cognate membrane receptors.

The interpretation of the experiments with conditioned media of resting and challenged cardiac fibroblasts is hampered by the notion that the factors released are diluted in the cellular supernatant to a much greater extent ( 70 times, see addendum chapter 3 for calculations) than in vivo in the intercellular compartment.

It should also be taken into account, when extrapolating the present findings to the in vivo situation, that the heart is composed of more cell types than cardiomyocytes and fibroblasts. Endothelial cells and smooth muscle cells could also partake in the paracrine regulation of the cardiomyocyte mRNA expression in the intact heart. 


\section{CONCLUSION}

Cyclic stretch is a strong, direct trigger to increase the expression of CTGF and TGF $\beta 1$ in cardiomyocytes. The collective findings suggest that cyclic stretch-mediated CTGF expression in cardiomyocytes might be mediated by autocrine and/or paracrine action of TGF $\beta 1$. Beside cardiac fibroblasts, cardiac myocytes from adult rabbits can also contribute to extracellular matrix (ECM) remodelling. 


\section{REFERENCES}

1. Weber KT. Cardiac interstitium in health and disease: the fibrillar collagen network. Journal of the American College of Cardiology. 1989;13(7):1637-1652.

2. Daniels $A$, van Bilsen $M$, Goldschmeding $R$, van der Vusse GJ, van Nieuwenhoven FA. Connective tissue growth factor and cardiac fibrosis. Acta Physiol (Oxf). 2009;195(3):321-338.

3. Dean RG, Balding LC, Candido R, Burns WC, Cao Z, Twigg SM, Burrell LM. Connective tissue growth factor and cardiac fibrosis after myocardial infarction. J Histochem Cytochem. 2005;53(10):1245-1256.

4. Chen MM, Lam A, Abraham JA, Schreiner GF, Joly AH. CTGF expression is induced by TGF- beta in cardiac fibroblasts and cardiac myocytes: a potential role in heart fibrosis. J Mol Cell Cardiol. 2000;32(10):18051819.

5. Bujak M, Frangogiannis NG. The role of TGF-beta signaling in myocardial infarction and cardiac remodeling. Cardiovasc Res. 2007;74(2):184-195.

6. Gupta V, Grande-Allen KJ. Effects of static and cyclic loading in regulating extracellular matrix synthesis by cardiovascular cells. Cardiovasc Res. 2006;72(3):375-383.

7. van Wamel AJ, Ruwhof C, van der Valk-Kokshoom LE, Schrier PI, van der Laarse A. The role of angiotensin II, endothelin-1 and transforming growth factor-beta as autocrine/paracrine mediators of stretchinduced cardiomyocyte hypertrophy. Mol Cell Biochem. 2001;218(1-2):113-124.

8. Ruwhof $C$, van Wamel AE, Egas JM, van der Laarse A. Cyclic stretch induces the release of growth promoting factors from cultured neonatal cardiomyocytes and cardiac fibroblasts. Mol Cell Biochem. 2000;208(1-2):89-98.

9. Sadoshima J, $\mathrm{Xu} \mathrm{Y,} \mathrm{Slayter} \mathrm{HS,} \mathrm{Izumo} \mathrm{S.} \mathrm{Autocrine} \mathrm{release} \mathrm{of} \mathrm{angiotensin} \mathrm{II} \mathrm{mediates} \mathrm{stretch-induced}$ hypertrophy of cardiac myocytes in vitro. Cell. 1993;75(5):977-984.

10. Atamas SP. Complex cytokine regulation of tissue fibrosis. Life Sci. 2002;72(6):631-643.

11. Blom IE, Goldschmeding R, Leask A. Gene regulation of connective tissue growth factor: new targets for antifibrotic therapy? Matrix Biol. 2002;21(6):473-482.

12. Ahmed MS, Oie E, Vinge LE, Yndestad A, Oystein Andersen G, Andersson $Y$, Attramadal $T$, Attramadal $H$. Connective tissue growth factor--a novel mediator of angiotensin II-stimulated cardiac fibroblast activation in heart failure in rats. J Mol Cell Cardiol. 2004;36(3):393-404.

13. Lindahl GE, Chambers RC, Papakrivopoulou J, Dawson SJ, Jacobsen MC, Bishop JE, Laurent GJ. Activation of fibroblast procollagen alpha $1(\mathrm{I})$ transcription by mechanical strain is transforming growth factorbeta-dependent and involves increased binding of CCAAT-binding factor (CBF/NF-Y) at the proximal promoter. J Biol Chem. 2002;277(8):6153-6161.

14. Hu BS, Landeen LK, Aroonsakool N, Giles WR. An analysis of the effects of stretch on IGF-I secretion from rat ventricular fibroblasts. American journal of physiology. 2007;293(1):H677-683.

15. Samuel JL, Barrieux A, Dufour S, Dubus I, Contard F, Koteliansky V, Farhadian F, Marotte F, Thiery JP, Rappaport L. Accumulation of fetal fibronectin mRNAs during the development of rat cardiac hypertrophy induced by pressure overload. J Clin Invest. 1991;88(5):1737-1746.

16. Farhadian F, Contard F, Corbier A, Barrieux A, Rappaport L, Samuel JL. Fibronectin expression during physiological and pathological cardiac growth. J Mol Cell Cardiol. 1995;27(4):981-990.

17. Eghbali M, Tomek R, Sukhatme VP, Woods C, Bhambi B. Differential effects of transforming growth factor-beta 1 and phorbol myristate acetate on cardiac fibroblasts. Regulation of fibrillar collagen mRNAs and expression of early transcription factors. Circ Res. 1991;69(2):483-490.

18. Wynn TA. Cellular and molecular mechanisms of fibrosis. J Pathol. 2008;214(2):199-210.

19. Abe N, Matsunaga T, Kameda K, Tomita H, Fujiwara T, Ishizaka H, Hanada H, Fukui K, Fukuda I, Osanai T, Okumura K. Increased level of pericardial insulin-like growth factor-1 in patients with left ventricular dysfunction and advanced heart failure. J Am Coll Cardiol. 2006;48(7):1387-1395.

20. Vandesompele J, De Preter K, Pattyn F, Poppe B, Van Roy N, De Paepe A, Speleman F. Accurate normalization of real-time quantitative RT-PCR data by geometric averaging of multiple internal control genes. Genome Biol. 2002;3(7):RESEARCH0034. 
21. Pathak M, Sarkar S, Vellaichamy E, Sen S. Role of myocytes in myocardial collagen production. Hypertension. 2001;37(3):833-840.

22. Sarkar S, Vellaichamy E, Young D, Sen S. Influence of cytokines and growth factors in ANG II-mediated collagen upregulation by fibroblasts in rats: role of myocytes. Am J Physiol Heart Circ Physiol. 2004;287(1):H107-117

23. Kemp TJ, Aggeli IK, Sugden PH, Clerk A. Phenylephrine and endothelin-1 upregulate connective tissue growth factor in neonatal rat cardiac myocytes. J Mol Cell Cardiol. 2004;37(2):603-606.

24. He Z, Way KJ, Arikawa E, Chou E, Opland DM, Clermont A, Isshiki K, Ma RC, Scott JA, Schoen FJ, Feener $E P$, King GL. Differential regulation of angiotensin II-induced expression of connective tissue growth factor by protein kinase C isoforms in the myocardium. J Biol Chem. 2005;280(16):15719-15726.

25. Matsui Y, Sadoshima J. Rapid upregulation of CTGF in cardiac myocytes by hypertrophic stimuli: implication for cardiac fibrosis and hypertrophy. J Mol Cell Cardiol. 2004;37(2):477-481.

26. Lee YS, Kim JA, Kim KL, Jang HS, Kim JM, Lee JY, Shin IS, Lee JS, Suh W, Choi JH, Jeon ES, Byun J, Kim DK. Aldosterone upregulates connective tissue growth factor gene expression via p38 MAPK pathway and mineralocorticoid receptor in ventricular myocytes. J Korean Med Sci. 2004;19(6):805-811.

27. Ohnishi H, Oka T, Kusachi S, Nakanishi T, Takeda K, Nakahama M, Doi M, Murakami T, Ninomiya Y, Takigawa M, Tsuji T. Increased expression of connective tissue growth factor in the infarct zone of experimentally induced myocardial infarction in rats. J Mol Cell Cardiol. 1998;30(11):2411-2422.

28. Bishop JE, Lindahl G. Regulation of cardiovascular collagen synthesis by mechanical load. Cardiovasc Res. 1999;42(1):27-44.

29. Flanders KC, Holder MG, Winokur TS. Autoinduction of mRNA and protein expression for transforming growth factor-beta S in cultured cardiac cells. J Mol Cell Cardiol. 1995;27(2):805-812.

30. Wang X, McLennan SV, Allen TJ, Twigg SM. Regulation of pro-inflammatory and pro-fibrotic factors by CCN2/CTGF in H9c2 cardiomyocytes. J Cell Commun Signal.4(1):15-23.

31. Nishida M, Sato $Y$, Uemura A, Narita $Y$, Tozaki-Saitoh $H$, Nakaya M, Ide T, Suzuki K, Inoue K, Nagao T, Kurose H. P2Y6 receptor-Galpha12/13 signalling in cardiomyocytes triggers pressure overload-induced cardiac fibrosis. Embo J. 2008;27(23):3104-3115.

32. Ruperez M, Lorenzo O, Blanco-Colio LM, Esteban V, Egido J, Ruiz-Ortega M. Connective tissue growth factor is a mediator of angiotensin II-induced fibrosis. Circulation. 2003;108(12):1499-1505.

33. Iwanciw D, Rehm M, Porst M, Goppelt-Struebe M. Induction of connective tissue growth factor by angiotensin II: integration of signaling pathways. Arterioscler Thromb Vasc Biol. 2003;23(10):1782-1787.

34. Horio T, Maki T, Kishimoto I, Tokudome T, Okumura H, Yoshihara F, Suga S, Takeo S, Kawano Y, Kangawa K. Production and autocrine/paracrine effects of endogenous insulin-like growth factor-1 in rat cardiac fibroblasts. Regul Pept. 2005;124(1-3):65-72.

35. Palmieri EA, Benincasa G, Di Rella F, Casaburi C, Monti MG, De Simone G, Chiariotti L, Palombini L, Bruni CB, Sacca L, Cittadini A. Differential expression of TNF-alpha, IL-6, and IGF-1 by graded mechanical stress in normal rat myocardium. American journal of physiology. 2002;282(3):H926-934.

36. van Wamel AJ, Ruwhof C, van der Valk-Kokshoorn LJ, Schrier PI, van der Laarse A. Stretch-induced paracrine hypertrophic stimuli increase TGF-beta1 expression in cardiomyocytes. Mol Cell Biochem. 2002;236(1-2):147-153. 

Chapter 7

Effect of AT-1 receptor blockade on ventricular pacing-induced asymmetric hypertrophy in rabbits 


\section{ABSTRACT}

Background: Asynchronous electrical activation of the left ventricle (LV) results in large differences in regional mechanical workload and consequently in regional hypertrophy. Both mechanical and humoral triggers have been put forward to explain the hypertrophic response of overloaded cardiac muscle, angiotensin II being one of the prime humoral factors.

Aim: To investigate whether regional workload-induced hypertrophy in asynchronously activated rabbit hearts is mediated via autocrine/paracrine action of Angll by studying the effect of the specific AT-1 receptor blocker irbesartan (IRB) on this hypertrophy.

Methods: Seventeen male rabbits received a pacemaker with the electrode positioned at the LV posterior wall (PW). Five days after pacemaker implantation, the rabbits were randomly assigned to two groups. Group $1(n=10)$ received IRB $(P+I R B)$ and group 2 $(n=7)$ received solvent $(P+S O L V)$ released by subcutaneously implanted osmotic minipumps. After 3 weeks of LV pacing, LV dimensions and hemodynamics were measured. Subsequently, the hearts were harvested and BNP, CTGF, IGF-1 and TGF $\beta 1$ mRNA expression was measured.

Results: The ratio of wall thickness of interventricular septum (IVS) and LV PW (IVS/PW ratio) increased in the $P+$ SOLV group $(p=0.08)$, whereas it tended to decrease in the $P$ + IRB group $(p=0.27)$. The change in IVS/PW ratio was significantly different between the groups $(p=0.02)$. Despite asymmetric hypertrophy in the $P+S O L V$ group expression of CTGF, IGF-1, BNP and TGF $\beta 1$ was uniform between the PW and IVS. In the P + IRB group expression of CTGF tended to be higher in IVS than in PW $(p=0.10)$.

Conclusion: Three weeks of LV pacing in the rabbit heart results in asymmetrical hypertrophy, the development of which is inhibited by IRB. This data indicate that AT-1 receptor activation plays an important role in workload-induced regional hypertrophy in vivo, probably effectuated by autocrine/paracrine signalling. 


\section{INTRODUCTION}

Patients with chronic left ventricular (LV) overload develop LV hypertrophy. The primary trigger for the load-mediated growth is still under debate. In particular, angiotensin II (AngII) is often regarded as an important humoral (systemic) and autocrine/paracrine (local) factor exerting potent trophic effects on cardiac cells both in vivo $^{1-4}$ and in vitro ${ }^{5-8}$. The trophic effect of Angll is mediated via Angll binding to its Angll type-I receptor, which can be inhibited by Angll receptor blockers (ARB) ${ }^{9,10}$. These data support the idea that the trophic effects of Angll are mediated via Angll-AT-1 binding. On the other hand, the hypertrophic effect of Ang II might also be mediated by its pressor effect. Our study described in chapter 4 , showed that cardiac myocytes isolated from adult rabbit hearts, subjected to cyclic stretch develop hypertrophy, and that irbesartan and candesartan, two specific AT-1 receptor blockers, do not block this response. Moreover, exposure of rabbit cardiomyocytes to exogenous Angll did not lead to a hypertrophic phenotype nor increased expression of hypertrophic genes, including $\mathrm{BNP}^{11}$. These data could indicate that other factors than Angll (also) mediate the hypertrophic response.

It was the aim of the present study to investigate the involvement of Angll in stretch-induced hypertrophy in an animal model that allows studying (local) hypertrophy independent from its hemodynamic effects. In this respect a potentially useful model is that of asymmetric hypertrophy induced by ventricular pacing ${ }^{15}$. Ventricular pacing results in asynchronous contraction patterns that result in large inhomogeneities in regional mechanical workload ${ }^{15}$ and, on the long run, in atrophy of early activated regions and hypertrophy of late activated regions ${ }^{15}$.

In the present study, the effect of Angll on the hypertrophic response was investigated by studying the effect of a specific AT-1-receptor blocker (irbesartan) on the asymmetric hypertrophy in rabbit hearts during ventricular pacing. To this end, LV dimensions and function were determined by 2-D echocardiography at baseline, and 3 weeks after ventricular pacing. In addition blood pressure and gene expression analysis were performed.

\section{MATERIALS AND METHODS}

\section{Animals}

Experiments were performed on adult male White New Zealand rabbits ( $3 \mathrm{~kg}$ ). Experiments were performed with approval of the Animal Ethical Committee of Maastricht University conform to the Guide for the Care and Use of Laboratory Animals published by the US National Institutes of Health (NIH Publication No. 85-23 revised 1996). Animals were housed separately with food and water ad libitum. 


\section{Pericardial and subcutaneous irbesartan delivery}

In a pilot study consisting of 5 rabbits, intrapericardial and systemic delivery of irbesar$\tan (\mathrm{IRB})$ (infusion rate of both delivery systems were $1.5 \mathrm{mg} /$ day) were compared to ensure optimal drug delivery. In 2 animals irbesartan was delivered via a subcutaneously implanted osmotic minipumps (OMP) (SC group, $n=2$ ). Intrapericardial infusion (IPC group, $n=3$ ) was performed using catheters positioned in the pericardium using minimal thoracotomy and connected to subcutaneously implanted OMP, as previously described for rats $^{16}$. Briefly, for the intrapericardial catheter insertion, rabbits were anaesthetized with ketamine (15 mg/kg, i.m) and xylazine (5 mg/kg, s.c). A high thoracotomy (between 4 and $5^{\text {th }}$ rib) was performed and a retractor applied. The pericardial sac was opened at the LV free epicardial wall by making a small incision (1-2 $\mathrm{mm}$ ) with iris scissors in order to place the catheter in the pericardial space. Subsequently, the pericardial sac was closed by sealing it with histoacryl tissue glue (Braun, Melsungen, Germany). Thereafter, the catheter was guided to the neck and externalized via a small incision in the skin. Osmotic minipumps (Alzet Osmotic Pump 2ML4; Charles River Wiga $\mathrm{GmbH}$, Sulzfeld, Germany) were connected to the intrapericardial catheter and placed subcutaneously.

After $72 \mathrm{~h}$, the hearts were harvested and $\sim 100-200 \mu \mathrm{L}$ pericardial fluid and $\sim 4 \mathrm{ml}$ venous blood samples were collected. Similar samples were taken before installing pumps, to serve as control. Samples were collected in EDTA-containing vascular tubes. Blood samples were directly centrifuged at $3500 \mathrm{~g}, 10 \mathrm{~min}$ at $4{ }^{\circ} \mathrm{C}$, and plasma was stored at $-80^{\circ} \mathrm{C}$.

\section{Irbesartan extraction from cardiac tissue and plasma}

Irbesartan content in cardiac muscle was quantified via HPLC-UV. Thereto, the total heart was cut into distal short axis slices of $\sim 3-5 \mathrm{~mm}$ thickness. A middle segment of $\sim 5$ $\mathrm{mm}$ in length was dissected out of the right ventricle (RV), septum and LV and used for HPLC-UV analysis. Thereafter, the LV and septal myocardial wall was divided in approximately three similar segments, containing an epicardial, mid-cardial and endocardial part. The RV part was divided in only an epicardial and endocardial piece. All tissue samples were stored at $-80^{\circ} \mathrm{C}$. Cardiac tissue samples (50 mg wet weight) were thawed on ice and homogenized in $2 \mathrm{ml}$ acetonitrile using a tissue blender to extract compounds of interest. After tissue homogenisation, proteins were precipitated via centrifugation at $5000 \mathrm{~g}$ for $10 \mathrm{~min}$ at $4^{\circ} \mathrm{C}$ and supernatant was collected in a $10 \mathrm{ml}$ glass tube. Supernatant was evaporated to dryness under a flow of nitrogen at $37^{\circ} \mathrm{C}$. Residue was resolved in $500 \mu \mathrm{l} 1 \mathrm{M}$ sodium acetate, $\mathrm{pH} 4.5$, and extracted in a mixture of $1 / 1$ $(\mathrm{v} / \mathrm{v})$ heptane and diethylether, centrifuged $\left(5000 \mathrm{~g}, 10 \mathrm{~min}\right.$ at $4^{\circ} \mathrm{C}$ ) and dried under nitrogen at $37^{\circ} \mathrm{C}$. The residue was reconstituted in $100 \mu \mathrm{L} 50 \%$ acetonitrile in milli- $\mathrm{Q}$ water and transferred to an auto-injector vial. A $10 \mu \mathrm{l}$ aliquot of the reconstituted ex- 
tract was injected by the auto-injector for irbesartan determination. For blood samples analysis the same protocol was used, only the cardiac homogenate was substituted by $100 \mu \mathrm{l}$ of plasma sample. Losartan (L) was added as internal control at a concentration of $2.0 \mu \mathrm{g} / \mathrm{ml}$ to each cardiac or plasma sample in which the content of irbesartan was measured.

\section{HPLC-UV analysis}

The HPLC system consisted of a Shimadzu LC-10AD liquid chromatograph, a SIL-10AD auto-injector and a SP8490 variable wavelength UV-detector (Newport Spectra-Physics, Utrecht, the Netherlands) set at $254 \mathrm{~nm}$ emission and $371 \mathrm{~nm}$ excitation. HPLC separations were performed on an ODS3 C18 column (50 mm×4.6 mm, $2.5 \mu \mathrm{m}$ ) (Shimadzu, Kyoto, Japan) as stationary phase. Each 10-min chromatographic run was carried out at a flow rate of $1 \mathrm{ml} / \mathrm{min}$ for plasma samples and pericardial fluid samples, and 0.5 $\mathrm{ml} / \mathrm{min}$ for cardiac homogenates, with a mobile phase of $350 \mathrm{ml}$ acetonitrile (Biolsolve MW 41.05), $650 \mathrm{ml}$ milli-Q water and $1 \mathrm{ml}$ Tri-Fluor-Acetic acid (proportion 350/650/1, $\mathrm{v} / \mathrm{v} / \mathrm{v}$ ). LabSolutions software (Shimadzu, Kyoto, Japan) was used for instrument control and data acquisition. A dilution curve of losartan $(0,0.0625,0.125,0.25,0.5$, and 1.0 $\mu \mathrm{g} / \mathrm{ml}$ ) was prepared and used to calculate a trend line with a correlation coefficient $\left(R^{2}\right)$ of 0.9991 . The losartan trend line formula, which was calculated from the losartan dilution curve, was used to calculate final irbesartan concentrations using the following formula: $\mathrm{Y}(=$ calculated HPLC area $)=5000000 * \mathrm{X}(=$ unknown concentration irbesar$\tan )+102629$.

\section{Osmotic pumps}

Irbesartan $(25 \mathrm{mg} / \mathrm{ml})$ was dissolved in $1 \%$ ammonium/Phosphate Buffered Salt (PBS) solution. Thereafter, the irbesartan solution was evaporated to dryness under nitrogen at $37^{\circ} \mathrm{C}$. The residue was reconstituted with $1 \mathrm{ml}$ vehicle solution, consisting of $40 \%$ Polyethylene glycol (PEG)/PBS and $1 \mathrm{M} \mathrm{NaHCO}_{3}$ (proportion 9:1, v/v), per $25 \mathrm{mg}$ irbesartan. Irbesartan solution was sterilized using a $0.2 \mu \mathrm{m}$ filter and stored at room temperature and protected from light. The osmotic pumps were filled $24 \mathrm{~h}$ before implantation with $2 \mathrm{ml}$ sterile irbesartan or sterile solvent solution under sterile conditions in air-flow cabinet. Thereafter, the osmotic pumps were placed in a sterile $0.9 \% \mathrm{NaCl}$ solution $\left(37^{\circ} \mathrm{C}\right)$ for activation.

\section{Pacemaker implantation and activation}

Seventeen male rabbits were used in this study and all underwent the same surgical procedure. Anaesthesia was induced with ketamine $(15 \mathrm{mg} / \mathrm{kg}$, i.m) and xylazine (5 $\mathrm{mg} / \mathrm{kg}, \mathrm{s.c})$ and maintained by ventilation of the lungs with isoflurane $(0.5 \%-1.0 \%)$. 
Furthermore, all rabbits were pre-treated with antibiotics ( $0.5 \mathrm{ml} / \mathrm{kg}$ ampicillin s.c.) and an analgesic $\left(0.05 \mathrm{mg} / \mathrm{ml}\right.$ Buprenorphine/Temgesic ${ }^{\circledR}$ i.m). All rabbits underwent implantation of a programmable cardiac pacemaker (Guidant InSignia, Natick, MN, USA). After shaving, the pacemaker lead was placed on the epicardium of the LV posterior wall (PW), via a high median thoracotomy. Pacemaker leads were connected via the atrial port to the pacemaker. All rabbits were allowed to recover for at least 5 days after chest surgery, before pacemaker was programmed in VVI mode $(+10 \%$ above sinus rhythm, ultimately $240 \mathrm{bpm}$ ) in order to start the 3 week pacing protocol. Proper pacemaker function was checked directly after implantation, at the time of programming, and subsequently every 7 days.

\section{Experimental groups}

After 5 days of pacemaker implantation, rabbits were anaesthetised with ketamine (15 $\mathrm{mg} / \mathrm{kg}, \mathrm{i} . \mathrm{m}$ ) and xylazine ( $5 \mathrm{mg} / \mathrm{kg}, \mathrm{s.c}$ ). Thereafter, osmotic minipumps (Alzet Osmotic Pump 2ML4; Charles River Wiga Gmbh) were placed subcutaneously in a pocket above the shoulder blades. Animals were randomly allotted to receive an osmotic pumps filled with either vehicle solvent $(P+$ SOLV group, $n=7)$ or irbesartan $(P+I R B$ group, $n=10)$. These pumps provided a constant infusion rate $(2.5 \mu \mathrm{l} / \mathrm{h})$ for at least 4 weeks.

\section{Echocardiography}

The effect of pacing on LV dimensions was determined using 2D echocardiography. Echocardiograms were made in conscious animals using an ESAOTE Megas ultrasound system equipped with a 5-7.5 MHz transducer. Two-dimensional echocardiographic short axis views at mid-papillary level images of the LV were recorded at baseline (day 0 = control) and after 3 weeks of LV pacing. Parameters like intraventricular septum (IVS), and PW thickness, LV diameter (LVD), ejection fraction (EF) and fractional shortening (FS) were measured in three heart beats per time point. Digital images were stored and used for later analysis. Left ventricular wall mass (LVM) was calculated from the crosssectional M-mode images by using the American Society of Echocardiography equation slightly adapted by Devereux et $a{ }^{17}$.

$$
\operatorname{LVM}(\mathrm{g})=0.8 \cdot\left(1.04\left([L V D d+P W d+I V S d]^{3}-[L V D d]^{3}\right)\right)+0.6 g
$$

\section{Hemodynamics}

Hemodynamic measurements were performed at 0 and 3 weeks. In all animals blood pressures were measured in the ear artery at baseline and at 3 weeks. After 3 weeks, the animals were anaesthetised again and hemodynamic measurements were performed using a $4 \mathrm{~F}$ Millar pressure transducer. All signals (ECG, pressure) were digitized 
at $1 \mathrm{kHz}$ and stored using custom-made software (IDEEQ, Maastricht Instruments, the Netherlands) and later analyzed using custom software. Mean arterial blood pressure (MAP) was measured using the following equation:

$\operatorname{MAP}(\mathrm{mmHg})=\frac{2 \cdot D B P+S B P}{3}$

After all measurements had been completed, the heart was removed, weighed and different sections of the intraventricular septum and the posterior free wall were frozen in liquid nitrogen for mRNA gene analysis

\section{RNA isolation and real-time quantitative PCR (qPCR)}

Total RNA was extracted from LV tissue with TRI-Reagent (Sigma, Steinheim, Germany). RNA concentration and purity were determined using the Nanodrop ND-1000 (Witec, Luzern, Switzerland). Total RNA (500 ng) was used for DNasel treatment (Sigma) to remove contaminating genomic DNA and subsequently for cDNA synthesis (IscriptcDNA synthesis kit; Biorad, Hercules, CA, USA). Gene expression analysis was performed by qPCR on an iCycler Real-Time PCR detection system (Biorad) using iQ SYBR-Green supermix (Biorad). Primer sets are indicated in Table 1. Gene expression differences were normalized to the reference gene Cyclophilin-A.

Table 1: Sequences of oligonucleotide primers used for real-time quantitative PCR. Cyclo, BNP, CTGF, IGF-1 and TGF1 $\beta$ refer to Cyclophilin-A, Brain Natriuretic Peptide, Connective Tissue Growth Factor, Insulin-like Growth Factor-1, and Transforming Growth Factor-beta1, respectively.

\begin{tabular}{llll}
\hline Gene & Forward 5'- & Reverse 5'- & Tm \\
\hline Cyclo & AAGAAGATCACCATTGCCAAC & GAGCTAGAGGAATGGTCAGGTG & $63^{\circ} \mathrm{C}$ \\
BNP & GCTCTCCTGCTCCTCCTCTT & GCAGCTGGGAGACCTTGTT & $64^{\circ} \mathrm{C}$ \\
CTGF & CACAGAGTGGAGCGCCTGTTC & GATGCACTTTTTGCCCTTCTTAATG & $63^{\circ} \mathrm{C}$ \\
IGF-1 & AGCTGGTGGATGCTCTTCAGTT & GAAGCAGCACTCATCCACGAT & $60^{\circ} \mathrm{C}$ \\
TGF $\boldsymbol{\beta} \mathbf{1}$ & AAGGGCTACCACGCCAACTT & CCGGGTTGTGCTGGTTGTAC & $60^{\circ} \mathrm{C}$ \\
\hline
\end{tabular}

\section{Statistical analysis}

Data are expressed as mean \pm SD or median values and 25-75 percentiles. Statistical analyses were performed using SPSS software (version 15.0). Data between groups were analyzed by non-paired Student t-test and data between regions of the same heart by paired Student t-test, or (in case of the data in table 3) Wilcoxon signed-rank test. A p-value $<0.05$ was considered statistically significant. 


\section{RESULTS}

\section{Pericardial and subcutaneous irbesartan delivery study}

In the pilot study irbesartan was measured in blood plasma, pericardial fluid and cardiac tissue. The retention times for losartan and irbesartan using HPLC-UV method for cardiac tissue were 4.9 and $8.2 \mathrm{~min}$, respectively (figure $1 \mathrm{~A}$ and $1 \mathrm{~B}$ ) and 2.3 and 3.55 min, respectively, for blood plasma and pericardial fluid (figure $1 \mathrm{C}$ and $1 \mathrm{D}$ ).

On average the irbesartan concentration in the entire LV wall and in the RV epicardium was $\sim 4$ times higher in the IPC group than in the SC group, though variability between experiments was relatively large (table 1 ). It was noticed that the irbesartan concentration was similar in the RV endocardium of the SC and IPC animals as well in the blood plasma and intrapericardial fluid of the two groups (table 1). During IPC, irbesartan concentration showed large regional variations. Because the aim of the study requires an equal distribution of irbesartan between septum and LV free wall and because distribution between septum and free wall was not significant different between the two ways of administration, the easier subcutaneous infusion of irbesartan was chosen for the subsequent study.

Table 1: Effect of intrapericardial (IPC) and subcutaneous (SC) infusion of irbesartan on its distribution within the heart, blood plasma and pericardial fluid. Irbesartan was administered via an osmotic minipump for $72 \mathrm{~h}$. Indicated are irbesartan concentrations $(\mathrm{ng} / \mathrm{ml})$ in cardiac tissue, blood plasma (BP) and pericardial fluid (PCF). LVepi, LVmid, LVend, RVepi, RVend, refer to LV epicardial, LV middle, LV endocardial, RV epicardial, and RV endocardial, respectively.

\begin{tabular}{lcccccccc}
\hline & LVepi & LVmid & LVendo & RVepi & RVendo & Septum & BP & PCF \\
\hline IPC1 & 24.4 & 8.7 & 17.6 & 37.5 & 28.1 & 11.3 & 2.5 & 16.8 \\
IPC 2 & 90.2 & 52.5 & 108.0 & 131.3 & 155.7 & 125.6 & 2.3 & 15.3 \\
IPC3 & 31.2 & 57.5 & 125.9 & 165.9 & 49.4 & 3.7 & 2.5 & 15.3 \\
Average & 48.6 & 39.6 & 83.9 & 111.5 & 77.7 & 46.9 & 2.5 & 16.1 \\
\hline & LVepi & LVmid & LVendo & RVepi & RVendo & Septum & BP & PCF \\
\hline SC1 & 13.3 & 8.8 & 9.6 & 46.8 & 87.6 & 6.2 & 2.2 & 15.9 \\
SC2 & 5.6 & 18.4 & 24.4 & 19.7 & 57.5 & 6.4 & 2.7 & 10.1 \\
Average & 9.4 & 13.6 & 17.0 & 33.2 & 72.6 & 6.3 & 2.5 & 13.0 \\
\hline
\end{tabular}


A

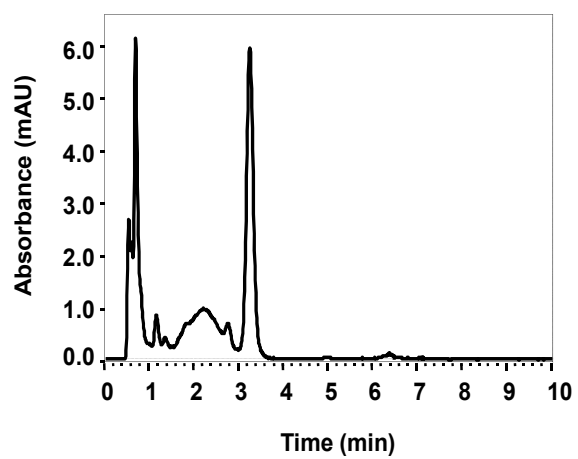

C

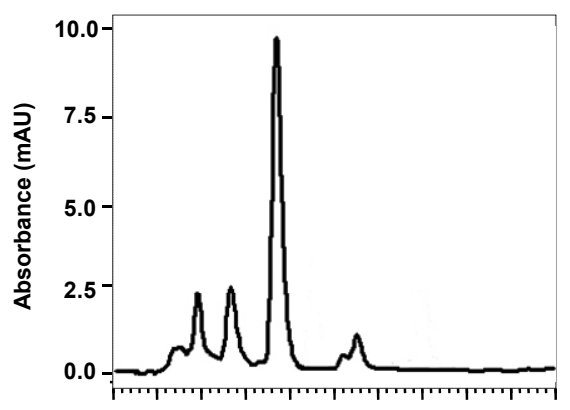

$\begin{array}{lllllllllll}0.0 & 0.5 & 1.0 & 1.5 & 2.0 & 2.5 & 3.0 & 3.5 & 4.0 & 4.5 & 5.0\end{array}$

Time (min)
B

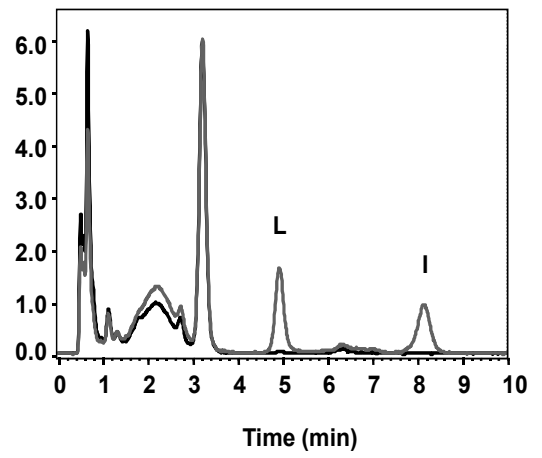

D

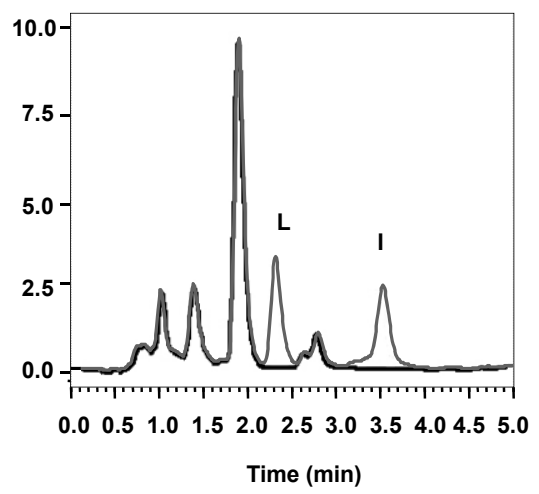

Figure 1: Representative HPLC-UV chromatograms of (A) control rabbit LV cardiac tissue, (B) control rabbit LV cardiac tissue spiked with $10 \mathrm{ng} / \mathrm{ml}$ losartan (L) and $10 \mathrm{ng} / \mathrm{ml}$ irbesartan (I) (C) control blood plasma rabbit, and (D) control rabbit blood plasma spiked with $10 \mathrm{ng} / \mathrm{ml} \mathrm{losartan} \mathrm{(L)} \mathrm{and} 10 \mathrm{ng} / \mathrm{ml}$ irbesartan (I). 


\section{CHRONIC PACING STUDY}

\section{Echocardiographic and hemodynamics changes}

The results presented in table 2 indicate that in the P + SOLV group diastolic, systolic and mean arterial pressure were significantly lower at 3 weeks than at baseline in contrast to the $\mathrm{P}+$ IRB group. During the 3 week experimental period body weight, LV wall mass and LV diameter tended to increase similarly in both groups. Fractional shortening was not affected in the $P+$ SOLV group, but tended to decrease $(p=0.06)$ in the $P+I R B$ group. In the $\mathrm{P}+\mathrm{SOLV}$ group diastolic thickness of the late-activated IVS increased, whereas thickness of the early-activated LV PW tended to decrease over the 3 week experimental period. Opposite trends in changes of absolute wall thickness were seen the $P+I R B$ group. The IVS/PW wall thickness ratio showed a strong tendency to increase over time $(p=0.08)$ in the $P+$ SOLV group and tended to decrease $(p=0.27)$ in the $\mathrm{P}+$ IRB group (table 2, figure 2). As a consequence, the difference in change of IVS/PW wall thickness ratio over time between the two groups $(\Delta+0.2+0.3$ vs. $\Delta-0.1+0.2)$ was statistically significant $(p=0.022)$.

\section{Effects of pacing and irbesartan on LV mRNA levels}

In the P + SOLV group expression levels of CTGF, IGF-1, BNP and TGF $\beta 1$ were comparable between the PW and IVS. In contrast, in the P + IRB group mRNA level of CTGF tended to be higher in the IVS than in the PW $(p=0.10)$. Moreover, CTGF mRNA levels in the IVS of the $P+$ SOLV group were significantly lower than in the IVS of the $P+I R B$ group ( $p=0.01$, table 3 ). Values of IVS/PW ratios for BNP, and CTGF tended to be higher in the $P+I R B$ group than in the $P+$ SOLV group $(p=0.10-0.20)$.

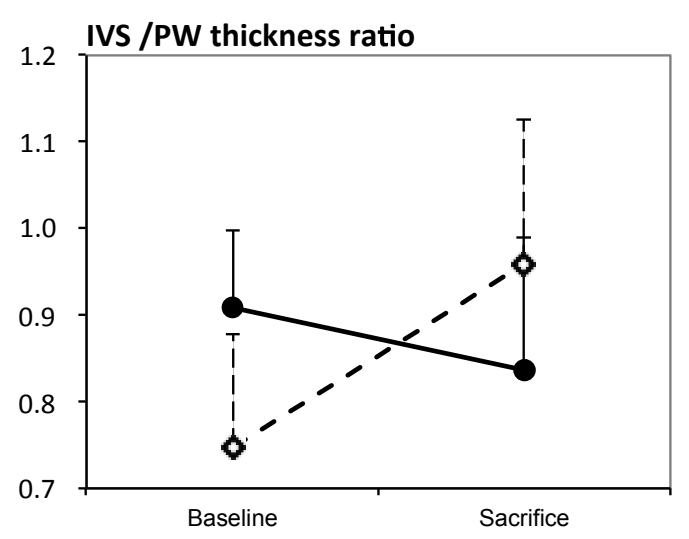

Figure 2: Ratio of wall thickness of interventricular septum and posterior wall (IVS/PW) in $\mathrm{P}+$ SOLV (open symbols) and P + IRB groups (closed symbols) at baseline and sacrifice at 3 weeks. Presented are mean values and S.D. 
Table 2: Baseline (day 0 ) and 3 week data of body weight, blood pressure and echocardiographic parameters in the P + SOLV and P + IRB groups. SBP, DBP, MAP, IVSd, PWd, LVDd, FS, and EF refer to systolic blood pressure, diastolic blood pressure, mean arterial pressure, LV weight, width of interventricular septum diastole, width of posterior wall diastole, LV diameter diastole, and fractional shortening, respectively. \# $\# p<0.05$ compared to baseline and $\$=p<0.05 P+S O L V$ compared to $P+I R B . \Delta=3$ weeks - baseline.

\begin{tabular}{lccc|ccc}
\hline & \multicolumn{3}{c|}{$P+$ SOLV group (n=7) } & \multicolumn{3}{c}{ P + IRB (n=10) } \\
\hline Weight (kg) & baseline & 3 weeks & $\Delta$ & baseline & 3 weeks & $\Delta$ \\
SBP (mmHg) & $2.6 \pm 0.1$ & $2.9 \pm 0.0$ & $+0.3 \pm 0,1$ & $2.7 \pm 0.1$ & $2.9 \pm 0.1$ & $+0.2 \pm 0.1$ \\
DBP (mmHg) & $73 \pm 20$ & $76 \pm 25 \#$ & $-22 \pm 65$ & $92 \pm 12$ & $82 \pm 17$ & $-10 \pm 23$ \\
MAP (mmHg) & $81 \pm 15$ & $62 \pm 20 \#$ & $-19 \pm 50$ & $73 \pm 13$ & $68 \pm 15$ & $-5 \pm 22$ \\
IVSd (mm) & $2.6 \pm 0.4$ & $2.9 \pm 0.3$ & $+0.3 \pm 0.7$ & $2.8 \pm 0.3$ & $2.7 \pm 0.5$ & $-0.1 \pm 0.5$ \\
PWd (mm) & $3.5 \pm 0.5$ & $3.0 \pm 0.5$ & $-0.5 \pm 0.9$ & $3.1 \pm 0.4$ & $3.3 \pm 0.7$ & $+0.2 \pm 0.6$ \\
LVDd (mm) & $14.4 \pm 1.9$ & $15.1 \pm 1.4$ & $+0.7 \pm 2.8$ & $14.8 \pm 1.2$ & $15.1 \pm 0.9$ & $+0.3 \pm 1.4$ \\
FS (\%) & $33 \pm 3$ & $33 \pm 6$ & $-0 \pm 7$ & $38 \pm 9$ & $30 \pm 12$ & $-8 \pm 12$ \\
Ratio IVS/PW & $0.8 \pm 0.1$ & $1.0 \pm 0.2$ & $+0.2+0.3$ & $0.9 \pm 0.1$ & $0.8 \pm 0.2$ & $-0.1+0.2^{\$}$ \\
\hline
\end{tabular}

\section{DISCUSSION}

\section{Main findings}

The findings in the present study demonstrate that 3 weeks asynchronous electrical activation, as induced by ventricular pacing in rabbits hearts, leads to increased LV cavity diameter and asymmetrical changes in LV wall thickness. The early-activated LV free wall becomes thinner and the late-activated septal wall becomes thicker. Development of this asymmetry in wall thickness is prevented by administration of the Angll type-1 receptor antagonist irbesartan. These findings indicate that the AT-1 receptor is involved in cardiac hypertrophy that is induced by local differences in mechanical load. Regional expression of CTGF changed opposite to that of regional wall thickness. 
Table 3: Effect of 3 weeks of pacing $(240 \mathrm{bpm})$ at the LV free wall, alone ( $n=5: P+S O L V)$ or in combination with subcutaneous infusion of irbesartan $(n=7: P+I R B)$ on mRNA expression levels of Connective Tissue Growth Factor (CTGF), Insulin-like growth factor-1 (IGF-1), Brain Natriuretic Peptide (BNP) and Transforming Growth Factor beta (TGF $\beta 1$ ) measured in septal (IVS) and left ventricular posterior wall (PW) myocardium. mRNA levels, normalized on Cyclophilin-A, are expressed in arbitrary units (AU) and as median values (25-75 percentiles). $\$=p<0.05$ for IVS/PW ratio in $P+$ SOLV compared to $P+I R B$ group. $\#=p<0.05$ compared to IVS in $P+I R B$.

\begin{tabular}{|c|c|c|c|c|c|c|c|}
\hline \multicolumn{4}{|c|}{$P+S O L V$ group } & \multicolumn{4}{|c|}{$P+$ IRB group } \\
\hline & IVS & PW & $\begin{array}{l}\text { Ratio } \\
\text { IVS/PW }\end{array}$ & IVS & PW & Ratio IVS/PW & $P$ value\$ \\
\hline CTGF & $\begin{array}{c}2.1^{\#} \\
(1.7-2.5)\end{array}$ & $\begin{array}{c}2.5 \\
(1.8-4.1)\end{array}$ & $\begin{array}{c}0.7 \\
(0.5-1.2)\end{array}$ & $\begin{array}{c}5.3 \\
(4.7-5.6)\end{array}$ & $\begin{array}{c}2.7 \\
(2.3-4.3)\end{array}$ & $\begin{array}{c}1.9 \\
(1.4-2.0)\end{array}$ & 0.20 \\
\hline IGF-1 & $\begin{array}{c}2.2 \\
(1.9-2.3)\end{array}$ & $\begin{array}{c}2.5 \\
(2.4-2.6)\end{array}$ & $\begin{array}{c}0.9 \\
(0.6-1.0)\end{array}$ & $\begin{array}{c}1.9 \\
(1.3-3.4)\end{array}$ & $\begin{array}{c}2.4 \\
(2.1-3.1)\end{array}$ & $\begin{array}{c}0.8 \\
(0.7-0.9)\end{array}$ & $>0.20$ \\
\hline BNP & $\begin{array}{c}27.3 \\
(5.5-31.0)\end{array}$ & $\begin{array}{c}16.7 \\
(3.6-30.9)\end{array}$ & $\begin{array}{c}1.1 \\
(0.4-1.5)\end{array}$ & $\begin{array}{c}26.6 \\
(21.6-27.9)\end{array}$ & $\begin{array}{c}13.1 \\
(11.5-25.0)\end{array}$ & $\begin{array}{c}2.3 \\
(1.1-2.6)\end{array}$ & $\begin{array}{c}0.10- \\
0.20\end{array}$ \\
\hline TGF $\beta 1$ & $\begin{array}{c}1.7 \\
(1.3-1.7)\end{array}$ & $\begin{array}{c}1.7 \\
(1.5-1.7)\end{array}$ & $\begin{array}{c}1.0 \\
(0.9-1.0)\end{array}$ & $\begin{array}{c}1.5 \\
(1.2-1.9)\end{array}$ & $\begin{array}{c}1.3 \\
(1.2-1.4)\end{array}$ & $\begin{array}{c}1.2 \\
(1.0-1.3)\end{array}$ & $>0.20$ \\
\hline
\end{tabular}

\section{Regional hypertrophic response during ventricular pacing}

Asynchronous electrical activation via ventricular pacing induces aberrant contraction patterns and, hence, different levels of workload within the LV wall ${ }^{18}$. LV pacing is associated with early electrical activation and contraction of the LV posterior wall, and delayed electrical activation and early systolic pre-stretch of cardiac cells in the late activated septal wall. The differences in pre-stretch also lead to regional differences in mechanical load within the LV wall, the higher load being observed in the late-activated septum $^{18}$. As a consequence, asymmetric hypertrophy develops during prolonged LV pacing, characterized by mass growth of the septal wall, as has previously been shown in a dog study ${ }^{15}$ and is demonstrated in rabbits in the present study. A similar, but opposite asymmetrical hypertrophy has been demonstrated for left bundle branch block (LBBB), where the sequence of electrical activation is opposite to that during LV pacing $^{19,20}$. With this knowledge, ventricular pacing can be used as tool to understand stretch-mediated growth changes in the cardiac wall. After all, since blood pressure is not affected much by pacing and regional changes in LV wall thickness are considerable, local cardiac mechanisms underlying the induction of hypertrophy can be studied, because all regions within the heart are exposed to the same circulating levels of hormones. An advantage of using this animal model is that it allows comparing different regions within the LV wall allowing using each animal as its own control. 


\section{Irbesartan blocks asymmetric hypertrophy}

The most important finding of the present study is that administration of irbesartan abrogates the asymmetric change in wall mass induced by ventricular pacing. This observation is in keeping with findings in other studies showing or proposing that stretch initiates (neonatal) cardiomyocyte growth via both autocrine and paracrine Angll release ${ }^{5,8,21}$. However, the present data are in conflict with our previous findings, reported in chapter 4 of this thesis, that isolated rabbit cardiomyocytes from adult rabbits exposed to Angll do not show a hypertrophic response ${ }^{11}$. In that study also the stretchmediated hypertrophic response of rabbit cardiomyocytes was not inhibited by the specific Angll type-1 antagonists irbesartan and candesartan. Therefore, these in vitro findings argued against a role of (i) Angll-AT-1 binding ${ }^{11}$ and (ii) stretch mediated AT-1 activation $^{9}$ in the hypertrophic response of adult cardiac muscle cells.

A possible explanation for the discrepant findings between the aforementioned studies in neonatal cardiomyocytes and our studies in adult cardiomyocytes might be the presence of $5-10 \%$ 'contaminating' fibroblasts in the primary neonatal cardiomyocyte cultures22, 23. Previous in vitro studies showed that cardiac fibroblasts express AT-1 receptors ${ }^{12}$. Furthermore, we (chapter 5 ) and others showed that stretch of these non-cardiomyocytes results in enhanced mRNA transcription of growth factors, including TGF $\beta^{24}$ and IGF-1 $1^{14}$.

In chapter 5 and 6 of this thesis, we have shown that exposure of rabbit cardiomyocytes and fibroblasts to conditioned media from stretched cardiac cells results in hypertrophic and fibrogenic responses. Because myocardial stretch will influence both cardiomyocytes and fibroblasts, these data suggest that stretch-induced hypertrophy is a concerted action of the various cell types in the myocardium, partly mediated by paracrine neurohumoral factors.

This process can clearly also be active in the in vivo situation, as employed in the present study. The demonstration that in the in vivo setting irbesartan is capable of inhibiting asymmetric hypertrophy supports the notion that angiotensin II mediates hypertrophy through the secretion of paracrine substances ${ }^{13,24}$ in an interplay between cardiomyocytes and non-cardiomyocytes.

The contrasting findings in isolated cardiomyocytes (chapter 4) and the in vivo intact heart (this chapter) are of special interest, because both studies were performed in the same species (rabbit) using animals of similar (young adult) age.

\section{Does irbesartan elicit a redistribution of molecular remodelling?}

A remarkable finding was that in the hearts of the P+SOLV group, with its strong tendency for asymmetrical hypertrophy, the distribution of mRNA expression of molecular hypertrophy markers CTGF, BNP, IGF-1 and TGF $\beta$ was uniform. In contrast, regional differences in mRNA expression appear to develop when regional mass growth in the 
paced rabbit hearts is blocked by irbesartan. This finding is remarkable, because these substances are often, and especially BNP, regarded as a marker of hypertrophy, as has also been shown to be the case for the hypertrophic response in stretched myocytes (chapter 4). The most pronounced effect is observed for CTGF in the late-activated septum, which increases by a factor two by irbesartan administration. This mismatch between macroscopic hypertrophy and molecular markers and between association of mass growth and molecular response between in vivo and in vitro situation is not well understood and requires further studies.

\section{Clinical implications of the present study}

One of the possible clinical implications of this study is that cardiac geometry and gene expression in pacemaker patients may be influenced by angiotensin-modulating medication. After all, many patients where pacemakers have been implanted for treating brady arrhythmia or dyssynchronous heart failure take ACE-inhibitors or ARBs as medication. Very few studies report on asymmetry in wall thickness or gene expression in patients.

In one study LBBB patients were shown to have asymmetric wall thickness, but the degree of asymmetry was considerably smaller than in animals ${ }^{25}$. It is likely, but not reported, that many of these patients used ACE-inhibitors. In another study in patients with heart failure and LBBB (96\% using ARBs or ACE-inhibitors), no asymmetric hypertrophy was observed and neither did the distribution of wall thickness change after cardiac resynchronization therapy for normalization of the activation pattern ${ }^{26}$. The data from the present study suggest that this lack of changes in regional wall thickness may be due to the use of ACE-inhibitors or ARBs.

\section{Limitations of the present study}

LV pacing was performed using a fixed heart rate, which was slightly above the physiological heart rate at rest, in order to over-pace natural sinus rhythm. When natural heart rate increases above the pacemaker rate, there is no ventricular pacing and activation sequence becomes normal again. This incomplete ventricular artificial pacing may have reduced the remodelling effects of ventricular pacing.

This study lacks sham operated non-paced and irbesartan-only animals in order to investigate the effect of irbesartan in non-paced animals. However, the main focus of this study was on the regional differences in hypertrophic response within the LV wall. Clearly, the current results warrant a more complete study with all four groups and over a longer time period. 


\section{CONCLUSIONS}

Asynchronous electrical activation induced by LV pacing in rabbit hearts results in asymmetric hypertrophy, which is not accompanied with regional differences in mRNA expression levels of BNP, CTGF, TGF $\beta 1$ and IGF-1. The asymmetric wall growth induced by LV pacing can be prevented by the AT-1-receptor blocker irbesartan. 


\section{REFERENCES}

1. Kim NN, Villarreal FJ, Printz MP, Lee AA, Dillmann WH. Trophic effects of angiotensin II on neonatal rat cardiac myocytes are mediated by cardiac fibroblasts. Am J Physiol. 1995;269(3 Pt 1):E426-437.

2. Geenen DL, Malhotra A, Scheuer J. Angiotensin II increases cardiac protein synthesis in adult rat heart. Am J Physiol. 1993;265(1 Pt 2):H238-243.

3. Dostal DE, Baker KM. Angiotensin II stimulation of left ventricular hypertrophy in adult rat heart. Mediation by the AT1 receptor. Am J Hypertens. 1992;5(5 Pt 1):276-280.

4. Higashi M, Shimokawa H, Hattori T, Hiroki J, Mukai Y, Morikawa K, Ichiki T, Takahashi S, Takeshita A. Long-term inhibition of Rho-kinase suppresses angiotensin Il-induced cardiovascular hypertrophy in rats in vivo: effect on endothelial NAD(P)H oxidase system. Circ Res. 2003;93(8):767-775.

5. Miyata S, Haneda T. Hypertrophic growth of cultured neonatal rat heart cells mediated by type 1 angiotensin II receptor. Am J Physiol. 1994;266(6 Pt 2):H2443-2451.

6. Booz GW, Baker KM. Role of type 1 and type 2 angiotensin receptors in angiotensin II-induced cardiomyocyte hypertrophy. Hypertension. 1996;28(4):635-640.

7. Sadoshima J, Xu Y, Slayter HS, Izumo S. Autocrine release of angiotensin II mediates stretch-induced hypertrophy of cardiac myocytes in vitro. Cell. 1993;75(5):977-984.

8. Frank D, Kuhn C, Brors B, Hanselmann C, Ludde M, Katus HA, Frey N. Gene expression pattern in biomechanically stretched cardiomyocytes: evidence for a stretch-specific gene program. Hypertension. 2008;51(2):309-318.

9. Zou Y, Akazawa H, Qin Y, Sano M, Takano H, Minamino T, Makita N, Iwanaga K, Zhu W, Kudoh S, Toko H, Tamura K, Kihara M, Nagai T, Fukamizu A, Umemura S, liri T, Fujita T, Komuro I. Mechanical stress activates angiotensin II type 1 receptor without the involvement of angiotensin II. Nature cell biology. 2004;6(6):499-506.

10. Sadoshima J, Izumo S. The heterotrimeric G q protein-coupled angiotensin II receptor activates p21 ras via the tyrosine kinase-Shc-Grb2-Sos pathway in cardiac myocytes. The EMBO journal. 1996;15(4):775787.

11. Blaauw E, van Nieuwenhoven FA, Willemsen P, Delhaas T, Prinzen FW, Snoeckx LH, van Bilsen M, van der Vusse GJ. Stretch-induced hypertrophy of isolated adult rabbit cardiomyocytes. Am J Physiol Heart Circ Physiol. 2010;299(3):H780-787.

12. Gray MO, Long CS, Kalinyak JE, Li HT, Karliner JS. Angiotensin II stimulates cardiac myocyte hypertrophy via paracrine release of TGF-beta 1 and endothelin-1 from fibroblasts. Cardiovasc Res. 1998;40(2):352363.

13. van Wamel AJ, Ruwhof C, van der Valk-Kokshoom LE, Schrier PI, van der Laarse A. The role of angiotensin II, endothelin-1 and transforming growth factor-beta as autocrine/paracrine mediators of stretchinduced cardiomyocyte hypertrophy. Mol Cell Biochem. 2001;218(1-2):113-124.

14. Horio T, Maki T, Kishimoto I, Tokudome T, Okumura H, Yoshihara F, Suga S, Takeo S, Kawano Y, Kangawa K. Production and autocrine/paracrine effects of endogenous insulin-like growth factor-1 in rat cardiac fibroblasts. Regulatory peptides. 2005;124(1-3):65-72.

15. van Oosterhout MF, Prinzen FW, Arts T, Schreuder JJ, Vanagt WY, Cleutjens JP, Reneman RS. Asynchronous electrical activation induces asymmetrical hypertrophy of the left ventricular wall. Circulation. 1998;98(6):588-595.

16. Hermans JJ, van Essen $H$, Struijker-Boudier HA, Johnson RM, Theeuwes F, Smits JF. Pharmacokinetic advantage of intrapericardially applied substances in the rat. J Pharmacol Exp Ther. 2002;301(2):672678.

17. Devereux RB, Alonso DR, Lutas EM, Gottlieb GJ, Campo E, Sachs I, Reichek N. Echocardiographic assessment of left ventricular hypertrophy: comparison to necropsy findings. Am J Cardiol. 1986;57(6):450458.

18. Prinzen FW, Hunter WC, Wyman BT, McVeigh ER. Mapping of regional myocardial strain and work during ventricular pacing: experimental study using magnetic resonance imaging tagging. J Am Coll Cardiol. 1999;33(6):1735-1742. 
19. Vernooy K, Verbeek XA, Peschar M, Crijns HJ, Arts T, Cornelussen RN, Prinzen FW. Left bundle branch block induces ventricular remodelling and functional septal hypoperfusion. Eur Heart J. 2005;26(1):9198.

20. Vernooy K, Cornelussen RN, Verbeek XA, Vanagt WY, van Hunnik A, Kuiper M, Arts T, Crijns HJ, Prinzen FW. Cardiac resynchronization therapy cures dyssynchronopathy in canine left bundle-branch block hearts. Eur Heart J. 2007;28(17):2148-2155.

21. Sadoshima J, Izumo S. Mechanical stretch rapidly activates multiple signal transduction pathways in cardiac myocytes: potential involvement of an autocrine/paracrine mechanism. The EMBO journal. 1993;12(4):1681-1692.

22. Sadoshima J, Izumo S. Signal transduction pathways of angiotensin II--induced c-fos gene expression in cardiac myocytes in vitro. Roles of phospholipid-derived second messengers. Circ Res. 1993;73(3):424438.

23. Sadoshima J, Izumo S. Molecular characterization of angiotensin II--induced hypertrophy of cardiac myocytes and hyperplasia of cardiac fibroblasts. Critical role of the AT1 receptor subtype. Circ Res. 1993;73(3):413-423.

24. van Wamel AJ, Ruwhof C, van der Valk-Kokshoorn LJ, Schrier PI, van der Laarse A. Stretch-induced paracrine hypertrophic stimuli increase TGF-beta1 expression in cardiomyocytes. Mol Cell Biochem. 2002;236(1-2):147-153.

25. Prinzen FW, Cheriex EC, Delhaas T, van Oosterhout MF, Arts T, Wellens HJ, Reneman RS. Asymmetric thickness of the left ventricular wall resulting from asynchronous electric activation: a study in dogs with ventricular pacing and in patients with left bundle branch block. Am Heart J. 1995;130(5):1045-1053.

26. Zhang $Q$, Fung JW, Auricchio A, Chan JY, Kum LC, Wu LW, Yu CM. Differential change in left ventricular mass and regional wall thickness after cardiac resynchronization therapy for heart failure. Eur Heart $J$. 2006;27(12):1423-1430.

27. Vanderheyden M, Mullens W, Delrue L, Goethals M, de Bruyne B, Wijns W, Geelen P, Verstreken S, Wellens F, Bartunek J. Myocardial gene expression in heart failure patients treated with cardiac resynchronization therapy responders versus nonresponders. J Am Coll Cardiol. 2008;51(2):129-136. 

Chapter 8

General discussion and conclusions 


\section{INTRODUCTION}

Cardiac hypertrophy and fibrosis are common patho-physiological processes in a great number of cardiovascular diseases, such as myocardial infarction, valvular disease and hypertension. In general, these patho-physiological changes have been considered adaptive responses to increased mechanical load in an attempt to restore ventricular wall stress to normal levels. However, this myocardial response to mechanical overload can eventually lead to compromised contractile performance, resulting in heart failure, as well as to lethal cardiac arrhythmias. Alterations in hemodynamic conditions are often associated with increased stretch of cardiomyocytes and other cell types present in the cardiac muscle such as fibroblasts. Despite increasing knowledge about the underlying mechanisms, it is still unclear whether stretch itself is the direct trigger for initiation and progression of the cardiac remodelling process, including hypertrophy and fibrosis, or that the effect of cellular stretch is mediated by biochemical factors (i.e., growth factors or cytokines acting in an autocrine or paracrine fashion ${ }^{1}$, as summarized schematically in figure 1.

\section{Objectives of the studies described in this thesis}

The major objective of the research reported in the present thesis was to elucidate the role of stretch and growth factors in the process of hypertrophy (enlarged cardiomyocyte volume) and fibrosis (enhanced net synthesis of extracellular matrix, ECM, components). Both in vitro experiments on isolated cardiac cells from adult rabbits and in vivo experiments on the intact heart in situ were performed. Prior to the start of the in vitro experiments, isolation and culture protocols for rabbit cardiac cells were improved and standardized (see chapter 3 ). The adult rabbit heart was chosen as source of cardiomyocytes and fibroblasts to facilitate extrapolation of the experimental findings to the clinical situation. In addition, culture protocols for stretching cardiac cells on silicone membranes were developed and validated ${ }^{2}$. 


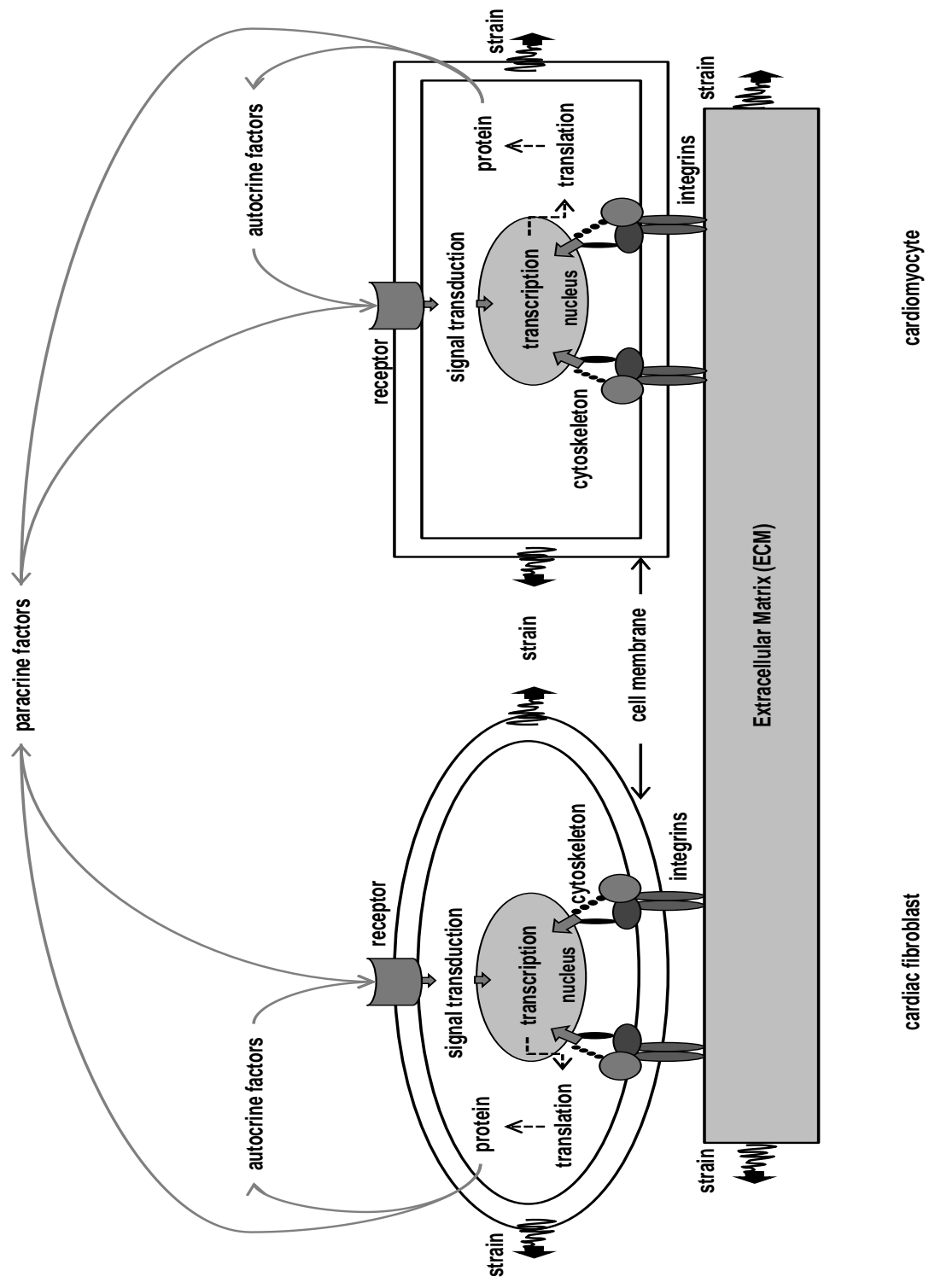

Figure 1: Simplified schema with different putative mechanisms how cardiac fibroblasts and cardiomyocytes may sense and respond to increased strain (stretch). Mechanical stretch is sensed via (i) ECM-integrins-cell connections or (ii) via specific membrane receptors. Mechanical stretch signals are transferred into biochemical signals via intracellular transduction pathways, leading to protein synthesis via DNA transcription and RNA translation. Thereafter, proteins are used as building blocks to enhance tissue mass. Additionally, newly formed proteins can also be secreted in the cardiac interstitium as autocrine and/or paracrine factors. In turn, autocrine/paracrine factors can bind to specific membrane receptors, resulting in activation of downstream signal transduction pathways involved in the early onset of cardiac hypertrophy and cardiac fibrosis. 
The major sub-aims of this thesis were to investigate whether

1) Cyclic stretch is a trigger for hypertrophic growth of cardiomyocytes i) directly, without involvement of autocrine/paracrine agents, or ii) indirectly, via release of autocrine factors from stretched cardiomyocytes and/or via the release of paracrine factors from stretched fibroblasts.

2) Cyclic stretch is a trigger for cardiac fibroblasts to induce the expression of ECM components i) directly, without involvement of autocrine/paracrine agents, or ii) indirectly, via release of autocrine factors released from stretched fibroblasts and/or via the release of paracrine factors from stretched cardiomyocytes.

3) Stretch up-regulates the expression of Connective Tissue Growth Factor (CTGF) in cardiomyocytes and cardiac fibroblasts.

In our in vitro studies in particular the potential autocrine/paracrine role of angiotensin II (AngII), Tissue Growth Factor- $\beta$ (TGF $\beta$ ) and Insulin-like Growth Factor-1 (IGF-1) were taken into consideration. The in vivo experiments were mainly dealing with the question whether stretch-mediated release of Angll could play a role in the hypertrophic response of the myocardium.

Special attention to CTGF was paid, since recent literature data suggest that mechanical load-induced cardiac hypertrophy and cardiac fibrosis were associated with induction of CTGF expression ${ }^{3}$.

In summary, the present thesis shows that (i) rabbit cardiomyocytes (CMC) and cardiac rabbit fibroblasts can be cultured under resting conditions for up to 4 days on silicone membranes, and that (ii) both cell types can be subjected to $48 \mathrm{~h}$ of cyclic equibiaxial strain $(10 \% / 1 \mathrm{~Hz})$, without significant effects on cell viability and morphology. Furthermore, this thesis describes that cyclic stretch is a strong, direct trigger for rabbit CMC to evoke a hypertrophic response, which is characterized by enhanced cell growth, up regulated BNP expression and increased protein synthesis. There was no evidence that (i) stretch-mediated Angll or the (ii) Angll type-1 (AT-1) receptor was involved in this stretch-mediated hypertrophic response of isolated CMC (table 1). Also IGF-1 could be ruled out as an autocrine factor involved in hypertrophy. On the other hand, TGF $\beta 1$ is a possible stretch-mediated autocrine factor. From data obtained in in vitro experiments with CMC we can cautiously rule out AngII and IGF-1 as autocrine factors. Experiments with conditioned medium from stretched rabbit fibroblasts showed that fibroblasts produce and excrete certain paracrine factors that might play a (additional) role in the induction of cardiomyocyte hypertrophy (table 1).

In contrast to the in vitro experiments, in vivo data obtained in a rabbit model of pacing induced asynchrony, strongly suggests that AT-1 receptor activation likely plays an important role in regional hypertrophy, probably effectuated by paracrine signaling. 
In line with the isolated $\mathrm{CMC}$ experiments, stretch is also a direct trigger for fibroblasts to induce TGF 31 (table 2). Additionally, the expression of IGF-1 was also induced. Unexpectedly, the expression of collagens was down regulated by stretch in fibroblasts (table 2). An interesting finding in this thesis is that both cardiomyocytes and fibroblasts express high mRNA levels of CTGF under baseline, non-stretched conditions (chapter 6; table 2). Stretching of both cell types resulted in a significant increase in CTGF gene expression. We found indications that TGF $\beta 1$ acts as autocrine/paracrine agent in stretch-induced cardiomyocyte CTGF expression. The role of CTGF in CMC hypertrophy and/or fibroblast mediated ECM synthesis requires further investigation.

Table 1: An overview of the in vitro results described in chapter 6 of this thesis. These results were obtained in rabbit cardiomyocytes. Cardiomyocytes were exposed to cyclic stretch $(10 \%, 1 \mathrm{~Hz})$ or biochemical factors IGF-1, AngII, TGF $\beta$ or CM-S-FB. Abbreviations: $(\downarrow)$ inhibitory effect; $(\uparrow)$ stimulatory effect; nd, not detectable; $=$, no effect; BNP, Brain Natriuretic Protein; CTGF, Connective Tissue Growth Factor; TGF $\beta$, transforming growth factor-beta; IGF-1, insulin-like growth factor-1; Angll, angiotensin II; CM-S-FB, conditioned medium from stretched fibroblasts.

\begin{tabular}{l|cccccc|}
\hline \multicolumn{5}{c|}{ Rabbit cardiomyocytes } \\
\hline Read-out & Trigger & Ttretch & TGF $\beta$ & IGF-1 & AngII & CM-S-FB \\
BNP & $\uparrow$ & $=$ & $=$ & $=$ & $\uparrow$ \\
CTGF & $\uparrow$ & $\uparrow$ & $\downarrow$ & $\downarrow$ & $\uparrow$ \\
TGF $\beta$ & $\uparrow$ & $\uparrow$ & $\uparrow$ & $\downarrow$ & $\uparrow$ \\
IGF-1 & nd & nd & nd & nd & nd \\
\hline
\end{tabular}

\section{FEATURES OF THE MODELS USED}

\section{Isolated cells as experimental model}

One of the most important advantages of the use of isolated cells as experimental model is that properties and behaviour of one particular cell type can be studied apart from other cell types present in the same organ. Inherent disadvantage, however, is that the cells under investigation are removed from their natural environment. To some extent we used this disadvantage as advantage, since this allows investigating the potential paracrine role of growth factors secreted by stretched cardiomyocytes or fibroblasts.

However, also the degradation of ECM components surrounding the isolated cell and, hence, influences of physiologically relevant cell environment are not or hardly taken into account. 
Table 2: An overview of the in vitro results described in chapter 5 of this thesis. These results were obtained in rabbit cardiac fibroblasts. Cardiac fibroblasts were exposed to cyclic stretch $(10 \%, 1 \mathrm{~Hz})$ or biochemical factors IGF-1, AngII, TGF $\beta$ or CM-S-CMC. Abbreviations: ( $\downarrow$ ) inhibitory effect; ( $\uparrow$ ) stimulatory effect; =, no effect; CTGF, Connective Tissue Growth Factor; TGF $\beta$, transforming growth factor-beta; IGF-1, insulin-like growth factor-1; AngII, angiotensin II; CM-S-FB, conditioned medium from stretched cardiomyocytes; Col-I , collagen type-I; Col-III, collagen type-III; FN, fibronectin.

\begin{tabular}{|c|c|c|c|c|c|}
\hline \multicolumn{6}{|c|}{ Cardiac fibroblast } \\
\hline Read-out & stretch & TGF $\beta$ & IGF-1 & Angll & CM-S-CMC \\
\hline Col-I & $\downarrow$ & $\uparrow$ & $=$ & $\uparrow$ & $=$ \\
\hline Col-III & $\downarrow$ & $\downarrow$ & $\uparrow$ & $\uparrow$ & $\downarrow$ \\
\hline FN & $\uparrow$ & $\uparrow$ & $=$ & $\uparrow$ & $=$ \\
\hline CTGF & $\uparrow$ & $\uparrow$ & $\downarrow$ & $\downarrow$ & $\uparrow$ \\
\hline TGF $\beta$ & $\uparrow$ & $\uparrow$ & $\downarrow$ & $\downarrow$ & $=$ \\
\hline IGF-1 & $\uparrow$ & $\uparrow$ & $\uparrow$ & $\uparrow$ & $=$ \\
\hline
\end{tabular}

\section{Stretch as mechanical trigger}

Evidence is accumulating that increased stretch is a powerful trigger to evoke cardiac remodelling ${ }^{1,4,5}$. Many studies ${ }^{6-9}$ have used static stretch as trigger, which could be considered as un-physiological. In the present thesis we studied the effect of $10 \%$ cyclic stretch and compared the outcome with non-stretched cardiac cells. This model seems certainly more physiological than the static stretch approach. However, under normal in vivo conditions, cardiac cells are continuously exposed to a certain degree of cyclic stretch. Therefore, it could be argued that the quiescent cells, used as controls in the present studies, are subjected to the non-physiological conditions and not the stretched cells. In the normal heart the length of myofibers (and probably also fibroblasts) during each cardiac cycle varies by $10-15 \%$, so in the same range as the stretch applied in our studies. At present, little quantitative information is available to which degree stretch is altered in patho-physiological situations. Our attempts to expose the isolated rabbit cardiomyocytes to a more pronounced degree of stretch (on the order of $15-20 \%$ ) failed because the cells rapidly lost their normal morphological appearance. Moreover, in situ cardiomyocytes are also electrically stimulated, which was not the case in the in vitro experiments described in this thesis. These experimental conditions should also be taken into account when interpreting the present findings.

\section{Use of mRNA as outcome parameter}

The choice of mRNA as outcome parameter is a matter of continuous dispute. Undoubtedly, alterations in mRNA expression in cardiac cells exposed cyclic stretch and/or growth factors indicate that the parameters under investigation are regulated on the transcriptional level. However, it cannot be denied that information about the gene 
products, i.e., proteins, as well as protein phosphorylation, are equally important to rate the effect of the intervention on its physiological significance. Altered mRNA expression does not automatically imply altered protein synthesis and, hence, a biological effect of the gene product under investigation. However, we showed in chapter 4 that stretch-induced upregulation of BNP mRNA expression correlated very well with enhanced protein synthesis, and increased cell surface area. Therefore, our data suggests that enhanced mRNA expression can go in parallel with increased protein levels and can be used as marker for hypertrophic response

\section{Time scale of in vitro experiments}

Because of morphological deformation, readily occurring in adult cardiac cells kept in culture for longer than $48 \mathrm{~h}$ and subjected to cyclic stretch, long-term studies with this in vitro experimental model are not feasible. Taking into account that overt signs of cardiac remodelling in vivo take usually weeks till months to develop, isolated cells are not appropriate to investigate the long-term effects of increased mechanical load on alterations in cell morphology and physiological function. However, the present in vitro rabbit cardiac cell model is appropriate to investigate the early onset of changes eventually leading to cardiac remodelling and the role of cardiomyocytes and fibroblasts in this process.

\section{Pacing- induced asynchrony as in vivo model to study cardiac remodelling}

In this thesis we described an in vivo rabbit model to study the long-term effect of increased stretch on cardiac tissue remodelling, if any. In anesthetized dogs, pacinginduced asynchronous contraction was applied to induce regional differences in mechanical behavior $^{10}$. Long-term exposure to these regional differences in mechanical load resulted in regional differences in hypertrophy in the canine heart ${ }^{11}$. As shown in chapter 7, the results of this intervention in the rabbit heart are qualitatively similar, but appear to be milder than in the canine heart: the ratio of LV free wall to septal thickness changed by $20 \%$ in the rabbits as opposed to $40 \%$ in the dogs. The quantitative differences between these models may be explained by the shorter duration of pacing in the rabbits than in dogs ( 3 weeks vs. 6 months) and the use of fixed rate ventricular pacing vs. atrial-sensed ventricular pacing. When, during fixed rate pacing, natural heart rate increases above the pacemaker rate, ventricular pacing is lost and activation sequence becomes normal again. Because we had no access to (clinical) pacemakers using atrio-ventricular pacing, single chamber pacemakers, modified to reach heart rates up to $300 \mathrm{bpm}$, a pacing rate about $50 \mathrm{bpm}$ higher than the natural heart of $250 \mathrm{bpm}$ in the rabbits under investigation, were used. 


\section{STRETCH-INDUCED CARDIOMYOCYTE HYPERTROPHY}

\section{Stretch-induced hypertrophy in isolated cardiomyocytes, independent of growth factors...}

The experiments described in chapter 4 clearly indicated that cyclic stretch evokes a hypertrophic response in isolated rabbit cardiomyocytes, corroborating earlier findings in different isolated cardiomyocyte models ${ }^{12-14}$. Also the findings presented in chapter 7 in the in vivo rabbit heart model are in line with the notion that increased (local) stretch results in (local) cardiomyocyte hypertrophy. These findings lead to the question whether cardiomyocyte stretch per se is the sole and ultimate trigger evoking cardiac growth or whether also autocrine and/or paracrine effects of growth factors are involved after being released from stretched cardiac cells. As discussed in detail in chapter 4 no convincing evidence could be obtained to conclude that Angll and/or IGF-1 are instrumental in eliciting a hypertrophic response evoked to increased stretch of the isolated cardiomyocyte. By contrast, earlier findings by other investigators have suggested that these agents might be involved in hypertrophic growth in an autocrine fashion ${ }^{15-19}$. Especially Angll has been subject of intense investigation ${ }^{13,20-26}$. Our results, in combination with previous deliberations ${ }^{27}$ and experimental observations ${ }^{23,28}$, strengthen the theory that Angll itself is not involved in the initial process of cardiomyocyte hypertrophy. Moreover, Wenzel and colleagues ${ }^{29}$ suggested that Angll is involved in the transition from cardiac hypertrophy to failure rather than in the onset of hypertrophy. This notion supports our view that Angll is not primarily involved in early activation process of cardiomyocyte growth. The obvious discrepancies in (interpretation of) experimental findings concerning the role of putative autocrine agents in the onset of hypertrophy require further research.

Zou and co-workers ${ }^{22}$ proposed an alternative theory about how cell stretch could lead to hypertrophy through an Angll independent Angll receptor activation. They showed that stretch of cardiac cells resulted in a conformational change of the AT-1 receptor. This conformational change, in turn, elicited an activation of downstream hypertrophic signaling pathways. The activation of these pathways appeared to be Angll independent. We tested the hypothesis of Zou and colleagues in our in vitro setting. We showed, in line with Zou and co-workers, that cyclic stretch indeed resulted in an Angllindependent hypertrophic response. However, we could not find any evidence that the Angll receptor type-1 is involved in the hypertrophic response of rabbit cardiomyocytes $^{2}$ (chapter 4), since the AT-1 receptor antagonists irbesartan and candesartan did not affect BNP mRNA expression in the stretched cells. The apparent discrepancy between Zou's findings ${ }^{22}$ and ours could be explained by (i) species differences: rat vs. rabbit (ii) the AT-1 antagonist applied: losartan vs irbesartan and candesartan (iii) timeframe of experiments: minutes vs. hours/days and (iv) parameter readout: protein vs. 
mRNA. Although there are notable differences between the experimental design of the study of Zou and colleagues and ours, the present findings allow us to conclude that the AT-1 receptor does not play an important role in stretch-mediated rabbit cardiomyocyte hypertrophy, since the administration of specific AT-1 antagonists did not prevent BNP expression and increase in cell surface area, compared to non-stretched control. Although we did not provide direct proof of the presence of the AT-1 receptor in rabbit cardiomyocytes, these cardiac cells most likely express an AT-1 receptor, since exposure to Angll resulted in a significant downregulation of fibronectin (FN), collagen type-I (Col-I) and Connective Tissue Growth Factor (CTGF) gene expression in rabbit cardiomyocytes (chapter 6).

An intriguing question is still how cardiomyocytes sense and transfer mechanical signals into a hypertrophic response. A number of different models have been put forward to explain the sensing of changes in stretch of cardiac muscle cells ${ }^{1,30}$. Stretch-activated ion channels in the sarcolemma are potential candidates for mechano-sensing by modulating the intracellular $\mathrm{Ca}^{2+}$ concentration. In addition, integrins and associated proteins, such and integrin-linked kinase, are thought to transmit the mechanical signal to the cytoskeleton ${ }^{1,31,32}$. Sarcolemmal nonreceptor-type tyrosine kinases have also been linked to stretch sensing. Furthermore, sarcomere-associated proteins, such as titin and melusin, have been proposed to represent molecular structures sensing cardiomyocyte deformation ${ }^{33,34}$. As discussed above, the potential hypertrophic effect of Angllindependent stimulation of the AT-1 receptor (by stretch induced conformational change of the receptor molecule) has been advocated by Zou and colleagues ${ }^{13,22}$. Subsequently, a plethora of intracellular signaling pathways has been proposed to transmit the signal from the stretch sensor to the nucleus, eventually resulting in enhanced protein synthesis, and other aspects of the hypertrophic response $\mathrm{e}^{1,35}$. The present findings, however, do not allow for identifying which sensor(s) and signaling pathways could be involved in a direct hypertrophic response.

\section{...but inhibition of hypertrophic response by Angll blockade in vivo}

In contrast to the aforementioned lack of effect of Angll on inducing hypertrophic growth in isolated cardiomyocytes and an equal lack of inhibition of stretch-induced hypertrophy by Angll-receptor blockers, we obtained indications of inhibition of regional hypertrophy in the rabbit heart in situ after three weeks of ventricular pacing by AT-1 blockade. It is known that ventricular pacing induces considerable regional differences in myocardial work and stretch, leading to local hypertrophy in the most stretched region $^{11}$. The observation that irbesartan was able to inhibit this local hypertrophy therefore appears to contradict the data from the isolated cell experiments. A possible explanation for these discrepant results is that in vivo cardiomyocytes and fibroblasts are in their natural environment, in close contact with each other and em- 
bedded by extracellular fluid and intact ECM able to transmit the biological activity of all kind of factors derived from both cell types. Support for the role of other cell types in the process of cardiomyocyte hypertrophy is provided by Harada and colleagues ${ }^{36}$, who concluded from in vitro studies that the hypertrophic response is dependent on the presence of non-cardiomyocytes in cardiomyocytes cultures. They showed that cyclic stretch of 'pure' cultures of rat neonatal cardiomyocytes did not result in a hypertrophic response, characterized by increased BNP mRNA expression. When the stretched rat neonatal cardiomyocytes were cultured in the presence of noncardiomyocytes they found a significant hypertrophic response of the stretched cardiomyocytes. The stimulatory effect could be partially inhibited by addition of the specific AT-1 blocker candesartan. This observation might imply that AT-1 receptors expressed on fibroblasts are involved in the cardiomyocyte hypertrophic response, which seems to be in accordance with our in vivo data. The theory of Harada and co-workers is strengthened by Sadoshima and colleagues, who wrote in their manuscript that: 'The experiments presented above were performed in primary culture of cardiac myocytes, which contain $5 \%$ to $10 \%$ of 'contaminating' non-myocytes, primarily fibroblast ${ }^{\prime 37}$. It is of note that all our in vitro studies were visually checked for the presence of fibroblasts, and no evidence was found regarding the presence of fibroblasts contaminating the rabbit cardiomyocyte cultures. Using conditioned media we also found some evidence that fibroblasts indeed could play a role in the in the cardiomyocyte hypertrophic process. Conditioned medium from stretched fibroblasts increased BNP expression in quiescent cardiomyocytes, strongly suggesting the presence of a paracrine acting growth factor released by the challenged fibroblasts. Unfortunately, we failed to identify the nature of the stimulating agent. Altogether these data point to the possibility that in situ, stretch of cardiomyocytes increases their endogenous production and release of biologically active factors, probably Angll, which, in turn, may prompt the release of other growth factors or cytokines from non-cardiomyocytes in the intact heart. Subsequently, these compounds may modulate the (initially stretch-induced) hypertrophic response of the neighboring cardiomyocytes, potentially mediated by matricellular proteins like CTGF.

\section{Involvement of CTGF in cardiac hypertrophy}

Hemodynamic overload is an important trigger for cardiac structural remodelling and CTGF (CCN2) is considered to be a critical modulator of this process ${ }^{38,39}$. This thesis clearly showed that cyclic stretch up regulates the CTGF expression in both cardiomyocytes and fibroblasts (chapter 5 and 6). CTGF has been associated with the development of cardiac hypertrophy, as CTGF treatment of neonatal cardiomyocytes induced cellular growth ${ }^{40}$ and mice with cardiomyocyte-specific CTGF overexpression showed age-dependent cardiomyocyte hypertrophy and cardiac dysfunction ${ }^{41}$. By contrast, a recent study of Ahmed and colleagues ${ }^{42}$ showed that cardiac restricted overexpression 
of CTGF attenuated rather than stimulated pressure-overload induced cardiac growth. However, our in vitro data are in line with the notion that CTGF might play a role in the hypertrophic response of the cardiomyocyte as suggested earlier ${ }^{40,41}$. This idea is further corroborated by recent data obtained in our laboratory from an in vivo rabbit model, where combined pressure and volume overload is induced by aortic valve regurgitation followed by abdominal aortic constriction. Twenty weeks of combined volume and pressure overload resulted in eccentric LV hypertrophy, with a $36 \%$ increase in LV internal diameter and a $50 \%$ increase in LV weight in the absence of significant changes in wall thickness and fibrosis. Myocardial CTGF mRNA levels were 5-fold higher and CTGF protein levels were substantially increased in the overloaded animals (table $3)^{43}$. The precise nature of the role of CTGF in the hypertrophic response of cardiomyocytes, however, is still elusive and subject of future studies.

Table 3: Left ventricle gene expression levels measured by qPCR in rabbits with hemodynamic overload relative to sham-operated animals, the mean expression of which was arbitrarily set at $1.0^{43}$. Abbreviations: CTGF, Connective Tissue Growth Factor; Col-I, collagen type-I; Col-III, collagen type-III.

\begin{tabular}{lccc}
\hline & Sham $(\mathbf{n}=\mathbf{3})$ & Overload $(\mathbf{n}=\mathbf{5})$ & P value \\
\hline Col-I & $1.0 \pm 0.5$ & $0.5 \pm 0.1$ & 0.049 \\
Col-III & $1.0 \pm 0.7$ & $0.4 \pm 0.1$ & 0.097 \\
CTGF & $1.0 \pm 0.3$ & $5.0 \pm 2.4$ & 0.031 \\
\hline
\end{tabular}

\section{The cellular source and initial trigger of CTGF expression}

In vitro experiments on isolated rabbit cardiac cells described in this thesis showed that the mRNA expression level of CTGF was moderately higher in cardiomyocytes compared to cardiac fibroblasts under non-stretching conditions (chapter 6). Although the relative contribution of cardiomyocytes and fibroblasts to total cardiac CTGF mRNA production cannot precisely be deduced from our data, it seems fair to conclude that both cardiomyocytes and cardiac fibroblasts substantially contribute to overall expression of CTGF in the unchallenged rabbit heart. Furthermore we revealed that stretch is a primary trigger for the induction of CTGF, particularly in cardiomyocytes. These findings suggest that under challenging conditions the cardiomyocytes importantly contribute to the sustained upregulation of CTGF in cardiac muscle. Although a direct action of stretch upon cardiomyocyte CTGF mRNA expression cannot be excluded, our data are also in favor of an autocrine action of TGF $\beta 1$ released from stretched cardiomyocytes, since stretch appeared to increase cardiomyocyte TGF $\beta 1$ expression and exposure of cardiomyocytes to this growth factor resulted in enhanced cellular CTGF mRNA levels. It is of interest to note that a positive feed-forward loop might potentiate the stimulatory TGF $\beta 1$ effect as exposure of cardiomyocytes to TGF $\beta 1$ resulted in enhanced cellular TGF $\beta 1$ mRNA expression (table 1). The existence of this putative feed-forward loop has been suggested previously by Flanders and colleagues ${ }^{44}$. Paracrine signaling from 
stretched fibroblasts might also occur since conditioned media from stretched fibroblasts elevated CTGF expression in non-stretched cardiomyocytes. Thus, the stretchinduced CTGF upregulation in cardiomyocytes may partly be mediated by the autocrine/ paracrine action of TGF $\beta 1$ induced by the stretching of both cardiomyocytes and fibroblasts as shown in chapter $4^{2}$ and the direct stimulatory effect of TGF $\beta 1$ on cardiomyocyte CTGF expression. Since conditioned media of stretched fibroblasts enhanced the expression of cardiomyocyte TGF $\beta 1$ mRNA expression (table 1), an observation corroborating earlier findings in rat neonatal fibroblasts and cardiomyocytes ${ }^{6,45}$ cardiac fibroblasts might also be able to reinforce the positive feed-forward loop of TGF $\beta 1$-induced cardiomyocyte CTGF expression ${ }^{44}$. It is of note that the presence of a positive feed-forward loop implies the existence of a mitigating factor to avoid overstimulation of the process. At present, the nature of this brake in TGF $\beta 1$-induced TGF $\beta 1$ expression remains to be elucidated.

Cyclic stretch is associated with mildly enhanced expression of CTGF in cardiac rabbit fibroblasts (chapter 5). The present data suggest that TGF $\beta 1$ might play an autocrine role in fibroblast CTGF upregulation since stretch-induced TGF $\beta 1$ expression in fibroblasts and exposure of cardiac fibroblasts to TGF $\beta 1$ increased their CTGF mRNA levels (table 2). The latter is in line with previous findings ${ }^{3,46}$. From this we concluded that stretch-mediated fibroblast CTGF expression likely involves stretch-mediated autocrine TGF $\beta 1$.

\section{STRETCH-INDUCED CARDIAC REACTIVE FIBROSIS}

\section{The effect of stretch on extracellular matrix (ECM) formation}

Under normal conditions, a balance exists between synthesis and degradation of ECM components. A misbalance favoring synthesis over degradation of ECM eventually results in cardiac fibrosis. In particular alterations in mechanical stimuli have been suggested to altering the balance of ECM production and degradation in the heart ${ }^{32,47-49}$. At present, it is generally accepted from in vitro studies with neonatal rat cardiac fibroblasts, that fibroblasts are the main source of myocardial ECM proteins, such as collagen-I, collagen-III and non-collagen proteins such as Fibronectin ${ }^{50,51}$. Our study indicates that, with respect to the mRNA expression of collagens, this also holds for rabbit heart fibroblasts (chapter 5 ).

In this thesis we focused on stretch-induced cardiac remodelling as a model for myocardial overload. Many forms of cardiac overload are associated with reactive interstitial fibrosis. This type of fibrosis is characterised by, among others, enhanced deposition of collagen type-I and collagen type- $\mathrm{III}^{52}$. However, in contrast to our expectations the in vitro studies described in chapter 5 indicated that cyclic stretch reduces the transcription of collagen type-I and type-III in rabbit fibroblasts. This finding op- 
poses those in previous studies, where an increase rather than a decline in collagen type-I and type-III mRNA expression was found in challenged neonatal rat fibroblasts ${ }^{53}$. At present, no explanation is at hand for the conflicting findings. However, our findings of downregulation of collagen in stretched isolated fibroblasts are also corroborated by the data from the combined pressure-volume overload rabbit model (table 3 ). The phenotype of this model is predominantly eccentric hypertrophy, suggesting that the volume overload dominates. Indeed, in volume overload hypertrophy fibrosis is not a common finding ${ }^{54,55}$.

Differences between pressure and volume overload hypertrophy may be understood by considering differences in sensing of the mechanical stimulus. The various ECM and intramyocyte structures, that all may respond to stretch may be triggered under different loading conditions, that is, depending on at what fiber stress these fibers are stretched. In the completely relaxed state, as in volume overload, stretch may be predominantly translated into stretch of the actin-myosin apparatus, whereas stretch under higher stresses may be sensed more in the Z-lines and ECM, thus leading to different signaling and ultimately phenotype ${ }^{1}$.

\section{Involvement of autocrine and paracrine factors in stretch-induced collagen expression}

The stretch-induced fibrotic response is believed to depend on the production of stretch-mediated growth factors, which are supposed to modulate collagen transcription $^{56}$. We found that stretch is a trigger for fibroblasts to increase their production of the growth factors TGF $\beta 1$ and IGF-1, which is in line with previous findings ${ }^{50}$. However, we found no evidence that these factors were responsible for the decrease in collagen mRNA expression in stretched fibroblasts. Moreover, Pathak et al. showed that cardiomyocytes affect collagen production via cross talk with cardiac fibroblasts ${ }^{57}$, indicating that cardiomyocytes are able to regulate ECM remodelling indirectly via the production of paracrine factors, such as interleukine-6 (IL-6) and tumor necrosis factor-alpha $(\mathrm{TNF} \alpha)^{58}$. Our studies with conditioned medium from stretched cardiomyocytes did not support the notion of paracrine action of growth factors released by cardiomyocytes on fibroblast collagen production. The explanation for the deviant findings is subject for future investigation.

\section{Potential role of CTGF in cardiac fibrosis}

In a recent review CTGF was described to play a crucial role in promoting renal fibrosis and circumstantial evidence was brought forward that CTGF also acts as stimulatory factor in the induction of cardiac fibrosis ${ }^{3}$. Moreover, increased CTGF expression is being used as a marker for fibrotic remodelling ${ }^{59}$. The data in chapter 5 clearly show that stretch-induced upregulation of CTGF and TGF $\beta$ expression in isolated cardiac fibroblasts did not coincide with enhanced expression of collagen type-I and type-III. 
Moreover, in hemodynamically overloaded rabbits in vivo, cardiac collagen type-I and type-III tended to decrease in conjunction with an unchanged degree of fibrosis while the expression of cardiac CTGF, both on the level of mRNA and protein, was substantially increased (table 3$)^{43}$. Our findings therefore indicate that the functional relationship of cardiac CTGF and ECM formation is still enigmatic and should be explored in more detail.

The generally accepted notion that CTGF could be a functional intermediate in cardiac fibrosis is mainly based on the molecular structure, extracellular position and recently identified properties of CTGF. CTGF contains four modules, positioned in close vicinity of the outer leaflet of the cellular membrane ${ }^{3}$. In this respect CTGF can be considered as a matricellular protein modulating the activity of growth factors in the interstitial compartment by interacting with the signal transduction to the cell membrane. A direct interaction of CTGF with specific receptors in the cell membrane has not been demonstrated. Therefore, it is less likely that CTGF acts as a signal transducing agent on its own right. The first module of the CTGF molecule interacts with the pro-fibrotic signaling of IGF-1. The second and third module is thought to modulate the biological activity of TGF $\beta^{3}$. Since the latter growth factor has been shown to exert pro-fibrotic effects, it has been postulated that also in the heart CTGF plays a prominent, albeit indirect, role in the onset and progression of myocardial fibrosis. The present observation that stretch induces CTGF expression in cardiac cells in conjunction with increased TGF $\beta$ expression indeed points to a mediating action of CTGF under challenging conditions. Moreover, TGF1 stimulated CTGF expression in fibroblasts (chapter 5), thus supporting the hypothesis of Daniels and colleagues (2009) ${ }^{3}$ that a vicious circle may ensue in which TGF $\beta$ and CTGF exert a positively feedback on each other, leading to detrimental ECM deposition and eventually resulting in cardiac fibrosis and dysfunction.

\section{Future perspectives}

Despite enhanced understanding of mechanical load-induced cardiac remodelling and its unfavourable consequences on cardiac hemodynamic function during the past decade, information on details of this process and the ultimate nature of triggers, signalling pathways and target genes involved is still incomplete. In the present thesis attempts have been made to shed new light on this intriguing and clinically relevant subject.

Various important issues remain to be explored. Since evidence is accumulating that cross-talk between various cell types in the challenged heart does play a role in cardiac remodelling, in vitro experiments of stretched cardiomyocytes in co-culture not only with cardiac fibroblasts, but also with vascular endothelial and smooth muscle cells should be performed. Proteomic analysis of supernatants of the stretched cells will provide detailed information on the secretome of the cells under investigation. Proteomic analysis of interstitial fluid of the intact challenged heart will allow for extrapo- 
lation of in vitro to in vivo findings. Second, the biological activity of potential candidates for autocrine/paracrine action in cardiac remodelling should be subsequently investigated by use of specific neutralizing antibodies or pharmacological blockade of relevant signalling pathways both in vitro and in vivo; iii) the nature of the interrelationship, if any, between cardiac hypertrophy and increased deposition of ECM material (fibrosis) requires further experimentation; iv) various models of cardiac remodelling should be included to discriminate between remodelling processes involved in pressure and volume overload hypertrophy and pathological and physiological remodelling, and the specific role of the various growth factors therein. Studies in isolated cardiomyocytes in the Flexcell system could be adapted in this regard by applying different combination of stretch and electrical stimulation, so that stretch is also applied in contracting cardiomyocytes.

\section{CONCLUSIONS}

Our efforts in unraveling the role of cellular stretch in the process of cardiac hypertrophy and fibrosis have yielded a number of new insights. We described for the first time that cyclic stretch is capable to induce a hypertrophic response in rabbit cardiomyocytes. This stretch-mediated hypertrophic response is independent of Angll and AT-1. Both cardiomyocytes and fibroblasts seem to play a role in ECM remodelling. In addition, both cardiomyocytes and fibroblasts are a source for CTGF and stretch is an important trigger for CTGF induction in both cell types. Our data support the idea that in the adult heart cardiomyocytes and fibroblasts communicate via stretch-mediated paracrine factors to give rise to cardiac hypertrophy and ECM formation. From findings in this thesis the cautious conclusion can be drawn that IGF-1 is not one of these stretch-mediated factors. Further research is warranted to understand the role of AngII, TGF $\beta 1$ and CTGF in stretch-mediated hypertrophy and ECM remodelling in vivo and in vitro. New insights in the mechanisms underlying the response of cardiac cells to increased stretch could help to find new therapeutic targets or improve treatment for pathological cardiac remodelling. 


\section{REFERENCES}

1. Ruwhof C, van der Laarse A. Mechanical stress-induced cardiac hypertrophy: mechanisms and signal transduction pathways. Cardiovasc Res. 2000;47(1):23-37.

2. Blaauw E, van Nieuwenhoven FA, Willemsen $P$, Delhaas $T$, Prinzen FW, Snoeckx LH, van Bilsen M, van der Vusse GJ. Stretch-induced hypertrophy of isolated adult rabbit cardiomyocytes. Am J Physiol Heart Circ Physiol. 2010;299(3):H780-787.

3. Daniels A, van Bilsen M, Goldschmeding R, van der Vusse GJ, van Nieuwenhoven FA. Connective tissue growth factor and cardiac fibrosis. Acta Physiol (Oxf). 2009;195(3):321-338.

4. Gupta V, Grande-Allen KJ. Effects of static and cyclic loading in regulating extracellular matrix synthesis by cardiovascular cells. Cardiovasc Res. 2006;72(3):375-383.

5. Wakatsuki T, Schlessinger J, Elson EL. The biochemical response of the heart to hypertension and exercise. Trends Biochem Sci. 2004;29(11):609-617.

6. Ruwhof $C$, van Wamel AE, Egas JM, van der Laarse A. Cyclic stretch induces the release of growth promoting factors from cultured neonatal cardiomyocytes and cardiac fibroblasts. Mol Cell Biochem. 2000;208(1-2):89-98.

7. Sadoshima J, Izumo S. Mechanical stretch rapidly activates multiple signal transduction pathways in cardiac myocytes: potential involvement of an autocrine/paracrine mechanism. The EMBO journal. 1993;12(4):1681-1692.

8. Kudoh S, Komuro I, Hiroi Y, Zou Y, Harada K, Sugaya T, Takekoshi N, Murakami K, Kadowaki T, Yazaki Y. Mechanical stretch induces hypertrophic responses in cardiac myocytes of angiotensin II type 1a receptor knockout mice. J Biol Chem. 1998;273(37):24037-24043.

9. Lal H, Verma SK, Golden HB, Foster DM, Smith M, Dostal DE. Stretch-induced regulation of angiotensinogen gene expression in cardiac myocytes and fibroblasts: opposing roles of JNK1/2 and p38alpha MAP kinases. J Mol Cell Cardiol. 2008;45(6):770-778.

10. Prinzen FW, Hunter WC, Wyman BT, McVeigh ER. Mapping of regional myocardial strain and work during ventricular pacing: experimental study using magnetic resonance imaging tagging. J Am Coll Cardiol. 1999;33(6):1735-1742.

11. van Oosterhout MF, Prinzen FW, Arts T, Schreuder JJ, Vanagt WY, Cleutjens JP, Reneman RS. Asynchronous electrical activation induces asymmetrical hypertrophy of the left ventricular wall. Circulation. 1998;98(6):588-595.

12. Yamamoto K, Dang QN, Maeda Y, Huang H, Kelly RA, Lee RT. Regulation of cardiomyocyte mechanotransduction by the cardiac cycle. Circulation. 2001;103(10):1459-1464.

13. Zhou N, Li L, Wu J, Gong H, Niu Y, Sun A, Ge J, Zou Y. Mechanical stress-evoked but angiotensin IIindependent activation of angiotensin II type 1 receptor induces cardiac hypertrophy through calcineurin pathway. Biochem Biophys Res Commun. 2010;397(2):263-269.

14. Leychenko A, Konorev E, Jijiwa M, Matter ML. Stretch-induced hypertrophy activates NFkB-mediated VEGF secretion in adult cardiomyocytes. PLoS One. 2011;6(12):e29055.

15. Sadoshima J, Jahn L, Takahashi T, Kulik TJ, Izumo S. Molecular characterization of the stretch-induced adaptation of cultured cardiac cells. An in vitro model of load-induced cardiac hypertrophy. J Biol Chem. 1992;267(15):10551-10560.

16. van Wamel JE, Ruwhof C, van der Valk-Kokshoorn EJ, Schrier PI, van der Laarse A. Rapid gene transcription induced by stretch in cardiac myocytes and fibroblasts and their paracrine influence on stationary myocytes and fibroblasts. Pflugers Arch. 2000;439(6):781-788.

17. Parker TG, Packer SE, Schneider MD. Peptide growth factors can provoke "fetal" contractile protein gene expression in rat cardiac myocytes. J Clin Invest. 1990;85(2):507-514.

18. Villarreal FJ, Lee AA, Dillmann WH, Giordano FJ. Adenovirus-mediated overexpression of human transforming growth factor-beta 1 in rat cardiac fibroblasts, myocytes and smooth muscle cells. $J$ Mol Cell Cardiol. 1996;28(4):735-742. 
19. Horio T, Maki T, Kishimoto I, Tokudome T, Okumura H, Yoshihara F, Suga S, Takeo S, Kawano Y, Kangawa K. Production and autocrine/paracrine effects of endogenous insulin-like growth factor-1 in rat cardiac fibroblasts. Regulatory peptides. 2005;124(1-3):65-72.

20. van Wamel AJ, Ruwhof C, van der Valk-Kokshoom LE, Schrier PI, van der Laarse A. The role of angiotensin II, endothelin-1 and transforming growth factor-beta as autocrine/paracrine mediators of stretchinduced cardiomyocyte hypertrophy. Mol Cell Biochem. 2001;218(1-2):113-124.

21. Yamazaki T, Komuro I, Kudoh S, Zou Y, Shiojima I, Mizuno T, Takano H, Hiroi Y, Ueki K, Tobe K, et al. Angiotensin II partly mediates mechanical stress-induced cardiac hypertrophy. Circ Res. 1995;77(2):258-265.

22. Zou Y, Akazawa H, Qin Y, Sano M, Takano H, Minamino T, Makita N, Iwanaga K, Zhu W, Kudoh S, Toko H, Tamura K, Kihara M, Nagai T, Fukamizu A, Umemura S, liri T, Fujita T, Komuro I. Mechanical stress activates angiotensin II type 1 receptor without the involvement of angiotensin II. Nature cell biology. 2004;6(6):499-506.

23. van Kesteren CA, van Heugten HA, Lamers JM, Saxena PR, Schalekamp MA, Danser AH. Angiotensin IImediated growth and antigrowth effects in cultured neonatal rat cardiac myocytes and fibroblasts. $J \mathrm{Mol}$ Cell Cardiol. 1997;29(8):2147-2157.

24. van Kesteren CA, Saris JJ, Dekkers DH, Lamers JM, Saxena PR, Schalekamp MA, Danser AH. Cultured neonatal rat cardiac myocytes and fibroblasts do not synthesize renin or angiotensinogen: evidence for stretch-induced cardiomyocyte hypertrophy independent of angiotensin II. Cardiovasc Res. 1999;43(1):148-156.

25. Sil P, Sen S. Angiotensin II and myocyte growth: role of fibroblasts. Hypertension. 1997;30(2 Pt 1):209-216.

26. Sadoshima J, Izumo S. Molecular characterization of angiotensin Il--induced hypertrophy of cardiac myocytes and hyperplasia of cardiac fibroblasts. Critical role of the AT1 receptor subtype. Circ Res. 1993;73(3):413-423.

27. Reudelhuber TL, Bernstein KE, Delafontaine P. Is angiotensin II a direct mediator of left ventricular hypertrophy? Time for another look. Hypertension. 2007;49(6):1196-1201.

28. Xiao HD, Fuchs S, Bernstein EA, Li P, Campbell DJ, Bernstein KE. Mice expressing ACE only in the heart show that increased cardiac angiotensin II is not associated with cardiac hypertrophy. Am J Physiol Heart Circ Physiol. 2008;294(2):H659-667.

29. Wenzel S, Abdallah Y, Helmig S, Schafer C, Piper HM, Schluter KD. Contribution of PI 3-kinase isoforms to angiotensin II- and alpha-adrenoceptor-mediated signalling pathways in cardiomyocytes. Cardiovasc Res. 2006;71(2):352-362.

30. Sadoshima J, Izumo S. Mechanotransduction in stretch-induced hypertrophy of cardiac myocytes. J Recept Res. 1993;13(1-4):777-794.

31. Lammerding J, Kamm RD, Lee RT. Mechanotransduction in cardiac myocytes. Ann $N$ Y Acad Sci. 2004;1015:53-70.

32. MacKenna D, Summerour SR, Villarreal FJ. Role of mechanical factors in modulating cardiac fibroblast function and extracellular matrix synthesis. Cardiovasc Res. 2000;46(2):257-263.

33. Linke WA. Sense and stretchability: the role of titin and titin-associated proteins in myocardial stresssensing and mechanical dysfunction. Cardiovasc Res. 2008;77(4):637-648.

34. Samarel AM. Costameres, focal adhesions, and cardiomyocyte mechanotransduction. Am J Physiol Heart Circ Physiol. 2005;289(6):H2291-2301.

35. Tavi $\mathrm{P}$, Laine $\mathrm{M}$, Weckstrom $\mathrm{M}$, Ruskoaho $\mathrm{H}$. Cardiac mechanotransduction: from sensing to disease and treatment. Trends Pharmacol Sci. 2001;22(5):254-260.

36. Harada M, Saito Y, Nakagawa O, Miyamoto Y, Ishikawa M, Kuwahara K, Ogawa E, Nakayama M, Kamitani S, Hamanaka I, Kajiyama N, Masuda I, Itoh H, Tanaka I, Nakao K. Role of cardiac nonmyocytes in cyclic mechanical stretch-induced myocyte hypertrophy. Heart and vessels. 1997;Suppl 12:198-200.

37. Sadoshima J, Izumo S. Signal transduction pathways of angiotensin II--induced c-fos gene expression in cardiac myocytes in vitro. Roles of phospholipid-derived second messengers. Circ Res. 1993;73(3):424438.

38. Bornstein P, Sage EH. Matricellular proteins: extracellular modulators of cell function. Curr Opin Cell Biol. 2002;14(5):608-616. 
39. White ES, Baralle FE, Muro AF. New insights into form and function of fibronectin splice variants. J Pathol. 2008;216(1):1-14.

40. Hayata N, Fujio Y, Yamamoto Y, Iwakura T, Obana M, Takai M, Mohri T, Nonen S, Maeda M, Azuma J. Connective tissue growth factor induces cardiac hypertrophy through Akt signaling. Biochem Biophys Res Commun. 2008;370(2):274-278.

41. Panek AN, Posch MG, Alenina N, Ghadge SK, Erdmann B, Popova E, Perrot A, Geier C, Dietz R, Morano I, Bader M, Ozcelik C. Connective tissue growth factor overexpression in cardiomyocytes promotes cardiac hypertrophy and protection against pressure overload. PLoS One. 2009;4(8):e6743.

42. Ahmed MS, Gravning J, Martinov VN, von Lueder TG, Edvardsen T, Czibik G, Moe IT, Vinge LE, Oie E, Valen G, Attramadal H. Mechanisms of novel cardioprotective functions of CCN2/CTGF in myocardial ischemia-reperfusion injury. Am J Physiol Heart Circ Physiol. 2011;300(4):H1291-1302.

43. Blaauw E. Stretch-induced upregulation of connective tissue growth factor in rabbit heart. submitted for publication. 2012.

44. Flanders KC, Holder MG, Winokur TS. Autoinduction of mRNA and protein expression for transforming growth factor-beta S in cultured cardiac cells. J Mol Cell Cardiol. 1995;27(2):805-812.

45. van Wamel AJ, Ruwhof C, van der Valk-Kokshoorn LJ, Schrier PI, van der Laarse A. Stretch-induced paracrine hypertrophic stimuli increase TGF-beta1 expression in cardiomyocytes. Mol Cell Biochem. 2002;236(1-2):147-153.

46. Farhadian F, Contard F, Corbier A, Barrieux A, Rappaport L, Samuel JL. Fibronectin expression during physiological and pathological cardiac growth. J Mol Cell Cardiol. 1995;27(4):981-990.

47. Rosenkranz S. TGF-beta1 and angiotensin networking in cardiac remodeling. Cardiovasc Res. 2004;63(3):423-432.

48. Banerjee I, Yekkala K, Borg TK, Baudino TA. Dynamic interactions between myocytes, fibroblasts, and extracellular matrix. Ann N Y Acad Sci. 2006;1080:76-84

49. Heineke J, Molkentin JD. Regulation of cardiac hypertrophy by intracellular signalling pathways. Nat Rev Mol Cell Biol. 2006;7(8):589-600.

50. Eghbali M, Tomek R, Sukhatme VP, Woods C, Bhambi B. Differential effects of transforming growth factor-beta 1 and phorbol myristate acetate on cardiac fibroblasts. Regulation of fibrillar collagen mRNAs and expression of early transcription factors. Circ Res. 1991;69(2):483-490.

51. Weber KT. Cardiac interstitium in health and disease: the fibrillar collagen network. Journal of the American College of Cardiology. 1989;13(7):1637-1652.

52. Fan D, Takawale A, Lee J, Kassiri Z. Cardiac fibroblasts, fibrosis and extracellular matrix remodeling in heart disease. Fibrogenesis Tissue Repair. 2012;5(1):15

53. Carver W, Nagpal ML, Nachtigal M, Borg TK, Terracio L. Collagen expression in mechanically stimulated cardiac fibroblasts. Circ Res. 1991;69(1):116-122.

54. Benes J, Jr., Melenovsky V, Skaroupkova P, Pospisilova J, Petrak J, Cervenka L, Sedmera D. Myocardial morphological characteristics and proarrhythmic substrate in the rat model of heart failure due to chronic volume overload. Anat Rec (Hoboken). 2011;294(1):102-111.

55. Piper C, Schultheiss HP, Akdemir D, Rudolf J, Horstkotte D, Pauschinger M. Remodeling of the cardiac extracellular matrix differs between volume- and pressure-overloaded ventricles and is specific for each heart valve lesion. J Heart Valve Dis. 2003;12(5):592-600.

56. Chiquet $M$, Renedo AS, Huber F, Fluck M. How do fibroblasts translate mechanical signals into changes in extracellular matrix production? Matrix Biol. 2003;22(1):73-80.

57. Pathak M, Sarkar S, Vellaichamy E, Sen S. Role of myocytes in myocardial collagen production. Hypertension. 2001;37(3):833-840.

58. Sarkar S, Vellaichamy E, Young D, Sen S. Influence of cytokines and growth factors in ANG II-mediated collagen upregulation by fibroblasts in rats: role of myocytes. Am J Physiol Heart Circ Physiol. 2004;287(1):H107-117

59. D'Souza A, Howarth FC, Yanni J, Dobryznski H, Boyett MR, Adeghate E, Bidasee KR, Singh J. Left ventricle structural remodelling in the prediabetic Goto-Kakizaki rat. Exp Physiol. 2011;96(9):875-888. 


\section{Addendum I}

\section{Materials for cardiomyocyte and fibroblast isolation}

\begin{tabular}{|c|c|c|}
\hline Materials & Order number & Company \\
\hline Ketamine & 69208 & $\begin{array}{l}\text { Eurovet Animal Health B.V., Bladel, the Nether- } \\
\text { lands }\end{array}$ \\
\hline Xylazine & 06L06 & $\begin{array}{l}\text { Produlab Pharma, Raamsdonksveer, the Nether- } \\
\text { lands }\end{array}$ \\
\hline Heparin & DC0952 & Leo Pharma B.V., Breda, the Netherlands \\
\hline $\begin{array}{l}\text { Bottle Top low binding filter (pore size } \\
0.22 \mu \mathrm{M})\end{array}$ & 431118 & Costar Europe \\
\hline Bovine Serum Albumine, fraction $\mathrm{V}$ & 10735086011 & Roche Diagnostics, Mannheim, Germany \\
\hline Collagenase type II & $\begin{array}{l}45 \mathrm{E} 8058 \text { and } \\
47 \mathrm{~A} 9405\end{array}$ & Worthington, Lakewood, USA \\
\hline Nylon Gauze $=$ ES Kompressen & 401515 & Paul Hartmann, Nijmegen, Netherlands \\
\hline Laminin & 23017-015 & Invitrogen, Breda, the Netherlands \\
\hline Medium 199 & 31153 & Gibco \\
\hline Fetal Bovine Serum & 10270-106 & Gibco \\
\hline BioFlex plates & BF-3001-C & Flexcell ${ }^{\circledR}$ International Corp., Hillsborough, USA \\
\hline $\begin{array}{l}\text { Porcine Pancreas Insulin } \\
(26.8 \mathrm{U} / \mathrm{mg})\end{array}$ & $12584-58-6$ & INC Biomedicals Inc., Ohio, USA \\
\hline Penicillin/Streptomyocin & 15140 & Gibco \\
\hline Gentamicin & $1575-037$ & Gibco \\
\hline cytosine-1- $\beta$-D-arabinofuranoside & C-1768 & Sigma \\
\hline L-carnitine & C-0283 & Sigma \\
\hline $\mathrm{NaCl}$ & 1.05833 & Merck \\
\hline $\mathrm{KCl}$ & 1.04936 & Merck \\
\hline $\mathrm{MgCl}_{2} \bullet 6 \mathrm{H}_{2} \mathrm{O}$ & 1.05833 & Merck \\
\hline $\mathrm{NaH}_{2} \mathrm{PO}_{4} \bullet \mathrm{H}_{2} \mathrm{O}$ & 1.06346 & Merck \\
\hline$D(+)$-glucose & 1.04074 & Merck \\
\hline HEPES & $\mathrm{H} 4034$ & Sigma \\
\hline Taurine & 8.08616 & Merck \\
\hline Creatine & 1.05208 & Merck \\
\hline $\mathrm{CaCl}_{2} \bullet 2 \mathrm{H}_{2} \mathrm{O}$ & 1.02382 & Merck \\
\hline BDM & B0753 & Sigma \\
\hline Watson Marlow pump & Type $501 U$ & Watson Marlow , Fallmouth, Cornwall, England \\
\hline Water pump unit & 80796 & HAAKE, Berlin, Germany \\
\hline DMEM & 22320 & Gibco \\
\hline trypsin-EDTA & 25200 & Gibco \\
\hline $\begin{array}{l}75 \mathrm{~cm}^{2} \text { plastic cell culture flask with } \\
\text { ventilation Cap }\end{array}$ & 430720 & Corning Inc., NY, USA \\
\hline
\end{tabular}




\section{Composition of the isolation solutions KH-A and KH-B}

Table 1: Composition of Krebs-Henseleit buffer A.

\begin{tabular}{llll}
\hline Compound & Molecular Weight & Final concentration & $\begin{array}{l}\text { For } \mathbf{1} \text { isolation } \mathbf{1} \mathbf{L} \text { KH-A } \\
\text { is needed }\end{array}$ \\
\hline $\mathrm{NaCl}$ & 58.44 & $133 \mathrm{mM}$ & $7.8 \mathrm{~g}$ \\
$\mathrm{KCl}$ & 74.55 & $5 \mathrm{mM}$ & $0.37 \mathrm{~g}$ \\
$\mathrm{MgCl} \cdot 6 \mathrm{H}_{2} \mathrm{O}$ & 203.3 & $2 \mathrm{mM}$ & $0.41 \mathrm{~g}$ \\
$\mathrm{NaH}_{2} \mathrm{PO}_{4} \bullet \mathrm{H}_{2} \mathrm{O}$ & 137.99 & $1.2 \mathrm{mM}$ & $0.17 \mathrm{~g}$ \\
$\mathrm{D}(+)-\mathrm{glucose}_{\mathrm{HEPSS}}$ & 198.17 & $10 \mathrm{mM}$ & $1.98 \mathrm{~g}$ \\
Taurine & 238.31 & $10 \mathrm{mM}$ & $2.38 \mathrm{~g}$ \\
$\mathrm{Creatine}$ & 125.15 & $6 \mathrm{mM}$ & $0.75 \mathrm{~g}$ \\
$\mathrm{CaCl}$ & 113.12 & $6 \mathrm{mM}$ & $0.68 \mathrm{~g}$ \\
\hline
\end{tabular}

** from $100 \mathrm{mM} \mathrm{CaCl}_{2} \bullet 2 \mathrm{H}_{2} \mathrm{O}$ stock solution

Table 2: Composition of Krebs-Henseleit buffer B.

\begin{tabular}{|c|c|c|c|}
\hline Compound & Molecular Weight & Final concentration & $\begin{array}{l}\text { For } 1 \text { isolation } 0.5 \text { L KH-B } \\
\text { is needed }\end{array}$ \\
\hline $\mathrm{NaCl}$ & 58.44 & $120 \mathrm{mM}$ & $3.5 \mathrm{~g}$ \\
\hline $\mathrm{KCl}$ & 74.55 & $5 \mathrm{mM}$ & $0.19 \mathrm{~g}$ \\
\hline $\mathrm{MgCl}_{2} \bullet 6 \mathrm{H}_{2} \mathrm{O}$ & 203.3 & $2 \mathrm{mM}$ & $0.20 \mathrm{~g}$ \\
\hline $\mathrm{NaH}_{2} \mathrm{PO}_{4} \bullet \mathrm{H}_{2} \mathrm{O}$ & 137.99 & $1.2 \mathrm{mM}$ & $0.08 \mathrm{~g}$ \\
\hline $\mathrm{D}(+)$-glucose & 198.17 & $10 \mathrm{mM}$ & $1.00 \mathrm{~g}$ \\
\hline HEPES & 238.31 & $10 \mathrm{mM}$ & $1.19 \mathrm{~g}$ \\
\hline Taurine & 125.15 & $6 \mathrm{mM}$ & $0.38 \mathrm{~g}$ \\
\hline Creatine & 113.12 & $6 \mathrm{mM}$ & $0.34 \mathrm{~g}$ \\
\hline $\mathrm{CaCl}_{2} \cdot 2 \mathrm{H}_{2} \mathrm{O}$ & 147.02 & $10 \mu \mathrm{M}$ & $50 \mu \mathrm{L}^{* *}$ \\
\hline BSA & - & $1 \% w / v$ & $5.0 \mathrm{~g}$ \\
\hline BDM & 101.11 & $20 \mathrm{mM}$ & $1.01 \mathrm{~g}$ \\
\hline
\end{tabular}

** from $100 \mathrm{mM} \mathrm{CaCl}{ }_{2} \bullet 2 \mathrm{H}_{2} \mathrm{O}$ stock solution 


\section{Addendum II}

\section{Chapter 3. Calculation of dilution factors of conditioned medium}

\section{A. Cardiomyocytes in vitro}

Experimental conditions:

- Culture dish with a diameter of $35 \mathrm{~mm}(r=17.5 \mathrm{~mm})$

- $2 \mathrm{ml}$ of supernatant

- In case of "conditioned medium" experiment (see chapter 5), the conditioned medium is diluted 1:1 with normal culture medium.

\section{Assumptions and facts:}

- Cardiomyocyte (CMC) height: 18 micron $=0.018 \mathrm{~mm}$ (see data chapter 3 )

- Coverage of CMC in a culture dish is approximately 70\%

\section{Calculation of dilution factor:}

- Culture dish surface was calculated using the formula: $\pi \cdot r^{2}=3.14 \times(17.5)^{2}=960 \mathrm{~mm}^{2}$

- CMC with a height of $0.018 \mathrm{~mm}$ and assumed dish coverage of $70 \%$. Total volume of the cultured CMCs was calculated: $0.7 \times 0.018 \times 960 \mathrm{~mm}^{3}=12 \mathrm{~mm}^{3}=0.012 \mathrm{ml}$

- Ratio of CMC volume to supernatant volume amounts: $0.012: 2.0=1: 166$

- In vivo, the ratio of CMC volume over interstitial fluid (ISF) volume is $3.9: 1$ (reference: Vinnakota and Bassingthwaighte ${ }^{1}$ ). The difference between the in vitro and in vivo dilution factor is: $3.9 \times 166=646$ times

- In the "conditioned medium" experiments, the conditioned medium is $1: 1$ diluted with normal culture medium. This resulted in an extra dilution factor of 2 .

Conclusion: stretch-released growth factors released in vitro by rabbit cardiomyocytes are at least 600 times more diluted than the in vivo situation. 


\section{Fibroblasten in vitro}

Experimental conditions:

- Culture dish with a diameter of $35 \mathrm{~mm}$

- $2 \mathrm{ml}$ of supernatant

- In case of "conditioned medium" experiments (see chapter 6), the conditioned medium is diluted 1:1 with normal culture medium.

\section{Assumptions and facts:}

- Cardiac fibroblast (FB) height: 9.8 micron $=0.0098 \mathrm{~mm}$. (The estimated fibroblast

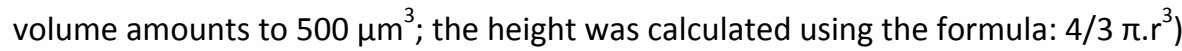

- Coverage of FB in a culture dish is approximately $70 \%$

- FB volume in vivo is $2 \%$ of total heart volume, hence the volume ratio FB vs ISF volume is $1: 8.35$

\section{Calculation dilution factor:}

- Culture dish surface was calculated using the formula: $\pi \cdot r^{2}=3.14 \times(17.5)^{2}=960 \mathrm{~mm}^{2}$ - $\quad$ From the FB height of $0.0098 \mathrm{~mm}$ and a dish coverage of $70 \%$, the total volume of the cultured FB was calculated: $0.7 \times 0.0098 \times 960 \mathrm{~mm}^{3}=6.6 \mathrm{~mm}^{3}=0.0066 \mathrm{ml}$

- Therefore, the ratio of FB volume over supernatant volume is: $0.0066: 2.0=1: 303$

- In vivo, the ratio of FB volume over ISF volume ratio is $1: 8.35$ (reference: Vinnakota and Bassingthwaighte ${ }^{1}$ ). The difference between the in vitro and in vivo dilution factor is: $303 / 8.35=36$ times

- In the "conditioned medium" experiment, the conditioned medium is $1: 1$ diluted with normal culture medium. This resulted in extra dilution factor of 2.

Conclusion: stretch-released growth factors by fibroblasts in vitro are at least $2 \times 36=$ 72 times more diluted compared to the in vivo situation.

\section{REFERENCE}

1. Vinnakota KC, Bassingthwaighte JB. Myocardial density and composition: a basis for calculating intracellular metabolite concentrations. Am J Physiol Heart Circ Physiol. 2004;286(5):H1742-1749. 


\section{List of abbreviations}

\begin{tabular}{|c|c|}
\hline$\alpha-\mathrm{MHC}$ & alpha-Myosin Heavy Chain \\
\hline ACE & Angiotensin Converting Enzyme \\
\hline ANF & Atrial Natriuretic Factor \\
\hline Angll & Angiotensin II \\
\hline AraC & cytosine-1- $\beta-D-A r a b i n o f u r a n o s i d e$ \\
\hline AT-1 & Angiotensin II receptor Type-1 \\
\hline$\beta-\mathrm{MHC}$ & beta-Myosin Heavy Chain \\
\hline BNP & Brain Natriuretic Protein \\
\hline BP & Blood Pressure \\
\hline C & control \\
\hline Can & Candesartan \\
\hline $\mathrm{CM}$ & Conditioned Medium \\
\hline CMC & cardiomyocytes \\
\hline Col-I & collagen type-I \\
\hline Col-III & collagen type-III \\
\hline CTGF & Connective Tissue Growth Factor \\
\hline cyclo & Cyclophilin-A \\
\hline ECM & Extracellular Matrix \\
\hline EF & Ejection Fraction \\
\hline ERK & Extracellular signal Regulated Kinase \\
\hline ET-1 & Endothelin-1 \\
\hline FB & Fibroblast \\
\hline FBS & Fetal Bovine Serum \\
\hline FN & Fibronectin \\
\hline FS & Fractional Shortening \\
\hline GSK & Glycogen Synthase Kinase \\
\hline HF & Heart Failure \\
\hline IGF-1 & Insulin-like Growth Factor-1 \\
\hline IGFBPs & Insulin-like Growth Factor Binding Proteins \\
\hline IPC & Intrapericardial Infusion \\
\hline Irb & Irbesartan \\
\hline IRS & Insulin Receptor Substrate \\
\hline
\end{tabular}


IVS

JAK

JNK

LBBB

LV

LVH

MAP

MAPK

MMPs

OMP

$\mathbf{P}$

PCF

PW

qPCR

RAS

RV

$S$

SAPK

SC

SD

SEM

SOLV

STAT

TGF $\beta 1$

TIMPs

B-MHC

intraventricular septum

Janus-associated kinases

c-Jun $\mathrm{NH}_{2}$-terminal kinase

Left Bundle Branch Block

Left Ventricle

Left Ventricle Hypertrophy

Mean Arterial Pressure

Mitogen-Activated Protein Kinase

Matrix Metalloproteinases

Osmotic Mini Pump

pacing

pericardial fluid

Posterior Wall

quantitative real time Polymerase Chain Reaction

Renin-Angiotensin System

Right Ventricle

stretch

Stress-Activated Protein Kinase

subcutaneous

Standard Deviation

Standard Error of the Mean

Solvent

Signal Transducers and Activators of Transcription

Transforming Growth Factor $\beta 1$

Tissue Inhibitors of Metalloproteinases

beta-Myosin Heavy Chain 


\section{Summary}

Overload of the heart due to systemic hypertension or valvular defects often results in enlargement of cardiomyocytes (hypertrophy) and increase in connective tissue (fibrosis) of the cardiac muscle. Chapter 1 provides a summary of the goals of the research presented in this thesis. One of the main objectives of this thesis was to investigate which trigger is primarily responsible for the development of cardiac hypertrophy and fibrosis in vitro and in vivo: mechanical strain (physical load) and / or growth factors (biochemical compounds).

In Chapter 2, the current scientific literature on the effects of mechanical stress (strain) and growth factors on the processes of cardiac hypertrophy and fibrosis is summarized. Specifically the possible involvement of angiotensin II (AngII), Insulin-like Growth Factor-1 (IGF-1) and Transforming Growth Factor-beta (TGF $\beta$ ) therein is described. These three factors can be produced as both autocrine (produced by the same cell type, whereon it also exerts a biological effect) as paracrine produced by cell type $A$, but with a biological effect on cell type $B$, which is situated in the vicinity of the producing cell) factor. Furthermore, a description was given how cardiomyocytes and fibroblasts possibly detect changes in hemodynamic loading, and how they convert mechanical signals in intracellular biochemical signals. The conclusion of chapter 2 is that it is still unclear which activator (mechanical or biochemical) is primarily responsible for initiation of the hypertrophic process. This uncertainty seems partly be caused by the fact that most research has been done on neonatal cardiac cells and hearts of small rodents. There are, however, strong indications that hearts and cardiac muscle cells of humans and rodents differ considerably and so do neonatal and adult cells. In contrast, the adult rabbit heart has more similarities with the human heart. Therefore, hearts and cardiac cells of adult rabbits were used in all experiments described in this thesis.

Chapter 3 describes an improved technique how to isolate and culture adult rabbit cardiomyocytes (heart muscle cells) and fibroblasts (connective tissue cells). The improved technique has led to a standardized protocol in which rod-shaped rabbit cardiomyocytes can be cultured for up to 4 days, and subjected to $10 \%$ cyclic equibiaxial strain $(1 \mathrm{~Hz})$ for 48 hours on silicone membranes. Using these in vitro culture and strain settings, it is possible to mimic overload-mediated cardiac hypertrophy and fibrosis in vivo.

Chapter 4 describes the hypertrophic effect of cyclic stretch on rabbit cardiomyocytes. Cyclic stretch results in a hypertrophic response, characterized by a significant increase in cell surface, protein synthesis and transcription of hypertrophy marker Brain Natriuretic Peptide (BNP). Interestingly, pharmacological inhibition of the Angll type-1 
receptor has no influence on the stretch-induced hypertrophy response. The effect of Angll and other autocrine or paracrine factors on cardiac hypertrophy was investigated in unstretched rabbit cardiomyocytes, which were exposed to in the literature described hypertrophic growth factors AngII, TGF $\beta 1$ and IGF-1. These factors appeared to have no influence on the BNP mRNA expression. In addition, there are indications that stretched fibroblasts produce as yet unidentified growth factors that affect the transcription of hypertrophy marker BNP in cardiomyocytes. In summary, the findings in Chapter 4 show that cyclic stretch plays a crucial role in cardiomyocyte hypertrophy and that this stretch-mediated response is independent from autocrine and paracrine factors, such as AngII, TGF $\beta 1$ and IGF-1.

In the overloaded heart, hypertrophic growth is often associated with increased deposition of fibrotic material. Fibrosis of the heart muscle is characterized by excessive production and incorporation of collagens and matricellular proteins in the interstitial space of the heart muscle, such as collagen-1, collagen-3, Connective Tissue Growth Factor (CTGF) and fibronectin. Mainly fibroblasts are responsible for the production and deposition of these extracellular matrix (ECM) proteins. However, it is still unclear which stimulus is primarily responsible for the activation of fibroblasts to excrete these ECM proteins. Chapter 5 describes how rabbit fibroblasts respond to cyclic stretch and exposure to growth factors, such as AngII, TGF $\beta 1$ and IGF-1. Cyclic stretch of fibroblasts appears to have a direct impact on the transcription of ECM proteins, such as fibronectin and CTGF. In addition, cyclic stretch also increases the transcription of the growth factors TGF $\beta 1$ and IGF-1. Direct exposure of fibroblasts to TGF $\beta 1$ or IGF-1 results in activation of a regulating system, wherein (autocrine) TGF $\beta 1$ and IGF-1 increase their own expression via a positive feedback loop. On the other hand, Angll induces both ECM proteins (collagen-1, collagen and fibronectin) and growth factors (TGF $\beta 1$ and IGF-1). Furthermore, Chapter 5 describes that cardiomyocytes and fibroblasts can communicate via as yet unidentified factors released during stretching of these cells.

Chapter 6 shows that cardiomyocytes from adult hearts might contribute to changes in the ECM, since cyclic stretch increases the expression of CTGF. In addition, there are indications that TGF $\beta 1$ is involved in the induction of CTGF in rabbit cardiomyocytes. As described in Chapter 5 for fibroblasts, also rabbit cardiomyocytes possess a positive feedback system for the expression of TGF $\beta 1$. In contrast, Angll has an inhibitory effect on the transcription of TGF $\beta 1$. Remarkably, stretched fibroblasts also produce substances that stimulate cardiomyocyte transcription of CTGF. On basis of these data, it can be stated that TGF 1 probably plays an important role as autocrine and paracrine factor in cardiomyocytes and fibroblasts in the adult rabbit heart. After the description of the stretch-mediated hypertrophy and fibrosis response of rabbit cardiomyocytes and fibroblasts in vitro, the translation to an intact animal model is made.

Chapter 7 describes a rabbit model in which asymmetric hypertrophy (i.e., regionally different) is induced by electrical stimulation (pacing) of the left ventricle. From literature it is known that pacing results in regional differences in stretch and in me- 
chanical stresses. This in vivo model is therefore closely related to the in vitro model of stretching cardiac cells. The finding that pacing induces hypertrophy in vivo, supports the in vitro finding that stretch is a stimulus for hypertrophy. In contrast to the in vitro results, systemic administration of a specific Angll type-1 receptor (AT-1) blocker prevented the pacing induced asymmetric left ventricular hypertrophy in vivo. The complexity of the in vivo model was further underlined by the fact that the asymmetric hypertrophy was not accompanied by regional differences in the transcription of BNP, CTGF and TGF $\beta 1$, and that their expression levels was not affected in AT-1 blockertreated animals. These results point to the presence of a complex relationship between still unknown systemic circulating and locally in the heart produced autocrine and paracrine factors, which are involved in the process of asymmetric hypertrophy. It cannot be ruled out that the hypertrophy markers under investigation describe the initiation of tissue growth, but are not representative of long-term hypertrophy as assessed in this in vivo animal model.

In Chapter 8 the results described in this thesis were placed in the light of the existing literature. In addition, new research questions were formulated and recommendations for future studies were done. In summary, this thesis shows new insights into the underlying mechanisms that may be involved in the process of stretch-mediated cardiac hypertrophy and fibrosis. These findings may ultimately help to identify new therapeutic targets and improving existing therapies for the treatment of cardiac diseases. 



\section{Samenvatting}

Overbelasting van het hart door bijvoorbeeld hoge bloeddruk of klepgebreken leidt veelal tot vergroting (hypertrofie) en verbindweefseling (fibrose) van de hartspier. Hoofdstuk 1 geeft een opsomming van de doelen van het onderzoek dat in dit proefschrift beschreven wordt. Een van de belangrijkste doelstellingen van dit proefschrift was om te onderzoeken wat de primaire oorzaak is voor het ontstaan van cardiale hypertrofie en fibrose in vitro en in vivo: mechanische rek (belasting) of groeifactoren.

In Hoofdstuk 2 wordt de bestaande wetenschappelijke literatuur samengevat inzake de effecten van mechanische overbelasting (rek) en groeifactoren op cardiale hypertrofie en fibrose. Er wordt specifiek ingegaan op de mogelijke betrokkenheid van angiotensine II (AngII), Insulin-like Growth factor-1 (IGF-1) en Transforming Growth factorbeta (TGF $\beta$ ) in deze processen. Deze drie biochemische verbindingen kunnen zowel autocrien (geproduceerd door hetzelde celtype waar het ook een biologische werking op heeft) als paracrien (geproduceerd door celtype A, maar met een biologische effect op celtype $B$ dat gelegen is in de nabijheid van de producerende cel) van aard zijn. Daarnaast wordt een beschrijving gegeven hoe cardiomyocyten en fibroblasten mogelijk de veranderingen in hemodynamische belasting waarnemen en deze omzetten in biochemische signalen. De conclusie van hoofdstuk 2 is dat het op grond van bestaande literatuur nog steeds onduidelijk is welke factor (mechanisch of biochemisch) primair verantwoordelijk is voor initiatie van het hypertrofisch proces. Deze onduidelijkheid lijkt mede veroorzaakt te worden doordat veel onderzoek gedaan is met cellen en harten van ratten en muizen, veelal zelfs uit pas geboren dieren. Er zijn evenwel sterke aanwijzigingen dat harten en hartspiercellen van mensen en die van kleine knaagdieren aanzienlijk van elkaar verschillen. Het konijnenhart vertoont meer overeenkomsten met het menselijk hart. Daarom is in dit onderzoek gekozen om gebruik te maken van harten en hartcellen van volwassen konijnen.

Hoofdstuk 3 beschrijft een verbeterde isolatie en optimale kweekmethode van volwassen konijnen- cardiomyocyten (hartspiercellen) en fibroblasten (bindweefselcellen). De verbeterde methode heeft ertoe geleid dat volwassen cardiomyocyten en fibroblasten 4 dagen te kweken zijn op een flexible siliconenondergrond en 48 uur lang cyclisch kunnen worden opgerekt met $10 \%$ lengte verandering bij een frequentie van $1 \mathrm{~Hz}$. Door gebruik te maken van deze in vitro kweek- en rekmethoden is het mogelijk om veranderingen in mechanisch belaste volwassen konijnencardiomyocyten en fibroblasten te bestuderen.

In hoofdstuk 4 wordt beschreven dat het cyclisch oprekken van volwassen konijnencardiomyocyten leidt tot een hypertrofische reactie, gekarakteriseerd door een 
significante toename in celoppervlak, eiwitsynthese en transcriptie van de hypertrofiemarker Brain Natriuretic Peptide (BNP). Opvallend was dat farmacologische blokkering van de Angll type-1 receptor geen invloed heeft op de rek-geïnduceerde hypertrofie van volwassen konijnencardiomyocyten. Om de rol van Angll en andere autocriene dan wel paracriene factoren uit te sluiten, zijn ongerekte cardiomyocyten blootgesteld aan, in de literatuur beschreven, hypertrofie stimulerende groeifactoren zoals AngIl, TGFB1 en IGF-1. Deze bleken geen invloed te hebben op de BNP mRNA expressie. Daarnaast zijn er wel aanwijzingen gevonden dat gerekte fibroblasten niet nader geïdentificeerde groei factoren produceren die de transcriptie van de hypertrofie marker BNP in cardiomyocyten verhogen. Kortom, de bevindingen in hoofdstuk 4 laten zien dat cyclische rek een cruciale rol speelt in cardiomyocyt hypertrofie en dat deze rek-gemedieerde respons in volwassen cardiomyocyten onafhankelijk is van autocriene en paracriene factoren zoals Angll, TGF $\beta 1$ en IGF-1.

In het overbelaste hart gaat hypertrofische groei vaak samen met fibrose. Het fibrotiseren van de hartspier wordt gekenmerkt door overmatige productie en inbouw van collagenen en matricellulaire eiwitten in de interstitiële ruimte van de hartspier, zoals collageen-1, collageen-3, Connective Tissue Growth factor (CTGF) en fibronectine. Voornamelijk fibroblasten zijn verantwoordelijk voor de productie en depositie van deze extracellulaire matrix (ECM) eiwitten. Het is echter onduidelijk welke stimulus primair verantwoordelijk is voor de activatie van fibroblasten om deze eiwitten aan te maken. In hoofdstuk 5 wordt beschreven hoe volwassen konijnenfibroblasten reageren op cyclische rek en blootstelling aan groeifactoren, zoals AngII, TGF $\beta 1$ en IGF-1. Het cyclisch oprekken van fibroblasten blijkt directe invloed te hebben op de transcriptie van ECM eiwitten, zoals CTGF en fibronectine. Naast de beïnvloeding van de expressie van deze eiwitten door rek, blijkt dat rek de transcriptie beïnvloedt van de groeifactoren TGF $\beta 1$ en IGF-1. Directe blootstelling van fibroblasten aan TGF $\beta 1$ dan wel IGF-1 resulteert in activatie van een regulerend systeem, waarbij TGF $\beta 1$ en IGF-1 door positieve feedback langs autocriene weg hun eigen expressie verhogen. Aan de andere kant induceert Angll zowel ECM eiwitten (collageen-1, collageen-3 en fibronectine) als groeifactoren (TGFß1 en IGF-1). Verder wordt in hoofdstuk 5 beschreven dat fibroblasten en cardiomyocyten kunnen communiceren via vooralsnog onbekende factoren die vrijkomen bij het oprekken van deze cellen.

Hoofdstuk 6 beschrijft dat volwassen cardiomyocyten mogelijk kunnen bijdragen aan veranderingen in de ECM ten gevolge van rek, omdat cyclische rek de expressie van CTGF in de cardiomyocyte verhoogt. Daarnaast zijn er aanwijzingen gevonden dat TGF $\beta 1$ een belangrijke transcriptie activator is voor de inductie van CTGF in dit celtype. Zoals in hoofdstuk 5 beschreven voor fibroblasten, bevatten ook volwassen cardiomyocyten een positief feedback systeem voor de expressie van TGF $\beta 1$. Daarentegen heeft Angll een remmende werking op de transcriptie van TGF $\beta 1$. Opmerkelijk is dat gerekte fibroblasten ook stoffen produceren die de cardiomyocyten aanzetten tot transcriptie van CTGF. Op grond van deze gegevens kan gesteld worden dat TGF $\beta 1$ waarschijnlijk 
een belangrijke rol speelt als autocriene en paracriene factor voor cardiomyocyten en fibroblasten in het volwassen konijnenhart.

$\mathrm{Na}$ het beschrijven van de rek-gemedieerde hypertrofie en de fibrose response van volwassen konijnencardiomyocyten en fibroblasten in vitro, is de vertaalslag naar een intact diermodel gemaakt. In hoofdstuk 7 wordt een konijnenmodel beschreven waarin asymmetrische (dwz regionaal verschillende) hypertrofie wordt opgewekt door electrisch stimuleren (pacen) van de linker ventrikel. Uit de literatuur is bekend dat door het pacen regionale verschillen in rek en mechanische belasting ontstaan. Dit in vivo model is dus nauw verwant aan het in vitro model van gerekte cellen. De bevinding dat in vivo pacen lokale hypertrofie opwekt ondersteunt daarmee de bevinding in het in vitro model dat rek een prikkel voor hypertrofie is. Echter, in tegenstelling tot wat in vitro gevonden werd, bleek dat in vivo systemische toediening van een specifieke Angll type-1 receptor (AT-1) blokker de pacing geïnduceerde asymmetrische linker ventrikel hypertrofie voorkwam. De complexiteit van het in vitro model bleek verder uit het feit dat de asymmetrische hypertrofie niet gepaard ging met regionale verschillen in de expressie van BNP, CTGF en TGF $\beta 1$, en dat in de met AT-1 blokker behandelde dieren de expressieniveaus niet significant veranderden. Hieruit blijkt dat er vermoedelijk een gecompliceerde relatie bestaat tussen nog steeds onbekende systemische circulerende en lokaal in het hart geproduceerde autocriene en paracriene factoren die betrokken zijn in het proces van asymetrische hypertrofie. Ook kan niet uitgesloten worden dat de beschreven hypertrofie markers de initiatie van weefsel toename beschrijven en niet representatief zijn voor langdurige hypertrofie zoals onderzocht in dit in vivo diermodel.

In Hoofdstuk 8 worden de resultaten in de verschillende experimentele hoofdstukken besproken, onderling en in het licht van de bestaande literatuur. Daarnaast worden nieuwe onderzoeksvragen geformuleerd en aanbevelingen gedaan voor vervolgstudies. Samenvattend heeft dit proefschrift nieuwe inzichten gegeven in de onderliggende mechanismen die mogelijk betrokken zijn bij het ontstaan van rek-gemedieerde cardiale hypertrofie en fibrose. Deze bevindingen kunnen uiteindelijk bijdragen aan het vinden van nieuwe therapeutische aangrijpingspunten of verbeteren van bestaande therapieën voor de behandeling van cardiale ziekten. 



\section{Dankwoord}

$\mathrm{Na}$ vele jaren onderzoek, gevolgd door lange periode van schrijven, ligt nu voor u mijn proefschrift. Men zegt vaak dat de laatste loodjes het zwaarst wegen. Deze uitdrukking is zeker op mij van toepassing geweest.

$\mathrm{Nu}$ is het tijd om iedereen te bedanken die samen met mij aan dit proefschrift hebben gewerkt. Mensen, die mij kennen, weten dat ik iemand ben van weinig woorden en zullen daarom ook niet verbaast zijn dat mijn dankwoord kort en krachtig zal zijn.

Bij deze wil ik iedereen bedanken die een bijdrage aan dit proefschrift heeft geleverd. Beste Ger, Frits, Marc en Frans, bedankt voor alle wetenschappelijke discussies en begeleiding tijdens mijn promotietraject! Geachte leden van de leescommissie, hartelijk dank dat u mijn proefschrift heeft willen beoordelen en dat u een positief advies heeft gegeven om de inhoud van dit proefschrift te mogen verdedigen.

Daarnaast wil ik mijn moeder, mijn broertje, mijn schoonfamilie, verdere familie en vrienden bedanken voor hun steun en het vertrouwen dat zij altijd in mij hebben gehad. Dank jullie wel!

En als laatste wil ik mijn vriendin Chantal bedanken. Jij bent samen met mij het Limburgse avontuur aangegaan. En samen hebben wij dit volbracht. Zonder jouw liefde, steun, vertrouwen en respect was mij dit nooit gelukt. Jij bent mijn grote steun en toeverlaat geweest in 'moeilijke' tijden. Lieve schat, dankjewel voor alles!

Erik 



\section{Curriculum Vitae}

\section{Erik Blaauw}

Born on 24 October 1980 in Stadskanaal, the Netherlands

\section{Education}

1993-1998, HAVO, Winkler Prins te Veendam

1998-1999, Propedeuse HBO Biotechnologie

1999-2002, Bachelor, Medische Biotechnologie, Noordelijke Hogeschool te Leeuwarden 2002-2004, Master, Medical Pharmaceutical Science, Groningen University

2001, Bachelor project

VEGF expression and the development of blood vessels after induction of cardiac damage.

Department of Medical Biology, GUIDE, Groningen University. Dr. Marco Harmsen

2003, Master project

Alkaline phosphatase: a new therapy against sepsis?

Department Pharmacokinetic \& Drug Delivery, GUIDE, Groningen University. Prof. Klaas Poelstra

\section{Experience}

2005-2013, PhD thesis

Stretch-mediated cardiac hypertrophy and extracellular matrix remodelling.

Department of Physiology, CARIM, Maastricht University, Prof. Frits Prinzen and Prof. Ger van der Vusse

2009-present

Sales representative at Merck Sharp \& Dohme 


\section{List of publications}

Stretch-induced upregulation of connective tissue growth factor in rabbit heart Blaauw E, Ilka Lorenzen-Schmidt, Fawzi A. Babiker, Chantal Munts, Frits W. Prinzen, Luc H. Snoeckx, Marc van Bilsen, Ger J. van der Vusse and Frans A. van Nieuwenhoven Accepted for publication in Cardiovascular Translational Research (2013)

Stretch-induced hypertrophy of isolated adult rabbit cardiomyocytes.

Blaauw E, van Nieuwenhoven FA, Willemsen P, Delhaas T, Prinzen FW, Snoeckx LH, van Bilsen M, van der Vusse GJ.

Am J Physiol Heart Circ Physiol. 2010 Sep;299(3):H780-7.

Re-expression of alpha skeletal actin as a marker for dedifferentiation in cardiac pathologies.

Driesen RB, Verheyen FK, Debie W, Blaauw E, Babiker FA, Cornelussen RN, Ausma J, Lenders $\mathrm{MH}$, Borgers $\mathrm{M}$, Chaponnier C, Ramaekers FC.

J Cell Mol Med. 2009 May;13(5):896-908.

Pacing-induced dys-synchrony preconditions rabbit myocardium against ischemia/reperfusion injury.

Vanagt WY, Cornelussen RN, Poulina QP, Blaauw E, Vernooy K, Cleutjens JP, van Bilsen $\mathrm{M}$, Delhaas T, Prinzen FW.

Circulation. 2006 Jul 4;114(1 Suppl):I264-9. 